\section{ORAL PRESENTATIONS ABSTRACTS}

\section{OP-001 \\ THE COMPARISON OF SIGMA VALUES CALCULATED ACCORDING TO DIFFERENT \%TEA STANDARDS OF URINE BIOCHEMISTRY TESTS AND EVALUATION OF ANALYTICAL STAGE}

Ugur Ercin

Ufuk University Faculty of Medicine, Dr. Ridvan Ege Hospital, Medical

Biochemistry Department, Ankara,Turkey

OBJECTIVES: The aim of this study was to compare the sigma values calculated according to different \% TEa (Total allowable error) standards of urine biochemistry tests consisting of Creatinine-U and Protein- $U$ and to improve IQC (Internal quality control) measurements using Westgard's sigma rules. MATERIALS and METHODS: The IQC data of urine biochemistry tests analyzed in the biochemistry autoanalyzer at Ufuk University Faculty of Medicine Hospital, Biochemistry Laboratory between 01.01 .2020 and 31.03.2020 were obtained from the laboratory information management system and examined. RESULTS: $75 \%$ of the sigma values calculated according to RILIBAK (German Guidelines for Quality) and BV (Based on biological variability) \% TEa standards from the two level IQC data were $>6$ and $25 \%$ were in the group between 4-6. Of the sigma values calculated according to CAP (College of American Pathologists), $50 \%$ were $>6$ and $50 \%$ were between $4-6$. Of the sigma values calculated according to WLSH (Wisconsin State Laboratory of Hygiene), $25 \%$ were $>6,25 \%$ were between $4-6$, and $50 \%$ were $<4$. Since the QTI (Quality Target Index) of the tests, whose sigma values were calculated according to RILIBAK, were $>1.2$, improvements in terms of accuracy were required for both tests. CONCLUSIONS: When the sigma values of the tests calculated according to RILIBAK were evaluated based on Westgard's sigma rules, it was found that creatinine-U (normal and pathological) and protein-U (normal) control results should be evaluated according to $1-3 \mathrm{~s}$ and protein- $U$ (pathological) control results should be evaluated according to $1-3 \mathrm{~s} / 2-2 \mathrm{~s} / \mathrm{R}-4 \mathrm{~s} / 4-1 \mathrm{~s} / 8 \mathrm{x}$ multiple rules. Keywords: Analytical Stage, Six Sigma, Total Allowable Error, Westgard Rules

\section{OP-002 \\ VOLTAMMETRIC DETERMINATION OF CYSTEINE BY FLUORESCEIN BASED DYE}

Lokman Liv

TUBITAK National Metrology Institute, Electrochemistry Laboratory, Kocaeli, Turkey

OBJECTIVES: Cysteine is a sulfur-containing amino acid that has some important features such as being powerful antioxidant and skin-whitening agent. It is widely used as a component of cosmetics and foods. Therefore, cysteine determination is very important. The main purpose of this study is to suggest a simple, cheap and disposable electrode material contrary to the voltammetric methods for the determination of cysteine in the literature. In addition, it was aimed to develop a sensitive and accurate method.

MATERIALS and METHODS: Fluorescein based dye was synthesized by the reaction between fluorescein derivative molecule and propiolic acid in the presence of dicyclohexylcarbodiimide (DCC). Three electrode system consisting of disposable pencil graphite as a working electrode, platinum wire as a counter electrode and $\mathrm{Ag} / \mathrm{AgCl}$ (sat. $\mathrm{NaCl}$ ) as a reference electrode was operated by Metrohm Autolab PGSTAT $128 \mathrm{~N}$ potentiostat/galvanostat. The measurements were performed in $\mathrm{pH} 7.5$ phosphate buffer and acetonitrile solution $(4: 6, \mathrm{v} / \mathrm{v})$. RESULTS: The cathodic peak belongs to the fluorescein based dye at $-770 \mathrm{mV}$ decreases with the increasing amounts of cysteine. This signal change was used for the determination of cysteine.

CONCLUSIONS: A novel, simple, cheap and sensitive voltammetric method for the determination of cysteine is proposed as an alternative to the methods in the literature. The developed method does not require additional operations such as preparation and modification of the electrode material since the pencil graphite is used, and thus has an important advantage.

Keywords: Fluorescein Based Dye, Cysteine, Disposable Pencil Graphite Electrode, Voltammetry

\section{OP-003 \\ EVALUATION OF MEASUREMENT UNCERTAINTY FOR TUMOR MARKERS}

Ahmet Rifat Balik

Etlik Zubeyde Hanim Gynecology Training and Research Hospital, Medical Biochemistry Laboratory, Ankara, Turkey

OBJECTIVES: Measurement uncertainty is an indication of the quality and reliability of the measurement result. Measurement uncertainty has been used for many years in clinical laboratories to "Define the range of values at which the actual value of the measurement result can be found". Therefore, we aimed to evaluate the measurement uncertainty of tumor markers, which have an important place in the follow-up of diseases and help the clinician in the diagnosis and prognosis stages.

MATERIALS and METHODS: Measurement uncertainty was determined for CEA, CA15-3, CA19-9, CA125, AFP, B-HCG, Total PSA and Free PSA parameters measured in the laboratory of our hospital. For the study, the interna quality control results for the dates 01.03.2020-31.08.2020 and the six-month external quality control results (RIQAS) obtained within the said date range were used. AFP test was analyzed with Beckman Coulter DXI 800 device and other tests were analyzed with Roche Cobas 8000 device. Nordtest method was used to determine the measurement uncertainty.

RESULTS: As a result of our analysis, expanded measurement uncertainty values for first and second level control values were found to be 11.81 and 10.92 for CEA, 23.39 and 23.17 for CA125, 17.30 and 15.79 for CA15-3, 21.50 and 21.02 for CA19-9, 21.02 and 19.13 for B-HCG, 23.58 and 23.60 for Total PSA, 11.92 and 12.12 for Free PSA, 21.62 ve 20.53 for AFP respectively.

CONCLUSIONS: Calculation of the measurement uncertainty of tumor markers, many of which are low-sensitivity tests, will provide valuable information regarding test quality.

Keywords: Measurement Uncertainty, Tumor Markers

\section{OP-004 \\ COMPARISON OF TWO ANALYTICAL PLATFORMS FOR QUANTIFICATION OF THE NEUROFILAMENT LIGHT CHAIN IN MULTIPLE SCLEROSIS PATIENTS' BLOOD AND CSF SAMPLES: ELISA AND SIMOA}

Burak Arslan $^{1}$, Gokce Ayhan Arslan ${ }^{2}$, Asli Tuncer ${ }^{2}$, Aylin Sepici Dincel $^{1}$ ${ }^{1}$ Gazi University, School of Medicine, Department of Medical Biochemistry, Ankara, Turkey

${ }^{2}$ Hacettepe University, School of Medicine, Department of Neurology, Ankara, Turkey

OBJECTIVES: Neurofilaments including the light chain subtype are the main components of the axonal cytoskeleton. Thus, their release into the extracellular area is a direct measure of neuronal injury.Hereby,we aimed to compare the commercial ELISA and Single Molecule Array (SIMOA) method for neurofilament light chain (NfL) in cerebrospinal fluid (CSF) and serum samples of Multiple Sclerosis (MS) patients.

MATERIALS and METHODS: We used pairs of serum $(n=55)$ and CSF $(n=20)$ samples.For CSF samples,a previously validated and recommended ELISA assay from Uman Diagnostic ${ }^{\circledR}$ was used. Serum NfL levels was performed with ELISA assay (Abbexa Ltd.). In addition, NfL analysis was done by SIMOA HD-X analyzer that has a greater sensitivity in terms of NfL detection in serum and CSF samples. For SIMOA, Limit of Detection (LOD) and Limit of Quantification (LOQ) was determined as $0.038 \mathrm{pg} / \mathrm{mL}$ and $0.174 \mathrm{pg}$ / $\mathrm{mL}$,respectively for serum sample. Intra-assay CVs were assessed between the concentrations of duplicates of the measured all samples. LOD was measured as $33 \mathrm{pg} / \mathrm{mL}$ for $\mathrm{CSF}$ and $6.2 \mathrm{pg} / \mathrm{mL}$ for serum samples for ELISA analysis. RESULTS: Mean values of CSF ELISA and SIMOA values have been found as $1239,5 \pm 693,0 \mathrm{pg} / \mathrm{mL}$ and $1269,9 \pm 852,8 \mathrm{pg} / \mathrm{mL}$, respectively. Also, we have found the mean values of serum ELISA and SIMOA values as $97,3 \pm 71,5 \mathrm{pg} / \mathrm{mL}$ and $16,8 \pm 10,0 \mathrm{pg} / \mathrm{mL}$, respectively. Besides, there was a strong positive correlation between SIMOA CSF and ELISA CSF $(p<0,001, r=0,924)$. We have found a strong positive correlation between serum and CSF SIMOA $(p<0,05, r=0,703)$ CONCLUSIONS: We concluded that SIMOA is a reliable method for serum NfL determinations. We can suggest to use this exclusive method for differen neurodegenerative diseases together with clinical findings for future studies. Keywords: Multiple Sclerosis, SIMOA, ELISA

\section{OP-005 \\ HOW SUCCESSFUL ARE LABORATORY TEST COMBINATIONS? A PRELIMINARY STUDY WITH DISCRIMINANT ANALYSIS}

Elmas Ogus ${ }^{1}$, Izzet Hamdi Ogus ${ }^{2}$

'Department of Medical Biochemistry, Ankara Training and Research Hospital, Ministry of Health, Ankara, Turkey

${ }^{2}$ Ankara, Turkey

OBJECTIVES: Many laboratory tests generally have low success in classifying cases as "healthy" or "patients". Appropriate test combinations have been developed to overcome this obstacle. In this preliminary study, two hypothetical diagnostic tests were evaluated together using the Discriminant Analysis (DA) method. The aim of the study is to investigate and discuss the level of classification success achieved with DA application by using routine test analysis. MATERIALS and METHODS: In this study, results obtained by two hypothetical tests in two groups (control and patient), each consisting of 30 cases were used. For each test, the degrees of overlapping of the groups and the AUC values were calculated. Hypothetical analysis results were evaluated by discriminant analysis method using SPSS program. 
RESULTS: The degrees of overlapping of the groups were $32 \%$ and $40 \%$ for the tests A and B, respectively. AUC values calculated by ROC analysis were 0.949 and 0.933 for the tests $\mathrm{A}$ and $\mathrm{B}$, respectively. The two groups were classified completely and accurately using the DA method. The result was confirmed by ROC analysis using discriminant coefficients $(\mathrm{AUC}=1.00$ ). CONCLUSIONS: DA provides a better group separation by using tests with insufficient classification success. It is an indispensable requirement to have a healthy database containing sufficient number of cases in DA applications, which are also used to select the most appropriate test combination from the test list. The continuity of the study and the cumulative feature of the database increase the success level gradually. Keywords: Discriminant Analysis, ROC Analysis

\section{OP-006 \\ DEVELOPMENT AND VALIDATION OF A SELECTIVE TANDEM MASS SPECTROMETRIC METHOD FOR SIMULTANEOUS MEASUREMENT OF D- AND L-2-HYDROXYGLUTARIC ACID IN BIOLOGICAL FLUIDS AND APPLICATION TO A GLIOMA STUDY}

Nazli Ecem Dal Bekar ${ }^{1}$, Gamze Tuna $^{1}$, Sertac Islekel $^{2}$, Huray Islekel ${ }^{3}$ ${ }^{1}$ Dokuz Eylul University, Graduate School of Health Sciences, Department of Molecular Medicine, Izmir, Turkey

${ }^{2}$ Kent Hospital, Department of Brain and Nerve Surgery, Izmir, Turkey ${ }^{3}$ Dokuz Eylul University, School of Medicine, Department of Medical Biochemistry, Izmir, Turkey

OBJECTIVES: Isocitrate dehydrogenase (IDH) mutations that may mostly be seen in certain malignancies can result in excessive production of 2-hydroxyglutaric acid $(2-\mathrm{HG})$ that can be referred to as an oncometabolite. Since 2-HG has the chiral carbon, there are two enantiomers named as D- and L-2-HG. Especially D- enantiomer of $2-\mathrm{HG}$ is increased in glioma, acute myeloid leukemia, myelodysplastic syndromes, and intrahepatic cholangiocarcinoma. On the other hand, excessive production of L-2-HG has been reported in some other brain tumors, renal cell carcinoma and in a rare neurological disorder called 2-Hydroxyaciduria. Therefore, it has great importance to measure these enantiomers separately and simultaneously for diagnosis and follow-up of different pathologies. MATERIALS and METHODS: Here, we present a fully optimized stable isotope dilution multiple reaction monitoring method for absolute quantification of $\mathrm{D}$ - and L-2-HG selectively, using a liquid chromatography tandem mass spectrometry system. The analytical method validation studies have been performed utilizing Clinical\&Laboratory Standards Institute (CLSI) and European Medicines Agency (EMA) guidelines.

RESULTS: This is the first analytical method validation study that has been performed for different matrices namely cerebrospinal fluid, urine, and plasma for selective measurement of D- and L-2-HG in addition to demonstrating the clinical applicability of the method with samples from glioma patients in different stages. The results of the method validation study have shown high accuracy and precision with considerably low LOD and LOQ values.

CONCLUSIONS: We believe that the presented comprehensive approach for absolute quantification of D- and L-2-HG simultaneously is highly suitable for basic and clinical research on related pathologies.

Keywords: Biomarker, D-2-Hydroxyglutaric Acid, Glioma, L-2-Hydroxyglutaric Acid, Tandem Mass Spectrometry

\section{OP-007 \\ EVALUATION OF THE PERFORMANCE OF 'TWIN AUTOANALYSERS" WORKING THE SAME ROUTINE BIOCHEMICAL ANALYTES USING DIFFERENT STATISTICAL METHODS}

Selin Onur, Banu Isbilen Basok, Fatma Demet Arslan, Inanc Karakoyun, Ayfer Colak

University of Health Sciences Izmir Tepecik Training \& Research Hospital, Department of Medical Biochemistry, Izmir, Turkey

OBJECTIVES: Due to the increasing number and variety of test orders, it is required to have two or more identical autoanalyzers that analyze the same biochemical parameters in laboratories. Although it assumed that there are no/minor analytical differences between those in routine, there is a lack of evidence. We aim to compare the tests produced by twin-analyzers and if there is a clinical difference to visualize it. MATERIALS and METHODS: In the study, we compared the following test results of twin analyzers (AU5800;Beckman Coulter Inc.,USA): glucose, urea, creatinine, uric acid, AST, ALP, GGT, LDH, direct and total bilirubin, total protein, albumin, triglyceride, cholesterol, high-density lipoprotein, amylase, lipase, calcium, magnesium, phosphorus, C-reactive protein, iron, unsaturated iron-binding capacity, creatine kinase, ferritin, sodium, potassium, and chlorine. These parameters were measured by using liquid-stable third-party internal quality control (IQC) samples (Bio-Rad Lab.,USA) for consecutive 31 days. Results were analyzed with several statistical techniques for statistical and clinical evaluation. The difference between twin-analyzers visualized by exponential weighted moving average (EWMA) charts

RESULTS: Statistically, but not clinically significant differences observed for the parameters: glucose, creatinine, $\mathrm{LDH}$, total protein, albumin, cholesterol, calcium, magnesium, phosphorus, sodium, and chlorine. A critical difference observed on the 11th day at the second level of the IQC sample was presented on the EWMA chart.

CONCLUSIONS: The critical error in calcium is observed as a value above the upper limit on the EWMA chart. The difference shown on the EWMA chart without using complex mathematical calculations promises that EWMA charts can be useful in continuously monitoring of twin-analyzers.

Keywords: Autoanalyzer, Twin-Analyzer, Instrument Comparison, Exponentially Weighted Moving Average (EWMA)

\section{OP-008}

\section{EVALUATION OF ETHANOL TEST MEASUREMENT UNCERTAINTY}

Hediye Cigdem Simsek ${ }^{1}$, Murat Keles ${ }^{2}$, Esra Dokumcu

${ }^{1}$ Aksaray University Training and Research Hospital, Clinical Biochemistry Laboratory, Aksaray, Turkey

${ }^{2}$ Bursa Public Health Laboratory, Clinical Biochemistry Laboratory, Bursa, Turkey

${ }^{3}$ Edirne Public Health Laboratory, Clinical Biochemistry Laboratory, Edirne Turkey

OBJECTIVES: It is now known that patient test results given in clinical laboratories do not accurately reflect the true value and are an approximate value attributed to the measured size. Measurement uncertainty is a quantitative indicator of the extent to which the obtained test result represents the true value. Total permissible error (TEa) is now widely used to assess the compliance of measurement uncertainty with analytical quality objectives. Clinical laboratories awaiting accreditation under the ISO 15189 standard must determine the measurement uncertainty for each measurement procedure, define the relevant performance requirements and check regularly. In our study, we aimed to evaluate the measurement uncertainty, measurement uncertainty limits according to the Nordtest guideline in analytical performance evaluation and evaluate them together with the Total Permissible Error (TEa).

MATERIALS and METHODS: For ethanol test, expanded uncertainty was calculated using two levels of internal quality results for May, June, July, August, September 2020 and the results of the 18-month Randox Riqas external quality control program between 03/2019-08/2020. Expanded measurement uncertainty (U) was calculated by the formula $(\mathrm{U})=20 \mathrm{O} \mathrm{EQA} 2+\% \mathrm{CV} 2$. CV\% obtained from internal quality control data and the uncertainty obtained from external quality control (UEQA) data was calculated by the formula (UEQA) $=\ddot{O} \%$ bias $2 / n(n$. number of laboratories involved). The uncertainty value we found was evaluated with the TEa\% value determined by CLIA 88 for ethanol.

RESULTS: The expanded measurement uncertainty for ethanol test normal and pathological quality control was found to be 10.15 and 9.36 , at $95 \%$ confidence interval, respectively. The TEa \% value determined by CLIA 88 for ethanol is \pm $25 \%$

CONCLUSIONS: The measurement uncertainty calculated for the ethanol test in our laboratory is below the targeted \% TEa. We think that reporting patient test results with calculated measurement uncertainty in laboratories will make a significant contribution to increase the reliability of the results It is within acceptable limits within the $95 \%$ confidence interval. Ethanol test results close to legal limits should be reported with a $95 \%$ confidence interval. Keywords: Measurement Uncertainty, Ethanol, Total Allowable Error

\section{OP-009 \\ THE RELIABILITY OF PLATELET CLUMPS FLAG GENERATED BY SYSMEX XN-1000 HEMATOLOGY ANALYZER}

\section{Serif Ercan}

Luleburgaz State Hospital, Department of Medical Biochemistry, Kirklareli, Turkey

OBJECTIVES: Platelet (PLT) count is important parameter to evaluate the hemostasis. There are many factors that may cause falsely decreased PLT counts. PLT clumps (PC), which are arisen from either a peculiar pathology in the patient or the mistakes during blood collection, is one of the most common causes. Hematology analyzers are capable to generate PC flag. This present study was aimed to determine the agreement of PC flag produced by hematology analyzer with the findings of peripheral blood smear (PBS).

MATERIALS and METHODS: Hemogram analysis was performed on Sysmex XN-1000 analyzer. The PBSs prepared from 151 whole blood samples with PC flag and 270 without flag were reviewed for PC. PBSs were prepared by MayGrunwald-Giemsa method. Based on the findings of PBS, sensitivity, specificity, positive and negative predictive values were estimated for PC flag produced by hematology analyzer

RESULTS: For PC flag, sensitivity, specificity, positive and negative predictive values were calculated as $77.9 \%, 74.9 \%, 44.4 \%$ and $93 \%$, respectively. In addition, only taking into account the samples with PLT counts of $<150 \times 10^{9} / \mathrm{L}$ sensitivity, specificity, positive and negative predictive values were computed as $78.5 \%, 86.2 \%, 72.1 \%$ and $89.8 \%$, respectively.

CONCLUSIONS: The falsely PC flags are frequently encountered on Sysmex 
$\mathrm{XN}-1000$ hematology analyzer. However, specificity and positive predictivity was higher in the samples with PLT count of $<150 \times 10^{9} / \mathrm{L}$. Therefore, when encountered trombocytopenia accompanying with PC flag, if available, PBS should be reviewed for PC before approve the results, otherwise PLT clumps should be referred in the result report and re-counting of PLT should be recommended in fresh sample. Keywords: Automated Platelet Counting, Hemogram, Peripheral Blood Smear, Platelet Clumps

\section{OP-010 \\ COMPARISON OF THREE DIFFERENT METHODS FOR HBA1C MEASUREMENT}

Funda Eren

Ankara City Hospital, Central Biochemistry Laboratory, Ankara, Turkey

OBJECTIVES: HbA1c levels are included in the diagnostic criteria as well as being used in the follow-up of patients with Diabetes Mellitus. Therefore, it is important to produce reliable HbA1c results. Different methods are used for HbA1c measurements. In this study, it was aimed to compare the results of 3 different HbAlc methods.

MATERIALS and METHODS: Thirty samples with different levels of HbA1c were included in the study. HbA1c tests were performed using immunturbidimetric method in Siemens Atellica Solutions device, high performance liquid chromatography (HPLC) method in Variant II Turbo device and capillary electrophoresis method in Capillarys 3 Tera device. Wilcoxon signed ranks test, Bland-Altman and Passing-Bablok regression analyzes were used to compare the difference between reference method and other methods. The level of correlation between the methods was evaluated using Spearman correlation analysis. RESULTS: HbA1c results obtained from different devices were compared based on chromatographic method. Strong correlation was found between methods. No significant difference was found with the results of the Capillarys 3 Tera device $(\mathrm{p}=0.763)$. On the other hand, higher results were obtained from the Atellica Solutions device and the difference was found to be statistically significant (p $<0.001)$

CONCLUSIONS: When the HbAlc results measured with three different devices were evaluated, it was observed that the results of the chromatographic method and capillary electrophoresis method were consistent, but the results obtained from the immunturbidimetric method were higher than the other two methods. Keywords: Capillary Electrophoresis, Hbalc, HPLC, Immunoturbidimetry

\section{OP-011 \\ EVALUATION OF MEASUREMENT UNCERTAINTY OF TOTAL PROSTATE SPECIFIC ANTIGEN TEST}

\section{Esra Firat Oguz \\ Ankara City Hospital, Central Biochemistry Laboratory, Ankara, Turkey}

OBJECTIVES: Laboratory results are critical to clinical decision making. Therefore, it is extremely important for laboratories to produce reliable results. Measurement uncertainty is the quantitative expression of the quality of test results by evaluating the effect of possible sources of error. In this study, it is aimed to present the measurement uncertainty of total prostate specific antigen (PSA) test, one of the screening tests.

MATERIALS and METHODS: Total prostate specific antigen test was studied in Atellica Solutions device (Siemens Healthineers, Erlangen, Germany). Measurement uncertainty of the test was calculated according to CLSI EP29A guideline. Two levels of internal quality control data and external quality control bias uncertainty data were obtained.

RESULTS: For the total prostate specific antigen test, the internal quality control uncertainty value was $7.35 \%$, the external quality control uncertainty value was $0.20 \%$, and the expanded uncertainty value was $12.1 \%$ (coverage factor: 1.65 ).

CONCLUSIONS: The level of $4 \mu \mathrm{g} / \mathrm{L}$ for total PSA is the threshold value for making a prostate biopsy decision. When measurement uncertainty is included, the threshold value for total PSA in our laboratory was determined as $4 \pm 0.5 \mu \mathrm{g} / \mathrm{L}$. Calculation of measurement uncertainty is even more important for tests using clinical decision limits in diagnosis and treatment processes.

Keywords: Atellica Solutions, Measurement Uncertainty, Prostate Specific Antigen

\section{OP-012 \\ COMPARISON OF SOME AMINO ACID LEVELS STUDIED WITH LIQUID CHROMATOGRAPHY-MASS SPECTROMETRY METHOD IN PLASMA AND DRIED BLOOD SAMPLES}

Ozgur Aslan, Revsa Evin Canpolat Erkan

Health Sciences University Gazi Yasargil Training and Research Hospital

Department of Clinical Microbiology Laboratory, Diyarbakir, Turkey

OBJECTIVES: In the study, it was aimed to evaluate the amino acid levels of Phenylalanine (Phe), Tyrosine (Tyr), Valine (Val), Leu + Isoleucine (Leu + ILeu) in samples taken from simultaneously dried blood and plasma.

MATERIALS and METHODS: The results of 123 patients (46 female, 77 male) whose plasma amino acid and dried blood samples were taken simultaneously were included in the study. Samples were studied and analyzed in liquid chromatography-mass spectrometry/mass spectrometry (LC-MS/MS) device after extraction and derivatization processes.

RESULTS: For Phe, Tyr, Val, Leu + ILeu, plasma amino acid levels median (minimum - maximum) were found 57.90 (3.80 -747.10), $58.90(22.70-860.0)$, $176.80(35.70-512.40), 156.90(42.0$ - 516.50) $\mu \mathrm{mol} / \mathrm{L}$, dried blood amino acid levels median (minimum - maximum) were found $67.0(32.20-963.40)$, 75.70 (35.90 - 950.10), 176.60 (66.90 - 413.0), $141.10(62.70$ - 342.0) $\mu \mathrm{mol} / \mathrm{L}$ respectively. There were significant differences between dried blood samples and plasma amino acid levels for Phe, Tyr and Leu + ILeu $(p<0.001, p<0.001$, p $=0.02$, respectively), but was no significant difference for Val. $(\mathrm{p}=0.66)$. The mean differences between plasma and dried samples by Bland-Altman analysis were found at Val (-0.4), Tyr (-15.0), Phe (-9.5), Leu + Ileu (22.9), respectively. CONCLUSIONS: Method and sample differences affect the level of amino acids. For this reason, clinicians and laboratories should consider the fact that deviations in the samples and systems studied may be important for the diagnosis and follow-up of metabolic diseases.

Keywords: Amino Acids, Tandem Mass Spectrometry, Phenylalanine, Tyrosine, Branched Chain Amino Acids

\section{OP-013 \\ THE EVALUATION OF ANALYTICAL PERFORMANCE OF BIOCHEMICAL URINE TESTS USING SIX SIGMA METHODOLOGY AND QUALITY GOAL INDEX}

Yasemin Erdogan Doventas

Haseki Education and Research Hospital, Department of Medical Biochemistry, Istanbul, Turkey

OBJECTIVES: In clinical laboratories, sigma metric analysis is used to assess the performance of the laboratory process system. The aim of this study was to evaluate the analytical process performances of the biochemistry urine tests in the Beckman Coulter-Olympus AU5800 by using the six-sigma methodology.

MATERIALS and METHODS: The analytical performances of Beckman CoulterOlympus AU5800 running 11 Biochemical Urine tests (Microalbumin, Protein, Creatinine, Calcium, Phosphorus, Sodium, Potassium, Chlor, Magnesium, Urea, Uric Acid) were evaluated. The six months internal (level1-2) and external quality control programs were extracted for these parameters. As external quality control we used external quality assessment schemes (EQAS) data. CV\% was obtained from internal quality control programs. The percentage bias for these parameters was calculated from external quality control programs. Quality goal index (QGI) analysis) was used to discover potential problems for the analytes.

RESULTS: For parameters, Mikroalbumin, Calcium, Phosphor, Sodium, Klor, Magnesium, uric Acid (level 1 and 2), the sigma values were found to be between 3 to 6 . The sigma values were found to be less than 3 for parameters creatinine, potassium, urea (levels 1 and 2). Microalbumin,calcium and uric acid the sigma values were found to be more than 6 .

CONCLUSIONS: It was decided that sigma values of urine parameters at "low quality" levels and improvement studies should be done for these parameters. By evaluating Sigma levels, it is possible to identify tests with a high probability of failure, and these tests should undergo a rigorous quality control audit. In clinical biochemistry laboratories, appropriate quality control planning should be made for each test using the Six Sigma Methodology.

Keywords: Six Sigma, Analytical Performance, Quality Goal Index, Biochemical Urine Tests

\section{OP-014 \\ ELUCIDATION OF INTERACTION BETWEEN CTX-M-15 AND QUERCETIN BY MOLECULAR DYNAMICS SIMULATIONS}

Aysegul Saral $^{1}$, Emrah Sariyer $^{2}$

${ }^{1}$ Artvin Coruh University, Faculty of Health Sciences, Department of Nutrition and Dietetics, Artvin, Turkey

${ }^{2}$ Artvin Coruh University, Vocational School of Health Services, Medical Laboratory Techniques, Artvin, Turkey

OBJECTIVES: Global dissemination of CTX-M ESBLs and the limited options for treating infections caused by CTX-M-producing bacteria pose major challenges in clinical settings. In order to overcome CTX-M-mediated antibiotic resistance, phytochemicals which inhibits this enzyme can be used. The quercetin is a heterocyclic flavonoid and known to have anti-beta lactamase activity. MATERIALS and METHODS: Avibactam, sulbactam, clavulanic acid, tazobactam, and quercetin were docked to target protein CTX-M-15 in the previous study. In this study, the complexes were simulated for $100 \mathrm{~ns}$ by molecular dynamics methods to reveal information about whether the ligands docked at the target molecule remained stable at the initial binding position.

RESULTS: The average RMSD of avibactam, sulbactam, clavulanic acid, tazobactam and quercetin with CTX-M-15 were calculated as $1.04,1.16,1.23$, 1.05 and 1.10 during $100 \mathrm{~ns}$, respectively. Clavulanic acid was moved away 
from binding cavity about $10 \mathrm{~ns}$ and the interaction with CTX-M-15 completely disappeared at the end of simulation. But avibactam, sulbactam, tazobactam and quercetin remained binding-pocket along MD simulation. The effects of ligands on the secondary or primary structures of the CTX-M-15 were analyzed considering the fluctuation of each residue $\mathrm{C} \alpha$. Since the position of the clavulanic acid was most changing, the highest RMSD value and fluctuation were calculated in the clavulanic-acid with CTX-M-15 complex.

CONCLUSIONS: According to these results, quercetin was suggested to remain in the catalytic pocket of CTX-M-15 like other $\beta$-lactamases inhibitors. The results obtained in silico studies are predicted to be preliminary study for in vitro studies to discover natural compounds quercetin and similar bioactive compounds.

Keywords: B-Lactamases, Antibiotic Resistance, Quercetin, Molecular Dynamics Simulation

\section{OP-016 \\ SERUM ADVANCED GLYCATION END PRODUCTS AND THEIR SOLUBLE RECEPTORS LEVELS IN PATIENTS WITH SICKLE CELL ANEMIA AND THEIR RELATIONSHIP WITH DISEASE SEVERITY}

Bagdagul Emlik ${ }^{1}$, Oguzhan Ozcan ${ }^{1}$, Gul Ilhan ${ }^{2}$, Abdullah Arpaci $^{1}$

${ }^{1}$ Hatay Mustafa Kemal University, Faculty of Medicine, Department of Medical Biochemistry, Hatay, Turkey

${ }^{2}$ Hatay Mustafa Kemal University, Faculty of Medicine, Department of Hematology, Hatay, Turkey

OBJECTIVES: Sickle cell anemia (SCA) is an inherited blood disease and causes oxidative stress. Advanced glycation end products (AGEs) are formed non-enzymatically by Maillard reaction of protein structures and carbohydrates within the cell. We aimed to investigate serum AGE and their soluble receptors sRAGE levels in patients with SCA.

MATERIALS and METHODS: Patients with SCA at crisis $(n=30)$ and noncrisis period $(n=30)$ and gender and age-matched healthy controls $(n=30)$ were included in the study. Blood samples were obtained from all patients and healthy controls. After centrifugation at $1500 \mathrm{x}$ g for $30 \mathrm{~min}$., serum samples were portioned and stored at $-80^{\circ} \mathrm{C}$. Serum MDA, TAS and TOS levels were measured by spectrophotometric method and OSI values were calculated. Serum IL-6, TNF- $\alpha$, AGE, and sRAGE levels were measured by ELISA method. RESULTS: Serum MDA, AGE and IL-6 levels were found to be significantly higher and sRAGE levels lower in patients with SCA at both crisis and noncrisis period compared to controls $(\mathrm{p}<0.016)$. Serum TNF- $\alpha$, TOS and calculated OSI values were found to be significantly higher in patients with crisis compared to both controls and patients at non-crisis period $(\mathrm{p}<0.016)$. There was a weak positive correlation between TNF- $\alpha$ and IL-6 $(r=0.325, p=0.011)$

CONCLUSIONS: We found that serum AGE and sRAGE levels are associated with the pathogenesis of SCA and may have a potential as markers for disease severity. Acknowledgements: This work was supported by Hatay Mustafa Kemal University Scientific Research Projects Coordination Unit (project no, 18YL021). Keywords: Sickle Cell Anemia, Oxidative Stress, Advanced Glycation end Products

\section{OP-017 \\ LIVER-KIDNEY FUNCTIONS, SPHINGOLIPID LEVELS AND INFLAMMATION IN EXPERIMENTAL ER STRESS MODEL}

Mutay Aslan $^{1}$, Ozlem Elpek ${ }^{2}$, Bahar Akkaya ${ }^{2}$, Hazal Tuzcu Balaban ${ }^{2}$, Ebru Afsar ${ }^{1}$

${ }^{1}$ Akdeniz University Medical Faculty, Department of Medical Biochemistry,

Antalya, Turkey

${ }^{2}$ Akdeniz University Medical Faculty, Department of Pathology, Antalya,

Turkey

OBJECTIVES: Disorders of the endoplasmic reticulum (ER) lead to cellular damage but can cause cell death if ER dysfunction is prolonged. We aimed to examine liver/kidney functions, neutral sphingomyelinase (N-SMase) activity, sphingolipid levels, cytosolic phospholipase A2 (cPLA2) and cyclooxygenase-2 (COX-2) protein expression in rats under ER stress. MATERIALS and METHODS: ER stress was induced by tunicamycin (TM) and the ER stress inhibitor taurodeoxycholic acid (TUDCA) was injected before induction of ER stress. ER stress was confirmed by increased tissue levels of GRP78. Hematological and biochemical profiles were measured by autoanalyzers while hepatic and renal injury was evaluated via microscopy and histopathological scoring. Tissue levels of C16-C24 sphingomyelins (SM), C16-C24 ceramides (CERs) and sphingosine-1-phosphate (S1P) were determined by LC-MS/MS. Tissue cPLA2 and COX-2 were measured by western blot and activity assays. RESULTS: Tunicamycin treatment caused kidney and liver function test abnormalities, increased hematocrit and hemoglobin levels but decreased white blood cell counts. Histopathological findings showed hepatic necroinflammation and renal tubular damage in rats treated with TM. TUDCA administration attenuated WBC abnormalities and TM- induced hepatic/renal functional impairment in ER stress, as evident by significantly restored serum ALT, AST, creatinine, and total bilirubin levels. A significant increase was observed in
N-SMase activity, tissue levels of C16-C24 CERs, cPLA2 and COX-2 expression in liver and kidney tissue under ER stress. TUDCA administration decreased tissue CER levels, cPLA2 and COX-2 expression as well as prostaglandin E2 (PGE2) formation.

CONCLUSIONS: These results signify that ER stress causes hepatic and renal toxicity as well as CER-induced PGE2 formation in liver and kidney. Keywords: Endoplasmic Reticulum Stress, Ceramide, Cytosolic Phospholipase A2, Cyclooxygenase-2

\section{OP-018 \\ THE IMPACT OF THE COVID-19 PANDEMIC ON LABORATORY LOGISTICS MANAGEMENT}

Merve Ergin Tuncay

Department of Biochemistry, Ankara Yildirim Beyazit University, Faculty of Medicine, Ankara City Hospital, Biochemistry Laboratory, Ankara, Turkey

OBJECTIVES: The aim of the study was to investigate the impact of COVID-19 outbreak on laboratory logistics management.

MATERIALS and METHODS: The impact of the pandemic on logistics management was mainly evaluated by number of biochemical parameters affected.The 6 months before and after pandemic were compared.The effect of increasing and decreasing test numbers on logistics management will be evaluated under the headings of additional equipment and personnel requirement, problems encountered in kit and material supply.

RESULTS: The number of tests of catecholamines and its metabolites decreased from $233.83 \pm 61.21$ and $326.17 \pm 67.16$ months before the pandemic to $93.83 \pm 67.3$ and $123.17 \pm 103.7$ after the pandemic $(\mathrm{p}<0.05)$. While the number of protein $\mathrm{C}$ and $\mathrm{S}$ tests was $202.17 \pm 10.42$ and $194.16 \pm 9.64$ before the pandemic, it decreased to $114.83 \pm 61.54$ and $118.17 \pm 64.85$ after the pandemic $(\mathrm{p}<0.05)$. According to the contract, catecholamines and their metabolites and Proteins $\mathrm{C}$ and S, whose monthly test number is below 200 started to be sent to the contracted accredited external laboratory.In contrast to the decreasing test numbers, the number of D-dimer tests increased from $3670.5 \pm 583.14$ in the 6 months before the pandemic to $29910.17 \pm 16627.82$ after the pandemic $(p<0.05)$. Due to the increasing number of tests in parameters such as D-dimer and the inadequate capacity of the device additional devices were required.

CONCLUSIONS: This study reflects how logistics management of Central Laboratory of Ankara City Hospital, which is Turkey's largest pandemic hospital, is affected by the pandemic.Faced with environmental factors such as pandemics and natural disasters, it will guide us and laboratory logistics managements about what may be encountered in the laboratory and how to take measures. Keywords: COVID-19, Laboratory, Laboratory Parameters, Outbreak, Service Procurement

\section{OP-019}

\section{USE OF PROCALCITONIN IN COVID-19 PATIENTS}

Fikret Akyurek

Selcuk University, Faculty of Medicine, Department of Medical Biochemistry, Konya, Turkey

OBJECTIVES: The coronavirus (COVID-19) infection is a life threatening disease. It has been reported that there is a relationship between various biomarkers and disease severity. Procalcitonin (PCT) is secreted by many tissues in the body in response to sepsis. PCT is usually not affected in viral infections. PCT is considered as a prognostic marker in patients with sepsis. PCT testing is an efficient but costly marker. In this study, we aimed to evaluate the effectiveness of the use of PCT in COVID-19 patients.

MATERIALS and METHODS: This study was performed by cross-sectional evaluation of the PCT test requested from our laborator, in the same period, from COVID-19 patients and patients other than COVID-19. In this study, 1598 COVID patient and 1604 patients results without COVID-19 were included.The RESULTS: In COVID- 19 patients, $85 \%$ of PCT levels were $<0.5,8 \%$ were $0.5-2$ and $7 \%$ were $>2$, while in other patients, $69 \%$ of PCT levels were $<0.5,16 \%$ were 0.5 - and $15 \%$ were $>2$. In the COVID- 19 positive group, the low PCT percentage was higher than the other group.

CONCLUSIONS: There are studies reporting an increase in PCT levels in COVID-19 patients. This increase may be due to secondary infections. It is necessary to act rationally in the use of PCT. We think that early in the period PCT requests are high in COVID-19 patients. PCT should not be the first test to be requested in patients who are not considered for sepsis and whose general condition is good.

Keywords: COVID-19, Laboratory, Procalcitonin 
OP-020

\section{THE EFFECT OF URIC ACID LEVEL ON MORTALITY IN PATIENTS WITH FUNGAL INFECTION IN INTENSIVE CARE UNIT}

\section{Elif Binboga}

UHS, Bakirkoy Dr. Sadi Konuk Training and Research Hospital, General Surgery Department, Intensive Care Unit, Istanbul, Turkey

OBJECTIVES: Uric acid is synthesized from xanthine by the xanthine oxidase enzyme as the end product of purine metabolism. Uric acid is an important nonenzymatic antioxidant in the blood and exerts a protective effect on vitamin C. This study aimed to evaluate the use of uric acid level as a biomarker in predicting mortality outcomes in intensive care patients with fungal infections.

MATERIALS and METHODS: The data of 144 patients who were treated in the ICU for surgical or non-surgical reasons between 2018 and 2019 at the Dokuz Eylul University and who were found to have fungal infection were retrospectively analyzed. Patients older than 18 years of age who were hospitalized for the first time and stayed in the hospital for at least 24 hours, and the presence of fungal infection was included in the study. Demographic data, hospitalization diagnoses, comorbid diseases, inflammatory markers (crp, wbc, neu, serum uric acid levels, type of fungal infection, localization, hospitalization time and mortality results of the patients were evaluated.

RESULTS: $46 \%$ of the patients were women and 54\% were men. Arrhythmia increases mortality 3.2 times $(p=0.034)$ and malignancy increases 3.7 times $(p=$ $0.009)$. Increasing the Apache score increases mortality. Increased uric acid level increased survival 1.28 times $(\mathrm{p}=0.017)$, while uric acid $\leq 2.3 \mathrm{mg} / \mathrm{dl}$ may be associated with high mortality $(\mathrm{p}=0.002)$.

CONCLUSIONS: Fungal infections are common conditions in icu, increasing the length of stay and mortality. High uric acid level is a significant parameter in predicting mortality due to its antioxidant properties.

Keywords: Intensive Care, Mortality, Uric Acid

\section{OP-021 \\ THE ROLE OF HEMATOLOGICAL PARAMETERS IN PATIENTS WITH COVID-19 DIAGNOSIS}

Sueda Ucar, Fikret Akyurek, Bahadir Ozturk, Ali Unlu

Department of Biochemistry,Selcuk University Faculty of Medicine, Konya, Turkey

OBJECTIVES: SARS-CoV-2 is a viral infection that is transmitted mainly through the respiratory tract and has a multisystemic effect, with high morbidity and mortality. We aimed to contribute to the use of SARS-CoV-2 in this disease by examining its effect on hematological parameters.

MATERIALS and METHODS: In the study, the complete blood count (CBC) data of 118 COVID-19 patients diagnosed with COVID 19 by PCR test and 206 trauma patients as the control group were used in the study. The data were taken from the hospital automation system. CBC analyzes were performed on Beckman Coulter DXH 800 device using laser method.

RESULTS: The tests showing parametric distribution were expressed as mean $\pm \mathrm{SD}$ in the patient and control groups, respectively. For hemoglobin $[13.23 \pm$ $2.19 ; 2.29 \pm 2.08 ; \mathrm{p}<0.001]$ for RBC $[4.68 \pm 0.74 ; 4.32 \pm 0.66 ; \mathrm{p}<0.001]$. The tests showing nonparametric distribution were expressed as median (min-max) in patient and control groups. Accordingly, WBC [6.9 (2.5-32.1); 9.25 (3.6$30.2) ; \mathrm{p}<0.001]$, neutrophil count [4.4 (0.2-29.6); $6.29(2.38-27.24) ; \mathrm{p}<0.01)]$, Lymphocyte $[1.5(0-4.2) ; 1.66(0.4-8) ; \mathrm{p}=0.010]$. Eosinophil [0 (0.10.9); 0.10$1) ; \mathrm{p}<0.001]$, basophil [0.0 (0.0.2;0.041 $(0-0.21) ; \mathrm{p}<0.001]$ and monocyte 0.6 $(0-2.4)$ : $0.61(0.2-1.6) ; \mathrm{p}=0.06)$ found as. Units $\mathrm{Hgb}(\mathrm{g} / \mathrm{dL}), \mathrm{Rbc}(1012 / \mathrm{L})$, WBC; neutrophil; Lymphocyte; Eosinophil, basophil, Monocytes (K/uL)

CONCLUSIONS: Among the hematological parameters in COVID-19 patients, WBC, neutrophil count, lymphocyte count, eosinophil count, basophil count were significantly lower, hemoglobin was significantly higher. Increased hemoglobin level may be a prognostic marker in patients diagnosed with COVID-19.

Keywords: COVID-19, SARS-CoV-2, Hematological Parameters

\section{OP-022 \\ COMPARISON OF ANTISTREPTOLYSIN O, NEUTROPHIL, MONOCYTE, AND BASOPHIL COUNTS TO ALBUMIN AND LYMPHOCYTE RATIOS IN PANIC DISORDER WITH HEALTHY CONTROLS}

Mehmet Hamdi Orum

Kahta State Hospital, Psychiatry, Adiyaman, Turkey

OBJECTIVES: Although various hemogram and biochemistry parameters in panic disorder (PD) have been studied, the relationship of antistreptolysin $\mathrm{O}$ (ASO) and albumin with immune blood cells has not been investigated yet. PD causes various physiological symptoms such as palpitations, tremors, sweating, shortness of breath, numbness, and tingling. PB creates a general arousal-activity increase in the body. Considering that physiological changes may affect blood parameters, it was hypothesized that the hemogram and biochemistry parameters of PD patients will also differ compared to healthy people. In this study, we aimed to compare PD and healthy controls in terms of the ratios of the above mentioned parameters to each other.

MATERIALS and METHODS: In this retrospective study, the hemogram and biochemistry parameters of the PD and control groups measured with the "CELL-DYN 3700 SL Analyzer" and the "UniCel® DxI 800 Immunoassay System" were compared. Chi-square and independent samples t test were used. PD patients were selected from those who applied to the psychiatry outpatient clinic and had not used any medical drugs for at least the last six month. The healthy control group was selected from people who did not have any medical illness or medication. Forty-eight subjects with psychiatric or organic disorders other than PD were excluded from the patient group and 35 subjects from the control group.

RESULTS: The PD group consisted of 100 subjects ( 57 females, 43 males) and the control group consisted of 81 subjects ( 43 females, 38 males). The groups were similar in terms of mean age $(\mathrm{p}=0.356)$ and gender $(\mathrm{p}=0.599)$. While there were no significant differences between PD and control groups in terms of albumin $(p=0.452)$, lymphocyte count $(p=0.960)$, eosinophil count $(p=0.866)$, lymphocyte to albumin ratio $(p=0.327)$, eosinophil to lymphocyte ratio $(p=0.224)$; there were significant differences between PD and control groups in terms of neutrophil $(p=0.002)$, monocyte $(p=0.046)$, basophil count $(p=0.003)$, ASO to albumin ratio (AAR) $(\mathrm{p}<0.001)$, neutrophil to albumin ratio (NAR) $(\mathrm{p}=0.002)$, neutrophil to lymphocyte ratio (NLR) $(\mathrm{p}=0.003)$, monocyte to lymphocyte ratio $(\mathrm{p}=0.032)$ and basophil to lymphocyte ratio (BLR) $(\mathrm{p}=0.008)$.

CONCLUSIONS: Like many psychiatric disorders, PD is known to be associated with inflammation. ASO and such hemogram parameters are also reliable inflammation biomarkers. This study is the first study investigating the ratios of ASO, albumin and hemogram parameters. According to our study, biomarkers such as AAR, NAR, NLR, and BLR can be used to reflect the increased inflammatory status in PD.

Keywords: Antistreptolysin O, Panic Disorder, Albumin, Hemogram, Neutrophil to Lymphocyte Ratio

\section{OP-023 \\ EVALUATION OF ANTIOXIDANT AND ANTICANCER EFFECTS OF MALVA VERTICILLATA PLANT GROWING IN NORTH CYPRUS}

Ozde Buda $^{1}$, Duygu Gencalp ${ }^{2}$, Namik Kerkuklu ${ }^{2}$, Gokturk Biner $^{1}$, Emre Turgal $^{1}$, Dilara Polat $^{1}$, Fatma Irdem ${ }^{1}$, Nazife Kasapoglu ${ }^{1}$, Ergul Multu Altundag ${ }^{2}$ ${ }^{1}$ Eastern Mediterranean University, Faculty of Medicine, Famagusta, TRNC ${ }^{2}$ Eastern Mediterranean University, Faculty of Medicine, Medical Biochemistry, Famagusta, TRNC

OBJECTIVES: The extractions of certain plant species such as Malvaceae had been a subject of interest because of their varying levels of antioxidant and anticancer activities, as well as being used as a remedy for a set of diseases. In this study, the leaves of Malva verticillata (M. verticillata) which is an edible plant growing in North Cyprus and known as "mallow" in public, are used to assess potential in-vitro antioxidant or anticancer effects. Currently any study demonstrating those potential activities of $M$. Verticillata plant that is growing in North Cyprus, has not been found in the literature.

MATERIALS and METHODS: The experimental study was carried out by using standard chemical assay procedures. The antioxidant effects of the methanol extract of M.Verticillata was measured by using standard chemical assay procedures: $\alpha$-diphenyl- $\beta$-picrylhydrazyl (DPPH) free radical scavenging method, total phenolic content (TPC) and total flavonoid content (TFC) and anticancer activity was investigated on MCF-7 breast cancer cell line via MTT assay.

RESULTS: The highest antioxidant activity of $M$. verticillata methanol extract at the specified concentrations was found as $69.35 \% \pm 3.3 \%$ at $70 \mathrm{mg} / \mathrm{ml}$. At the same concentration $(70 \mathrm{mg} / \mathrm{ml})$, TPC was measured as $499 \pm 7.5 \mu \mathrm{g} / \mathrm{mg}$ extract and TFC was calculated as $502 \pm 1.8 \mu \mathrm{g} / \mathrm{ml}$ extract.

CONCLUSIONS: The conducted study serves evidence regarding the significant antioxidant and anticancer activities of $M$. Verticillata methanol extract. Keywords: Anti-Cancer, Antioxidant, Malva Verticillata, MCF-7, North Cyprus

\section{OP-024 \\ DISCORDANCE BETWEEN THE CLAIMS AND THE EVIDENCE PROVIDED BY HIGH-IMPACT CELL CULTURE STUDIES}

Ali Burak Ozkaya ${ }^{1}$, Caner Geyik ${ }^{2}$

Izmir University of Economics, Faculty of Medicine, Department of Medical Biochemistry, Izmir, Turkey

${ }^{2}$ Istinye University, Faculty of Medicine, Department of Medical Biochemistry, Istanbul, Turkey

OBJECTIVES: There is a robustness and reproducibility crisis in preclinical studies leading to decreased success rate in clinical trials, waste of resources and workforce. Cell culture studies dominating preclinical phase suffer from the crisis most severely and many approaches including cell line authentication, procedural standardization and design changes are suggested for improvement. In the current study we focused on another aspect of the problem and investigated if the evidence provided by preclinical studies is justified for their claims. 
MATERIALS and METHODS: We retrieved cell culture studies published in 2017 or 2018 containing at least one preclinical claim via Web of Science. We selected the articles cited the most and created an online spreadsheet in which we included each preclinical claim of these articles as well as the evidence provided by the authors to support these claims. Then we investigated validity of 282 claims asserted by 121 high-impact articles.

RESULTS: We determined that the 110 of 282 claims (39\%) lacks proper evidence, including 3 claims of apoptosis evidenced by tetrazolium reduction assay results. These claims without proper evidence were asserted by 68 unique articles each of which received 136 citations in average as of October 2020.

CONCLUSIONS: According to our findings there is an undeniable discordance between the claims and the evidence provided by high-impact cell culture studies. Researchers must be meticulous about the terminology as well as the sufficiency of the evidence provided by the chosen methods to support claims while designing or evaluating scientific work.

Keywords: Pre-Clinical, Cell Culture, Robustness, Reproducibility

\section{OP-025 \\ AN EXPERIMENTAL STUDY THAT INVESTIGATE EFFECTS OF ATRELEUTON IN METABOLIC SYNDROME}

Tevfik Noyan, Burhanettin Sertac Ayhan

Department of Medical Biochemistry, Ordu university, Ordu, Turkey

OBJECTIVES: The inflammation, LDL oxidation, and insulin resistance play an important role in the development of metabolic syndrome (MetS). It was aimed to investigate the effects of atreleuton on serum lectin-like oxidized low-density lipoprotein receptor-1 (LOX-1), leukotriene B4 (LTB-4), insulin and glucose transporter 4 (GLUT-4) levels in fat tissue in rats modeled on Mets.

MATERIALS and METHODS: For this aim, MetS was induced in rats by a highfructose and fat fed diet for 10 weeks. The rats were randomly divided into 3 groups: normal control (group 1, n=7), MetS control group treated with saline (group 2, $\mathrm{n}=8)$, MetS groups treated with atreleuton $(1,25 \mathrm{mg} / \mathrm{kg} /$ day $)$ orally for the last 4 weeks (group 3, $n=8$ ). The measurements of test parameters were performed by ELISA method.

RESULTS: The atreleuton caused to significantly decrease on levels of serum LTB-4 $(\mathrm{p}<0.001)$, LOX-1 $(\mathrm{p}<0.01)$, insulin $(\mathrm{p}<0.01)$, and homeostatic model assessment for insulin resistance (HOMA-IR) $(\mathrm{p}<0.001)$, while significantly increase on quantitative insulin sensitivity check index (QUICKI) $(p<0.01)$. However, no significant difference in tissue GLUT-4 level was found ( $p>0.05)$. CONCLUSIONS: In conclusion, the present study suggests that atreleuton might be a protect agent that improves the complications of MetS via decreased LTB-4 and LOX-1. The effects of atreleuton on tissue GLUT-4 pathway are also limited. Keywords: Atreleuton, GLUT-4, Insulin Resistancei, LOX-1,LTB-4

\section{OP-026}

\section{BENZIMIDAZOLIUM SALT AND BIOLOGICAL PROPERTIES}

Huseyin KARCI ${ }^{1}$, Muhammed Dundar ${ }^{2}$, Ilknur Ozdemir ${ }^{1}$, Nevin Gurbuz ${ }^{1}$ Ahmet $\mathrm{Koc}^{3}$

${ }^{1}$ Department of Chemistry, Faculty of Arts and Sciences, Inonu University, 44280-Malatya, Turkey

${ }^{2}$ Department of Medical Biology and Genetics, School of Medicine, Inonu University, Malatya, Turkey

${ }^{3}$ Department of Molecular Biology and Genetics, Faculty of Arts and Sciences, Inonu University, 44280-Malatya, Turkey

OBJECTIVES: Imidazolium salts can be classified as ionic liquids (ILs). Imidazolium salts (IMSs) are best known for their application in organic synthesis in ionic liquids at room temperature or as precursors of stable carbens, but they also show important biological properties. A wide range of these salts have been used as anti-inflammatory, antibacterial, antifungal and thromboxane synthetase enzyme inhibitors. We aim to use the benzimidazolium salt we synthesized in the treatment of various diseases in medicine and in the pharmaceutical industry MATERIALS and METHODS: The new benzimidazolium salt 1- (4- (tertbutyl) benzyl) -3- (2,2-diethoxyethyl) -5,6-dimethylbenzimidazolium bromide was synthesized according to the literature with alkyl halide in DMF [3] and 1 -alkylbenzimidazole. Characterization of azolium salts was explained by $1 \mathrm{H}$ NMR, 13C NMR and microanalysis techniques. In the next step, biological activity (such as antibacterial, antifungal) properties were investigated according to the EUCAST method.

RESULTS: Antifungal and antimicrobial test results; Candida Albicans 50 $\mu \mathrm{g}$ $/ \mathrm{ml}$, Candida Glabrata $200 \mu \mathrm{g} / \mathrm{ml}$ from yeast species with antifungal and antimicrobial activities subgroup of fungi, and Staphylococcus Aureus $12.5 \mu \mathrm{g}$ $/ \mathrm{ml}$, Pseudomonas Aeruginosa $800 \mu \mathrm{g} / \mathrm{ml}$, Escherichia Eoli $400 \mu \mathrm{g} / \mathrm{ml}$ bacteria species - MIC $(\mu \mathrm{g} / \mathrm{mL}) 1)$ their values were calculated.

CONCLUSIONS: The compounds were characterized by NMR spectroscopy (1H- and 13C-NMR). When MIC values were examined, it was found that the most active activity showed activity against $\mathrm{S}$. aureus bacteria. Activities at various intervals have also been observed in other bacteria and yeasts.

Keywords: Bezimidazolium Salts, Antimicrobial, Antibacterial

\section{OP-027 \\ OXIDATIVE STRESS AND PARAOXONASE ACTIVITY IN PREMATURE RETINOPATHY}

Mustafa Kalayci ${ }^{1}$, Ersan Cetinkaya ${ }^{1}$, Ayhan Vurmaz ${ }^{2}$

${ }^{1}$ Health Sciences University Antalya Training and Research Hospital

Ophthalmology Clinic, Antalya, Turkey

${ }^{2}$ Afyon Kocatepe University Faculty of Medicine Hospital Biochemistry Clinic, Afyon, Turkey

OBJECTIVES: The sharp transition from an intrauterine environment with low oxygen content to an environment with higher oxygen content after birth in premature babies exposes the baby to oxidative stress due to the low effectiveness of antioxidant protection. Autoregulation of the blood network of the retina is sufficient in a narrow perfusion pressure range in premature babies. Lack of autoregulation leads to retinal hyperoxia. The disruption in the balance of pro-oxidants and antioxidants initiates the inflammatory process in the retinal tissue that leads to the development of retinopathy of prematurity. Paroxonase 1 (PON 1) has antioxidant properties as it prevents the increase in the amount of reactive oxygen species by hydrolyzing lipid peroxidation products. It also protects the cell from damage caused by oxidative stress. Arylesterase (ARE)enzyme is accepted as the indicator of the main protein that is not affected by changes in PON 1. Assessment of total antioxidative stress (TAS) and total oxidative stress (TOS) in body fluid has been used as one of the biomarkers to monitor oxidative stress in humans. Our aim in this study is to investigate the effect of the development of retinopathy of prematurity on oxidant antioxidant balance and PON 1 serum level in preterm babies MATERIALS and METHODS: TAS, TOS, ARE and PON 1 at postmenstrual week 36 in preterm retinopathy (ROP) screening in babies born between August2018 and August2019 at 32 weeks and before blood serum levels were checked. The control group consisted of 16 patients, 11 babies with ROP were determined as the patient group. Results were compared between both groups. RESULTS: There was no significant difference between the groups in terms of gender, birth weight and gestational week. When the TAS, TOS and ARE results were examined, no significant difference was found between the groups. PON was found statistically higher $(\mathrm{p}=0.029)$ in the group with retinopathy $(62 \pm 48 \mathrm{U} / \mathrm{L})$ compared to the control group $(31 \pm 18 \mathrm{U} / \mathrm{L})$ CONCLUSIONS: Newborns, especially preterm babies, are at an increased risk of injury mediated by oxidative stress. Vascular dysregulation of the retina and reduced ocular perfusion result in hypoxia. When hypoxia continues for a long time, the regulation mechanisms of the cell are disrupted.As a result, reactive oxygen derivatives and free radicals and Vascular endothelial growth factor (VEGF) increase. It is known that VEGF is responsible for normal retinal vascularization, stops retinal vasoproliferation by decreasing at high oxygen levels and then is released from endothelial cells in response to hypoxia and causes neovascularization. In our study, possible compensatory increase in PON1 in preterm babies made the baby think of a protective factor from oxidative stress. We thought that PON could be a more reliable marker in terms of antioxidant protection in premature retinopathy. Further studies with more patients are needed to determine this.

Keywords: Premature Retinopathy, TAS, TOS, Arylesterase, Paraoxonase

\section{OP-028 \\ DETERMINATION OF ANTIOXIDANT EFFECTS OF SILYBUM MARIANUM (THISTLE) AND ARTEMISIA ABSINTHIUM (WORMWOOD) PLANTS}

Erkan Oner $^{1}$, Ilter Demirhan ${ }^{2}$, Ergul Belge Kurutas ${ }^{3}$

Mersin University, Faculty Of Pharmacy, Biochemistry, Mersin, Turkey ${ }^{2}$ Harran University, Health Occupation High-School, Biomedical Device Tecnology, Sanliurfa, Turkey

${ }^{3}$ Sutcu Imam University, Medical Faculty, Medical Biochemistry,

Kahramanmaras, Turkey

OBJECTIVES: Beacause of growing anxiety on synthetic antioxidants. Plants which has antioxidant structre, it is started to concern. As a result of metabolic activity in all cell reactiving oxidation, free radicals are formed, antioxidants press to free radicals, it has very important functions about press to oxidative stress. Purpose of this study, being searched of antioxidan activitive to harbs extraction for Silybum Marianum (Milk thistle) and Artemisia Absmthium(wormwood). MATERIALS and METHODS: Silybum marianum and Artemisia Absmthium gathered around Kahramanmaras country between June 2020-October 2020 dates. After dived plants specimens are pulverized with a mechanical grinder, getting $10 \mathrm{gr}$ as sample extracded with $100 \mathrm{ml} \% 70$ methanole and then fixed in herbs extraction same methods like catalase (CAT), superoxcid dismutase (SOD) enzym activites oxidative stress, indicator of oxidative stress malondialdehyde. RESULTS: It was found SOD;679,06 $\pm 0,98 \mathrm{U} / \mathrm{g}$ CAT; $121,1 \pm 0,21 \mathrm{U} / \mathrm{g}$ and MDA; $52,45 \pm 0,12 \mathrm{nmol} / \mathrm{g}$ for Silybum marianum plants and it was found $\mathrm{SOD} ; 592,3 \pm 0,65 \mathrm{U} / \mathrm{g}, \mathrm{CAT} ; 98 \pm 0,33 \mathrm{U} / \mathrm{g}$ and MDA;69,8 $\pm 0,11 \mathrm{nmol} / \mathrm{g}$ for Artemisia absthium plant. Compering the results of Silybum marianum and Artemisia absthium plants, it was found to have higher antioxidant capacity of silybum marianum plants.

CONCLUSIONS: Silybum marianum and Artemisa absthium plants have antioxidant capacity. Silybum marianum plants is more effective than artemisia 
XXXI. National Congress of the Turkish Biochemical Society 2020

absthium plant. It is thought that herbs which we used in this study, will lead complementery medicine studies.

Keywords: Silybum Marianum, Artemisia Absinthium, Antioxidan

\section{OP-029 \\ EVALUATION OF SUITABLE ANTICOAGULANT AND DIFFERENT ENVIRONMENTAL CONDITIONS FOR ADRENOCORTICOTROPIC HORMONE MEASUREMENT}

Ayse Ulusoy, Neslihan Sungur, Humeyra Acikan, Hatice Saracoglu, Didem Barlak Keti, Sabahattin Muhtaroglu

Department of Medical Biochemistry, Erciyes University, Kayseri, Turkey

OBJECTIVES: Adrenocorticotropic hormone (ACTH) is unstable in whole blood due to proteolytic degradation. Therefore, the samples must be stored on ice until centrifuged, centrifuged in a cooled centrifuge and analyzed within one hour. In this study; it was aimed to evaluate and compare how different anticoagulants, stored blood at different temperatures and times affect values in ACTH measurement.

MATERIALS and METHODS: Blood was drawn into EDTA, citrate, heparin and serum tubes from 8 healthy volunteers. Samples were centrifuged for 10 minutes in a cooled centrifuge at $4000 \mathrm{rpm}$. Samples were analyzed on Roche Cobas ${ }^{\circledR} 8000$. ACTH values of samples taken to other tubes were compared with routine EDTA tube. In addition, 8 plasma samples into EDTA tubes were stored taken at $+4^{\circ} \mathrm{C}$ for 2,8 and $24 \mathrm{~h}$; stored at the room temperature for $60,90,120$ and 240 minutes. The results were compared with the values measured without waiting at $+4{ }^{\circ} \mathrm{C}$ and room temperature (standard conditions). A change of more than $10 \%$ in ACTH concentration was considered clinically significant

RESULTS: Statistical analysis was performed with SPSS version 23.0 software Normality of the data repeated measurements were evaluated with the ANOVA test. ACTH concentrations were 5.6- $73 \mathrm{pg} / \mathrm{mL}$. When compared with the standard conditions, a statistically significant difference $(\mathrm{p}<0.05)$ was determined in the ACTH values of the samples using different anticoagulants, stored at room temperature and $+4^{\circ} \mathrm{C}$. ACTH values measured in only serum tube didn't differ clinically significant. Bias\% was observed as 7.23 for serum. Clinically significant difference wasn't showed in samples stored at room temperature for up to 120 minutes. A clinically significant difference was observed in the samples stored at $+4^{\circ} \mathrm{C}$ for $24 \mathrm{~h}(-15.77 \%)$.

CONCLUSIONS: Since there is no clinically significant difference, it has been suggested that a more practical and widely used serum tube may be preferred as an alternative to EDTA tube. In addition, plasma samples whose ACTH values are compared store at different temperatures; It has been determined that it may store for 2 hours at room temperature and 8 hours at $+4^{\circ} \mathrm{C}$.

Keywords: ACTH, Anticoagulant, Temperature

\section{OP-030 \\ THE EFFECTS OF VARIOUS PLANT GROWTH REGULATORS ON OVARY CULTURE IN PHASEOLUS VULGARIS L}

Asli Kucukrecep $^{1}$, Ilknur Akca ${ }^{1}$, Dilek Tekdal ${ }^{1}$, Selim $_{\text {Cetiner }}{ }^{2}$, Rustu Hatipoglu ${ }^{3}$ ${ }^{1}$ Department of Biotechnology, Institute of Science, Mersin University, Mersin, Turkey

${ }^{2}$ Biological Sciences and Bioengineering Program, Faculty of Engineering and

Natural Sciences, Sabanci University, Istanbul, Turkey

${ }^{3}$ Department of Field Crops, Faculty of Agriculture, Cukurova University,

Adana, Turkey

OBJECTIVES: This research aims to understand whether obtaining the entire plant from the ovary culture of Phaseolus vulgaris L. is possible using different concentrations and combinations of kinetin, 2,4-D, and activated charcoal in this study. Totally 40 different media were tested on 10 bean genotypes. This study>s second aim addresses another area that has received any attention in the literature: ovary culture in Turkish bean genotypes.

MATERIALS and METHODS: Unfertilizated ovaries of bean genotypes were picked on the day of anthesis, sliced in sterile conditions, and then cultured on MS medium supplemented with different concentrations of kinetin $(0,0.5,1.0$, $\left.2.0 \mathrm{mg} \mathrm{L}^{-1}\right), 2,4-\mathrm{D}\left(0,0.5,1.0,2.0 \mathrm{mg} \mathrm{L}^{-1}\right)$, and activated charcoal $(0,0.5,1.0$ $\mathrm{mg} \mathrm{L}^{-1}$ ). Ovary explants were incubated at $26^{\circ} \mathrm{C}$, having 4000 lux light density, possessing a $16 / 8 \mathrm{~h}$ light/ dark photoperiod for 2 months. The polyploidy level of the samples cultured was analyzed by flow cytometry analysis. The reaction rate of samples was determined by applying variance analysis in the MSTAT-C statistical package program.

RESULTS: As a consequence of ovary culture, callus formation occurred in all samples cultured, and the highest callus induction rate was $15.8 \%$ and obtained from MS, including Kinetin $\left(2.0 \mathrm{mg} \mathrm{L}^{-1}\right)$ and 2,4-D $\left(0.5 \mathrm{mg} \mathrm{L}^{-1}\right)$. All samples were diploid. No regeneration existed on the samples cultured in media, including activated charcoal.

CONCLUSIONS: Although ovary culture has been widely conducted in various plant species, to date there is no consideration has been given to the ovary culture of local genotypes of $P$. vulgaris $\mathrm{L}$.

Acknowledgments: The study described here was carried out within the Project (No. 1190003) funded by the Scientific and Technological Research Council of
Turkey (TUBITAK)

Keywords: 2,4-D, Activated Charcoal, Kinetin, Phaseolus Vulgaris L.

\section{OP-031 \\ GLUCOSE-POTASSIUM RATIO IN THE DIAGNOSIS OF POLYCYSTIC OVARY SYNDROME}

Doc. Dr. Kemal Turker Ulutas ${ }^{1}$, Dr. Serif Hurriyetoglu ${ }^{2}$

${ }^{1}$ Medical Biochemistry, Reyhanli State Hospital, Hatay, Turkey

${ }^{2}$ Gynecology and Obstetrics, Reyhanli State Hospital, Hatay, Turkey

OBJECTIVES: Screening in individuals with polycystic ovary syndrome (PCOS) is necessary to minimize long-term risks and metabolic morbidity. In the study, the biochemical analysis value of glucose-potassium $(\mathrm{Gp})$ ratio in individuals with PCOS was investigated.

MATERIALS and METHODS: The research was designed as a retrospective laboratory analysis study. According to the study criteria, 44 PCOS patients and 38 healthy individuals participated in the study. The Gp ratio was calculated by dividing venous blood fasting glucose by the potassium value.

RESULTS: Compared to the control group, the Gp value was significantly higher in PCOS $(p<0.0001)$. The area under the ROC curve for Gp ratio was 0.811 $(\mathrm{p}<0.001)$. According to the ROC analysis, the cut-off value of the Gp ratio for PCOS diagnosis was calculated as 19.7 at $79 \%$ sensitivity and $83 \%$ specificity. CONCLUSIONS: The Gp ratio showed strong sensitivity and specificity for PCOS, which showed that it might have a diagnostic value for PCOS. Keywords: Polycystic Ovary, Glucose-Potassium Ratio, Index, Marker

\section{OP-032}

\section{作 ARREST SPECIFIC PROTEIN 6, AXL AND SAXL PATHWAYS IN PATIENTS WITH TYPE 2 DIABETES}

Yasemin Atici ${ }^{1}$, Gulden Baskol$^{2}$, Fahri Bayram ${ }^{3}$

${ }^{1}$ Department of Medical Biochemistry, Lokman Hekim University, Ankara, Turkey

${ }^{2}$ Department of Medical Biochemistry, Erciyes University, Kayseri, Turkey ${ }^{3}$ Department of Internal Medicine, Erciyes University, Kayseri, Turkey

OBJECTIVES: Gas6/Axl signaling to be roles in regulating tissue homeostasis, inflammatory cytokine release, vascular disease, carcinogenesis and metabolic disorders associated with glucose intolerance. This research aimed to investigate the effects of Metformin and Metformin-Insulin combination, which are used in Type 2 Diabetes (T2DM) treatment on Growth Arrest Specific Protein 6, Axl and sAxl.

MATERIALS and METHODS: Patients applied to Erciyes University Faculty of Medicine who were diagnosed with T2DM, will start metformin treatmen and will start using insulin in combination with metformin are prospectively evaluated. Patients were divided into 4 groups as the Control group, Prediabetic group, Metformin group, Metformin + Insulin group. Gas6, Axl and sAxl levels within patients' serums obtained from their 0 . month and 6 . month blood samples were measured according to ELISA method.

RESULTS: In our study, no statistically significant change was found in the values of Gas6, Axl and sAxl in the groups who did not receive medication. However, there was a statistically significant decrease in Gas6 and Axl values for those diagnosed with T2DM; the Met group, who were diagnosed with T2DM, using metformin, and Met+Ins group whose metformin treatment was not sufficient and insulin was added to their treatment. On the other hand, there was no statistically significant change in sAxl values for these two group of patients. CONCLUSIONS: While Metformin, used in the treatment of T2DM, is regulating the blood glucose levels, it is thought to inhibit the Gas6/Axl pathway with various mechanisms. We think that this study will be clinically useful in designing therapeutic approaches targeting Gas6/Axl. Keywords: Gas6, Axl, sAxl, Tip 2 Diabetes Mellitus

\section{OP-033 \\ THE ASSOCIATION OF SERUM 15D-PGJ VE PPAR GAMMA LEVELS WITH METABOLIC SYNDROME IN PATIENTS WITH SCHIZOPHRENIA}

Kubranur Unal ${ }^{1}$, Rabia Nazik Yuksel ${ }^{2}$

${ }^{1}$ Gazi University Faculty of Medicine, Department of Medical Biochemistry, Ankara, Turkey

${ }^{2}$ Ankara City Hospital, Department of Psychiatry, Ankara, Turkey

OBJECTIVES: Many hypotheses have been proposed for the development metabolic syndrome in patients with schizophrenia, including the one proposing that exogenous and endogenous factors are linked to metabolic processes. In this study, it was aimed to examine the levels of serum 15d-PGJ and PPAR $\gamma$ levels in schizophrenia patients in order to elucidate the metabolic syndrome (MS).

MATERIALS and METHODS: Fourty patients with schizophrenia and fourty 
healthy controls were included in the study. According to ATP-III A criteria, $8(20 \%)$ of 40 patients has MS. Serum 15d-PGJ and PPAR gamma levels of schizophrenic patients with MS have been compared with both healthy controls and schizophrenia patients without MS.

RESULTS: Serum 15d-PGJ and PPAR gamma levels were significantly lower in schizophrenia patients without MS with respect to the healthy control group.There is no significant statistical difference between schizophrenia patients with MS and schizophrenia patients without MS in terms of 15d-PGJ and PPAR gamma levels. And there is no significant statistical difference between schizophrenia patients with MS and the control group.

CONCLUSIONS: In our study, the fact that 15d-PGJ and PPAR gamma levels were significantly lower in schizophrenia patients without MS with respect to the healthy control group does not comply with the literature. This suggests that the findings may be related not only to the MS but also to the pathogenesis of schizophrenia. It will be useful to examine the prostaglandin receptor relations with the data obtained from future studies in terms of understanding how the metabolic syndrome affects the etiology of the disease in schizophrenia.

Keywords: Schizophrenia, 15d-PGJ, PPAR Gamma, Metabolic Syndrome

\section{OP-034 \\ ACADEMIC EXAMINATION STRESS: EFFECTS ON SALIVARY CORTISOL, NEUROPEPTIDE Y AND INTERLEUKIN-1 $\beta$}

$\underline{\text { Rabia Semsi }}^{1}$, Emre Kanad Er ${ }^{2}$, Erdal Ergunol ${ }^{3}$, Aylin Sepici Dincel ${ }^{1}$ ${ }^{1}$ Department of Medical Biochemistry, Faculty of Medicine, Gazi University, Ankara, Turkey

${ }^{2}$ Department of Oral and Maxillofaxial Surgery, Faculty of Dentistry, Cyprus

Health and Social Sciences University, Morphou, TRNC

${ }^{3}$ Department of Oral and Maxillofaxial Surgery, Faculty of Dentistry,

International Cyprus University, Nicosia, TRNC

OBJECTIVES: Saliva is one of the preferred non-invasive body fluid for the biomarker studies. The aim of this study is to investigate the possible alteration of stress biomarkers of the students before and after the examinations by using cortisol, neuropeptide Y (NPY) and Interleukin-1 $\beta$ (IL-1 $\beta$ ) salivary levels.

MATERIALS and METHODS: Forty-four adults were included in the study and divided to two groups as pre-stress (Group I) and post-stress (Group II) groups. Salivary samples were collected between 8-9 am in the morning before the exam and after the exam that was ended at $5 \mathrm{pm}$ by SARSTEDT saliva collection tubes. Participants were asked to soak the swab with saliva and take out after 1 minute. Swabs were kept 15-30 minutes at room temperature and centrifuged for $10-15 \mathrm{~min}$ at $1500 \mathrm{~g}$. Salivary cortisol $(\mathrm{ng} / \mathrm{mL})$, NPY $(\mathrm{ng} / \mathrm{mL})$ and IL-1 $\beta$ $(\mathrm{pg} / \mathrm{mL})$ levels were analysed by Enzyme-linked immunosorbent assay (ELISA). RESULTS: The salivary cortisol, NPY and IL-1 $\beta$ levels were significantly increased in Group II compared to Group I $(9.65 \pm 4.53 \mathrm{ng} / \mathrm{mL}, 6.37 \pm 4,14 \mathrm{ng} / \mathrm{mL}, \mathrm{p}<0,019$; $27.10 \pm 4.71 \mathrm{ng} / \mathrm{mL}, 32.12 \pm 4.69 \mathrm{ng} / \mathrm{mL}, \mathrm{p}<0,001 ; 11.69 \pm 3.61 \mathrm{pg} / \mathrm{mL}, 7.20 \pm 3.49$ $\mathrm{pg} / \mathrm{mL}, \mathrm{p}<0,001$, respectively). The IL- $1 \beta$ levels were positively and significantly correlated with the salivary cortisol and NPY levels in Group II $(r=0.642$, $p=0.03 ; r=0.589, p=0.004$, respectively). Also, IL-1 $\beta$ levels were positively and sionificantly correlated with salivary NPY levels in Group I $(r=0.430, p=0.04)$. CONCLUSIONS: These data indicated that acute stress can alter inflamatory response and increase NPY release which is positively associated with cortisol. Keywords: Saliva, Neuropeptide Y, Interleukin-1 $\beta$, Stress

\section{OP-035 \\ PREDICTION OF LDL CHOLESTEROL CONCENTRATION BY ARTIFICIAL INTELLIGIENCE}

Hikmet Can Cubukcu ${ }^{1}$, Deniz Ilhan Topcu ${ }^{2}$

${ }^{1}$ Maresal Cakmak State Hospital Biochemistry Laboratory, Erzurum, Turkey

${ }^{2}$ Baskent University Faculty of Medicine Department of Medical Biochemistry,

Ankara, Turkey

OBJECTIVES: Low-density lipoprotein cholesterol (LDL-C), an evidence-based target for cardiovascular risk management, can be estimated by Friedewald and Martin-Hopkins formulas. We developed alternative LDL-C prediction models using multiple artificial intelligence methods and investigated the validity of the new models, Friedewald and Martin-Hopkins formulas in the Turkish population. MATERIALS and METHODS: The laboratory data (n: 58030) of directly measured LDL-C, high-density lipoprotein cholesterol, triglycerides (TG), and total cholesterol were partitioned into train and test data. Linear regression, gradient boosted trees, and artificial neural network models were formed from train data. The homogenous assay was regarded as a reference method for models' training. Group comparisons, correlation, and regression analysis of LDL-C prediction models were performed for the different TG concentrations range from test data. LDL-C classification performances were evaluated for essential LDL-C concentration ranges.

RESULTS: For TG levels $<177 \mathrm{mg} / \mathrm{dL}$, Friedewald, Martin-Hopkins formulas, and other models agreed with the homogenous assay. For TG levels $\geq 177 \mathrm{mg}$ / $\mathrm{dL}$, the Friedewald formula underestimated and the Martin-Hopkins formula overestimated LDL-C $(\mathrm{p}<0.001)$, which was substantial for LDL-C $<70 \mathrm{mg} /$ $\mathrm{dL}$. Linear regression, gradient boosted trees, and artificial neural network models outperformed Friedewald and Martin-Hopkins formulas for TG $>177$ and LDL-C $<70$ based upon comparison $(\mathrm{p}>0.001)$ with homogenous assay and classification accuracy.

CONCLUSIONS: Friedewald and Martin-Hopkins formulas are valid for TG levels $<177 \mathrm{mg} / \mathrm{dL}$. However, linear regression, gradient boosted trees, and artificial neural network models offer more accurate alternatives to the Friedewald and Martin-Hopkins formulas, especially for TG levels 177-399 mg/ $\mathrm{dL}$ and LDL-C levels $<70 \mathrm{mg} / \mathrm{dL}$.

Keywords: Low-Density Lipoproteins, Cholesterol, Lipid, Artificial Intelligence, Machine Learning

\section{OP-036 RELATIONSHIP BETWEEN MEAN PLATELET VOLUME-
LYMPHOCYTE RATIO IN PATIENTS WITH CORONARY ECTASIA}

Bedri Caner Kaya

Health Sciences University, Mehmet Akif Inan Training and Research Hospital, Sanliurfa, Turkey

OBJECTIVES: Inflammation markers may play a part in the pathogenesis of coronary artery ectasia (CAE).The aim of this study was to investigate the relationship between, the mean platelet volume to-lymphocyte ratio (MPVLR) an easily available inflammatory marker, and CAE.

MATERIALS and METHODS: After applying the exclusion criteria, the retrospective study population consisted of 184 patients, including 88 patients with isolated CAE, and 96 with normal coronary artery angiograms (NCA). The MPVLR and mean platelet volume (MPV) were measured as part of the automated complete blood count. The severity of isolated CAE was determined according to the Markis classification. SPSS 24.0 statistical package program was used for data analysis

RESULTS: Baseline demographic characteristics and medical history of groups were similar. The level of MPV $(10.83 \pm 1.13$ vs $10.04 \pm 1.12$ vs; $<<0.001)$, MPVLR (5.38 \pm 2.54 vs $4.87 \pm 2.27$; p:0.042) were significantly higher in CAE group than control subjects. In ROC analysis, a cut-off value of 4.49 for MPVLR had an $71 \%$ sensitivity and a $62 \%$ (Area Under Curve [AUC]: 0.695 95\%CI $0.616-0.714$; p: $0.000<0.001)$.

CONCLUSIONS: To the best of our knowledge, this study showed for the first time that MPVLR was significantly associated with CAE.

Keywords: Coronary Artery Ectasia, Inflammation, Platelet-to-Lymphocyte Ratio

\section{OP-037 \\ THE EFFECT OF TRAUMA ON SERUM BDNF LEVELS IN SPORTSMEN}

Murat Ozan ${ }^{1}$, Yusuf Buzdagli², Nurcan Kilic Baygutalp ${ }^{3}$, Neslihan Yuce ${ }^{4}$, Ebubekir Bakan ${ }^{4}$, Fatih Baygutalp

${ }^{1}$ Ataturk University Kazim Karabekir Education Faculty, Department of Physical Education and Sports, Erzurum, Turkey

${ }^{2}$ Erzurum Technical University Faculty of Sport Sciences, Department of Physical Education and Sports, Erzurum, Turkey

${ }^{3}$ Ataturk University Faculty of Pharmacy, Department of Biochemistry, Erzurum, Turkey

${ }^{4}$ Ataturk University Faculty of Medicine, Department of Medical Biochemistry, Erzurum, Turkey

${ }^{5}$ Ataturk University Faculty of Medicine, Department of Physical Medicine and Rehabilitation, Erzurum, Turkey

OBJECTIVES: BDNF has an important role in neuron development and maintenance of functions. In this study, it was aimed to investigate the effects of acute and chronic trauma on serum BDNF levels.

MATERIALS and METHODS: Serum BDNF levels were determined in 40 male elite athletes (boxing; n:10, teakwando; n:10, wrestling; n:10, soccer; n:10) before and after vigorous exercise (training match) with a high probability of being traumatized to the head region; and in 10 sedentary men (control group) before and after exercise (Astrand running protocol).

RESULTS: Serum BDNF levels were found as $11,50 \pm 5,00 \mathrm{ng} / \mathrm{ml} \mathrm{ng} / \mathrm{ml}$ before exercise and $14,02 \pm 6,29 \mathrm{ng} / \mathrm{ml}$ after exercise in the athlete group $(\mathrm{p}=0,02)$; and $12,18 \pm 6,55 \mathrm{ng} / \mathrm{ml}$ before exercise and $11,74 \pm 1,48 \mathrm{ng} / \mathrm{ml}$ in the sedentary group respectively $(p=0,873)$. Serum BDNF levels before exercise (baseline) were slightly lower in the athlete group than those in the sedentary group $(11,50 \pm 5,00$ and $12,18 \pm 6,55 \mathrm{ng} / \mathrm{ml}$, respectively), but the difference between groups is not significant $(\mathrm{p}=0,796)$.

CONCLUSIONS: As a result of the comparison of the values before and after exercise in the athlete groups, it was observed that serum BDNF levels did not decrease after acute trauma and exercise had an increasing effect on BDNF levels. As a result of the comparison of pre-exercise (baseline) values of athletes and sedentary individuals, it was seen that the chronic effects of trauma did not significantly reduce serum BDNF levels in athletes. Even if athletes are exposed to acute trauma, they may be protected from the chronic effects of trauma thanks to the protective effect of their non-sedentary lifestyle. Keywords: BDNF, Exercise, Trauma 


\section{OP-038 \\ HYPOTHYROIDISM AND BONE REMODELING: CONSTRUCTION OR DESTRUCTION?}

Fatih Kar

Eskisehir Osmangazi University, Faculty of Medicine, Department of Medical Biochemistry, Eskisehir, Turkey

OBJECTIVES: Thyroid hormones affect multiple organ systems and bone metabolism may be closely related to thyroid dysfunction. There are contradictory results in the literature regarding the production-destruction effects of TSH levels on bone turnover. In this study, we aimed to investigate the relationship between thyroid function tests and osteocalcin, parathyroid hormone (PTH), phosphorus, calcium and alkaline phosphatase (ALP) levels as markers of bone metabolism MATERIALS and METHODS: The data of patients $(n=182$, age $>18)$ who applied to Eskisehir Osmangazi University Hospital between January 2015 and November 2019 were used retrospectively. Patients with any bone disease, chronic disease and malignancy were excluded from the study. All data were evaluated statistically using SPSS 21 package program. The patients were divided into two groups according to their TSH levels and the markers were compared between these groups. Results are shown with median values of $25-75 \%$ and percentile. $\mathrm{P}<0.05$ values were considered statistically significant.

RESULTS: There were 115 (66 men, 49 women) patients (TSH=0.27-4.2 $\mu \mathrm{IU} /$ $\mathrm{ml}$ ) in the euthyroid group and 67 (34 men, 33 women) patients (TSH $>4.2 \mu \mathrm{IU} /$ $\mathrm{ml})$ in the subclinical hypothyroidism group. Serum osteocalcin $(\mathrm{ng} / \mathrm{mL})$ and PTH $(\mathrm{pg} / \mathrm{mL})$ levels were higher in the hypothyroid group $(26,35[18,98-41,31]$ ve $51,54[39,52-79,04]$, respectively) than in the euthyroid group $(22,54[18,25-$ $32,16]$ ve $42,85[31,80-62,67]$, respectively) $(\mathrm{p}<0.05)$. There was no statistically significant difference in ALP (U/L), phosphorus and calcium $(\mathrm{mg} / \mathrm{dL})$ levels between the groups

CONCLUSIONS: In subclinical hypothyroidism, high bone mass accompanying elevated TSH levels may be caused by increased osteocalcin levels. The increase in PTH levels may be due to the apoptosis inhibitory feature of osteoblast cells. Monitoring of bone markers in patients with subclinical hyperthyroidism who are treated to suppress TSH levels may be important in maintaining bone turnover homeostasis.

Keywords: Thyroid Dysfunction, Osteocalcin, PTH, ALP, Bone Metabolism

\section{OP-039 \\ THE ROLE OF ADROPIN AND IRISIN IN NONALCOHOLIC HEPATOSTEATOSIS IN THE PREOBESE AND OBESE INDIVIDUALS}

Yaprak Sule Orek $^{1}$, Cuma Mertoglu' ${ }^{1}$, Bulent Albayrak ${ }^{2}$, Yusuf Arslan ${ }^{1}$, Abdulkadir Coban ${ }^{1}$

${ }^{1}$ Departman of medical biochemistry, Erzincan Binali Yildirim University, Erzincan, Turkey

${ }^{2}$ Departman of internal diseases, Ataturk University, Erzurum, Turkey

OBJECTIVES: Nonalcholic fatty liver disease (NAFLD) is a disease that is considered to be the hepatic appearance of metabolic syndrome, which can be seen in healthy people with higher rates of obesity and type 2 diabetes. It was investigated the relationship between serum irisin and adropin levels withhepatosteatosis in preobese and obese adults with NAFLD. MATERIALS and METHODS: A total of 89 individuals were divided into four groups. Group 1; healthy people with normal weight $(n=25)$ (Body mass index (BMI); $18,5 \mathrm{~m} 2 / \mathrm{kg}-24,9 \mathrm{~m} 2 / \mathrm{kg}$ ), Group 2; preobez(BMI; $25 \mathrm{~m} 2 / \mathrm{kg}$ $29,9 \mathrm{~m} 2 / \mathrm{kg})$ and obese (BMI $\mathrm{m} 2 / \mathrm{kg} \geq 30)$ individuals $(\mathrm{n}=17)$ without NAFLD, Group 3; preobese and obese individuals with grade 1 hepatosteatosis $(n=24)$ with NAFLD and Group 4; preobese and obese individuals with grade 2 hepatosteatosis with NAFLD $(n=23)$. Demographic data of all subjects were recorded. Abdominal ultrasonography and anthropometric measurements were performed. Serum adropin and irisin levels were carried out by ELISA method. RESULTS: The serum adropin and iris levels were lower in group 3 and 4 with NAFLD than healthy group (Group 1$)(\mathrm{p}=0.006, \mathrm{p}=0.001$, respectively). However, adropine and irisin levels were similar between groups 3 and 4 with NAFLD. CONCLUSIONS: The reduction in serum adropin and irisin levels may play a role in the development of NAFLD regardless of the severity of the disease in preobese and obese individuals however this reduction is not associated with the severity of the disease.

Keywords: Nonalcoholic Fatty Liver Disease (NAFLD), Obesity, Adropin, Irisin

\section{OP-040}

\section{MEASUREMENT OF TWEAK LEVELS, WHICH IS AN INDICATOR OF ENDOTHELIAL DYSFUNCTION, BEFORE AND AFTER RADIOACTIVE IODINE TREATMENT}

Asena Gokcay Canpolat ${ }^{1}$, Arzu Kosem ${ }^{2}$, Mustafa Sahin ${ }^{1}$

${ }^{1}$ Department of Endocrinology and Metabolism, Ankara University, Ankara,

Turkey

${ }^{2}$ Ankara City Hospital, Medical Biochemistry Clinic, Ankara, Turkey

OBJECTIVES: Tumor necrosis factor-like weak inducer of apoptosis (TWEAK) is a member of the tumor necrosis factor (TNF) superfamily. Soluble form (sTWEAK) can be detected in plasma and has been shown to be associated with various diseases such as atherosclerosis, auto-immun diseases including hashimoto tiroiditis and graves orbitopathy. Moreover, radioactive iodine (RAI) treatment is accused of atherosclerosis with the evidence of increased intima media thickness of carotid artery independent of age and sex. As a novel biomarker of atherosclerosis and endotelial dysfunction, we aimed to evaluate the TWEAK levels before and after the RAI treatment for thyrotoxicosis.

MATERIALS and METHODS: This study was conducted with 26 patients who underwent RAI treatment for thyrotoxicosis. Hyperthyroidism was diagnosed according to thyroid function tests, thyroid ultrasonography,scintigraphy and radio-iodine uptake tests. Toxic nodular goitre, toxic multinodular goitre and relapses of toxic diffuse goitre were randomly assigned. Tweak levels were analyzed with ELISA method. Serum TSH, fT3, fT4 levels were assessed using a direct chemiluminescence immunoassay. Tweak levels before and 3 months after RAI treatment were recorded. Euthyroidism was restored at 3 months of treatment. Wilcoxon test was used to compare Tweak levels before and after RAI treatment. Carotis intima media thickness is measured in a small proportion of the patients, so, was not given in the abstract of the study.

RESULTS: Mean age was found $56 \pm 12,3$ years. The median Tweak levels before treatment was found $82(22-564) \mathrm{pg} / \mathrm{ml}$ and after treatment was $76(26-$ 454) $\mathrm{pg} / \mathrm{ml}$. The median TSH levels $(\mathrm{p}<0,01)$ and free T3 levels $(\mathrm{p}: 0,01)$ were found to be different while free T4 (p:0,06) and Tweak levels (p: 0,84) were found to be same before and after treatment

CONCLUSIONS: Although Tweak was suggested to be a biomarker for RAI induced endotelial dysfunction and atherosclerosis, we did not find such a difference for Tweak levels. The short time ( 3 months) elapsed from the RAI treatment could be a reason for our findings. Further studies on the long term of evaluation will further clarify the effectiveness of this novel biomarker for atherosclerosis.

Keywords: Thyrotoxicosis, Radioactive Iodine Treatment,Tweak, Atherosclerosis

\section{OP-041 \\ THIOL/DISULPHIDE HOMEOSTASIS IN PATIENTS WITH HASHIMOTO'S THYROIDITIS}

Emre Avci ${ }^{1}$, Alpaslan Karabulut ${ }^{2}$, Burcu Baba ${ }^{3}$, Gulcin Alp Avci ${ }^{1}$, Tugba Uysal Kilic ${ }^{1}$, Cumhur Bilgi ${ }^{3}$

${ }^{1}$ Faculty of Science and Arts, Department of Molecular Biology and Genetics,

Hitit University, Corum, Turkey

${ }^{2}$ Faculty of Medicine, Department of Internal Medicine, Hitit University,

Corum, Turkey

${ }^{3}$ Faculty of Medicine, Department of Biochemistry, Yuksek Ihtisas University, Ankara, Turkey

OBJECTIVES: Hashimoto's thyroiditis is a common cause of goiter and acquired hypothyroidism in individuals residing in areas of no iodine deficiency. Thiol/ disulphide homeostasis is crucial in antioxidative protection, detoxification, cell growth and apoptosis. It is believed that this homeostasis plays a very significant role in immune etiopathogenesis and the thiol/disulphide imbalance triggers the disease through oxidative stress and tissue inflammation. In this study, we aimed to investigate thiol/disulphide homeostasis in patients with Hashimoto's thyroiditis (HT).

MATERIALS and METHODS: A total of 112 HT patients and 120 healthy individuals were included in this study. The diagnosis of HT was determined according to the presence of parenchymal heterogeneity in thyroid ultrasonography and anti-TG and/or anti-TPO positivity in serum. Age (18-55 years for patients 25-55 years for controls), gender, TSH, anti-TPO, anti-TG, HDL cholesterol, and triglyceride levels were recorded. Anti-TPO and Anti-Tg were evaluated with chemiluminescence immunoassay. Thiol-disulfide homeostasis parameters were measured through automated spectrophotometric methods.

RESULTS: The TSH, anti-TPO and anti-Thyroglobulin, total thiol and disulphide levels, and also the levels of disulfide/total thiol and disulfide/native thiol were found to be significantly higher in Hashimoto patients when compared to controls $(p<0.05)$; however, the native thiol levels were lower $(p<0.05)$. While there was a negative correlation $(\mathrm{r}=-.859)$ between disulfide and native thiol, a positive correlation $(\mathrm{r}=.542)$ was detected between disulfide and total thiol. CONCLUSIONS: Thiol-disulfide balance in Hashimoto patients changes in favor of oxidants. Thiol-disulfide data may play an important role in observing the oxidative damage occurring in Hashimoto patients.

Keywords: Hashimoto's Thyroiditis, Oxidative Stress, Thiol/Disulphide Balance 


\section{OP-042 \\ IMPACT OF THE COVID-19 INFECTION ON THE PEOPLE WITH G6PD DEFICIENCY IN RELATION TO THE HEMOGRAM AND BIOCHEMISTRY RESULTS}

Duygu Aydemir ${ }^{1}$, Gulcin Daglioglu ${ }^{3}$, Aslihan Candevir ${ }^{4}$, Behice Kurtaran ${ }^{5}$, Tamer Cevat Inal ${ }^{6}$, Nuriye Nuray Ulusu ${ }^{2}$

${ }^{1}$ Koc University School of Medicine, Istanbul, Turkey

${ }^{2}$ Koc University Research Center for Translational Medicine (KUTTAM),

Istanbul, Turkey

${ }^{3}$ Cukurova University, Faculty of Medicine, Hospital Central Laboratory, Adana, Turkey

${ }^{4}$ Cukurova University, Faculty of Medicine, Infectious Disease and Clinic

Microbiology, Adana, Turkey

${ }^{5}$ Cukurova University, Faculty of Medicine, Department of Infectious Diseases,

Adana, Turkey

${ }^{6}$ Cukurova University, Faculty of Medicine, Department of Medica

Biochemistry, Adana, Turkey

OBJECTIVES: COVID-19 has become the major public health problem since December, 2019 worldwide and no treatment or vaccine have been found until now. Elderly population and people with secondary diseases such as diabetes, cancer, hypertension, cardiovascular diseases, endocrine diseases and metabolic syndrome. However people without comorbidities or individuals belonging to the young population have died because of COVID-19 infection. We have suggested that people with enzyme deficiencies including glucose- 6 phosphate dehydrogenase (G6PD) deficiency may become more vulnerable against COVID-19 infection.

MATERIALS and METHODS: We have evaluated hemogram and biochemistry results of two male patients at the same age and one them is diagnosed as G6PD deficiency.

RESULTS: Serum biochemistry and inflammation markers including CRP, fibrinogen, D-Dimer, total bilirubin, lactate, ALT, AST, ferritin, glucose and eGFR increased in the G6PD deficient patient, where CK levels decreased. WBC, MCH, Hgb, lymphocyte \#, lymphocyte \%, eosinophil \%, basophil \%, HCT and PLT levels as hemogram parameters decreased in the G6PD deficient upon COVID-19 infection, however monocyte \% and RDW levels increased during infection. On the other hand, magnesium, sodium, potassium, calcium and levels were evaluated in both patients to evaluate electrolyte balance. Only calcium levels decreased in G6PD deficient patient within 2 weeks following diagnosis. CONCLUSIONS: Clinical data showed that COVID-19 infection causes severe symptoms in the G6PD-deficicent patients. Our clinical report is important, because we have showed that currently used drugs may worsen COVID-19 symptoms in the G6PD deficient patients infected by COVID-19. Keywords: COVID-19, Oxidative Stress, Hemogram, Biochemistry, G6PD Deficiency

\section{OP-043 \\ RETROSPECTIVE COMPARISON OF PATIENTS WITH COVID-19 AND NORMAL INDIVIDUALS IN TERMS OF BIOCHEMISTRY PARAMETERS}

$\underline{\text { Hale Gok Dagidir }}^{1}$, Gulislam Agacan $^{2}$, Birce Eda Ercan $^{3}$, Nazrin Tombul $^{1}$, Neslihan Bukan

${ }^{1}$ Department of Medical Biochemistry, Gazi University, Ankara, Turkey ${ }^{2}$ Department of Forensic Medicine, Gazi University, Ankara, Turkey ${ }^{3}$ Department of Emergency Medicine,Beytepe Murat Erdi Eker State Hospital, Ankara, Turkey

OBJECTIVES: Coronavirus disease 2019 (COVID-19) is an infectious disease caused by a newly discovered type of coronavirus, identified as "severe acute respiratory syndrome coronavirus 2" (SARS-CoV-2). COVID-19 was declared a global epidemic by the WHO on March 11, 2020. The aim of this retrospective study is to evaluate the differences and correlations of biochemical parameters in blood between individuals with COVID 19 and other patients.

MATERIALS and METHODS: 294 individuals with COVID-19, including 148 women and 146 men, participated in the study, and a control group of 294 people, 157 women and 134 men, participated. The COVID-19 group was selected among people who were diagnosed with COVID-19 through PCR at the Infectious Diseases department of Gazi University Medical Faculty Hospital between April, May and June 2020. The control group was selected from patients who had not been diagnosed with COVID through PCR before and who did not have known chronic disease or any kind of malignant neoplasms registered in the system. The ethics committee permission was obtained from Gazi University Clinical Research Ethics Committee. Blood biochemistry parameters of the two groups; Glucose, BUN, Creatinine, Total cholesterol, HDL cholesterol, Triglyceride, TSH, T4, Insulin, Serum iron, Serum iron binding capacity, Ferritin, Vitamin B12, Folic acid, Calcium, Sodium, Potassium, Chlorine, AST, ALT, GGT, ALP, Procalcitonin, $\mathrm{D}$ dimer, CRP, Sedimentation, Fibrinogen were retrospectively analyzed. RESULTS: The mean age was 44,44 in the COVID-19 group, whose ages ranged from 18 to 90 , and the mean age was 39,23 in the control group, whose ages were between 18 and 83. According to our study; AST (n:577), GGT (n:520), ferritin $(n: 231)$, glucose $(n: 410)$, creatinine $(n: 580)$, calcium $(n: 475)$, sodium $(n: 578)$ and potassium (n:567) values were significantly different between COVID-19 patients and the control group $(\mathrm{p}<0,05)$

CONCLUSIONS: There are many unknowns in COVID-19. Our study shows the biochemical blood parameters of patients with COVID-19 at early stages of the disease. In order to better understand the damage caused by Sars-Cov-2 to the human body, it is very important to follow up with patients in the long term. Our study has limitations due to its retrospective nature, some parameters were not analyzed in the number of persons in equal proportions in both groups. Biochemical analytes such as D-Dimer, Fibrinogen, Procalcitonin, which determine prognosis, were examined in the COVID-19 group, although very few individuals in the control group were examined. Therefore, it may not have given meaningful results. Keywords: COVID-19, Biochemistry, Blood parameters

\section{OP-044 \\ THE RELATIONSHIP BETWEEN CLINICAL CHARACTERISTICS OF COVID-19 PATIENTS AND HYPOALBUMINEMIA}

Abdulkadir Cat ${ }^{1}$, Elif Sargin Altunok ${ }^{2}$

${ }^{1}$ Gaziosmanpasa Training and Research Hospital, Medical Biochemistry, Istanbul, Turkey

${ }^{2}$ Gaziosmanpasa Training and Research Hospital, Infectious Diseases and Clinical Microbiology, Istanbul, Turkey

OBJECTIVES: We aimed to investigate the relationship between hypoalbuminemia and the clinical features of COVID-19 patients with common systemic inflammation.

MATERIALS and METHODS: This study was conducted retrospectively by examining the records of patients who were hospitalized between March 16 and May 1, 2020 due COVID-19 disease and whose diagnoses were confirmed by RT-PCR test. A total of 520 adult patients, 263 patients with hypoalbuminemia $(<3.5 \mathrm{~g} / \mathrm{dL})$ for whom albumin test was requested during their first hospitalization and 257 patients with normal albumin levels, were included in the study. RESULTS: $288(55.4 \%)$ of the patients included in the study were male, and $232(44.6 \%)$ were female. Average age of the patients was $59.1 \pm 16.2$. The findings related to age, hypertension, diabetes, cardiovascular diseases, chronic renal disease, cough and shortness of breath findings were significantly different between the hypoalbuminemic group and the group with normal albumin levels $(\mathrm{p}<0.05)$. Multivariate logistic regression analysis revealed that age at admission (relative risk $(\mathrm{RR})=1.036,95 \%$ confidence interval $(\mathrm{CI})=1.016-1.056$ $\mathrm{p}<0.001)$, albumin $(\mathrm{RR}=0.233,95 \% \mathrm{CI}=0.131-0.378, \mathrm{p}<0.001)$ and respiratory rate of $30 / \mathrm{min}(\mathrm{RR}=8.769,95 \% \mathrm{CI}=3.322-23.146, \mathrm{p}<0.001)$ parameters were each important independent predictors of mortality. In addition, Kaplan-Meier survival analysis showed that patients with albumin value less than $3.5 \mathrm{~g} / \mathrm{dL}$ cutoff value were significantly more likely to develop mortality $(\log$-rank, $\mathrm{p}<0.001)$ CONCLUSIONS: We think that low serum albumin levels at admission reflected the severity of systemic inflammation in COVID-19 patients and are associated with the poor clinical course of the disease.

Keywords: COVID-19, Hypoalbuminemia

\section{OP-045 \\ HEMOGRAM PARAMETERS IN PREDICTING THE NEED FOR INTENSIVE CARE IN COVID-19}

Merve Sena Odabasi ${ }^{1}$, Erdinc Serin $^{1}$, Guven Ozkaya ${ }^{3}$, Anil Akkus ${ }^{1}$,

Pinar Sucu $^{1}$, Ismet Sayan ${ }^{2}$

${ }^{1}$ Biochemistry of Department, Sisli Hamidiye Etfal Research and Trainning Hospital, Istanbul, Turkey

${ }^{2}$ Anesthesia and Reanimation of Department, Sisli Hamidiye Etfal Research and Trainning Hospital, Istanbul, Turkey

${ }^{3}$ Biostatistics of Department, Uludag University, Bursa, Turkey

OBJECTIVES: The number of COVID-19 infected patients has exceeded 40 million and deaths has exceeded 1 million. While the disease is mild in most people, it can be serious and mortal in few. Laboratory findings of the patients are important in terms of course and severity of disease. The aim of this study is to examine the relationship between hematological parameters and clinical course of patients

MATERIALS and METHODS: Routinely studied parameters were evaluated from 222 patients who applied to Sisli Hamidiye Etfal Training and Research Hospital with positive COVID-19 PCR test. Patients were followed up and categorized as those in need of intensive care $(n=37)$ and those who did not $(n=$ $185)$. The data were analyzed in SPSS program.

RESULTS: There was a significant difference between groups in terms of age $(\mathrm{p}<0.001)$ and gender $(\mathrm{P}=0.023)$. Neutrophil, RDW, PDW, MCV, NLR (neutrophil / lymphocyte ratio), PLR (platelet / lymphocyte ratio), NMR (neutrophil / monocyte ratio), procalcitonin, CRP and D-dimer values were significantly higher in patients requiring intensive care, while hemoglobin and hematocrit values were found to be significantly lower. When the values adjusted according to age and gender were examined, significant difference was observed in only neutrophils $[1.22(1.08-1.38), \mathrm{p}=0.001], \mathrm{Hb}[0.97$ $(0.95-0.99), \mathrm{p}=0.002], \mathrm{NMR}[1.05(1.02-1.09), \mathrm{p}=0.001], \mathrm{CRP}[1.00$ $(1.00-1.02), \mathrm{p}=0.003], \mathrm{D}$-dimer $[1.00(1.00-1.02), \mathrm{p}=0.037]$ parameters CONCLUSIONS: In terms of showing course of COVID-19, the most 
XXXI. National Congress of the Turkish Biochemical Society 2020

valuable indicator among laboratory parameters at the time of admission is neutrophil count, and it was found that $75 \%$ sensitivity $(95 \% \mathrm{Cl} ; 57.8-$ $87.9]$ and $78.92 \%$ specificity $[95 \% \mathrm{Cl} ; 72.3-84.6]$ for 0,814 cut-off value. Keywords: COVID-19, Intensive Care Unit

\section{OP-046 \\ THIOL-DISULPHIDE HOMOEOSTASIS IN COVID-19: EVALUATION OF RELATIONSHIP WITH COMPLETE BLOOD COUNT PARAMETERS}

Mehmet Ramazan Sekeroglu ${ }^{1}$, Erdem Cokluk ${ }^{1}$, Selcuk Yaylaci ${ }^{2}$

Ali Fuat Erdem ${ }^{3}$, Fatima Betul Tuncer ${ }^{1}$, Hamad Dheir $^{2}$, Ertugrul Guclu ${ }^{4}$ Aziz Ogutlu ${ }^{4}$, Deniz Cekic ${ }^{2}$, Abdulkadir Aydin

${ }^{1}$ Sakarya University School of Medicine, Department of Medical Biochemistry, Sakarya, Turkey

${ }^{2}$ Sakarya University School of Medicine, Medical Department of Internal

Medicine, Sakarya, Turkey

${ }^{3}$ Sakarya University School of Medicine, Department of Anesthesia and

Reanimation, Sakarya, Turkey

${ }^{4}$ Sakarya University School of Medicine, Department of Infectious Diseases,

Sakarya, Turkey

${ }^{5}$ Sakarya University School of Medicine, Department of Family Medicine,

Sakarya, Turkey

OBJECTIVES: It was aimed to evaluate the relationship between thiol-disulfide homoeostasis, and the hemogram parameters and intensive care treatment need in COVID-19 patients.

MATERIALS and METHODS: Total thiol (TT), Native thiol (NT), dynamic disulfide status (DDS), DDS/NT, DDS/TT, NT/TT ratio and CBC parameters were analyzed in 68 patients with positive COVID-19 (33 wards and 35 intensive care units) and 31 healthy individuals, The relationship of these parameters with intensive care and mechanical ventilation needed, survival and death of the patients were examined.

RESULTS: TT, NT, DD, hemoglobin and hematocrit levels were higher in the control group than in patient groups. TT, NT, DD and lymphocyte levels of COVID-19 patients treated in the ward were higher than those treated in intensive care; WBC, neutrophil and NLR were low $(\mathrm{p}<0.05)$. PLR was higher in only intensive care patients than in the control group $(p<0.05)$. When COVID-19 patients who do not need mechanical ventilation are grouped according to survival and death at the end of the process; TT, NT, DDS and lymphocyte levels were higher in survivors; WBC, Neutrophil, PLR and NLR were lower $(\mathrm{p}<0.05)$. When evaluated with ROC analysis, it was found that the decrease in TT, NT and DDS levels showed high sensitivity and specificity for the intensive care treatment needed $(\mathrm{p}<0.05)$.

CONCLUSIONS: In COVID-19, it has been observed that the thiol-disulfide balance is disrupted, and it may be beneficial to monitor the thiol-disulfide balance in the follow-up of the patients clinical processes and the processes of going to intensive care.

Keywords: COVID-19, Total Thiol, Native Thiol, Dynamic Disulfide Status, Complete Blood Count

\section{OP-047 \\ EVALUATION OF COAGULATION PARAMETERS ACCORDING TO \\ INFLAMMATION SEVERITY IN COVID-19 PATIENTS}

Sema Kardesler ${ }^{1}$, Ahmet Erkin Bozdemir ${ }^{1}$, Inanc Karakoyun ${ }^{1}$, Fatma Deme Arslan $^{1}$, Hulya Parildar ${ }^{2}$, Nisel Yilmaz ${ }^{3}$, Banu Isbilen Basok ${ }^{1}$, Ayfer Colak ${ }^{1}$ University of Health Sciences, Tepecik Training and Research Hospital, Department of Medical Biochemistry, Izmir, Turkey

${ }^{2}$ University of Health Sciences, Tepecik Training and Research Hospital, Family Medicine, Izmir, Turkey

${ }^{3}$ University of Health Sciences, Tepecik Training and Research Hospital,

Department of Medical Microbiology, Izmir, Turkey

OBJECTIVES: Cytokine storm and associated inflammation findings are seen in COVID-19 patients. In our study, we aimed to evaluate the coagulation parameters according to the severity of inflammation in COVID-19 patients.

MATERIALS and METHODS: 184 PCR positive patients over the age of 18 who applied to the emergency department and outpatient clinic were included in the study. C-Reactive protein (CRP), D-Dimer, Fibrinogen, Prothrombin Time (PT), Activated Partial Thromboplastin Time (APTT) tests were evaluated retrospectively. The cases were divided into three groups according to the CRP parameter values created according to the Ministry of Health Guide and meta-analysis studies; Group 1: CRP $<10 \mathrm{mg} / \mathrm{L}$ ( = 84), Group 2: CRP 10-40 mg / L $(\mathrm{n}=45)$ and Group 3: CRP $>40 \mathrm{mg} / \mathrm{L}$ $(\mathrm{n}=55)$. Coagulation parameters were compared between the three groups. RESULTS: Fibrinogen $(p=0.001)$ and D-Dimer $(p<0.001)$ parameters between 1st and 2nd group; PZ parameter between 2nd and 3rd group (p $=0.005)$; Fibrinogen $(\mathrm{p}=0.016)$, D-Dimer $(\mathrm{p}<0.001)$ and PT $(\mathrm{p}=0.001)$ parameters between the $1 \mathrm{st}$ and 3rd group were statisticaly significant. CONCLUSIONS: High D-Dimer and Fibrinogen parameters and PT prolongation in COVID-19 patients, especially in patients with CRP $>40 \mathrm{mg} / \mathrm{L}$, suggested that there may be changes in the hemostasis system due to the severity of inflammation

Keywords: COVID-19, C-Reactive protein, D-Dimer, Fibrinogen, Prothrombin Time

\section{OP-048 LABORATORY PARAMETERS IN EARLY STAGE CORONAVIRUS (COVID-19) PATIENTS}

Ayfer Colak $^{1}$, Veli Iyilikci ${ }^{1}$, Fatma Demet Arslan ${ }^{1}$, Inanc Karakoyunlu ${ }^{1}$, Nisel Yilmaz ${ }^{2}$, Dilek Oncel ${ }^{3}$, Banu Basok

${ }^{1}$ Health Sciences University, Tepecik Training and Research Hospital, Department of Clinical Biochemistry, Izmir, Turkey

${ }^{2}$ Health Sciences University, Tepecik Training and Research Hospital, Department of Medical Microbiology, Izmir, Turkey

${ }^{3}$ Health Sciences University, Tepecik Training and Research Hospital,

Department of Radiology, Izmir, Turkey

OBJECTIVES: The early diagnosis of COVID-19 disease, which has become a worldwide epidemic, is critical for its control and treatment of patients. For this reason, the diagnostic value of laboratory parameters in the early detection of COVID-19 disease has been investigated.

MATERIALS and METHODS: Among the patients with suspected COVID 19 who admitted to our hospital between 01 April 2020 and 30 May 2020, those with positive RT-PCR results were included in this retrospective study. Patients with normal chest CT results were considered as early stages. Chest CT results obtained with biochemical tests studied at the first application were evaluated. RESULTS: Fifty patients with negative RT-PCR and chest CT findings constituted the control group, and 80 patients with positive RT-PCR and no chest CT findings comprised the patient group. Among the groups, a significant difference was found between hemoglobin, white blood cell, neutrophil count, lymphocyte count, percentage of monocyte and serum D-Dimer, C-Reactive Protein, procalcitonin, and total bilirubin levels. In ROC analysis, percentage monosit value exhibited the largest area under the curve at 0.787 , with the highes specificity $(97.9 \%)$ and sensitivity $(50.6 \%)$.

CONCLUSIONS: Percentage monocyte value, one of the parameters of complete blood count, can guide the diagnosis of early stage COVID patients with normal CT findings.

Keywords: COVID19, Biochemical Tests, RT-PCR

\section{OP-049 \\ EVALUATION OF SARS-COV-2 IgG AND SARS-COV-2 IgM LEVELS IN COVID-19 INFECTION}

Ozlem Unay Demirel $^{1}$, Demet Yalcin ${ }^{2}$, Arif Ataberk Buyukyatikci ${ }^{3}$, Meral Yuksel $^{4}$

${ }^{1}$ Medical Biochemistry, School of Medicine Bahcesehir University Goztepe Medical Park hospital, Istanbul, Turkey

${ }^{2}$ Infectious diseases and clinical microbiology, School of Medicine Bahcesehir University Goztepe Medical Park hospital, Istanbul, Turkey

${ }^{3}$ School of Medicine, Bahcesehir University, Istanbul, Turkey

${ }^{4}$ Department of Medical Laboratory, Vocational School of Health related services, Marmara University, Istanbul, Turkey

OBJECTIVES: The SARS-Cov-2 IgM and SARS-Cov-2 IgG assays are intended to be used as an aid in the diagnosis of COVID-19 infection both with clinical presentation and other laboratory tests. We aimed to investigate SARS-Cov-2 IgG and SARS-Cov-2 IgM levels in infected patients.

MATERIALS and METHODS: Blood samples are taken from patients who have either a suspicion of SARS-Cov-2 infection or a screening purpose. SARSCov-2 IgG and SARS-Cov-2 IgM levels were analysed by a chemiluminescent microparticle immunoassay (CMIA) by Abbott Architect ci8200 (Abbott park IL, USA).

RESULTS: In this study 1025 individuals were included. The cutoff is 1.4 Index $(\mathrm{S} / \mathrm{C})$ in SARS-Cov-2 IgG and 1.0 Index (S/C) SARS-Cov-2 IgM assay. Gray zone is accepted as $0.49-1.39$ Index $(\mathrm{S} / \mathrm{C})$. In patients with a negative PCR test $5.46 \% \mathrm{IgG}$ levels and with a positive PCR test $18,5 \% \mathrm{IgG}$ levels were found to be in the gray zone.

CONCLUSIONS: Cut off values for IgG and IgM antibodies against SARS-Cov-2 is expected to change more as more research will be needed to be done in this area. Monitoring these antibodies in infected patients at specified time intervals will aid us to show developing immunity to COVID-19 infection in future. Keywords: COVID-19, SARS-CoV-2 IgM, SARS-CoV-2 IgG 


\section{OP-050 \\ EVALUATION OF NUCLEATED RED BLOOD CELL LEVELS IN SARS-COV-2 INFECTED PATIENTS}

Ozlem Unay Demirel ${ }^{1}$, Demet Yalcin ${ }^{2}$, Arif Ataberk Buyukyatikci $^{3}$, Meral Yuksel $^{4}$

${ }^{1}$ Department of Medical Biochemistry, School of Medicine, Bahcesehir University Medical Park Goztepe Hospital, Istanbul, Turkey

${ }^{2}$ Department of Infectious Diseases, School of Medicine, Bahcesehir University Medical Park Goztepe Hospital, Istanbul, Turkey

${ }^{3}$ School of Medicine, Bahcesehir University, Istanbul, Turkey

${ }^{4}$ Department of Medical Laboratory, Vocational School of Health-Related Services, Marmara University, Istanbul, Turkey

OBJECTIVES: Nucleated red blood cells (NRBC) which are precursors of red blood cells are not present in the circulation of a healthy individual. NRBC levels is a parameter of complete blood count test. Studies suggest that increased NRBC levels may be seen in hypoxia patients. Our aim is to evaluate NRBC levels in hospitalized SARS-Cov-2 infected patients with hypoxia.

MATERIALS and METHODS: Blood samples were taken into EDTA containing tubes and nasopharyngeal samples were taken from patients with SARS-Cov-2 infection.

Complete blood count levels were analysed with Sysmex XN-1000 hematology analyzer (Sysmex corporation, Kobe, Japan). Real time polymerase chain reaction (qRT-PCR) assay is performed for SARS-Cov-2 virus by Senteligo SARS-Cov-2 detection reagent.

RESULTS: In this study 79 hospitalized patients either in the intensive care unit or with SARS-Cov-2 infection were included. The level of NRBC was $0,026 \pm 0,00810^{3} / \mu \mathrm{L}$ in patients with negative COVID-19 PCR test $(n=44)$ and $0,022+0,00710^{3} / \mu \mathrm{L}$ in patients with positive COVID-19 PCR test $(n=35)$. CONCLUSIONS: Since SARS-Cov-2 infection is new, more research must be done on possible blood parameters that have an effect on the progression of the disease. Therefore analysis of NRBC levels which is practical and a part of a routine test might shed a light on the clinical course of this infection. Keywords: COVID-19, SARS-CoV-2, NRBC, Complete Blood Count

\section{OP-051 \\ INVESTIGATION OF GHRELIN HORMONE LEVEL IN ACUTE APPENDICITIS PATIENTS AND COMPARISON OF GHRELIN HORMONE LEVEL WITH C-REACTIVE PROTEIN AND WHITE BLOOD CELL LEVELS}

Rifat Peksoz

Mus State Hospital General Surgery, Mus, Turkey

OBJECTIVES: This study aims to investigate the diagnostic value of ghrelin in acute appendicitis and the correlation between ghrelin and routine laboratory tests such as white blood cell (WBC), C-reactive protein (CRP). MATERIALS and METHODS: We prospectively evaluated patients aged 1680 years who were operated for acute appendicitis between October 2018 and December 2018. Blood was preoperatively collected for ghrelin, hemogram, and CRP assessments. The patients were divided into 3 groups and evaluated in terms of age, gender, comorbidities, anorexia, ghrelin, leukocyte, CRP, and body mass index (BMI). The blood taken into the biochemistry tube for the ghrelin hormone was preserved at -80 degrees after centrifugation. Measurements were made after the frozen serum samples were dissolved. Human Ghrelin ELISA Kit Catalog No: E-EL-H1919 96T was used to study serum samples in the Biochemistry laboratory in accordance with the test procedure. RESULTS: The study included 30 healthy individuals, 29 patients with noncomplicated appendicitis, and 29 patients with complicated appendicitis. The groups were not statistically different in terms of age, gender, comorbidities, BMI, or ghrelin levels $(\mathrm{p}>0.05)$. Anorexia and leukocyte and CRP levels were significantly higher in patients with acute appendicitis $(p<0.001)$. Ghrelin level and leukocyte count were not significantly correlated. CONCLUSIONS: Serological tests such as WBC and CRP can be used in the diagnosis of acute appendicitis and in determining its severity. Ghrelin levels increased with increasing acute appendicitis severity, but this finding was not statistically significant. Further studies with larger samples are needed to better understand how appetite is affected in acute appendicitis. Keywords: Acute Appendicitis, C-Reactive Protein, Leukocyte, Ghrelin, Loss Of Appetite

\section{OP-052}

A COMPARISON OF SYMPTOMPS, COMORBID DISEASES AND LABORATORY DATA OF PATIENTS WHO DID and DID NOT SURVIVE AFTER COVID-19 DISEASE

Leyla Demir $^{1}$, Tugba Oncel ${ }^{2}$, Serap Cuhadar ${ }^{2}$, Saliha Aksun

Izmir Katip Celebi University Faculty of Medicine, Department of Medical Biochemistry, Izmir, Turkey

${ }^{2}$ IKCU Ataturk Training and Research Hospital, Department of Medical Biochemistry, Izmir, Turkey

OBJECTIVES: It was aimed to evaluate the relationship with mortality by retrospectively investigating the symptoms, comorbid diseases and laboratory data of COVID -19 patients.

MATERIALS and METHODS: Totally 113 COVID-19 PCR $(+)$ patients treated in our hospital between March-June 2020 were included Clinical and laboratory data were obtained from the hospital information system and the study group was divided into two as dead $(n=14)$ and recovered $(n=99)$. RESULTS: The median ages (min-max) of the groups with no statistica difference in terms of age and gender in the ex and recovering groups were 68(32-88) and 51(20-89) years, respectively. The most common symptoms were shortness of breath in the ex-group ( 9 patients, $64.2 \%$ ), and cough in those who recovered $(44.4 \%)$. In the ex group comorbid diseases were hypertension ( 8 patients, $57.1 \%$ ) and diabetes mellitus (4 patients, $28.6 \%$ ), in the recovered it were hypertension $(32.3 \%)$ and diabetes mellitus (16 patients, $16.2 \%)$. WBC $(\mathrm{p}=0.011)$, neutrophil $(\mathrm{p}=0.001)$, neutrophil-lymphocyte ratio $(\mathrm{N}$ $\mathrm{L}$ ratio) $(\mathrm{p}<0.001)$, CRP $(\mathrm{p}<0.001)$ were found to be significantly higher in the ex group, while lymphocytes $(\mathrm{p}=0.005)$ was found significantly lower. CONCLUSIONS: Evaluating according to the comorbidity, hypertension was found to be high in the ex group (57.1\%). Hypertension was found as one of the most common comorbid diseases accompanying COVID-19, and increasing the possibility of developing ARDS and the need for intensive care. Leukocyte and neutrophils were significantly higher and lymphocyte results were found to be significantly lower in the ex group. These fast-running tests are valuable in the follow-up of patients. CRP, the important acute phase reactant, was found to be higher in the ex group. Severe CRP elevation can be used as an indicator of clinical deterioration.

Keywords: COVID 19, Laboratory, CRP

\section{OP-053 \\ CHANGES IN PLASMA AMINO ACID LEVELS OF CRIMEAN-CONGO HEMORRHAGIC FEVER PATIENTS}

Zeynep Ertemur ${ }^{1}$, Huseyin Aydin ${ }^{2}$, Aynur Engin $^{3}$

${ }^{1}$ Sivas Cumhuriyet University Hospital Chest Surgery Department, Sivas, Turkey

${ }^{2}$ Sivas Cumhuriyet University Faculty of Medicine Department of Medical Biochemistry, Sivas, Turkey

${ }^{3}$ Sivas Cumhuriyet University Hospital Department of Infectious Diseases and Clinical Microbiology, Sivas, Turkey

OBJECTIVES: In this study, it was aimed to determine the plasma amino acid profiles and possible metabolic pathways affected in patients infected with the Crimean Congo Hemorrhagic Fever (CCHF) virus in the acute and convalescent period and to contribute to the pathophysiology of the disease.

MATERIALS and METHODS: 35 volunteers diagnosed with CCHF were selected. The blood samples taken on the first day of hospitalization of these patients were acute group, and the convalescent group was formed with blood samples taken before discharge from the hospital. A control group was formed with samples taken from 35 healthy volunteers who were similar to the patient group in terms of age and gender. Plasma amino acid levels were measured using the CE-IVD certified Jasem Amino Acid Kit in the LC-MS/MS device from the plasma obtained from these groups

RESULTS: According to the findings, when the control and acute group are compared; We found that while the amino acids taurine, phenylalanine, tyrosine, GABA, glutamate, leucine, aspartate, ornithine increased significantly $(\mathrm{p}<0.05)$, tryptophan, glutamine, proline, arginine, citrulline decreased $(\mathrm{p}<0.05)$. Was found a statistically significant decrease in plasma amino acid levels in the convalescent group (alanine, asparagine, aspartate, phenylalanine, glutamine, histidine, leucine, serine, citrulline, tyrosine, tryptophan) compared to the acute group $(\mathrm{p}<0.05)$.

CONCLUSIONS: It was observed that the amino acid profiles of CCHF patients changed between acute and convalescent periods. It shows that altered plasma amino acid levels can guide further studies to investigate its relationship with the immune system and provide an important support for the prognosis of $\mathrm{CCHF}$ disease.

Keywords: Crimean-Congo Hemorrhagic Fever (CCHF), Amino Acid, Protein, Nutrition 


\section{OP-054 \\ EFFECTS OF TOPIRAMATE ON INFLAMMATORY PARAMETERS IN MIGRAINE PROPHYLAXIS}

Ahmet Donder ${ }^{1}$, Hasan Huseyin Ozdemir

${ }^{1}$ Mardin Artuklu University, Vocational School of Health Services, Department

of Medical Services and Techniques, Mardin, Turkey

${ }^{2}$ Istanbul A Hospital, Department of Neurology, Istanbul, Turkey

OBJECTIVES: Many medical agents are used in migraine prophylaxis. Topiramate is used as a first-line treatment option for migraine prophylaxis. It has different side effects but its effects on inflammatory markers are unknown. In this study we investigate the effects of topiramate in neutrophil/lymphocyte ratio (NLR), platelet/lymphocyte ratio (PLR), and C reactive protein (CRP) with migraine patients without aura.

MATERIALS and METHODS: In our retrospective study 60 healthy controls, 75 patients who were followed up and had a diagnosis of migraine and took a topiramate therapy were evaluated before treatment, and 3 and 6 months after treatment. The number of days with pain, duration of pain and MIDAS and VAS scores, of the patients were evaluated before treatment and during the controls. RESULTS: A significant decrease was observed in the painful days, duration of pain, MIDAS and VAS scores in the evaluations in the 3 and 6 -month periods after the initiation of topiramate. Thrombocytopenia developed in two patients, generalize paresthesia in two patients, and treatment was discontinued four patients. Neutrophil count, lymphocyte count, thrombocyte count, NLR, PLR, MPV and CRP values before the topiramate treatment were statistically higher than the values at 3 and 6 months of treatment. There was no statistically significant difference between inflamatory parameters and number of days with pain, duration of pain and MIDAS and VAS scores.

CONCLUSIONS: It was seen that NLR, PLR, MPV and CRP values decreased topiramate threapy. Studies are needed to evaluate the anti-inflammatory effectiveness of topiramate in the treatment of migraine.

Keywords: Migren, Topiramate, Neutrophil/Lymphocyte Ratio (NLR), Platelet/ Lymphocyte Ratio (PLR)

\section{OP-055 \\ EVALUATION OF ADENOSINE DEAMINASE ACTIVITY IN TERMS OF INFLAMMATION IN PATIENTS WITH ROMATOID ARTHRITIS}

Humeyra Acikan, Neslihan Sungur, Ayse Ulusoy, Furkan Oguzhan Karalar, Sabahattin Muhtaroglu

Erciyes University, Faculty of Medicine, Department of Biochemistry. Kayseri, Turkey

OBJECTIVES: Rheumatoid arthritis (RA) is a chronic systemic inflammatory disease, primarily affecting the joints of hands and feet causing corrosive, symmetrical polyarthritis. Several measures are used for the evaluation of disease activity in rheumatoid arthritis and laboratory tests such as erythrocyte sedimentation rate (ESR) and C-Reactive protein (CRP) are being used as markers of inflammation.

Cyclic citrulled peptide antibody (anti-CCP) is a test that detects citrulline qualities in the blood. Studies have shown that CCP has a higher percentage of positivity in early stage RA.

Adenosine deaminase (ADA), an enzyme of purine metabolism, is considered a marker of cell-mediated immunity and has been proposed as a marker of the inflammatory process in RA.

This study aimed to examine the efficacy of serum ADA activity as an inflammatory marker in RA.

MATERIALS and METHODS: In our study, the results obtained were compared by studying the CRP and ESR and ADA levels of 15 patients with joint pain complaints, positive and negative anti-CCP. Anti-CCP chemiluminescence immunometric assay, CRP immunoturbimetric, ESR photometric and ADA spectrophotometric methods were used.

RESULTS: The ADA activity $(p<0.001)$ CRP $(p=0.006)$ and ESR $(p<0.001)$ levels of patients with positive anti-CCPs increased compared to patients with negative results, and it showed a statistically significant difference.

CONCLUSIONS: Although this study shows that serum ADA levels can predict disease activity in RA patients, it can also be proposed as a marker of inflammation. However, studies involving more patients are needed to determine its role as an inflammatory marker.

Keywords: Rheumatoid arthritis, Anti-CCP, Adenosine Deaminase, Inflammation

\section{OP-056 \\ DYNAMIC THIOL/DISULFIDE BALANCE IN PREGNANT WOMEN WITH PREECLAMPSIA AND ITS RELATIONSHIP WITH INFLAMMATION}

Zeynep Akaslan ${ }^{1}$, Oguzhan Ozcan ${ }^{1}$, Ilay Gozukara ${ }^{2}$, Abdullah Arpaci ${ }^{1}$ ${ }^{1}$ Hatay Mustafa Kemal University, Faculty of Medicine, Department of Medical Biochemistry, Hatay, Turkey

${ }^{2}$ Hatay Mustafa Kemal University, Faculty of Medicine, Department of Obstetrics and Gynecology, Hatay, Turkey

OBJECTIVES: Preeclampsia is characterized by hypertension due to endothelial dysfunction. Deterioration of oxidative balance and increased inflammation are important in the pathogenesis of preeclampsia. We aimed to determine the relationship between serum dynamic thiol balance and TNF- $\alpha$ in pregnant women with preeclampsia.

MATERIALS and METHODS: Thirty pregnant women with preeclampsia and 30 healthy controls were included in the study. Fasting blood samples were collected from all pregnant women in the second or third trimester. After all samples were centrifuged at $1500 \mathrm{xg}$ for 10 minutes, serum samples were aliquoted and stored at $-80^{\circ} \mathrm{C}$. Serum total and native thiols were measured by colorimetric method and disulfide values were calculated. Serum TNF- $\alpha$ was measured by the ELISA method.

RESULTS: While gestational week and birth weight were significantly lower in the preeclampsia group compared to the controls, systolic and diastolic blood pressures were significantly higher $(\mathrm{P}<0.001)$. A high negative correlation was found between the week of gestation and systolic and diastolic pressures $(\mathrm{r}=$ $0.768, \mathrm{p}<0.001 ; \mathrm{r}=-0.782, \mathrm{p}<0.001$, respectively). Disulfide and TNF- $\alpha$ were significantly higher in the preeclampsia, while the total and native thiol levels were significantly lower $(\mathrm{p}<0.001)$. There was a significant positive correlation between disulfide levels and TNF- $\alpha$ in the patient group $(\mathrm{r}=0.575, \mathrm{p}<0.001)$. CONCLUSIONS: Dynamic thiol balance is impaired in preeclampsia and it is associated with inflammation. Dynamic thiol balance may have a role in the pathogenesis of preeclampsia.

Acknowledgements: This work was supported by Hatay Mustafa Kemal University Scientific Research Projects Coordination Unit (project no, 18YL22). Keywords: Thiol Balance, Pregnancy, Preeclampsia, Disulfide

\section{OP-057 \\ THE URINE FOAMING TEST IN COVID-19 AS A USEFUL TOOL IN DIAGNOSIS, PROGNOSIS AND FOLLOW-UP: PRELIMINARY RESULTS}

Mehmet Serhan Kurtulmus ${ }^{1}$, Cemal Kazezoglu ${ }^{2}$, Busra Cakiroglu ${ }^{3}$,

Habip Yilmaz ${ }^{4}$, Abdullah Emre Guner

${ }^{1}$ Memorial Hospital Group, Department of Physical Therapy and Rehabilitation, Istanbul, Turkey

${ }^{2}$ University of Health Sciences, Kanuni Sultan Suleyman Research and Training Hospital, Department of Medical Biochemistry, Istanbul, Turkey

${ }^{3}$ University of Health Science Kanuni Sultan Suleyman Training and Research

Hospital, Department of Infectious Diseases and Clinical Microbiology,

Istanbul, Turkey

${ }^{4}$ TR Ministry of Health, Istanbul Provincial Health Directorate, Public Hospitals Services Presidency-3, Istanbul Dr. Siyami Ersek Chest Heart and Vascular Surgery Training and Research Hospital, Department of Anesthesiology and Reanimation, Istanbul, Turkey

${ }^{5}$ TR Ministry of Health, Istanbul Provincial Health Directorate, Public Health Services Presidency, Istanbul, Turkey

OBJECTIVES: We aimed to develop a simple, rapid urine test based on the level of foaming that occurs in the urine sample as a result of the excretion of peptide structures containing amino acids specific to the antigenic structure of COVID-19.

MATERIALS and METHODS: After obtaining the approval of the ethics committee, urine samples were taken from 3 groups of patients whose informed consent was obtained. The groups were created according to the COVID-19 Diagnostic Guide of Ministry of Health. A: outpatients with suspected COVID-19, $\mathrm{B}$ : inpatients for follow-up and treatment, $\mathrm{C}$ : patients treated in intensive care unit (ICU). Also, 30 healthy volunteers were included as the control group D. Urine samples taken from all groups were delivered to the laboratory. Urine sample was added to the test tube and shaken. The level of foam was visually evaluated according to the color scale.Other data of the patients were obtained from the HIS. Performance characteristics were statistically calculated according to the RT-PCR result and/or CT.

RESULTS: A statistically significant difference was observed between UFT distributions of control, outpatient, inpatient and ICU patients $(\mathrm{p}=0.0001)$. The results of UFT orange and red in inpatients and ICU patients were statistically significantly higher than in the control and outpatient groups. The diagnostic accuracy of UFT was detected in all group, the pooled sensitivity was $92 \%(95 \%$ CI:87-95\%) and specificity was $89 \%(95 \%$ CI: $80-98 \%)$.

CONCLUSIONS: Our preliminary results show that the UFT is useful in predicting the clinical severity of COVID-19. The UFT could be recommended as a point of care test, rapid and non-invasive method in the follow-up of COVID-19. Keywords: COVID-19, Urine Foaming Test, Prognostic Predictive Value 


\section{OP-058 \\ ALKALINE PHOSPHATASE INTERFERENCE IN IMMUNO- ENZYMATIC ASSAYS}

Osman Oguz 1 , Huriye Serin ${ }^{2}$

${ }^{1}$ Acibadem LabMed Clinical Laboratories, Central Biochemistry Laboratory,

Istanbul, Turkey

${ }^{2}$ University of Health Sciences Istanbul Training and Research Hospital,

Biochemistry Laboratory, Istanbul, Turkey

OBJECTIVES: Alkaline phosphatase (ALP) enzymes are widely used as signal amplifiers in immunoenzymatic methods. Conditions that cause ALP elevations, such as bone, liver and small intestine diseases and pregnancy, can cause interference in immunoenzymatic methods. We aimed to examine ALP's effect on methods and tests by adding isolated pure ALP enzyme to the serum pool prepared for this study.

MATERIALS and METHODS: Method In our lab, total $\beta$ hCG (5th IS) and High Sensitivity Troponin I (hsTnI) tests are measured immunoenzymatically by means of Access II (BeckmanCoulter, Brea, CA) and Ferritin, Free T4 (FT4), Thyroid-stimulating hormone (TSH) (3rd IS) and Vitamin B12 tests by means of UniCelDxl 800 (Beckman Coulter, Brea, CA) auto-analyzer. We prepared a serum pool and divided into 4 groups. By adding isolated pure ALP enzyme at different concentrations to each group, we obtained sample groups containing ALP enzyme at concentrations of $85 \mathrm{U} / \mathrm{L}, 340 \mathrm{U} / \mathrm{L}, 870 \mathrm{U} / \mathrm{L}$ and $1570 \mathrm{U} / \mathrm{L}$. In each group, 20-repetition $\beta$ hCG, Ferritin, FT4, TSH, Troponin I and Vit B12 tests were performed. Coefficient of variation (CV), bias, and total error values were calculated for the studied parameters. Total Error values were evaluated by comparing them with acceptable error limits that reported by RiliBÄK.All groups were compared by using Friedman test and Bonferroni correction for paired samples.

RESULTS: After ALP addition, the calculated total error percentages of FT4, BhCG and Troponin I tests were found to be above the acceptable error limits. With the addition of ALP, positive interference was observed in $\beta$ hCG test, while negative interference was observed in Troponin I test.

CONCLUSIONS: Isolated ALP elevations can be a source of interference for immunoenzymatic methods using ALP as conjugate.

Keywords: Alkaline Phosphatase, Immuno-Enzymatic Assay, Interference, Total Error

\section{OP-059 \\ INVESTIGATION OF THE EFFECT OF DEXAMETHASONE AND BETAMETHASONE ON PETINIA IMMUNASSAY MEASUREMENT METHOD}

Murat Caglayan $^{1}$, Ataman Gonel ${ }^{2}$

${ }^{1}$ Yildirim Beyazit University, Yeni Mahalle Training and Research

Hospital,Department of Biochemistry, Ankara, Turkey

${ }^{2}$ Harran University, Faculty of Medicine, Department of Biochemistry,

Sanliurfa, Turkey

OBJECTIVES: Similarities of dexamethasone and betamethasone to some hormone molecules may cause false test results in the analytic phase. Drugrelated measurement errors can lead misinterpretation of the tests. The aim of this study is to investigate the effect of dexamethasone and betamethasone on tests (AFP, CA 125, CA 15-3, CA19-9, CEA, complex PSA, total PSA, troponin I, mass CK-MB, cortisol, TSH, FT3, FT4, FSH, LH, progesterone, prolactin, total testosterone, estradiol(E2), HCG, parathyroid hormone, vitamin B12, folate and ferritin) measured by PETINIA method.

MATERIALS and METHODS: The study was carried out using the PETINIA immunoassay method (Siemens,Atellica,USA) with hormone control material (BioRad Lyphocheck Immunoassay Plus Control). $1800 \mu \mathrm{L}$ of control solution was taken and $200 \mu \mathrm{L}$ of dexamethasone and betamethasone were added, respectively. After vortexing the sample, it was incubated at room temperature for 20 minutes. From the control sample, AFP CA 125, CA 15-3, CA19-9, CEA, complex PSA, total PSA, troponin I, mass CK-MB, cortisol, TSH, FT3, FT4, $\mathrm{FSH}, \mathrm{LH}$, progesterone, prolactin, total testosterone, E2, HCG, parathyroid hormone, vitamin B12, folate and ferritin tests were performed.The study was reproduced by adding $200 \mu \mathrm{L}$ of distilled water.The measurements were repeated 3 times and the mean values were recorded. Percentage deviations from the target value were calculated with bias.

RESULTS: Due to betamethasone,concentrations of AFP,CK-MB mass, cortisol,E2 and progesterone was exposured positive and negative interference at the rate of $10.27 \%,-27.66 \%, 457.62 \%, 88.86 \%$ and $39.51 \%$, respectively. The deviations were $-11.64 \%$ in AFP, $-48.94 \%$ in mass CK-MB, $79.47 \%$ in cortisol, $86.21 \%$ in E2, $-10.23 \%$ in complex PSA and $-25.19 \%$ in FT3 after adding dexamethasone. Deviations in other tests were observed at minimal rates.

CONCLUSIONS: Negative interference occurring in CK-MB mass due to dexamethasone and betamethasone may cause to miss acute cardiac syndrome, deviations in progesterone and E2 may cause erroneous treatment practices in infertility. Sampling is recommended before cortisol infusion.

Keywords: Dexamethasone, Betamethasone, CK-MB Mass, Progesterone, False Result

\section{OP-060 \\ CAN PLASMA OR SERUM BE USED INTERCHANGEABLY FOR DIFFERENT IMMUNOCHEMICAL ANALYTES?}

Didem Barlak Keti, Sabahattin Muhtaroglu

Department of Medical Biochemistry, Erciyes University, Kayseri, Turkey

OBJECTIVES: Studies revealing the difference in plasma and serum test results for immunochemical analytes are limited and the results are also contradictory. The aim of this study was to evaluate whether there is a difference between serum and plasma for 10 immunochemical analytes.

MATERIALS and METHODS: Total of 30 healthy volunteers were included in the study. Blood samples were collected in clot-activator with gel (Vacuette) and containing lithium heparin tubes with barrier (Barricor). Serum and plasma were obtained by centrifugation at $2000 \mathrm{~g}$ for 10 minutes. Hemolysis index was lower than 20 in serum and plasma samples. Paired t test was used for statistical analysis. Bias\% results were compared with the desirable specification $(\mathrm{B} \%)$ obtained from the Ricos database for clinically significant. Vitamin B12 (B12), ferritin, folate, free triiodothyronine (FT3), free thyroxine (FT4), insulin, ProBNP, parathyroid hormone (PTH), thyroid stimulating hormone (TSH) and vitamin D levels analysed on a Roche COBAS 8000 device.

RESULTS: There was a statistically significant difference for B12, ferritin, folate insulin, proBNP, PTH, vitamin D between serum and plasma. Only, plasma PTH levels were clinically significant higher than serum. PTH levels were stable up to 8 hours at room temperature in plasma with lithium heparin. However, insulin levels remained stable up to 8 hours at room temperature in serum.

CONCLUSIONS: Plasma cannot be used instead of serum for PTH analysis. Therefore serum reference range is not suitable for this analyte. Unlike insulin, PTH levels are more stable in plasma with lithium heparin at room temperature. Keywords: Plasma, Serum, Lithium Heparin, Parathyroid Hormone, Insulin

\section{OP-061 \\ SAMPLE REJECTION RATE IN THE PRE-ANALYTICAL PHASE
IN BIOCHEMISTRY LABORATORIES OF VAN YUZUNCU YIL UNIVERSITY DURSUN ODABAS MEDICAL CENTRE}

Bunyamin Ucar, Hamit Hakan Alp, Ayfer Meral, Zubeyir Huyut Yuzuncu Yil University, Department of Biochemistry, Van, Turkey

OBJECTIVES: Our aim in this study is to determine the rates and reasons of rejected samples for some of our test groups.

MATERIALS and METHODS: The counts of rejected samples between January 1 and December 31, 2019 was obtained retrospectively from the laboratory information system. Samples were classified according to analysis purposes as biochemistry, hormone, emergency biochemistry, complete urine analysis, blood gas, cardiac and $\mathrm{HbAlc}$.

RESULTS: The total counts of samples that arrived in our laboratory were 872.253 and the total counts of the rejected sample were 7.354 (the rejection rate was $0.84 \%$ ). The rejection rates in biochemistry, hormone, emergency biochemistry, complete urine analysis, blood gas, cardiac and $\mathrm{HbA} 1 \mathrm{c}$ analysis were $\% 0.047, \% 0.11, \% 0.26, \% 0.13, \% 0.22, \% 0.027$ and $\% 0.027$, respectively. The most frequent first three reasons for sample rejection were insufficient (48.9 $\%)$, clotted $(20.8 \%)$ and haemolyzed $(11.1 \%)$ samples, respectively.

CONCLUSIONS: The fact that insufficient sample collection is the most common reason for sample rejection shows that phlebotomists do not have enough information on this subject. We believe that the training on this issue will contribute to reducing our rejection rates.

Keywords: Pre-Analytical Phase,Sample Rejection Rates

\section{OP-062 \\ THE EFFECTS OF POINT OF CARE BLOOD GAS DEVICES ON SOME QUALITY INDICATORS}

Derya Sonmez

Department of Biochemistry, Istanbul Traning and Research Hospital, Istanbul, Turkey

OBJECTIVES: Blood gas tests from the intensive care unit constitute a significant part of emergency laboratories' workload. Blood gas samples must be transported to the laboratory quickly, studied and finalized. In laboratory practice, blood gas samples were sent from intensive care to the laboratory collectively. The arrival of many blood gas samples to the laboratory at the same time reduces the reliability of the results and increases rejected samples and results not given in time at the emergency unit. We examined whether point of care blood gas devices contribute to quality process management by evaluating some of the quality indicators.

MATERIALS and METHODS: We analyzed the percentage changes in some quality indicators in point of care blood gas device in our hospital set up in February 2020. We retrospectively evaluated two quality indicators before and after this date.

RESULTS: According to our findings, for three months before and after February 2020 quality indicator percentage changes are: result not given in a time: 9.08 , $10.98,8.05$ and $5.25,5.95,7.25$. Rejected sample percentages were $6.82,8.91$, 
7.70 and $5.62,3.96,3.87 \%$

CONCLUSIONS: Setting up point of care blood gas devices in intensive care units, improves quality indicators such as results not given on time and percentage of rejected samples, contributes positive effect to the total testing process of the laboratory.

Keywords: Quality, Indicator, Point of Care Test

\section{OP-063
EVALUATION OF BILECIK PUBLIC HEALTH LABORATORY SAMPLE REJECTION RATES WITH SIX SIGMA APPROACH}

Kamil Taha Ucar

Bilecik Public Health Laboratory, Medical Biochemistry Laboratory, Bilecik, Turkey

OBJECTIVES: Errors in the Total test process (TTP) are most frequently observed in the extraanalytical phase. One of the quality indicators to assess the TTP is sample rejection rates (SRRs). In this study, it was aimed to evaluate the SRRs with the Six Sigma approach, and rejection causes of the samples accepted to Bilecik Public Health Laboratory in 2020.

MATERIALS and METHODS: SRRs in January-September 2020 were obtained via Fonet LIS. Groups were assigned as biochemistry, ESR, hematology, immunoassay, urine, $\mathrm{HbA} 1 \mathrm{c} / \mathrm{HbA} 2 / \mathrm{HbF}$, and blood type. The SRRs of the groups were calculated. Subsequently, the SRRs were calculated with a formula of defects per million opportunities (DPMO), and the corresponding Sigma metric (SM) was determined. While calculating the SM, a 1.5 SD shift was not added due to the non-normally distributed data. Moreover, the causes of rejection and their rates within the rejected samples were identified.

RESULTS: Total SRR and SM were calculated as $0.094 \%-3.11$. These values for biochemistry, ESR, hematology, immunoassay, urine, $\mathrm{HbA} 1 \mathrm{c} / \mathrm{HbA} 2 / \mathrm{HbF}$, and blood type were $0.009 \%-3.73,16.07 \%-0.99,0.72 \%-2.45,0.012 \%-3.66,0.874 \%$ $2.38,0.154 \%-2.96$, and $0.159 \%-2.95$, respectively. The most common causes of rejection were founded as clotted sample $(68.8 \%)$, insufficient sample $(11.97 \%)$, and unsuitable sample $(6.2 \%)$, respectively.

CONCLUSIONS: The use of the Six Sigma approach in the extraanalytical phase may benefit laboratories in terms of evidence-based evaluation. Further studies are needed to determine the quality goals. Besides, it is thought that the rate of hemolyzed samples may decrease in centers where routine blood collection recommendations can be applied easily.

Keywords: DPMO, Extraanalytical Phase, Quality Management, Sample Rejection Rates, Six Sigma

\section{OP-064 \\ SERUM OSMOLARITY AND ITS RELATIONSHIP WITH PROGNOSIS IN STROKE PATIENTS UNDERGOING INTRAVENOUS THROMBOLYSIS}

Fettah Eren ${ }^{1}$, Kamile Yucel $^{2}$

${ }^{1}$ Health Sciences University, Konya Training and Research Hospital,

Department of Neurology, Konya, Turkey

${ }^{2}$ KTO Karatay University, School of Health Sciences, Medical Biochemistry,

Konya, Turkey

OBJECTIVES: In this study, the relation of serum osmolarity calculated before treatment with mortality, cerebral hemorrhagic transformation and short-term prognosis in stroke patients who received intravenous thrombolytic therapy (IVT) was evaluated.

MATERIALS and METHODS: 361 acute ischemic stroke patients who were given IVT were included in the study. The patients were divided into 2 groups as NIH Stroke Scale (NIHSS) score above 15 and below. Hemorrhagic transformation was evaluated by brain computed tomography at 24 and 72 hours. The patients were divided into 2 groups according to the NIHSS difference between admission and discharge. NIHSS 4 and above was accepted as reduction and improvement. Patients were divided into 3 groups according to their blood gas and serum osmolarity (less than $285 \mathrm{mmol} / \mathrm{kg}, 285-300 \mathrm{mmol} / \mathrm{kg}$ and over $300 \mathrm{mmol} / \mathrm{kg}$ ). Results were analyzed with SPSS 17.0 software package.

RESULTS: The study included $188(52.1 \%)$ female and $173(47.9 \%)$ male patients. Their mean age was $71.67 \pm 12.060$ (35-97). Potassium and glucose levels were higher in patients with severe disability $(\mathrm{p}<0.001, \mathrm{p}=0.005$, respectively). Glucose level and serum osmolarity were higher in patients with mortality ( $\mathrm{p}=0.001, \mathrm{p}=0.010$, respectively). There was no relationship between the recovery status and development of hemorrhagic transformation and serum osmolarity $(\mathrm{p}>0.05)$. Disability and mortality were higher in patients with high osmolarity ( $\mathrm{p}=0.006, \mathrm{p}=0.001$, respectively).

CONCLUSIONS: High serum osmolarity in patients given IVT is particularly associated with stroke severity and mortality.

Keywords: Ischemic Stroke, Intravenous Thrombolysis, Serum Osmolarity

\section{OP-065}

\section{EVALUATION OF PREANALYTICAL VARIABLES AND} LABORATORY CONDITIONS IN BLOOD GAS ANALYSIS

Neslihan Sungur, Ayse Ulusoy, Humeyra Acikan, Hatice Saracoglu, Didem Barlak Keti, Sabahattin Muhtaroglu

Departman of Medical Biochemistry, Erciyes University, Kayseri,Turkey

OBJECTIVES: Preanalytical errors in blood gas tests significantly affect the test results. The aim of the study is to evaluate the effect of preanalytical errors in sampling and transfer on the results and the performance of the analyzer.

MATERIALS and METHODS: Samples were taken from 8 volunteers into heparinized venous blood gas injectors. Standard conditions were applied to the first group (control). Groups 2nd and $3 \mathrm{rd}$ contained $0.5 \mathrm{ml}$ and 0.25 $\mathrm{ml}$ of air bubbles, respectively. In the 4th group, while the samples were transported to laboratory by pneumatic system, 5th group was kept for 90 and 120 minutes and compared with control. The 13 samples (arterial blood) received routinely were serially reanalyzed a second time immediately after the first analysis and the effect of waiting during analysis on the results was evaluated. The samples were studied with the Siemens Rapiblab 1265 device. RESULTS: Statistical analysis was performed with SPSS version 23.0 software. Normality of the data Repeated measurements were evaluated with the ANOVA test. No significant difference was found in samples sent by pneumatic system. For samples with air bubbles and kept $+4^{\circ} \mathrm{C}$ for 90 minutes only $\mathrm{pO} 2$ was found significantly different. $\mathrm{PH}$ and $\mathrm{pCO} 2$ showed significant difference in samples kept at $+4^{\circ} \mathrm{C}$ for 120 minutes. In the samples that have been studied twice in series $\mathrm{pO} 2, \mathrm{pCO} 2$ and $\mathrm{HCO} 3$ were found different $(\mathrm{p}<0.05)$.

CONCLUSIONS: Samples are stable on ice for up to 90 minutes. Keeping the samples at room temperature disrupts the stability. PO2 is affected in samples with an air bubbles. Pneumatic system can be used in emergency situations. In addition, it is appropriate to keep the samples waiting for analysis at least on ice. Keywords: Blood Gas, Temperature, Pneumatic System

\section{OP-066 \\ THE RELATIONSHIP OF SST-2, OSTEOPONTIN AND MYELOPEROXIDASE LEVELS IN ACUTE CORONARY SYNDROME PATIENTS WITH FRAGMENTED QRS}

Seda Suzan Memecan $^{1}$, Prof. Dr. Tevfik Noyan ${ }^{1}$, Doc. Dr. Osman Bektas ${ }^{2}$ ${ }^{1}$ Department of Medical Biochemistry, Ordu University, Ordu, Turkey ${ }^{2}$ Department of Cardiology, Ordu University, Ordu, Turkey

OBJECTIVES: In this study, we aimed to investigate the myeloperoxidase (MPO), osteopontin (OPN) and soluble ST2 (sST2) levels in acute coronary syndrome (ACS) patients with and without a fragmented QRS (fQRS).

MATERIALS and METHODS: 60 Acute coronary syndrome(ACS) patients and 26 healthy individuals were included the study. Patients were divided into two groups: +fQRS $(n=30)$ and $-\mathrm{fQRS}(\mathrm{n}=30)$. OPN, sST2, MPO and other parameters were measured.

RESULTS: In ACS patients, serum MPO (33.7 U/L),OPN (103.29 ng/mL) and sST2 $(495.4 \mathrm{pg} / \mathrm{mL})$ levels were found significantly higher than the control group $(23.14 \mathrm{U} / \mathrm{L}, 42.65 \mathrm{ng} / \mathrm{mL}, 344.11 \mathrm{pg} / \mathrm{mL}$, respectively; $<00.01, \mathrm{p}<0.01, \mathrm{p}<0.05)$ However, there were no significant difference between MPO (32.74 U/L),OPN $(101.89 \mathrm{ng} / \mathrm{mL})$ and sST2 $(451.97 \mathrm{pg} / \mathrm{mL})$ levels of patients with fQRS(+fQRS) and without fQRS(-fQRS) (34.67 U/L, $104.69 \mathrm{ng} / \mathrm{mL}, 535.73 \mathrm{pg} / \mathrm{mL} ; \mathrm{p}>0.05)$. There were positive correlations between MPO and platelet $(\mathrm{r}=0.376, \mathrm{p}<0.05)$ levels in (+) fQRS group, sST2 and triglyceride levels in (-) fQRS group, as well as sST2 and troponin-I $(r=0.276 ; \mathrm{p}<0.05)$ levels in ACS patients. When the diagnostic performances for ACS was examined, the sensitivity of CKMB,troponin-I, MPO,OPN and sST2 were $83 \%, 80 \%, 65 \%, 85 \%, 58 \%$ and specificity $96 \%, 100 \%, 72 \%, 96 \%, \% 80$, respectively.But, these parameters were not found to have a diagnostic value for the diagnosis of fQRS $(p>0.05)$ CONCLUSIONS: The results of our study indicated that diagnostic value of MPO, OPN and sST2 in fQRS diagnosis are not significant.Nevertheless, the discovery of the high diagnostic sensitivity and specificity of OPN is a new finding obtained in this study.This study is the first study to exhibit the relationship between MPO,OPN and SST2 and fQRS development. Keywords: Acute Coronary Syndrome, Fragmented QRS, Myeloperoxidase, Osteopontin, Soluble ST-2

\section{OP-067 \\ COMPARATIVE INHIBITORY EFFECT OF SAFRANIN O ON CHOLINESTERASES}

Seda Onder ${ }^{1}$, Suat Sari², Ozden Tacal

${ }^{1}$ Hacettepe University, Faculty of Pharmacy, Department of Biochemistry, Ankara, Turkey

${ }^{2}$ Hacettepe University, Faculty of Pharmacy, Department of Pharmaceutical Chemistry,Ankara,Turkey

OBJECTIVES: Inhibition of cholinesterases is a mainstay strategy in the treatment of Alzheimer's disease (AD) that involves critical loss of acetylcholine 
in the central nervous system. Recently, we have shown that a phenazinederived synthetic dye, methylene violet $3 \mathrm{RAX}$ is an effective inhibitor of acetylcholinesterase (AChE) and butyrylcholinesterase (BChE). In the present study, the inhibitory mechanism and effect of a synthetic phenazine dye, safranin $\mathrm{O}$ (SO) on human erythrocyte $\mathrm{AChE}$, human plasma $\mathrm{BChE}$ and recombinant BChE mutants (A328F and A328Y) was studied for comparison.

MATERIALS and METHODS: AChE and BChE activities were assayed spectrophotometrically in $50 \mathrm{mM}$ MOPS buffer $(\mathrm{pH}$ 8) containing 0.05-0.4 $\mathrm{mM}$ acetylthiocholine or butyrylthiocholine as substrate, $0.125 \mathrm{mM}$ DTNB and $0-40 \mu \mathrm{M} \mathrm{SO}$ at $25^{\circ} \mathrm{C}$. Initial rate data were analyzed using a simplified rapid equilibrium model for mixed inhibition The kinetic results were supported by molecular modelling studies.

RESULTS: SO leaded to linear competitive inhibition of human plasma BChE $(\mathrm{Ki}=0.44 \pm 0.085 \mu \mathrm{M} ; \alpha=\infty)$ and hyperbolic noncompetitive inhibition of human erythrocyte $\mathrm{AChE}(\mathrm{Ki}=0.69 \pm 0.13 ; \alpha=1 ; \beta=0.08)$. On the other hand, SO caused linear mixed type inhibition of $\mathrm{A} 328 \mathrm{~F}(\mathrm{Ki}=0.033 \pm 0.003 \mu \mathrm{M} ; \alpha=45 \pm 9)$ and $\mathrm{A} 328 \mathrm{Y}$ BChE mutants $(\mathrm{Ki}=0.078 \pm 0.014 \mu \mathrm{M} ; \alpha=74 \pm 30)$. The molecular modelling results showed that human BChE's affinity against SO increases with replacement of Ala328 to Phe or Tyr.

CONCLUSIONS: SO is a potent inhibitor of cholinesterases and may be useful in the design and development of new drugs for the treatment of AD.

Keywords: Safranin O, Cholinesterase İnhibition, Acetylcholinesterase, Butyrylcholinesterase, Molecular Docking

\section{OP-068 \\ PURIFICATION OF LIPASE ENZYME FROM BOVINE PANCREAS AND INVESTIGATION OF INHIBITION EFFECTS OF NATURAL INHIBITORS ON THIS ENZYME ACTIVITY}

Zeynep Bayat Sarioglu

Department of Biochemistry, Dumlupinar University, Kutahya, Turkiye

OBJECTIVES: The aim of this study is searching purification of pancreatic lipaz enzyme with chromatographic techniques that are gathered from biological sources and frequently used in medical and drug industry, effect of some crucial natural propolis sources that can show inhibitor effect on enzyme activity thus investigating availability of natural inhibitors for bariatric treatment.

MATERIALS and METHODS: In the study, pancreatic lipase enzyme (EC.3.1.1.3), which is responsible for digestine of triglyceride and released by acinar cells of pancreas, was purified with gel-filtration chromatography method from bovine pancreas and lipase activity which is obtained with 17,94 $\%$ productivity ratio and 568.58 purification ratio and characterized with sodium dodecyl sulfate polyacrylamide gel electrophoresis. Propolis samples were collected from six different regions and after their extraction, their effect on pancreatic lipase activity was analyzed. All propolis extracts indicated inhibitor effect and their IC50 values were calculated.

RESULTS: IC50 values are as $4,00 \mathrm{mg} / \mathrm{mL}$ (Duzce propolis), $11,80 \mathrm{mg} / \mathrm{mL}$ (Balikesir propolis), 7,69 mg/mL (Kirmizi propolis), 6,91 mg/mL (Hakkâri propolis), $12,68 \mathrm{mg} / \mathrm{mL}$ (Kirklareli propolis), $9,23 \mathrm{mg} / \mathrm{mL}$ (Artvin propolis). According to this data Duzce propolis extract has the highest inhibition effect with ratio of IC $504,00 \mathrm{mg} / \mathrm{mL}$. To define composition of propolis extracts, total amount of polyphenol and flavanoid matter were calculated spectrophotometrically. This sample with the highest total amount of polyphenol and flavanoid matter has been with ratio of $41,35+0,43 \mathrm{mgGAE} / \mathrm{mL}$ and $5,69+0,05 \mathrm{mgQUE} / \mathrm{mL}$.

CONCLUSIONS: The gathered findings show that inhibition effect can be depended on propolis composition and propolis extracts have the potential to be used as anti-obesity agent.

Keywords: Enzyme purification, Pancreatic lipase, Obesity, Inhibition, Propolis

\section{OP-069 \\ PURIFICATION AND PRESERVING THE STABILITY OF PLANT GLUTATHIONE TRANSFERASES}

Yaman Musdal $\frac{1,2}{,}$, Bengt Mannervik

${ }^{1}$ Department of Biochemistry and Biophysics, Stockholm University,

Stockholm, Sweden

${ }^{2}$ Department of Pediatrics, Department of Pediatric Genetics, School of

Medicine, Hacettepe University, Ankara, Turkey

OBJECTIVES: Plant glutathione transferases (GST) consist of eight distinct main classes and numerous subclasses that are involved mainly in detoxication, growth and development, stress tolerance, signalling and transport of secondary metabolites. Most of these members are uncharacterized, and structures, chemical properties, active-site residues and other functions need to be clarified. Compared to mammalian GSTs, purification of these plant GSTs are quite cumbersome due to short stability of proteins, that usually results in precipitated product after a short time. In this study, purification of some plant GSTs were optimized and stability of enzymes were performed using glycerol. MATERIALS and METHODS: Histidine-tagged tau class GSTs were codonoptimized and heterologously expressed in Escherichia coli and purified using $\mathrm{Ni}$ sepharose activated His GraviTrap columns (GE Healtcare). Additional changes in standart purification protocol were made in binding/elution and dialysis buffers.
Proteins were eluted using $100 \mathrm{mM}$ imidazole into a tube containing $50 \mu \mathrm{l}$ of potassium phosphate buffer $(1 \mathrm{M})$. Stability of proteins is maintained in glycerol. RESULTS: Protein's were purified without any precipitated product, kept half in fridge $\left(+4{ }^{\circ} \mathrm{C}\right)$ and the other half in $-80^{\circ} \mathrm{C}$. GST activities were stable with the CDNB substate for several weeks when glycerol concentration is kept \% 30 or above in samples of purified proteins.

CONCLUSIONS: Plant GSTs are not stable as mammalian GSTs. However stability and activities can be enhanced by improvements in purification and keeping enzyme mixed with glycerol.

Keywords: Plant Glutathione Transferases, Purification, Stability, Glycerol, NiSepharose Affinity Chromatography

\section{OP-070 \\ ASSESSING THE INHIBITORY EFFECTS OF SELECTED PHYTOHORMONES ON HUMAN PLACENTAL GLUTATHIONE S-TRANSFERASE}

Mohammad Abu Zaid ${ }^{1}$, Ozlem Dalmizrak ${ }^{1}$, Kerem Terali ${ }^{1}$, Nazmi Ozer ${ }^{2}$ ${ }^{1}$ Department of Medical Biochemistry, Faculty of Medicine, Near East University, Nicosia, TRNC

${ }^{2}$ Department of Biochemistry, Faculty of Pharmacy, Girne American University, Kyrenia, TRNC

OBJECTIVES: Phytohormones are involved in the control of growth, reproduction, and stress response in plants. The fact they are ingested in considerable amounts in the diet may reasonably suggest their relevance to human health and disease. Humans are able to conjugate potentially toxic electrophiles to glutathione (GSH) by a class of phase II detoxification enzymes known as glutathione S-transferases (GSTs). GSTP1-1 is the predominant GST isozyme in the placenta, meaning that the general detoxifying function of GSTs also extends to the protection of fetal health. GSTP1-1 has also been shown to be a cancer-promoting enzyme overexpressed in various malignancies. Here, we aim at evaluating the inhibitory actions of dormin and gibberellin on human placental GSTP1-1 (hpGSTP1-1). MATERIALS and METHODS: The percent remaining activity of hpGSTP1-1 in the presence of dormin or gibberellin was assayed against GSH and 1-chloro2,4-dinitrobenzene (CDNB) as co-substrates in an in vitro setting. The binding mode of each phytohormone was predicted through molecular docking, and non-covalent interactions between the enzyme and the top-ranked inhibitor was calculated accordingly.

RESULTS: Both dormin and gibberellin were found to inhibit hpGSTP1-1 in competitive manner, with $I C 50$ values of $5.2 \mathrm{mM}$ and $5.0 \mathrm{mM}$, respectively. Also, they were able to establish multiple non-covalent interactions with key residues lining the G- and H-subsites of the enzyme's active site.

CONCLUSIONS: Inhibitory interactions between hpGSTP1-1 and selected phytohormones may leave the fetus prone to the potentially toxic effects of xenobiotics and noxious endobiotics. On the other hand, they may guide medicinal chemists through the structure-based design of new anti-cancer drugs. Keywords: Dormin, Enzyme Inhibition, Gibberellin, Human Placental Glutathione S-Transferase, Molecular Docking

\section{OP-071 \\ DETERMINATION OF ANTIBACTERIAL ACTIVITIES AND} CYTOTOXICITIES OF DIFFERENT NITZSCHIA SP. EXTRACTS

Duygu Ova Ozcan, Bikem Ovez

Ege University, Chemical Engineering Department, Izmir, Turkey

OBJECTIVES: This study aimed to reveal the antibacterial and cytotoxic properties of different Nitzschia sp. extracts.

MATERIALS and METHODS: Diatome Nitzschia sp., grown in a $5 \mathrm{~L} \mathrm{~F} / 2$ medium, was cultivated under 16 different temperature, light intensity and aeration rate conditions determined by experimental design. Antimicrobial activities of freeze-dried extracts, obtained by ethanol/water extraction, were determined by disk diffusion and minimum inhibition concentration (MIC) methods at 3 different concentrations. Antibiotics used for Escherichia coli and Staphylococcus aureus, were Streptomycin and Vancomycin, respectively. Cytotoxicity response was determined by the viability of NIH/3T3 mouse fibroblast cells with MTT test for 24 and 48 hours at 7 different concentrations. RESULTS: Based on the MIC results, the growth of $E$. coli was suppressed in each extract concentration, whereas, there was still $S$. aureus growth at 25 and $50 \mathrm{mg} / \mathrm{mL}$, but complete inhibition was encountered at $100 \mathrm{mg} / \mathrm{mL}$. The cytotoxicity test was carried out with the extracts exhibiting antibacterial properties. For the first 24 hours, the viability was the highest $(98 \%)$ in cases of low temperature at constant aeration rate; and low light intensity at constant temperature. Also, for the first 48 hours, it was concluded that high temperature $\left(35^{\circ} \mathrm{C}\right)$ and light intensity $(538 \mu \mathrm{mol} \mathrm{m}-2 \mathrm{~s}-1)$ affected the viability negatively. CONCLUSIONS: Microalgal extracts showed the desired antibacterial effect for both E. coli and S. aureus, and the MIC value was determined as $100 \mathrm{mg}$ / $\mathrm{mL}$. Although the undesirable cytotoxic effect varies depending on the extract concentration and time, it has been observed that mouse fibroblast cells still maintain their viability. 
Acknowledgements:This work was supported by TUBITAK 1002 (Project No: 213M623), EBILTEM (Project No: 2015 / BIL / 016), and Ege University Scientific Research Projects Coordinator (Project No: 17-MUH043). In addition, we extend our gratitude to all experts in Izmir High Technology Institute, Biotechnology and Bioengineering Application and Research Center (IYTE-BIYOMER) for the bioactivity tests performed. Keywords: Cytotoxicity, \{Escherichia Coli\}, NIH/3T3 Mouse Fibroblast Cells, $\{$ Nitzschia Sp.\}, \{Staphylococcus Aureus\}

\section{OP-072 \\ COLORIMETRIC BROTH MICRODILUTION METHOD FOR THE ANTIMICROBIAL SCREENING OF AMPHIROA RIGIDA (J.V.LAMOUROUX 1816) EXTRACTS AGAINST SOME TEST MICROORGANISM}

Hatice Banu Keskinkaya ${ }^{1}$, Erdogan Gunes ${ }^{1}$, Cengiz Akkoz ${ }^{1}$, Emine Sukran Okudan ${ }^{2}$

${ }^{1}$ Selcuk University, Department of Biology, Konya,Turkey

${ }^{2}$ Akdeniz University, Department of Marine Biology, Antalya, Turkey

OBJECTIVES: In this study, we aimed to screening the antimicrobial activities of methanol, ethanol, acetone and water extracts of $A$. rigida (J.V.Lamouroux 1816) a pharmaceutically important marine macroalgae against different pathogenic microorganisms.

MATERIALS and METHODS: According to Colorimetric Broth Microdilution Method; antimicrobial activities of different extracts of $A$. rigida against Escherichia coli (ATTC 25922), Pseudomonas aeruginosa(ATTC 27853), Klebsiella pneumoniae (ATTC 70603), Staphylococcus aureus(ATTC 43300), Salmonella enteritidis (ATTC 13076), Sarcina lutea (ATTC 9341) and Bacillus cereus (ATTC 11778) standard bacterial and Candida albicans yeast strain were evaluated by determining the Minimum Inhibition Concentration (MIC).

RESULTS: It was observed that the water extract of the $A$. rigida showed no antimicrobial activity against any test microorganism. The highest antimicrobial effect was observed in $A$. rigida acetone extract and the most effective strains were Sarcina lutea and Candida albicans $(1.562 \mathrm{mg} / \mathrm{ml})$. Besides this, methanol extract had highest antimicrobial effect and the most effective strain was Pseudomonas aeruginosa $(1.562 \mathrm{mg} / \mathrm{ml})$. According to the findings we obtained, it was determined that the extracts obtained by using different solvents belonging to $A$. rigida the used in our study had different degrees of antimicrobial effects against the tested bacteria and yeast. With future studies, it would be appropriate to optimize the production conditions of the bioactive metabolites to characterize and to clarify the mechanism of action.

CONCLUSIONS: We think this experimental report indicate that the $A$ rigida have great potential for pharmaceutical applications. So, it is thought that this study will be provided as a basis for the studies aimed at reducing the use of commonly used antibiotic against microorganisms.

Keywords: \{Amphiroa Rigida\}, Antimicrobial Screening, Broth Microdilution Method, Gram Negative Bacteria, Gram Positive Bacteria.

\section{OP-073 \\ FLOW CYTOMETRIC ANALYSIS OF ERYTROCYTES OSMOTIC FRAGILITY TEST}

Mesude Yilmaz Falay ${ }^{1}$, Ali Fettah ${ }^{2}$, Ebru Keskin ${ }^{3}$, Guchan Alanoglu ${ }^{3}$,

Hulya Dalgali ${ }^{4}$, Gulsum Ozet ${ }^{4}$

${ }^{1}$ Private Lab, Ankara, Turkey

${ }^{2}$ Sami Ulus Children Hospital, Ankara, Turkey

${ }^{3}$ Suleyman Demirel University Medical Faculty, Isparta, Turkey

${ }^{4}$ Ankara City Hospital, Ankara, Turkey

OBJECTIVES: The guidelines do not currently recommend the traditional OF test in the diagnosis of Hereditary Hemolytic anemias. Flow cytometric osmotic fragility (FC-OF) test has been defined in recent years. This test is simple, fast, inexpensive and more sensitive and more specific than the traditional OF test. The FC-OF test is still in development, and some variables have not yet been fully tested and the cut-off value is not clear either. We aimed to find the optimum cut-off level - measurement time and $\mathrm{NaCl}$ concentration in our laboratory. MATERIALS and METHODS: We performed FC-OF test in FACS-CANTO (BD) brand Flow Cytometry device with EDTA-containing peripheral fresh blood at two separate $\mathrm{NaCl}$ concentrations of $6.0 \mathrm{~g} / \mathrm{L}-8 \mathrm{~g} / \mathrm{L}$ in 30 diagnosed Hereditary Spherocytosis (HS) cases and 40 healthy individuals. We determined the percentages of residual red blood cells (\% residual RBC) at 140 seconds, 160 seconds, and 300 seconds after the addition of distilled water to the test.

RESULTS: While we found the most reliable $\mathrm{NaCl}$ concentration to be $6.0 \mathrm{~g} / \mathrm{L}$ to distinguish HS cases from healthy controls, we determined the cut-off value for $\%$ residual RBC as $25 \%$. We found no difference between $\%$ residual RBC between 300 th second and 160 th second.

CONCLUSIONS: The FC-OF test is an easy, inexpensive and more reliable screening test than the traditional OF test, which provides results in an hour. Keywords: Flow Cytometry, Hereditary Spherocytosis, Osmotic Fragility

\section{OP-074 \\ ULTRA FAST GLIOBLASTOMA DETECTION BY CRISPR BASED BIOSENSOR}

Zihni Onur Uygun, Sevcan Atay

Department of Medical Biochemistry, Faculty of Medicine, Ege University, Bornova, Izmir, Turkey

OBJECTIVES: Glioblastoma (GBM, WHO stage IV astrocytoma) is the most common and most aggressive malignant brain tumor. Somatic single nucleotide mutations in the isocitrate dehydrogenase (IDH1) gene mutation are an important biomarker in the correct diagnosis of both glioblastomas. However, the detection of this mutation, which is determined by sequencing method, is very limited as it requires high cost and time. In this study, a biosensor system was developed to determine mutations of the IDH1 gene with the CRISPR-dCas9 system.

MATERIALS and METHODS: This biosensor system has been developed as an impedimetric/capacitive DNA biosensor using dCas9 proteins without endonuclease activity. A gold electrode was first coated with PAMAM after cystamine to increase the sensitivity, then the dCas9 proteins were immobilized to this modification with glutaraldehyde, and IDH was modified with synthetic guide (sg) RNAs targeting the R132 codon, that is, target isocitrate dehydrogenase (IDH) enzyme mutations. It has been made to recognize its mutations RESULTS: The CRISPR system, which will be linked to the target DNA sequence on the entire genome, as impedimetric biosensor to detect the presence of target mutation, and the presence of the target genome sequence and its approximate length were also determined by capacitive measurements. The biosensor system, which provides measurement in 92 seconds and selectivity up to a single base, can determine the target point mutation faster than PCR. CONCLUSIONS: The DNA biosensor we developed has succeeded in analyzing the IDH1 gene point mutation for glioma diagnosis in 92 seconds by accurately determining the target point mutation at a rate of 0.9923

Keywords: CRISPR, Biosensor, Impedance, Glioblastoma, IDH

\section{OP-075 \\ ANTIGEN RETRIEVAL IN FORMALIN-FIXED PARAFFIN- EMBEDDED GASTRIC BIOPSY SAMPLES: ESCAPE PROTEINS IN BUFFER SOLUTION}

Busra Ergun $^{1}$, Sinem Oktem Okullu ${ }^{2}$, Umit Ince ${ }^{3}$, Aysel Ozpinar ${ }^{1}$, Yasemin Ucal ${ }^{1}$ Acibadem Mehmet Ali Aydinlar University, Faculty of Medicine, Department of Medical Biochemistry, Istanbul, Turkey

${ }^{2}$ Acibadem Mehmet Ali Aydinlar University, Faculty of Medicine, Department of Medical Microbiology, Istanbul, Turkey

${ }^{3}$ Acibadem Mehmet Ali Aydinlar University, Faculty of Medicine, Department of Medical Pathology, Istanbul, Turkey

OBJECTIVES: Formalin-fixed paraffin-embedded(FFPE) tissues are valuable for mass spectrometry-based proteomic studies as they correlate with clinical data. In the matrix-assisted laser desorption/ionization(MALDI) imaging(MSI) method histological information and the spatial distribution of analytes on the tissue is determined. Successful results of MALDI-MSI applications on FFPE tissues depend on the effect of antigen retrieval. Antigen retrieval allows the detection of various proteins by unmasking epitopes by hydrolysis of formalin-induced methylene cross-links with the aid of heat. Since there are many optimization steps in MALDI-MSI analysis, the aim of study is to compare different buffers in terms of protein amount in samples taken into tubes in order to evaluate the effect of antigen retrieval.

MATERIALS and METHODS: Sections of $14 \mu \mathrm{m}$ thickness were taken into tubes by microtome. For tissue preparation, different antigen retrieval procedures were performed using buffer solutions of $10 \mathrm{mM}$ Citrate(pH 6), $10 \mathrm{mM}$ Citrate + $2 \% \mathrm{SDS}$ and $10 \mathrm{mM}$ Tris(pH 9), followed by washing with xylene and decreasing alcohol concentrations. Protein concentrations obtained as a result of methanol/ chloroform precipitation were measured by Bradford assay and LC-MS/MS analysis was performed. MALDI-MSI analysis was performed using citrate buffer in the selected biopsy sample.

RESULTS: It was observed that the protein concentration obtained as a result of antigen retrieval in Citrate+SDS buffer solution was the highest.As a result of LC-MS/MS proteomic analysis, keratin proteins escape into the buffer solution were detected.

CONCLUSIONS: It is important to eliminate methylene cross-links caused by formalin fixation in FFPE tissues and to optimize the sample preparation steps of MALDI-MSI analysis of tissues.

Keywords: FFPE, MALDI-MSI, Sample Preparation, Optimization, Antigen Retrieval 


\section{OP-076 \\ PROTECTIVE EFFECT OF ALPHA-LIPOIC ACID AGAINST SKIN FIBROSIS IN BLEOMYCIN-INDUCED SCLERODERMA MODEL}

Ayse Kocak $^{1}$, Cemre Ural ${ }^{1}$, Duygu Harmanci ${ }^{1}$, Mehmet Asi Oktan ${ }^{2}$,

Aysan Afagh $^{1}$, Sulen Sarioglu ${ }^{3}$, Osman Yilmaz ${ }^{4}$, Merih Birlik ${ }^{5}$,

Gul Guner Akdogan ${ }^{6}$, Zahide Cavdar ${ }^{1}$

${ }^{1}$ Department of Molecular Medicine, Institute of Health Sciences, Dokuz Eylül University, Izmir, Turkey

${ }^{2}$ Department of Nephrology, Faculty of Medicine, Dokuz Eylul University, Izmir, Turkey

${ }^{3}$ Department of Pathology, Faculty of Medicine, Dokuz Eylül University, Izmir, Turkey

${ }^{4}$ Department of Laboratory Animal Sciences, Institute of Health Sciences,

Dokuz Eylül University, Izmir, Turkey

${ }^{5}$ Department of Rheumatology, Faculty of Medicine, Dokuz Eylül University, Izmir, Turkey

${ }^{6}$ Department of Medical Biochemistry, Medical Faculty, Izmir University of

Economics, Izmir, Turkey

OBJECTIVES: Scleroderma (SSc) is a connective tissue disease characterized by fibrosis of the skin and internal organs. It is well known that oxidative stress plays a major role in that period. The aim of this study was to investigate the protective effect of alpha-lipoic acid (ALA), called as antioxidant of antioxidants, and molecular mechanisms mediating its antioxidant, antifibrotic and anti inflammatory effect against bleomycin induced scleroderma in mice.

MATERIALS and METHODS: 32 healthy female Balb-c mice were used in this study and randomly divided into four groups: control $(\mathrm{n}=8)$, ALA(100mg/ $\mathrm{kg})(\mathrm{n}=8), \operatorname{BLM}(5 \mu \mathrm{g} / \mathrm{kg})(\mathrm{n}=8), \operatorname{BLM}+\operatorname{ALA}(\mathrm{n}=8)$. Skin tissue specimens and blood were collected. Connective tissue fibrosis in the dermis area was evaluated histopathologically. mRNA expressions of the subunit of NADPH oxidase (NOX4), tumor necrosis factor (TNF- $\alpha$ ), fibronectin, $\alpha$-smooth muscle actin and type I collagen in skin tissue samples were analysed by qPCR. Also, activation of p38 MAPK signaling was evaluated by western blot. Serum total antioxidant status (TAS) and total oxidant status (TOS) were analysed by using a colorimetric kit. RESULTS: In the ALA groups, connective tissue fibrosis in the dermis area was significantly lower than that of the BLM group $(\mathrm{p}<0.05)$. ALA also significantly reduced mRNA expressions of NOX4 in the BLM group, which was parallel to significant decreases of TNF- $\alpha$, fibronectin, a-smooth muscle actin, and type I collagen mRNA expressions $(p<0.05)$. In serum samples, ALA increased TAS and decreased TOS compared to the BLM group $(p<0.05)$. ALA could suppress the activation of p38 MAPK during BLM administration. CONCLUSIONS: ALA not only plays as an antioxidant but also an antifibrotic role in the SSc bleomycin induced mouse model. Our study suggests that ALA could be beneficial for patients with SSc. Keywords: Scleroderma, Alfa Lipoic Acid, Antioxidant, Antifibrotic

\section{OP-077 \\ INVESTIGATION OF THE EFFECT OF CONTRAST MEDIA ON ROUTINE UROONCOLOGICAL TUMOR MARKERS}

Erkan Arslan ${ }^{1}$, Ataman Gonel $^{2}$

${ }^{1}$ Harran University, Faculty of Medicine, Department of Urology, Sanliurfa,

Turkey

${ }^{2}$ Harran University, Faculty of Medicine, Department of Biochemistry Sanliurfa, Turkey

OBJECTIVES: Contrast media drugs frequently used in imaging techniques have many side effects, from urticaria to anaphylaxis. Although clinicians are cautious about these side effects, they may not have enough information about the interference effects on laboratory test results. If contrast media drugs cause false high or false low test results, especially on tumor markers, it may cause misdiagnosis. The aim of this study is to investigate the effects of three different parenteral contrast media on AFP, HCG, PSA, CA15-3, CEA, CA125 tests results. MATERIALS and METHODS: The study was carried out using the chemiluminescence immunoassay method (Siemens, Atellica,USA) with BioRad hormone control material. $1800 \mu \mathrm{L}$ of control solution was mixed with $200 \mu \mathrm{L}$ of fluorescein, ioversol, gadopentetic acid, respectively. After the sample was vortexed,it was incubated for 20 minutes at room temperature. AFP, HCG, PSA, CA15-3, CEA, CA125 were measured from the control sample. The study was reperformed by adding $200 \mu \mathrm{L}$ of distilled water. The measurements were repeated three times and the mean values were recorded. Percentage deviations from the target value were calculated with bias. RESULTS: Fluorescein related deviations were determined as AFP $-17.46 \%$, HCG $-15.25 \%$, PSA $-9.91 \%$, CA $15-3-99.79 \%$, CEA $-12.18 \%$, CA 125 $-18.62 \%$. Ioversol related deviation values were determined as AFP $-6.88 \%$, HCG $-5.77 \%$, PSA $9.91 \%$, CA $15-3 \quad 27.08 \%$, CEA $6.96 \%$, CA125 $-4.93 \%$. Gadopentetic acid related deviation values were determined as AFP $-1.59 \%$, HCG $-1.41 \%$, PSA $8.62 \%$, CA $15-3$ 18.75\%, CEA $6.35 \%$, CA125 -7.72\%. CONCLUSIONS: Due to fluorescein, a significant deviation in tumor markers was observed between $-9.91 \%$ and $-99.79 \%$. Ioversol and gadopentetic acid produced positive interference in CA15-3 at ratio $27.08 \%$ and $18.75 \%$,respectively. After contrast medium infusion, interference in test results may lead to false interpretation of tests and malpractice.

Keywords: Ioversol, Gadopentetic Acid, Fluorescein, Tumor Markers, False Result

\section{OP-078 \\ DETERMINATION OF TRACE ELEMENT AND MINERAL LEVELS IN DIFFERENT TISSUES OF SOME FISH SPECIES (CAPOETA) LIVING IN BOTAN (SIIRT) RIVER}

Alper Yildirim $^{1}$, Suat Ekin ${ }^{2}$, Mahire Bayramoglu Akkoyun ${ }^{3}$

${ }^{1}$ Department of Chemistry and Chemical Processing, Vocational School of Technical Sciences, Siirt University, Siirt, Turkey

${ }^{2}$ Department of Chemistry, Science Faculty, Van Yuzuncu Yil University, Van, Turkey

${ }^{3}$ Basic Sciences, Division of Biochemistry, Faculty of Veterinary Medicine, Siirt University, Siirt, Turkey

OBJECTIVES: In this study Capoeta damascina, Capoeta caelestis, Capoeta capoeta and Capoeta umbla fish species in liver, brain, gills and muscle tissue in Botan Stream (Ulucay) in the province of Siirt were investigated for mineral and trace elements (As, $\mathrm{Cd}, \mathrm{Co}, \mathrm{Cr}, \mathrm{Cu}, \mathrm{Fe}, \mathrm{Mg}, \mathrm{Mn}, \mathrm{Ni}, \mathrm{Pb}, \mathrm{Zn}$ ). MATERIALS and METHODS: Fish liver, brain, gill and muscle tissues samples were prepared for analysis using the dry ashing method. Subsequently, trace element and mineral levels were then determined using Inductively Coupled Plasma Atomic Emission Spectrometer (ICP-OES) RESULTS: $\mathrm{Mg}, \mathrm{Fe}$ and $\mathrm{Zn}$ levels of liver, brain, gill and muscle tissues of Capoeta damascina, Capoeta caelestis, Capoeta capoeta and Capoeta umbla species were found to be higher than the other elements studied. CONCLUSIONS: Among the Capoeta fish species (Capoeta damascina Capoeta caelestis, Capoeta capoeta, Capoeta umbla), which are consumed at the some time by the people and have economic value, living in the Botan Stream (Ulucay), levelsof trace elements and minerals (As, Cd, Co, $\mathrm{Cr}, \mathrm{Cu}, \mathrm{Fe}, \mathrm{Mg}, \mathrm{Mn}, \mathrm{Ni}, \mathrm{Zn}$ ) in the liver, brain, gill and muscle tissues were below the recommended acceptable values for fish in Turkish Food Codex, Environmental Protection Agency and World Health Organization. However, $\mathrm{Pb}$ level was higher than the values determined in all tissues. Acknowledgements: This work was supported by a grant from the Scientific Research Projects Presidency of Van Yuzuncu Yil University (FYL-2018-7538). Keywords: Capoeta, Mineral, Trace Element.

\section{OP-079 \\ INVESTIGATION OF IN VITRO AND IN VIVO ANTICANCER EFFECT OF OLEUROPEIN ON COLORECTAL CANCER}

Eray Metin Guler, Abdurrahim Kocyigit

Bezmialem Vakif University Medical Faculty Department of Medical Biochemistry, Istanbul, Turkey

OBJECTIVES:ColorectalCancer(CRC)isthethirdmostcommoncancerdiagnosed in the world. Although 5-Fluorouracil (5-FU) is the primary antineoplastic used in therapy, its insufficient treatment efficiency has led to the search for new herbalbased agents. Oleuropein (OLE), the phenolic active ingredient of olive leaf, shows anti-cancer properties at high doses. The aim of our study is to investigate the in vitro and in vivo anti-cancer effects of OLE and 5-FU combinations on CRC. MATERIALS and METHODS: Cytotoxicity, genotoxicity, apoptosis, intracellular ROS, intracellular glutathione, and mitochondrial membrane potential were measured in LoVo cells. Cells were given to nude mices by the xenograft method. After four weeks of single and combination therapy, tumor size was measured by in vivo imaging system (IVIS) and caliper. RESULTS: Combination therapy in vitro dose-dependently increased cytotoxicity, intracellular ROS, and calcium significantly compared to single therapy $(\mathrm{p}<0.001)$. DNA damage and apoptosis were induced higher in combined therapy than single therapy and increased statistically significantly ( $\mathrm{p}$ $<0.001)$. It was found that it decreased glutathione and MMP levels statistically significantly $(\mathrm{p}<0.01 ; \mathrm{p}<0.001)$. Combination therapy in vivo has been found to reduce tumor size by a minimum of $30 \%$ compared to single therapy. CONCLUSIONS: Our results showed that OLE has different anti-cancer properties in vivo and in vitro. The combined use of OLE and 5-FU may be an option for routine therapy.

Keywords: Oleuropein, Colorectal Cancer, IVIS, Anticancer 


\section{OP-080 \\ APOPTOTIC EFFECTS OF RESVERATROL IN HEPATOCELLULAR CARCINOMA CELL LINE}

Nadire Kiyak ${ }^{1}$, Eda Becer ${ }^{2}$, Hafize Seda Vatansever ${ }^{3}$, Aysel Kukner ${ }^{1}$ ${ }^{1}$ Department of Histology and Embryology, Faculty of Medicine, Near East University, Nicosia, Mersin 10 Turkey.

${ }^{2}$ Department of Biochemistry, Faculty of Pharmacy, Near East University, Nicosia, Mersin 10 Turkey.

${ }^{3}$ Department of Histology and Embryology, Faculty of Medicine, Celal Bayar University, Manisa, Turkey.

OBJECTIVES: Resveratrol is a polyphenol nonflavonoid compound which positively affects human health due to its anti-cancer, anti-inflammatory and anti-microbial properties. It had also been shown that resveratrol has role in preventive of cancer and anti-cancer properties. In this study, we aimed to investigate the effects of resveratrol on cell viability, apoptosis and cellular proliferation in human hepatocellular carcinoma cell (HepG2) line. MATERIALS and METHODS: Cytotoxicity was analyzed via MTT assay on HepG2 cells. HepG2 were treated with different resveratrol concentrations $(5,10,25,50$, and $100 \mathrm{mM})$. Anti-cancer and proapoptotic properties of resveratrol were determined by immunocytochemistry using antibodies against caspase-3, cytochrome-c, Fas Ligand and Ki-67. RESULTS: The effective dose for inhibition of cell growth in HepG2 cells was determined to be $100 \mu \mathrm{M}$ resveratrol for 48 hours. The immunoreactivity of cytochrome-c was significantly higher in resveratrol-treated HepG2 cells than the control group $(\mathrm{p}<0.05)$. Also, immunoreactivity of Ki-67 in resveratroltreated HepG2 cells was significantly lower than the control group $(p<0.05)$. CONCLUSIONS: Our results suggested that resveratrol induced apoptosis in human hepatocellular carcinoma cells. Interestingly, resveratrol triggered intrinsic apoptotic pathway in human hepatocellular carcinoma cells. Moreover, resveratrol decreased significantly Ki-67 immunoreactivity and showed anti-proliferative effects in HepG2 cells. Keywords: Resveratrol, Apoptosis, Human Hepatocellular Carcinoma

\section{OP-081 \\ INVESTIGATION OF PHOTOTOXIC EFFECTS OF SILICON PHTHALOCYANINE AGAINST A549 CELL LINE}

Burak Barut $^{1}$, Can Ozgur Yalcin ${ }^{2}, Z_{\text {Zekeriya Biyiklioglu }}$

${ }^{1}$ Karadeniz Technical University, Faculty of Pharmacy, Department of

Biochemistry, Trabzon, Turkey

${ }^{2}$ Karadeniz Technical University, Faculty of Pharmacy, Department of

Toxicology, Trabzon, Turkey

${ }^{3}$ Karadeniz Technical University, Department of Chemistry, Trabzon, Turkey

OBJECTIVES: Lung cancer is the most common cause of cancer-related mortality in global. According to the World Health Organization, about 2 million people died in 2018 because of lung cancer. Photodynamic therapy (PDT) is an alternative method to treat lung cancer in recent years. Phthalocyanines are used as PDT agents for cancer treatment. In this study, we aimed to investigate the potential of water soluble silicon phthalocyanine containing dimethylamino groups (SiPcMS) as a PDT agent for lung cancer. MATERIALS and METHODS: The DNA photodamage effects of SiPcMS were examined using agarose gel electrophoresis $(1$ and $5 \mu \mathrm{M}$, white light, $17.5 \mathrm{~mW} / \mathrm{cm} 2,5-10-15 \mathrm{~min}$ ). The cytotoxic/phototoxic (white light, $17.5 \mathrm{~mW} /$ $\mathrm{cm} 2,30 \mathrm{~min}$ ) effects of SiPcMS were investigated using MTT cell viability test against human lung carcinoma (A549) cell line ( $n=6,0.01-10 \mu \mathrm{M}, 24 \mathrm{~h})$. Cisplatin was used as a positive control. To determine the cell death mechanism of SiPcMS, Anneksin V-FITC apoptosis test and cell cycle analysis were used. RESULTS: SiPcMS had high photodamage on DNA depending on the light dose and concentration whilst it showed low nuclease effect without irradiation. MTT results showed that SiPcMS had higher phototoxic activities than its cytotoxicity $(\mathrm{p}<0.001)$. The IC50 values of SiPcMS (at light) and cisplatin were determined as $0.18 \pm 0.04$ and $9.37 \pm 2.70 \mu \mathrm{M}$. The apoptotic cells at $1 \mu \mathrm{M}$ were $15.10 \%$ and $61.60 \%$, respectively, in the absence and presence of light. As a result of the cell cycle analysis, SubGo/G1 phase increased at $1 \mu \mathrm{M}$ in the presence of light. The cell death mechanism studies showed that SiPcMS induced apoptosis on A549 cells. CONCLUSIONS: These results showed that SiPcMS has high DNA photodamage and phototoxic effects and the compound is a promising candidate for PDT agent. Keywords: A549, Photodynamic Therapy, Cancer, Apoptosis

\section{OP-082 \\ A COMPARATIVE EVALUATION OF CYTOTOXIC AND CELLULAR ANTIOXIDANT ACTIVITY OF ORIGANUM ONITES L. ESSENTIAL OIL AND ITS TWO COMPONENTS IN HCT-116 CELLS}

Eda Becer ${ }^{1}$, Ergul Mutlu Altundag ${ }^{2}$, Kemal Husnu Can Baser ${ }^{3}$

${ }^{1}$ Department of Biochemistry, Faculty of Pharmacy, Near East University, Nicosia, Turkish Republic of Northern Cyprus; DESAM Institute, Near East University, Nicosia, TRNC.

23Department of Biochemistry, Faculty of Medicine, Eastern Mediterranean University, Famagusta, TRNC.

${ }^{3}$ Department of Pharmacognosy, Faculty of Pharmacy, Near East University, Nicosia, TRNC.

OBJECTIVES: Origanum onites L. (Turkish Oregano) is one of the cultivated Origanum species in Turkey. Origanum onites L. essential oil has medicinal and preservative importances, including antiviral, antimicrobial, antioxidant, anticancer and proapoptotic properties. Carvacrol and p-cymene are the important compounds of $\mathrm{O}$. onites essential oil. In this study, we aimed to determine the effects of essential oil from Origanum onites L. and its two components, carvacrol and p-cymene, on cytotoxicity and to investigate their cellular antioxidant effects in human colorectal carcinoma (HCT-116) cells. MATERIALS and METHODS: Origanum onites essential oil components were analyzed by GC/MS and GC/FID. Cytotoxicity was analyzed via the MTT assay on HCT-116 cells. HCT-116 were separately treated with Origanum onites essential oil, carvacrol and p-cymene concentrations $(100-500 \mu \mathrm{g} / \mathrm{ml})$. Cellular antioxidant activities of Origanum onites essential oil, carvacrol and p-cymene were determined with dichloro-dihydro-fluorescein diacetate (DCFH-DA). RESULTS: GC/MS analysis identified carvacrol (\%78.4) as the main constituent of Origanum onites essential oil. The effective dose for inhibition of cell growth in HCT-116 was determined to be $400 \mu \mathrm{g} / \mathrm{ml}$ Origanum onites essential oil, carvacrol and p-cymene after 48 hours treatment period. The cellular antioxidant effect of the carvacrol was found to be significantly higher than the control group. Also, carvacrol showed higher cellular antioxidant activity than Origanum onites essential oil and p-cymene. CONCLUSIONS: Our results suggested that Origanum onites essential oil, carvacrol and p-cymene have anti-proliferative effects on HCT-166 cells. Moreover, carvacrol exhibited higher cellular antioxidant activity than Origanum onites essential oil and p-cymene in HCT-116 cells.

Keywords: Origanum Onites L. Essential Oil, Carvacrol, P-Cymene, Colon Cancer

\section{OP-083}

\section{NEURTURIN: A NEUROTROPHIC FACTOR IN BREAST CANCER}

$\underline{\text { Tuba Taskan }}^{1}$, Farshad Noori ${ }^{2}$, Niyazi Karaman ${ }^{3}$, Osman Kurukahvecioglu $^{2}$, Aymelek Gonenc ${ }^{1}$

${ }^{1}$ Gazi University Pharmacy Faculty, Department of Biochemistry, Ankara, Turkey

${ }^{2}$ Gazi University Medical Faculty, Department of General Surgery, Ankara,

Turkey

${ }^{3}$ Dr. Abdurrahman Yurtaslan Ankara Oncology Training and Research Hospital, Department of General Surgery, Ankara, Turkey

OBJECTIVES: The glial cell line-derived neurotrophic factor family ligands comprise a group of four homologous and potent growth factors that includes GDNF, neurturin (NRTN), artemin, and persephin. NRTN, one of the neurotrophic factors, is a protein that mediates both the development of the organism and the growth and survival of neurons. NRTN binds to GFR $\alpha 2$ coreceptor and exerts its effects through Ret tyrosine kinase. In our study, we aimed to examine the possible role of NRTN in breast cancer pathogenesis. MATERIALS and METHODS: Gazi University Medical Faculty Hospital General Surgery Outpatient Clinic and Dr. Abdurrahman Yurtaslan Ankara Oncology Training and Research Hospital General Surgery Outpatient Clinic 110 patients diagnosed with breast cancer (regardless of staging) and 110 healthy women without any systemic disease. Serum NRTN level was measured in blood samples taken from the study group using commercial ELISA kits. Findings were evaluated with SPSS 20.0 statistical program. RESULTS: Serum NRTN levels $(1.81 \pm 0.25 \mathrm{ng} / \mathrm{mL})$ in patients with breast cancer were found to be significantly higher than the healthy control group levels $(1.1 \pm 0.16 \mathrm{ng} / \mathrm{mL})(\mathrm{p}=0,019)$

CONCLUSIONS: In our study, it was found that soluble NRTN levels increased in the serum of breast cancer patients. In the light of these findings, it is thought that NRTN may play a role in breast cancer pathogenesis

*Acknowledgement; This work is supported by Gazi University Scientific Research Projects with the code of 02 / 2019-3.

Keywords: Breast Cancer, Neurturin, Neurotrophic Factor 


\section{OP-084 \\ EVALUATION OF SERUM TRAIL AND DR5 LEVELS IN PATIENT WITH BREAST CANCER}

Kubra Kader Demirdogen ${ }^{1}$, Tuba Taskan ${ }^{1}$, Farshad Noori ${ }^{2}$,

Osman Kurukahvecioglu' ${ }^{2}$, Aymelek Gonenc

'Department of Biochemistry, Gazi University Faculty of Pharmacy, Ankara, Turkey

${ }^{2}$ Department of General Surgery, Gazi University Faculty of Medicine, Ankara, Turkey

OBJECTIVES: Breast cancer is the most common type of cancer among women in the world. One of the factors developing of cancer is the impaired apoptosis mechanism. Changes in serum levels of TNF-associated apoptosis inducing ligand (TRAIL) and its receptor DR5, some of the extrinsic apoptotic pathway elements, are associated with the prognosis of cancer. In our study, it was aimed to evaluate serum TRAIL, DR5 levels in with breast cancer patients. MATERIALS and METHODS: Our study group includes 62 newly diagnosed patients with breast cancer who not treated and 62 healthy individuals in the Department of General Surgery, Gazi University Medical Faculty Hospital. The mean age of the breast cancer patients and the control group was $53.82 \pm$ 1.56 and $52.23 \pm 1.37$, respectively; mean body mass index is $27.55 \pm 0.59$ and $28.41 \pm 0.64$, respectively. Serum TRAIL and DR5 levels were measured with a commercial kits in blood of the study group. The results were evaluated by SPSS 20.0 package program

RESULTS: Serum DR5 levels were measured as $1.57 \pm 0.11 \mathrm{ng} / \mathrm{mL}$ in breast cancer patients and $1.03 \pm 0.10 \mathrm{ng} / \mathrm{mL}$ in the healthy control group, and a significant difference was found between the two groups ( $<<0.01$ ). TRAIL levels were measured as $6.53 \pm 0.51 \mathrm{ng} / \mathrm{mL}$ in breast cancer patients and $6.99 \pm 0.43 \mathrm{ng} / \mathrm{mL}$ in the healthy control group, and there was no significant difference between the two groups ( $>>0.05)$. CONCLUSIONS: In a previous study, serum DR5 levels were reported to be significantly higher in colorectal cancer patients compared to the control group. Similarly, it was found that DR5 levels increased in the serum of breast cancer patients in our study. Additionally, there are not significant change in serum TRAIL levels of breast cancer, which is consistent with the data in the literature. With increasing serum DR5 levels in breast cancer, it is thought that the apoptotic mechanism induced by TRAIL may be involved in the pathology of the disease. Keywords: TRAIL, DR5, Breast Cancer

\section{OP-085 \\ ASSOCIATION OF XPD LYS751GLN POLYMORPHISM WITH RENAL CELL CARCINOMA}

Sefika Nur Gumus $^{1}$, Sule Seckin ${ }^{1}$, Oner Sanli², Selcuk Erdem², Canan Kucukgergin

${ }^{1}$ Department of Medical Biochemistry, Istanbul University, Istanbul, Turkey ${ }^{2}$ Department of Urology, Istanbul University, Istanbul, Turkey

OBJECTIVES: Renal cell carcinoma makes $2-3 \%$ of all malignant cancers and is the third often cancer amongst all urogenital cancers. An abnormality in DNA repair mechanism results in cancer and aging. For that reason, DNA repair mechanisms are very important to prevent cancer development. Nucleotide excision repair (NER) pathway, has a role in the repairment of DNA damages that affect double strand helix structure. XPD Lys751Gln gene polymorphism is indicated as a risk factor for various cancers. On the other hand, in some studies it is reported that this polymorphism has no impact on cancer development. Our goal in this study is to reveal the distribution of XPD Lys751Gln gene polymorphism genotype and its relation with renal cell carcinoma in Turkish population. MATERIALS and METHODS: The patients who were admitted to Istanbul Faculty of Medicine, Department of Urology between 2015 and 2018 and diagnosed for renal cell carcinoma $(\mathrm{n}=101$, mean age: 54,5 year) and healthy people ( $\mathrm{n}=94$, mean age: 55.2 years) have formed the control group. XPD Lys751Gln gene polymorphism was determined using polymerase chain reaction restriction fragment length polymorphism (PCR-RFLP). Results were evaluated with chi-square test, logistic regression analysis and Mann-Whitney U test. Our study is proceeding to increase $n$ number. RESULTS: Age and BMI were similar in patient and healthy control groups. Genotype and allele frequencies for XPD Lys751Gln gene polymorphism were not significantly different between the patient and healthy control groups. The genotype distribution of XPD Lys751Gln gene polymorphism was consistent with Hardy-Weinberg equilibrium in controls and patients $(\mathrm{p}>0.05)$. On the other hand, XPD Lys751Gln gene polymorphism was not associated with the clinicopathological characteristics of renal cell carcinoma. CONCLUSIONS: We suggest that the XPD Lys751 Gln gene polymorphism is not a risk factor for the development of renal cell carcinoma in Turkish population. Keywords: Renal Cell Carcinoma, XPD Lys751Gln Gene Polymorphism, Turkish Population, PCR-RFLP

\section{OP-086 \\ THE EVALUATION OF CATALASE (CAT) C-262T GENE POLYMORPHISM IN TURKISH RENAL CELL CARCINOMA PATIENTS}

Gozde Ceylan $^{1}$, Sule Seckin ${ }^{1}$, Oner Sanli², Selcuk Erdem², Canan Kucukgergin ${ }^{1}$ ${ }^{1}$ Medical Biochemistry Department, Istanbul University,Istanbul, Turkey ${ }^{2}$ Urology Department, Istanbul University,Istanbul, Turkey

OBJECTIVES: CAT is an enzyme involved in ROS neutralizing pathways participating in defence mechanisms against oxidative stress. This study was designed to explore whether the C-262Tsingle nucleotide polymorphism in catalase (CAT) gene influenced the development and progression of renal cell carcinoma (RCC).

MATERIALS and METHODS: The patients who were admitted to Istanbul Faculty of Medicine, Department of Urology between 2015 and 2018 and diagnosed for renal cell carcinoma $(\mathrm{n}=113$, mean age: $54,7 \pm 10,7$ year, mean BMI: $28,1 \pm 4,7)$ and healthy people $(\mathrm{n}=203$, mean age: $56,0 \pm 11,0$ year, mean BMI: $27,2 \pm 2,8$ ) have formed the control group. WHO/ISUP grade and clinical T stages of the patients were determined. G1 and G2 were recorded as low grade $(n=72), G 3$ and $G 4$ as high grade $(n=41)$; those with T stage T1 and T2 were recorded as low stage $(n=72)$, those with T3 and T4 as high grade $(n=41)$.DNA samples obtained from patients and healthy controls were analyzed for CAT C-262Tgene polymorphism by using Polymerase chain reaction (PCR), restriction fragment length polymorphism (RFLP) and Agarose Gel Electrophoresis techniques. Pearson Ki-square $(\chi 2)$ test, student-t test, Mann-Whitney U test and logistic regression test were used for statistical analyses of the results. RESULTS: No statistically significant difference was determined between patient and control groups in terms of age and body mass index (BMI). $\% 39,8$ of the patient group was CC, $\% 44,2 \mathrm{CT}, \% 16$ TT genotype; $\% 52,7$ of the control group were found in CC genotype, $\% 39,4$ in CT, $\% 7,9$ in TT genotype. In the patient group, the $\mathrm{C}$ allele was $\% 62$, $\mathrm{T}$ allele $\% 38$; in the control group, the $\mathrm{C}$ allele was $\% 72,4$ and $\mathrm{T}$ allele was $\% 27,6$. When CAT C-262T polymorphism was evaluated, it was observed that there was a significant increase in TT genotype distribution in patient group when compared to control group $(\mathrm{p}=0,012)$. There was no significant difference between high grade and advanced stage in terms of CAT C-262T polymorphism.

CONCLUSIONS: We suggest that CAT C-262T gene polymorphism may be effective in the initiation of renal cell carcinoma, but not in its development. Keywords: Renal Cell Carcinoma, CAT C-262T Polymorphism, Turkish Population, PCR-RFLP

\section{OP-087 \\ INVESTIGATION OF SERUM IRISIN LEVELS IN COLORECTAL CANCER PATIENTS}

Nurcan Kilic Baygutalp ${ }^{1}$, Zeynep Celik ${ }^{1}$, Adil Furkan Kilic ${ }^{2}$

Salim Basol Tekin ${ }^{2}$, Ebubekir Bakan ${ }^{3}$, Mehmet Ali Gul ${ }^{3}$, Neslihan Yuce 'Ataturk University School of Medicine Department of Biochemistry, Erzurum, Turkey

${ }^{2}$ Ataturk University School of Medicine Department of Internal Diseases, Erzurum, Turkey

${ }^{3}$ Ataturk University School of Medicine Department of Medical Biochemistry, Erzurum, Turkey

OBJECTIVES: Investigation of the serum irisin levels in obesity, obesity-related diabetes mellitus and obesity-related other diseases is a current issue. It was aimed to investigate serum irisin levels in colorectal cancer (CRC) patients and healthy volunteers.

MATERIALS and METHODS: The cross-sectional study included 53 patients diagnosed with colorectal cancer and 87 healthy volunteers. Serum irisin, glucose, insulin, c-peptide and plasma HbAlc levels were measured in venous blood samples taken from patients and the control group. This study was supported by Ataturk University Scientific Research Projects Coordinator. RESULTS: Serum irisin level was found $23.97 \pm 16.94 \mathrm{ng} / \mathrm{mL}$ in the patient group and $32.71 \pm 17.26 \mathrm{ng} / \mathrm{mL}$ in the control group. The mean serum irisin level was statistically significantly lower in the patient group compared to the control group $(\mathrm{p}=0.004)$. Serum glucose level was found $96,58 \pm 15,12 \mathrm{mg} / \mathrm{dL}$ in the patient group and $81.91 \pm 11.24 \mathrm{mg} / \mathrm{dL}$ in the control group. Serum glucose level was statistically significantly higher in the patient group compared to the control group $(p<0.01)$. CONCLUSIONS: Ourfindingsthatserumirisinlevelsare decreasedinCRCpatients compared to healthy controls made a significant contribution to the literature. In addition, glucose intolerance and insulin resistance, which are common in cancer patients, may have an effect on the low serum irisin levels in CRC patients. We hope that our results will lead to further studies including in-vitro, in-vivo and in large patient groups for the use of irisin in many diseases, especially CRC. Keywords: Colorectal Cancer, Irisin, Obesity 


\section{OP-088 \\ A RETROSPECTIVE EVALUATION OF FREE PROSTATE-SPECIFIC ANTIGEN ORDERS IN PROSTATE CANCER SCREENING}

Belkiz Ongen Ipek, Mustafa Erinc Sitar

Maltepe University Faculty of Medicine, Medical Biochemistry, Istanbul Turkey

OBJECTIVES: Prostate spesific antigen (PSA) is a tumor marker used for prostate cancer screening. PSA is found in serum two forms; free (fPSA) and complex PSA. It is recommended to measure fPSA levels when Total PSA (TPSA) levels are between $4-10 \mathrm{ng} / \mathrm{mL}$. The aim of the current study was to perform a crosssectional analysis rather than ensuring the harmony between medical laboratory and clinical branches.

MATERIALS and METHODS: TPSA, fPSA, fPSA test demand when TPSA values were $4-10 \mathrm{ng} / \mathrm{mL}$ were examined. Average age of the patients and the departments where the tests were requested were also examined. Patient data between October 2019 and September 2020 were accessed from laboratory information system retrospectively. RESULTS: TPSA test was requested from 1322, fPSA test was requested from 766 patients. The number of patients whose TPSA values were between 4-10 $\mathrm{ng} / \mathrm{mL}$ was 110 . Simultaneous fPSA test was requested for 89 patients and simultaneous or later fPSA test was not requested for 21 patients. The mean age of the patients was 61.55 . The departments requested for TPSA test were $26.3 \%$ Urology, 24.8\% Familiy Medicine, 22.8\% Internal Medicine, 9.6\% Oncology and 16.5 other departments.

CONCLUSIONS: fPSA test is expected to be ordered after TPSA test result. However, these two tests can be ordered together in routine clinical practice due to reasons such as possible false positive/negative values of TPSA test, possible incompatibilities in the follow up of patients who needs care, situations where the health system is burdened and the desire to avoid invasive biopsy procedures. Keywords: Prostate Cancer, Prostate Specific Antigen, Cancer Screening

\section{OP-089 \\ THE EFFECT OF METFORMIN AND VERTEPORFIN ON GROWTH ARREST SPECIFIC PROTEIN 6/AXL PATHWAY IN HUMAN CHOLANGIOCARCINOMA CELL LINE}

Merve Ozel $^{1}$, Fatma Gunes ${ }^{2}$, Busra Nur Dogru ${ }^{1}$, Gulden Baskol ${ }^{1}$, Mevlut Baskol ${ }^{3}$

${ }^{1}$ Erciyes University School of Medicine, Department of Biochemistry, Kayseri, Turkey

${ }^{2}$ Recep Tayyip Erdogan University School of Medicine, Department of

Biochemistry, Rize, Turkey

${ }^{3}$ Erciyes University School of Medicine, Department of Gastroenterology,

Kayseri, Turkey

OBJECTIVES: Cholangiocarcinom (CCA) is a malignant tumor originating from bile duct epithelial cells. Since tumor metastasis is associated with poor prognosis and short-term survival of patients, there is an urgent need for alternative therapeutic approaches for CCA. Growth arrest specific protein 6 (Gas6), a ligand of Axl, is known to play a role in the regulation of tissue homeostasis. Gas6/Axl has been shown to play an oncogenic role in many cancer studies, but it has also been reported to play a tumor suppressor role in a few studies. In this study, we investigated the effect of Metformin and Verteporfin on Gas6/Axl in cholangiocarcinoma (TFK-1) cell line. Moreover, the effect of Metformin and Verteporfin on apoptosis was investigated. MATERIALS and METHODS: TFK-1 cells were treated with $5 \mu \mathrm{M}$ Metformin and $13 \mu \mathrm{M}$ Verteporfin. Both drugs were dissolved in DMSO and used as negative control.Gas6, Axl, and sAxl protein concentrations were analyzed by the Elisa method. Apoptosis was performed by Muse ${ }^{\circledR}$ Cell Analyzer. RESULTS: Metformin and Verteporfin statistically increased Gas6 / Axl and sAxl protein concentrations $(\mathrm{p}<0.001, \mathrm{p}<0.04, \mathrm{p}<0.001 ; \mathrm{p}<0.02, \mathrm{p}<0.02, \mathrm{p}<0.001)$. Metformin and Verteporfin statistically increased apoptosis $(\mathrm{p}<0.001 ; \mathrm{p}<0.001)$ CONCLUSIONS: We observed the antiproliferative effects of both Metformin and Verteporfin in cholangiocarcinoma due to the induction of apoptosis. However, the role of Gas6 and Axl in cancer is a paradox, that is, experimental studies have reported that their functions may change according to tissue and cell type and may play a dual role in cancer. sAxl may have been increased by proteolysis of Axl. Gas6 and Axl expression may be increased by induction of apoptosis to maintain dormancy of cells remaining in the tumor microenvironment. Keywords: Cholangiocarcinoma, Metformin, Verteporfin, Gas6, Axl

\section{OP-090 \\ INVESTIGATION OF THE EFFECT OF CIVAN PERCEMI (ACHILLEA MILLEFOLIUM) ON EHRLICH ASCITES TUMOR}

Mustafa Nisari ${ }^{1}$, Neriman Inanc ${ }^{1}, \mathrm{Ozge}_{\mathrm{Al}^{2}}$, Sumeyye $\mathrm{Ucar}^{2}$, Mustafa Tastan ${ }^{3}$, Sukru Ates ${ }^{4}$, Adem Tokpinar $^{4}$

${ }^{1}$ Dept of Nutrition and Dietetics, Faculty of Health Sciences, University of Nuh Naci Yazgan, Kayseri,Turkey

${ }^{2}$ Dept. of Anatomy, Erciyes University, School of Medicine, Kayseri, Turkey

${ }^{3}$ Dept. of Anatomy, Lokman Hekim University,School of Medicine, Ankara, Turkey

${ }^{4}$ Dept. of Anatomy, Bozok University, School of Medicine, Yozgat, Turkey

OBJECTIVES: One of the most important health problems of today is cancer In addition to the basic methods used in cancer treatment, complementary and alternative treatment applications have increased recently. One of these applications is herbal treatment. The aim of this study was to investigate the in vitro effect of yarrow perch (CP) with known anticarcinogen effect on Ehrlich Ascites Tumor (EAT).

MATERIALS and METHODS: The above-ground part $(300 \mathrm{~g})$ of the CP was massaged with water and extracted three times in a shaking water bath at 37 - $\mathrm{C}$ for 24 hours. The extracts obtained were concentrated and lyophilized in rotavapor $\left(37-38{ }^{\circ} \mathrm{C}\right)$ under vacuum. The obtained extract was dissolved in a mixture of distilled water and $0.1 \%$ DMSO. In the study, EAT cells were divided into control, DMSO group 5-FU, 50, 100, 200, 400 and $800 \mu \mathrm{g} / \mathrm{ml} \mathrm{CP}$ groups. It was cultured at $37^{\circ} \mathrm{C}$ for 24,48 and 72 hours in an environment with $5 \%$ $\mathrm{CO} 2$. Cell cycle analyzes were performed using MuseAnnexin V, Muse Cell Cycle and Mito Potential kits compatible with the Muse Cell Analyzer device. RESULTS: At the end of the 48th hour, it was observed that total apoptosis increased significantly in CP groups (especially $50 \mu \mathrm{g} / \mathrm{ml}$ ) compared to the control group $(\mathrm{p}<0.05)$. It was observed that CP slowed the division of EAT cells (especially $800 \mu \mathrm{g} / \mathrm{ml}$ ) by halting the cell cycle at the G0 / G1 stage. It was concluded that $\mathrm{CP}$ (especially at high doses) triggered apoptosis by significantly increasing the percentage of total depolarized cells $(\mathrm{p}<0.001)$ in all three time periods. CONCLUSIONS: The results obtained as a result showed that CP extract may have an antitumoral effect on EAT cells. It is thought that this study will contribute to studies on cancer treatment.

Keywords: Yarrow, EAT, Apoptosis

\section{OP-091}

\section{THE EFFECT OF RESVERATROL ON HEART IN EXPERIMENTAL HYPERTHYROID RATS}

Hacer Merve Gurler ${ }^{1}$, Necmiye Canacankatan $^{1}$, Deniz Kibar ${ }^{2}$, Semra Erdogan $^{3}$, Banu Coskun Yilmaz ${ }^{2}$

${ }^{1}$ Mersin University Faculty of Pharmacy, Department of Biochemistry, Mersin, Turkey

${ }^{2}$ Mersin University Faculty of Medicine Department of Histology and Embryology, Mersin, Turkey

${ }^{3}$ Mersin University Faculty of Medicine Department of Biostatistics and Medical Informatics, Mersin, Turkey

OBJECTIVES: Hyperthyroidism is an endocrine disease characterized by overproduction of thyroid hormones FT3 and/or FT4. The aim of this study is; Investigation of the effect of resveratrol on the heart in rats with experimental hyperthyroidism with L-thyroxine.

MATERIALS and METHODS: 4 groups were formed as Control, Hyperthyroidism, Hyperthyroid Resveratrol ( $1 \mathrm{mg} / \mathrm{kg} /$ day), Hyperthyroidism Resveratrol $(5 \mathrm{mg} / \mathrm{kg} /$ day). The rats in the Control and Hyperthyroidism groups were sacrificed after hyperthyroidism was found to be statistically significant. After the occurrence of hyperthyroidism, indicated doses of resveratrol i.p. was applied to the Hyperthyroid Resveratrol $(1 \mathrm{mg} / \mathrm{kg} / \mathrm{day})$ and Hyperthyroid Resveratrol (5mg/kg/day) groups for 3 weeks. Caspase $-3,-8$ and -9 enzyme activities and Bcl-2 levels as apoptotic markers; nitric oxide (NO), endothelin-1 (ET-1) and hypoxia-induced factor-1-alpha (HIF1a) levels as angiogenic markers were determined in heart tissues; also FT3, FT4 HDL, LDL, total cholesterol and triglyceride levels were evaluated in serum. RESULTS: There was a significant decrease in Caspase $-3,-8$ and -9 enzyme activities in Hyperthyroidism+Resveratrol $(5 \mathrm{mg} / \mathrm{kg} /$ day $)$ group compared to Hyperthyroidism and Hyperthyroidism+Resveratrol (1mg/ $\mathrm{kg}$ /day) groups. There was no effect of resveratrol on $\mathrm{Bcl} 2$, FT3, FT4, NO, ET-1 and HIF-1a. Both doses of resveratrol, significantly increased HDL and total cholesterol levels and decreased LDL compared to Hyperthyroidism group. Triglyceride levels were significantly decreased in Hyperthyroidism+Resveratrol $(1 \mathrm{mg} / \mathrm{kg}$ /day) group compared to Control and Hyperthyroidism groups.

CONCLUSIONS: It may suggested that resveratrol have a cardioprotective effect on heart tissues with hyperthyroidism due to its suppression of apoptosis in the extrinsic and intrinsic pathways and beside its antilipidemic properties.

Acknowledgement: This study was supported by Mersin University Research Foundation (2019-1-TP2-3294).

Keywords: Hyperthyroidism, Resveratrol, Caspase, HDL, LDL 


\section{OP-092 \\ INVESTIGATION OF THE EFFECT OF OLEUROPEIN ON CD36 GENE EXPRESSION IN RAW264.7 CELL LINE}

Neslihan Saglam, Elif Sahin, Ahmet Alver, Ahmet Mentese

Department of Medical Biochemistry, Karadeniz Technical University, Trabzon, Turkey

OBJECTIVES: Olive and olive oil are an essential component of the Mediterranean diet (MD) and have positive effects on many diseases. One of the most important benefits of MD is its effect in preventing cardiac events and / or coronary heart disease. Oleuropein is the main polyphenolic compound of olive and olive oil. It has many beneficial effects such as antioxidant, anti-inflammatory and antiatherogenic effects. In this study, it was aimed to investigate the possible effects of oleuropein on CD36 gene expression which regulates Ox-LDL uptake in RAW 264.7 macrophage cell line. Thus, a contribution will be made to the literature to elucidate the mechanisms underlying the anti-atherogenic effect of oleuropein. MATERIALS and METHODS: RAW 264.7 macrophage cells were obtained from ATCC (American Type culture collection). MTT test was performed to determine the dose of oleuropein to be used in the study. Therefore, cells were treated with different concentrations of oleuropein $(0,1,5,10,25,50,100,250$ $\mu \mathrm{M})$ prepared by dissolving in DMEM. After dosage determination, cells were treated with determined concentrations of oleuropein for 48 hours. CD36 gene expression was examined by RT-PCR in the cDNAs obtained at the end of the period. Differences between groups were determined by paired samples T test. RESULTS: Since oleuropein concentration up to $100 \mu \mathrm{M}$ did not have a cytotoxic effect in RAW264.7 cells, oleuropein concentrations of 5-100 $\mu \mathrm{M}$ were used in the study. A significant reduction in CD36 gene expression of $100 \mu \mathrm{M}$ Oleuropein $(0.72 \pm 0.25$ Fold / Gapdh $)$ compared to control group $(0.00 \pm 0.00$ Fold / Gapdh) was observed in cells treated with oleuropein for 48 hours $(p=0.031)$. CONCLUSIONS: Oleuropein exhibited anti-atherogenic effect by inhibiting CD36 expression in RAW264.7 cell line. Therefore, oleuropein can be used as part of new therapeutic strategies for the prevention and treatment of atherosclerosis. Keywords: CD36, Oleuropein, Ox-LDL, RAW264.7, RT-PCR

\section{OP-093 \\ EVALUATION OF NOVEL MARTIN FORMULA AND FRIEDEWALD FORMULA FOR LDL-C ESTIMATION IN A ADULT POPULATION}

Medine Alpdemir, Mehmet Fatih Alpdemir

Clinical Biochemistry Laboratory, Balikesir State Hospital, Balikesir, Turkey

OBJECTIVES: Friedewald formula is used in the calculation of LDL-C However, several new formulas for prediction of LDL-C have been proposed in recent years but have not been validated in different populations. The aim of this study is to compare the directly measured LDL-C, Friedewald and a new Martin LDL-C formulas in the Turkish adults population. MATERIALS and METHODS: A total of 1558 patients between the ages of 18 and 65 with a triglyceride level of $<400 \mathrm{mg} / \mathrm{dL}$ were included in this study. Serum lipid profile concentrations of all patients were measured with Cobas 6000 c501 (Roche Diagnostic). d-LDL-C concentrations were measured by a homogeneous direct method using reagents. The d-LDL-C measurement results were used as a reference method. Friedawald [TC- (HDL-C + (TG/5)] and Martin [TC(HDL-C + TG / new adjustable factor)] formulas were used to estimate LDL-C RESULTS: The average age of the patients included in the study was $52.7 \pm 12.3$. Of the 1558 patients, $56 \%$ were women and $44 \%$ were men. The d-LDL-C, F-LDL-C and M-LDL-C concentrations in the all patient were $148.6 \pm 39.8$ $\mathrm{mg} / \mathrm{dL}, 123.9 \pm 38.7 \mathrm{mg} / \mathrm{dL}$ and $133.4 \pm 35.9 \mathrm{mg} / \mathrm{dL}$, respectively. The mean difference between F-LDL-C and M-LDL-C concentrations according to d-LDL-C in the patients was $24.6 \pm 10.7$ and $15.10 \pm 10.3$, respectively. In comparing the Scatter blot plot [estimated LDL-C (x) and d-LDL-C (y)] in patients, were calculated by the equations $y=1.1665 x+0$ for Friedewald and $y=1.1667 x+0$ for Martin. When compared to the dDL-C concentration, both the Friedewald and Martin formulas showed a strong correlation $(r=0.963, r=0.968$, respectively). The new adjustable factor mean of Martin formula was $6.1 \pm 0.9$. CONCLUSIONS: Although there was a strong correlation between formulas and dLDL-C in our study, there was a negative bias in the calculated LDL-C concentrations. These formulas show a lower risk in the determination of the risk of coroner heart disease and in the planning of treatment strategies. This may lead to delayed lipid-lowering treatment or improper diet for high-risk patients with coronary artery disease. This difference was less in the Martin formula. Martin formula showed a relatively better separation. Keywords: Friedewald Formula, Martin Formula, LDL Cholesterol, Direct LDL Measurement, LDL Cholesterol Estimation

\section{OP-094 \\ INVESTIGATION OF HERPES VIRIDEA FREQUENCIES IN LYMPHOPENIC MALIGNANT PATIENTS RECEIVING CHEMOTHERAPY}

\author{
Adil Furkan Kilic, Salim Basol Tekin \\ Ataturk University School of Medicine Department of Internal Diseases, \\ Erzurum, Turkey
}

OBJECTIVES: In this study, we aimed to investigate the frequency of EBV, HSV, CMV and Parvovirus B19 viral infections in patients diagnosed with cancer receiving chemotherapy in our clinic.

MATERIALS and METHODS: 138 lymphopenic patients who were hospitalized and received chemotherapy at the Medical Oncology Clinic of Ataturk University Medical Faculty Hospital, and 30 healthy controls were evaluated. The \% frequency of EBV, HSV, CMV and Parvovirus B19 in serum samples were determined by real time PCR method. RESULTS: The mean age of the patients was $58.93 \pm 13.28$ years, and the mean duration of diagnosis was $2,0 \pm 2,2$ years. EBV positively was detected in 9 patients $(6.5 \%)$, CMV positively in 12 patients $(8.7 \%)$, and EBV and CMV (together) positively in $1(0,7 \%)$ patient. HSV and parvovirus B19 positively were not determined in any patients. EBV, HSV, CMV and Parvovirus B19 positivity was not found in any healthy volunteers. According to the results of the survival analysis, the average survival time in all lymphopenic patients was 3.71 (\%95 confidence interval: $2,92-4,51$ ) months. It was observed that $65.21 \%$ of all lymphopenic patients die within 12 months following lymphopenia diagnosis. CONCLUSIONS: EBV and CMV positivity rates were determined in all lymphopenic patients receiving chemotherapy $(6.5 \%$ and $8.7 \%$, respectively). This study is the first to investigate the frequencies of HSV, CMV, EBV and parvovirus B19 in lymphopenic cancer patients receiving chemotherapy. Lymphopenic patients receiving chemotherapy should be followed up by physicians for viral infections and treated with antiviral therapy in the early stages of infection.

Keywords: Cancer, Chemotherapy, Lymphopenia, Viral Infections

\section{OP-095 \\ CHANGING THE PARADIGM OF EQAS THROUGH THE IMPLEMENTATION OF PATIENT-BASED REAL-TIME QUALITY CONTROL MONITORING}

Coskun Cavusoglu ${ }^{1}$, Abdurrahman Coskun ${ }^{1,2}$, Muhittin Serdar ${ }^{1,2}$

Mustafa Serteser ${ }^{1,2}$, Meltem Kilercik ${ }^{1,2}$, Fehime Aksungar ${ }^{1,2}$, Ibrahim Unsal $^{1}$ ${ }^{1}$ Acibadem Labmed Clinical Laboratories, Department of Medical Biochemistry, Istanbul, Turkey

${ }^{2}$ Acibadem Mehmet Ali Aydinlar University School of Medicine, Department of Medical Biochemistry, Istanbul, Turkey

OBJECTIVES: External quality assessment (EQA) or proficiency testing (PT) plays a crucial role in the standardization and harmonization. The performance of instruments/methods used in medical laboratories is routinely evaluated by EQA providers. Laboratories measure the concentrations of measurands using commercial samples obtained from EQA providers. However these samples are not commutable and therefore their measurements results may not represent the performance of the methods/instruments correctly. In this study we aimed to evaluate the reliability of the test performance reported by EQA providers using the trends of long term patients test results. MATERIALS and METHODS: We analyzed the results of three different measurands (ALT, Na and cholesterol) reported by two different EQA providers and compared with the trends of long term patients' results. RESULTS: The standard deviation indexes (SDIs) of ALT reported for three surveys were $-0.5,3.44,-0.23$ respectively. Although in the second survey the SDI was out of range, no shift in patients' results was detected. On the other hand, in the third survey the SDI was within acceptable range but a shift was detected. The SDIs of Na were $0.40,3.86,0.60$ respectively but no shifts were detected in patients' results. A similar pattern was observed for cholesterol. The D/Dmax of cholesterol were $-0.20,-1.67,-1.17$ but no shifts were detected in patients' results. CONCLUSIONS: The results reported by EQA providers may not reflect the trend of patients' tests results correctly. Therefore in addition to EQAS results the trend of patients' tests results should be monitored as a complementary factor and the corrective and preventive actions should be taken accordingly. Keywords: Patient-Based Real-Time Quality Control, External quality assessment, proficiency test 
OP-096

\section{EVALUATION OF TOTAL TESTING PROCESS FOR HBA1C WITH RISK ANALYSIS}

Canan Karadag, Nafi Nevrez Demirel

Kayseri Public Health Laboratory, Kayseri, Turkey

OBJECTIVES: Risk analysis has an increasing importance in improving the service quality of clinical laboratories, especially as a requirement of the ISO 15189 standard. CLIA regulations also recommend test -based risk analysis for individualized quality control plan (IQCP). In this study, it was aimed to evaluate the contribution of risk analysis applied for HbA1c test to total testing process.. MATERIALS and METHODS: Failure modes and effects analysis (FMEA) method was used for risk analysis. Risk priority numbers (RPNs) of pre-analytical, analytical and post-analytical risks for HbAlc testing were calculated using frequency, severity and detectability values. An evaluation scale was created with a maximum of 10 points for frequency and severity and a maximum of 3 points for detectability. ROS value $>150$ was considered as very severe risk, between $100-150$ as severe risk, between $50-100$ as medium risk, between $25-50$ as low risk, and $<25$ as very low risk. Corrective action was planned for those RPN $>50$. RESULTS: RPNs for pre-analytical and analytical risks were $<50$. RPNs for three of the analytical risks (random error, systematic error, interference) were calculated over 50 and the corrective action was applied by accepting them as medium risks. RPNs were recalculated at the end of three months, and RPNs for all risks were $<50$.

CONCLUSIONS: Test-based risk analysis in medical laboratories is a useful method for evaluating the total testing process, detecting and preventing laboratory errors.

Keywords: FMEA, Hba1c, Laboratory Errors, Risk Analysis

\section{OP-097 \\ DEVELOPMENT AND VALIDATION AN LC/MSMS METHOD FOR SIMULTANEOUS QUANTIFICATION OF VITAMIN D METABOLITES AND DETERMINATION OF SAMPLE STORAGE CONDITIONS}

Ali Yaman ${ }^{1}$, Goncagul Haklar ${ }^{2}$, Onder Sirikci ${ }^{2}$

${ }^{1}$ Clinical Biochemistry, Marmara University Pendik Education and Research Hospital, Istanbul, Turkey ${ }^{2}$ Clinical Biochemistry, Marmara University, Istanbul, Turkey

OBJECTIVES: Vitamin D deficiency has become an important public health problem due to its high prevalence. Plasma concentrations of $25(\mathrm{OH})$ $\mathrm{D}$ and other vitamin D metabolites are used as biomarkers to detect vitamin D deficiency or to investigate vitamin D metabolism. In our study, we developed an LC/MSMS method that can simultaneously measure the frequently investigated vitamin D metabolites $(25(\mathrm{OH}) 2 \mathrm{D} 3,1,25(\mathrm{OH}) 2 \mathrm{D} 3$ $24 \mathrm{R}, 25(\mathrm{OH}) 2 \mathrm{D} 3,25(\mathrm{OH}) \mathrm{D} 2$ and 3 -epi-25(OH)D3) and determined how different storage conditions affect these metabolites' stability in samples. MATERIALS and METHODS: We developed an LC/MSMS based method by using vitamin D metabolites' standard and internal standard solutions to quantitate the vitamin D metabolites in plasma samples. After validating the method according to CLSI C62-A guideline, we examined the stability of vitamin $\mathrm{D}$ metabolites in samples obtained from volunteers at different storage temperatures $\left(+25^{\circ} \mathrm{C},+4^{\circ} \mathrm{C},-20^{\circ} \mathrm{C}\right)$ and durations (up to 10 months). RESULTS: The method developed met the linearity and imprecision criteria within the measuring ranges chosen in accordance with the clinical decision-making levels of vitamin D metabolites. In imprecision studies; coefficient of variations of metabolites at different concentrations did not exceed $9.3 \%$ at all $\mathrm{CV} \%$ classifications evaluated. The highest bias\% results obtained from the measurement of the certified reference materials by NIST (SRM972a) for 25(OH)D3, 24R,25(OH)2D3, 25(OH)D2 and 3-epi$25(\mathrm{OH}) \mathrm{D} 3$ were $(+1,3 \%),(-3,8 \%),(-8 \%)$ and $(-8 \%)$, respectively. Vitamin D metabolites were found to be stable in the different storage conditions tested. CONCLUSIONS: LC/MSMS based methods have high sensitivity and specificity and can be used to monitor changes on vitamin D metabolites' concentrations in various clinical situations.

Keywords: Vitamin D, Mass Spectrometry, Storage Conditions

\section{OP-098 \\ REPEATABILITY OF BIOMERIEUX HIGH SENSITIVITY TROPONIN I IN SERUM IS SIGNIFICANTLY BETTER THAN IN Li-HEPARIN PLASMA SAMPLES}

Settar Kosova

Caycuma State Hospital Biochemistry Laboratory, Zonguldak, Turkey

OBJECTIVES: Emergency department and internal medicine physicians in Gokcebey District Hospital complained about the inconsistent bioMerieux Vidas High Sensitive Troponin I (hsTI) results in a 2-hour rule-out protocol. The study aimed to identify the source of the repeatability problem in the hsTI test system and develop a solution proposal.
MATERIALS and METHODS: For routine hsTI determination, Vacuette LiHeparin (Greiner Bio-One) tubes were used for venipuncture and centrifugated for $5 \mathrm{~min}$ at $4000 \mathrm{~g}$. We conducted a repeatability study of $41 \mathrm{Li}$-heparin plasma samples $(<100 \mathrm{ng} / \mathrm{L})$ analyzed in duplicate. We also prepared a pool of plasma concentration of hsTI close to the critical value of $19 \mathrm{ng} / \mathrm{L}$ to estimate the within precision and compare to the manufacturer's insert data. In another repeatability study, we analyzed 58 serum samples from Rapid Serum Tubes (RST tubes from Becton Dickinson). We calculated the Standard Deviation of duplicates (SDdup) as $\left(\sum \operatorname{diff}^{2} / 2 \mathrm{~N}\right)^{1 / 2}$. We made all calculations in Microsoft 365 Excel software. RESULTS: Repeatability testing of 41 plasma samples hsTI results expressed as $2 \mathrm{SD}$ (encompassing $95 \%$ range) was $12,5 \mathrm{ng} / \mathrm{L}$. This variation was two times the allowed difference for a two-hour rule-out algorithm $(<6 \mathrm{ng} / \mathrm{L})$. Within-run precision study with a plasma pool of $21,4 \mathrm{ng} / \mathrm{L}(\mathrm{N}=12)$ resulted in a $\mathrm{CV}$ of $5,7 \%$, similar to the manufacturer's within-run performance. We suspected that plasma samples could interfere with the test system. Indeed, our repeatability study showed much better precision in the subsequent investigation with 58 serum samples where $2 \mathrm{SD}$ was $2,4 \mathrm{ng} / \mathrm{L}$, which is five times less than for Liheparin plasma samples.

CONCLUSIONS: bioMerieux Vidas hsTI tests should be analyzed in serum rather than Li-heparin samples.

Keywords: hsTroponinI, Plasma, Serum, Repeatability, Vidas

\section{OP-099 \\ THE IMPACT OF AUTOVERIFICATION SYSTEM ON LABORATORY} TURNAROUND TIME

Bahar Unlu, Serdar Dogan, Oguzhan Ozcan, Hazal Fatma Erdogan, Abdullah Arpaci

Hatay Mustafa Kemal University, Faculty of Medicine, Department of Medical Biochemistry, Hatay, Turkey

OBJECTIVES: Recent advances in artificial intelligence technology and its current applications in medicine, the use of autoverification is becoming widespread to ensure rapid and accurate verification of clinical laboratory tests. The aim of our study is to evaluate impact of autoverification algorithm inserted in middleware for biochemistry tests on laboratory turnaround time (TAT). MATERIALS and METHODS: The turnaround time of biochemistry test results for emergency service was aimed up to 60 minutes in Hatay Mustafa Kemal University Hospital, Central Laboratory. 120 minutes was aimed for all polyclinics and services except for emergency service. A total of 199,895 biochemistry test results from 01.09.2018 to 31.08.2019 were collected. The impact of autoverification and manual verification of patient testresults on TAT was evaluated. RESULTS: The average of reported TAT from the time of sample receipt by the lab to result with manual verification on the LIS was calculated as 43,85 for emergency service and 71,79 minutes for polyclinics and services. However, implementation of autoverification led to reduction of emergency service by 35,85 minutes $(18.24 \%$ ), and all polyclinics and services by 61,79 minutes $(13.9 \%)$. When autoverification was implemented, the reported TAT was reduced. CONCLUSIONS: The autoverification system in clinical laboratories has contributed to raise the work efficiency by reducing TAT and eliminating workload of manual verification. The use of autoverification system shortened the TAT. We believe that autoverification system is able to prevent the samples with abnormal values for manual verification, guarantee medical safety, minimize the number of samples that needed staff revision.

Keywords: Autoverification System, Biochemistry Tests, Turnaround Time

\section{OP-100 \\ COMPARISON OF RESULTS OF DIFFERENT AUTOVERIFICATION ALGORITHMS DEVELOPED FOR LIVER FUNCTION TESTS}

Serdar Dogan

Hatay Mustafa Kemal University Faculty of Medicine Department of Medical Biochemistry, Hatay, Turkey

OBJECTIVES: The aim of our study was to evaluate the performance of different autoverification algorithms which have been developed for liver function tests (LFT) and to investigate their effect on the aotuverification process. MATERIALS and METHODS: In our study, ALT $(\mathrm{n}=48.208)$, AST $(\mathrm{n}=$ 38.781), LDH $(\mathrm{n}=15.766)$, GGT $(\mathrm{n}=15.863)$, ALP $(\mathrm{n}=17.534))$, Tota Bilirubin $(\mathrm{n}=17.898)$ and Direct Bilirubin $(\mathrm{n}=17.774)$, a total of 171.824 tests obtained from LBYS between 01.10.2019 - 31.12.2019 were evaluated. Autoverification algorithm criterias were; calibration/internal quality control, moving average, analytical measurement range, indices, critical value, delta check and reference range. The tests were subjected to last step consistency checks (ALT / AST $>0.25$ or $<4$, Direct Bil / Total Bil $<1$ ). The results were validated and compared according to the reference range, lower reference limit minus total allowable error and upper reference limit plus total allowable error and 2 nd and 98th percentile of cumulative patient data along with other criteria. RESULTS: According to the reference range, lower reference limit minus total allowable error and upper reference limit plus total allowable error and 2nd and 98th percentile of cumulative patient data algorithms; the average autoverification passing rates were $61.69 \%(\mathrm{n}=105.998), 73.41 \%(\mathrm{n}=126.137)$ and $84.38 \%$ 
$(\mathrm{n}=144.980)$, respectively.

CONCLUSIONS: Different approaches applied in autoverification algorithms affect the distribution of average autoverification passing rates. We think that it would be appropriate for each laboratory to create algorithms suitable for its own patient population and laboratory features.

Keywords: Autoverification, Algorithm, Liver Function Tests

\section{OP-101 \\ PRELIMINARY STUDY TO DIAGNOSE COVID-19 AND TO IDENTIFY SEVERE FROM NON-SEVERE CASES USING IMMATURE GRANULOCYTES AND INFLAMMATORY HEMOGRAM INDICES}

Said Incir

Department of Clinical

OBJECTIVES: We aimed to see the role of immature granulocytes (IG\%) and inflammatory complete blood count (CBC) indices in COVID-19 and to evaluate their predictive value in the diagnosis and determining disease severity.

MATERIALS and METHODS: In this study, 72 patients with COVID-19 (patient group) and age-, sex-matched 70 adults with no infection (control group) were enrolled. Patients were assigned to two groups (severe vs. non-severe) according to oxygen demand.

RESULTS: The IG\%, neutrophil count, Neutrophil-to-Lymphocyte Ratio (NLR), Platelet-to-Lymphocyte Ratio (PLR), and Systemic Immune-Inflammatory Index (SII) were higher in the patient group than in the control group $(p<0.001$ for all). The lymphocyte and platelet counts, as well as hemoglobin levels, were significantly lower in the patient group than in the control group $(p<0.001$, $\mathrm{p}=0.009$ and $\mathrm{p}=0.041$, respectively).

Regarding sub-group analysis, severe COVID-19 patients had significantly higher levels of the IG\%, leukocyte and neutrophil counts, NLR, PLR, and SII ( $p<0.001$ for all), with significantly lower levels of lymphocyte count and hemoglobin ( $\mathrm{p}=0.005$ and $\mathrm{p}=0.001$, respectively)

To determine disease severity, curve values from receiver operating characteristics for IG\%, NLR, PLR and SII were, 0.875 (95\% CI: 0.759-0.948), 0.861 (95\%CI: $0.742-0.939), 0.689$ (95\%CI: $0.551-0.806)$ and 0.851 (0.731-0.932) respectively. $\mathrm{IG} \%$ also had a sensitivity and specificity value of $73.21 \%$ and $83.72 \%$, for the diagnosis and $85.0 \%$ and $75.0 \%$, to detect the disease's severity, respectively. CONCLUSIONS: The IG\% and CBC indices, which can be obtained quickly from the hemogram test, a cost-effective and ready-made method, can be used in the diagnosis and classification of COVID-19 in addition to other laboratory tests.

Keywords: Blood Cell Count, Immature Granulocyte Ratio, COVID-19, SARSCov-2

\section{OP-102 \\ RETROSPECTIVE ASSESSMENT OF THE DIAGNOSTIC VALUE OF SOME HEMOGRAM PARAMETERS ON MORTALITY IN PATIENTS WITH COVID-19 RT-PCR TEST (+) ADMITTED IN A PANDEMIC HOSPITAL IN ISTANBUL}

Bagnu Orhan ${ }^{1}$, Zuhal Aydan Saglam², Levent Deniz ${ }^{1}$, Gulhan Eren ${ }^{3}$ Berrin Bercik Inal

${ }^{1}$ Department of Medical Biochemistry, University of Health Sciences, Istanbul Training and Research Hospital, Istanbul, Turkey

${ }^{2}$ Department of Family Medicine, University of Health Sciences, Istanbul

Training and Research Hospital, Istanbul, Turkey

${ }^{3}$ Department of Infectious Diseases and Clinical Microbiology, University of

Health Sciences, Istanbul Training and Research Hospital, Istanbul, Turkey

OBJECTIVES: We aimed to investigate the effect of the diagnostic value of platelet, WBC (White Blood Cell), MPV (Mean Platelet Volume), PDW (Platelet Distribution Width), neutrophil, lymphocyte, hemoglobin, NLR (Neutrophil Lymphocyte Ratio), PLR (Platelet Lymphocyte Ratio) on mortality in patients who applied to Istanbul Training and Research Hospital and were positive for the COVID-19 RT-PCR test.

MATERIALS and METHODS: The total number of COVID-19 RT-PCR $(+)$ patients who applied to Istanbul Training and Research Hospital between 10th March - 10th June 2020 was 2774, with 1308 outpatient, 1393 inpatient and 73 intensive care patients. The data of these patients were retrospectively obtained from the health information management system. Statistical analysis was performed in SPSS version 17.0.

RESULTS: Diabetes mellitus, hypertension, chronic renal failure, immunosuppressive therapy and COVID-19 compatible tomography; it was higher in patients with mortality $(\mathrm{p}<0.05)$. The differences between all hemogram parameters and age values except baseline platelet levels in the group with and without mortality were statistically significant $(\mathrm{p}<0.05)$. According to Spearman's rho correlation analysis results, there was a positive and significant relationship between age, WBC, neutrophil, NLR, PLR and mortality, and a negative significant relationship with hemoglobin, lymphocyte $(\mathrm{p}<0.01, \mathrm{r}: 0.198,0.116$, $0.179,0.224,0.139,0.165,0.168$ respectively). In accordance with the binary logistic regression analysis results, the significance of age, WBC, neutrophil, NLR, and hemoglobin parameters in determining mortality was statistically significant $(\mathrm{p}<0.05$, OR:1.065, $0.306,4.322,2.080,0.730$ respectively). CONCLUSIONS: It is suggested that hemogram values in patients with mortality may be an important variable in this clinical picture.

Keywords: COVID-19, Hemogram, Mortality

\section{OP-103 \\ SITE-SPECIFIC GLYCOSYLATION ANALYSIS OF HUMAN THYROGLOBULIN PROTEIN USING HIGH-THROUGHPUT MASS SPECTROMETRIC APPROACHES}

Haci Mehmet Kayili ${ }^{1}$, Bekir Salih ${ }^{2}$

Karabuk University, Karabuk, Turkey

${ }^{2}$ Hacettepe University, Ankara, Turkey

OBJECTIVES: Human thyroglobulin containing a high percentage of glycosylation sites is an important protein produced by the human thyroid glands. The glycosylation sites observed in the thyroglobulin protein modulate the hormone biosynthesis taking place in the thyroid gland. Therefore, to better understand the function of the glycosylation sites, the analysis of the glycosylation sites of the thyroglobulin protein should be performed using sensitive and reliable techniques. In this study, it was aimed to perform site-specific N-glycosylation analysis of thyroglobulin protein isolated from human thyroid glands.

MATERIALS and METHODS: Studies were performed using high-throughput mass spectrometric methods at both glycopeptide and glycan level. At the glycan level, in-gel glycan release was performed after SDS-PAGE analysis of thyroglobulin protein. Ethyl-esterification of the released N-glycans were then analyzed by MALDI-TOF/TOF-MS system. After in-gel proteolytic cleavage was performed, proteolytic products of the thyroglobulin protein were achieved using the nLC-TIMS-TOF-MS/MS system.

RESULTS: It was determined from the analyzes that the thyroglobulin protein contained high mannose type $\mathrm{N}$-glycans. It was found that the rate of fucosylation was high in complex type N-glycans. A large amount of sialylated N-glycans was found to be alpha2-6-linked. Most of the glycosylation regions of the thyroglobulin protein at the glycopeptide level were determined, and both the glycosylation sites and the glycan structures were confirmed.

CONCLUSIONS: The results showed that the glycosylation content of human thyroglobulin protein included high amount of mannose-type glycans. Acknowledgements: This study was supported by TUBITAK. Project No: 119 Z066 Keywords: Thyroglobulin, Glycomics, Glycoproteomics, Glycosylation

\section{OP-104 DIFFERENCES AMONG LABORATORY RESULTS FOR D-DIMER TEST}

Emis Deniz Akbulut

Ankara City Hospital, Clinical Biochemistry Laboratory, Ankara, Turkey

OBJECTIVES: D-dimer test has extensive usage as a component of diagnostic algorithms in exclusion of deep vein thrombosis and pulmonary embolism. Today, it has been reported to have also prognostic value for SARS-CoV-2/ COVID-19. Due to differences among methods, specificity of the antibodies used in reagents and reporting units there may be discordant results among laboratories. In this study investigation of the conformity of d-dimer results on various analytical systems using external quality control data is aimed. MATERIALS and METHODS: Peer group means of four different batches (3 samples for each) analyzed on ACL Top(IL HemosIL D-Dimer-HS), ACL 8000(IL HemosIL D-Dimer), Sysmex CS(Siemens Innovance), ACL Top(IL HemosIL D-Dimer-HS 500), Stago(STA-Liatest D-DI Plus) and BioMerieux VIDAS (dedicated reagent) in a cycle of Bio-Rad External Quality Assessment Program(US) were evaluated with grouping according to D-dimer unit (DDU) and fibrin equivalent unit (FEU). For systems in DDU group [ACL Top (IL HemosIL D-Dimer-HS), ACL 8000 (IL HemosIL D-Dimer)] difference between the systems was assessed using Mann-Whitney U test and inFEU group with Kruskal-Wallis test for each of the batches. A statistical significance level of $\mathrm{p}<0.05$ was established. RESULTS: Peer group mean values of DDU reporting systems were ranged between $0.119-0.189 \mathrm{mg} / \mathrm{L}$ for level $1,0.259-0.318 \mathrm{mg} / \mathrm{L}$ for level $2,0.695$ $0.762 \mathrm{mg} / \mathrm{L}$ for level 3 and $0.871-1.09 \mathrm{mg} / \mathrm{L}$ for level 4 .The difference between the systems was insignificant $(\mathrm{p}>0.05)$. Peer group mean intervals in FEU group were observed as; $0.229-0.324 \mathrm{mg} / \mathrm{L}$ for level $1,0.577-0.920 \mathrm{mg} / \mathrm{L}$ for level $2,1.310-2.540 \mathrm{mg} / \mathrm{L}$ for level 3 , and $2.160-3.820 \mathrm{mg} / \mathrm{L}$ for level 4 Significant difference was observed for four levels in FEU group $(p<0.05)$. CONCLUSIONS: It was thought that conformity in DDU group may be due to more traceable results obtained with different reagents of the same manufacturer. Since harmonization could not be achieved in D-dimer measurement, it is important to inform clinicians that different results can be obtained depending on method.

Keywords: D-Dimer, Harmonization 


\section{OP-105 \\ THE EFFECT OF DIAGNOSTIC VALUE OF BIOCHEMICAL PARAMETERS ON MORTALITY IN COVID-19 PATIENTS}

Bagnu Orhan ${ }^{1}$, Levent Deniz ${ }^{1}$, Zuhal Aydan Saglam², Gulhan Eren ${ }^{3}$, Berrin Bercik Inal

${ }^{1}$ University of Health Sciences, Istanbul Training and Research Hospital, Department of Medical Biochemistry, Istanbul, Turkey

${ }^{2}$ University of Health Sciences, Istanbul Training and Research Hospital, Department of Family Medicine, Istanbul, Turkey

${ }^{3}$ University of Health Sciences,Istanbul Training and Research Hospital,

Department of Infectious Diseases and Clinica IMicrobiology, Istanbul, Turkey

OBJECTIVES: We aimed to examine the effect of the diagnostic value of NLR, D-Dimer and some other biochemical parameters on mortality in patients with positive COVID-19 test who applied to Istanbul Training and Research Hospital. MATERIALS and METHODS: The data (Procalcitonin, Ferritin, CRP, LDH, hsTroponin-I, Fibrinogen, Albumin, AST, ALT, Creatinin, Urea, Total Bilirubin, CK, Uric acid, IL-6, Neutrophil and Lymphocyte count, D-Dimer) of COVID-19 RT-PCR $(+) 2774$ patients who applied to Istanbul Training and Research Hospital between 10th March and 10th June 2020 was admitted via health information system retrospectively. All statistical analysis was performed at SPSS 17.0 version at $95 \%$ confidence interval.

RESULTS: Patients were divided into two groups as mortality (N: 74) and nonmortality (2700).In both groups, the ratio of men was higher than women and the difference was not significant $(p>0.05) .87 .8 \%$ of those who lost their lives were treated in intensive care $(\mathrm{p}<0.05)$. All parameter differences except ALT initial, bilurbin final, uric acid final and fibrinogen final were statistically significant between mortality groups $(\mathrm{p}<0.05)$ In patients with mortality, DM, HT, COPD, malignancy, $\mathrm{CRF}$, immunosuppressive therapy and COVID-19 related CT were higher $(\mathrm{p}<0.05)$.

CONCLUSIONS: According to the correlation analysis results, all research parameters except gender, bilirubin and ALT were significantly associated with mortality $(p<0.05)$. Binaryl logistic regression analysis showed that NLR have diagnostic value for mortality in multivariate analysis $(\mathrm{p}<0.05)$. It is important that the NLR is separated from all other parameters and has a high diagnostic value among the values at the time of admission to the hospital in the study.

Keywords: COVID-19, Clinical Chemistry, Coagulation, Immunochemical Measurement, Mortality

\section{OP-106 \\ DIAGNOSTIC UTILITY OF C-REACTIVE PROTEIN TO ALBUMIN RATIO AS AN EARLY WARNING SIGN IN HOSPITALIZED SEVERE COVID-19 PATIENTS}

Inanc Karakoyun ${ }^{1}$, Ayfer Colak ${ }^{1}$, Melda Turken², Zeynep Altin ${ }^{3}$,

Fatma Demet Arslan ${ }^{1}$, Veli Iyilikci ${ }^{1}$, Nisel Yilmaz ${ }^{4}$, Sukran Kose ${ }^{2}$

${ }^{1}$ University of Health Sciences, Tepecik Training and Research Hospital,

Department of Medical Biochemistry, Izmir, Turkey

${ }^{2}$ University of Health Sciences, Tepecik Training and Research Hospital,

Department of Infectious Diseases and Clinical Microbiology, Izmir, Turkey

${ }^{3}$ University of Health Sciences, Tepecik Training and Research Hospital,

Department of Internal Medicine, Izmir, Turkey

${ }^{4}$ University of Health Sciences, Tepecik Training and Research Hospital,

Department of Medical Microbiology, Izmir, Turkey

OBJECTIVES: C-reactive protein-to-albumin ratio (CAR) has been used as an indicator of prognosis in various diseases and has a prognostic power comparable to other inflammation-related prognostic scores. Here, we intended to assess the CAR's diagnostic power in early differentiation of hospitalized severe COVID-19 cases.

MATERIALS and METHODS: In this retrospectively designed study, we evaluated 197 patients in total. They were divided into two groups based on their severity of COVID-19 as non-severe $(n=113)$ and severe $(n=84)$. The comparison of groups' demographic data, comorbidities, clinical symptoms, laboratory test results were done. The calculation of receiver operating characteristic (ROC) curve was used to determine the diagnostic power of CAR in differentiating severity of COVID-19. Independent risk factors predictive of COVID-19 severity were determined by using logistic regression analysis.

RESULTS: Age $(\mathrm{p}<0.001)$, hypertension $(\mathrm{p}=0.045)$, coronary heart disease $(p=0.002)$, diabetes mellitus $(p=0.001)$, dyspnea $(p=0.015)$, headache $(p=0.037)$, pharyngalgia $(\mathrm{p}=0.038)$, length of hospital stay $(\mathrm{p}<0.001)$, mortality frequency $(p<0.001)$, neutrophil count $(p=0.038)$, lymphocyte count $(p=0.012)$, neutrophilto-lymphocyte ratio $(\mathrm{p}=0.003), \mathrm{CRP}(\mathrm{p}<0.001)$, CAR $(\mathrm{p}<0.001)$, glucose $(\mathrm{p}=0.014)$, aspartate aminotransferase $(\mathrm{p}=0.047)$, ferritin $(\mathrm{p}=0.003)$, and prothrombin time $(\mathrm{p}=0.024)$ were significantly different between the two groups. Age $(\mathrm{OR}=1.046, \mathrm{p}=0.003), \mathrm{CAR}(\mathrm{OR}=1.264, \mathrm{p}=0.037)$, and AST $(\mathrm{OR}=1.029$, $\mathrm{p}=0.037$ ) were independent risk factors for severe COVID-19 based on the multivariate logistic regression analysis. ROC curve analysis determined an Area Under Curve of 0.718 for CAR in discrimination of severe COVID-19 cases.

CONCLUSIONS: CAR is a useful marker in early differentiation of severity in patients hospitalized due to COVID-19 that have longer hospital stay and higher mortality.

Keywords: C-Reactive Protein to Albumin Ratio, SARS-Cov-2, COVID-19

\section{OP-107 \\ MICROBIOLOGICAL ANALYSIS OF FRUIT BASED COMPLEMENTARY INFANT FOODS}

Tevhide Ziver Sarp, Betul Ozturk

Eastern Mediterranean University, Faculty of Health Sciences, Nutrition And Dietetic Department, TRNC

OBJECTIVES: Breast milk is the most natural food that can meet the nutritional and vitamin needs of the baby for the first 6 months. From the 6th month, in order to meet the increasing nutritional needs of babies, complementary foods are used in addition to breast milk. It has been reported that different microorganisms that threaten the health of babies are detected in the microbiological analysis of infant formula in various countries. In this study, it was aimed to investigate the presence of Cronobacter sakazakii, Staphylococcus aureus, Escherichia coli and Coliform bacteria in fruit-based complementary infant food offered for sale in the and to evaluate the infection risk of these products.

MATERIALS and METHODS: A total of 120 fruit-based complementary infant foods sold in different cities in the TRNC were included in this study. ISO / TS 22964: 2006 for C. sakazakii, ISO 4832 for coliform bacteria, ISO 16649 for E. coli and EN / ISO 6888 for S. aureus methods were used for the analysis of those products

RESULTS: C.sakazakii, Coliform, E.coli and S. aureus were not detected in any of the samples

CONCLUSIONS: Although C. sakazakii, coliform, E.coli and S.aureus were reported in some of the microbiological studies conducted on infant foods around the world, these agents were not found in any of the complementary infant foods in the study. Since there are limited studies that examine the relationship of infant food with microorganism in Turkey and in TRNC, new and extensive studies are needed to promote the prevalence of micro-organisms in infant food. Keywords: Cronobacter Sakazakii, Koliform, E.Coli, S. Aureus, Complementary Infant Food

\section{OP-108 \\ DEVELOPMENT OF POLYVINYLPYRROLIDONE, SODIUM ALGINATE AND NANOCELLULOSE-BASED COMPOSITE FILMS FOR SMART FOOD PACKAGING APPLICATIONS}

Ece Sogut

Suleyman Demirel University, Food Engineering Department, Isparta, Turkey

OBJECTIVES: Electrochemical biosensor studies have gained attention due their potential for determining food quality and safety easier than conventional methods. In this area, surface modified cellulose nanoparticles have potential to be used in biosensing applications due to their reactive functional properties such as being able to conjugate with biological moieties and metallic nanoparticles. The aim of this study was to prepare composite films of polyvinylpyrrolidone (PVP), sodium alginate (Al) with varying nanocellulose (NC) content.

MATERIALS and METHODS: PVP-Al blend films $(1: 1, \mathrm{w} / \mathrm{w})$ were prepared by casting method and the NC content in the films were varied between $2-10 \%$ $(\mathrm{w} / \mathrm{w})$. The morphological analysis such as scanning electron microscopy (SEM) and Fourier transform infrared spectrophotometry (FTIR) and electrical conductivity measurements of resulting films were carried out.

RESULTS: FTIR analysis indicated that intermolecular interactions could be possible in blend films, while SEM analysis revealed a uniform NC distribution inside the film matrix. The increase in $\mathrm{NC}$ content resulted in a decrease in electrical conductivity.

CONCLUSIONS: The results of this study showed that PVP-Al films including $\mathrm{NC}$ had a promising potential to be used in smart food packaging applications. Keywords: Nanocellulose, Polyvinylpyrrolidone, Smart Packaging, Sodium Alginate

\section{OP-109 \\ HIGH-FAT AND HIGH-SUCROSE DIET MODEL: ANATOMICAL BIOCHEMICAL AND HISTOPATHOLOGICAL EVALUATION OF THE TESTES OF RATS}

Duygu Akin ${ }^{1}$, Merve Ilhan $^{2}$, Didem Aydin Kabakci ${ }^{1}$, Pembe Oltulu ${ }^{3}$,

Mehmet Tugrul Yilmaz ${ }^{1}$, Muzaffer Seker ${ }^{1}$, Fatma Humeyra Yerlikaya Aydemir ${ }^{4}$, Mehmet $\mathrm{Oz}^{5}$

${ }^{1}$ Necmettin Erbakan University, Meram Faculty of Medicine, Department of Anatomy, Konya, Turkey

${ }^{2}$ Hitit University Vocational School of Health Services, Environmental Health Program, Corum, Turkey

${ }^{3}$ Necmettin Erbakan University, Meram Faculty of Medicine, Department of Pathology, Konya, Turkey

${ }^{4}$ Selcuk University Faculty of Medicine, Department of Medical Biochemistry, Konya, Turkey

${ }^{5}$ Necmettin Erbakan University, Meram Faculty of Medicine, Department of Physiology, Konya, Turkey

OBJECTIVES: Dietary content has important effects on normal physiology. High 
calorie-diets are associated with diseases such as obesity, diabetes, cardiovascular diseases, infertility and cancer. In particular, the potential effects of nutrition on male reproductive health are increasingly defined. In this study, it was aimed to investigate the effect of high-fat and high-sucrose diet on testicular tissues of male rats anatomically, biochemically and histologically.

MATERIALS and METHODS: In the study, 28 adult male Wistar Albino rats were used. Rats were divided into four groups according to their dietary consumption; standard feed $(n=7)$, high-fat diet $(n=7)$, high-sucrose diet $(n=7)$, high-fat and high-sucrose diet $(n=7)$. Testicles were removed and morphometric measurements were taken. Myeloperoxidase and catalase enzyme concentrations were analyzed by ELISA method. Hematoxylin-eosin staining, Johnson scoring, congestion, degeneration and mean tubular diameter measurements were examined histopathologically under light microscope. RESULTS: There was an increase in the final weights of the rats compared to their initial weight, but no significant difference was found $(\mathrm{p}>0.05)$. Comparing the right and left testicles, the significant differences were found that between transverse diameter and mean tubule diameters. When the groups were compared, only significant difference was defined between the right mean tubule diameters $(\mathrm{p}<0.05)$. Myeloperoxidase and catalase levels were statistically significant difference between the groups $(p<0.05)$. CONCLUSIONS: Although it was determined that a high-calorie diet had an effect on oxidative stress in testicular tissue, no significant histopathological changes were observed. In this context, it was concluded that advanced studies should be carried out, including physiological analyzes, regarding calorie level and duration. Keywords: High-Fat Diet, High-Sucrose Diet, Oxidative Stress, Testicles

\section{OP-110 \\ APPLICATION OF A NEW FORMULA FOR LDL CHOLESTEROL CALCULATION FOR PATIENTS WITH NORMAL OR HIGH TRIGLYCERIDE LEVELS}

Ilknur Alkan Kusabbi, Aysenur Macun Ayan, Neslihan Cihan,

Mehmet Senes, Elmas Ogus

Department of Medical Biochemistry, Ankara Health Training and Research

Center, Health Sciences University, Ankara, Turkey

OBJECTIVES: Comparison of directly measured low-density lipoprotein(d-LDL) results with results obtained from Friedewald formula(F-LDL), which is widely used in calculation, and a new formula (S-LDL) published by Sampson et al.. MATERIALS and METHODS: For the study, from lipid profile results of our laboratory, 201 results with $\mathrm{TG}$ (triglyceride) $<400 \mathrm{mg} / \mathrm{dL}$ between $19-23$ October2020 were randomly selected, and all results with $\mathrm{TG}>400 \mathrm{mg} / \mathrm{dL}$ between July2020 and October2020(n=761) were taken.d-LDL measurement was made with Roche-Cobas c702 instrument using homogeneous enzymatic colorimetric method.Calculations were made by Friedewald formula(F$\mathrm{LDL}=($ Total Kolesterol $)-(\mathrm{HDL})-(\mathrm{TG} / 5))$ and new formula(S-LDL $=($ Total Kolesterol/0.948)-(HDL/0.971)-((TG/8.56) $+(($ TGxNon-HDL-C)/2140)-( $\left.\mathrm{TG}^{\wedge} 2 / 16100\right)$ )-9.44). For comparison of methods,Passing-Bablok regression analysis and for evaluation of difference between methods,dependent group t-test and ANOVA were used RMSE(root mean square error) and $\mathrm{MAD}$ (mean absolute difference) measures were calculated to compare the accuracy of formulas. RESULTS: In our study, for $\mathrm{TG}<400$ results,S-LDL was more compatible with d-LDL than with F-LDL by Passing-Bablok regression analysis (R2 $0.345, \mathrm{p}<0.05$, for both equations; F-LDL intercept -3.33 (95\%CI -6to-0.429), slope 0.98 (95\%CI 0.952 to 1$)$; S-LDL intercept-3 (95\%CI -3.658 to 0.063$)$, slope $1.0(95 \%$ CI 0.969 to 1.005$)$ ). Similarly for TG $>400 \mathrm{mg} / \mathrm{dl}$ results S-LDL was more compatible with d-LDL than with F-LDL. (F-LDL R2 0.687, p<0.05; S-LDL R2 $0.789, \mathrm{p}<0.05 ; \mathrm{F}-L D L$ intercept-51.7 (95\% CI -56.79 to -46.84$)$, slope $1.17(95 \% \mathrm{CI}$ 1.122 to 1.210$)$; S-LDL intercept-1.125 (95\%CI -4.491 to 2.629$)$, slope 0.875 $(95 \%$ CI 0.843 to 0.906$))$. There was a significant difference between means of methods $(\mathrm{p}<0.05)$. For TG $<400 \mathrm{~g} / \mathrm{dl}$ results, compared to d-LDL values, F-LDL RMSE was $10.2 \mathrm{mg} / \mathrm{dL}$, MAD was $8 \mathrm{mg} / \mathrm{dl}$, S-LDL RMSE was $8.15 \mathrm{mg} / \mathrm{dL}$, MAD was $6 \mathrm{mg} / \mathrm{dl}$. For TG $>400 \mathrm{mg} / \mathrm{dl}$ values, RMSE was $44 \mathrm{mg} / \mathrm{dL}$ and MAD was $36 \mathrm{mg} /$ dl for F-LDL, while RMSE was $26 \mathrm{mg} / \mathrm{dL}$ and MAD was $20 \mathrm{mg} / \mathrm{dl}$ for S-LDL. CONCLUSIONS: New LDL-C formula can be easily applied by clinical laboratories with no additional cost. Especially for patients with TG level more than $400 \mathrm{mg} / \mathrm{dl}$, it may allow LDL-C level to be calculated more accurately than Friedewald formula.

Keywords: LDL Calculation, Lipid Profile, Triglyceride

\section{OP-111 \\ THE ROLE OF DECOY RECEPTOR 3 IN INFLAMMATION AND ATHEROSCLEROSIS IN PATIENTS WITH CHRONIC KIDNEY DISEASE AND RENAL TRANSPLANTATION}

Saliha Uysal ${ }^{1}$, Aysun Toker ${ }^{2}$, Kultigin Turkmen ${ }^{3}$, Suat Keskin ${ }^{4}$

${ }^{1}$ Balikesir University Medical School, Department of Medical Biochemistry, Balikesir, Turkey

${ }^{2}$ Necmettin Erbakan University Meram Medical School, Department of Medical Biochemistry, Konya, Turkey

${ }^{3}$ Necmettin Erbakan University Meram Medical School, Department of Internal Medicine, Nephrology Division, Konya, Turkey

${ }^{4}$ Necmettin Erbakan University Meram Medical School, Department of Radiology, Konya, Turkey

OBJECTIVES: The cardiovascular risk has been increased in Chronic Kidney Disease (CKD) associated with chronic inflammation and atherosclerosis Inflammatory process continues after renal transplantation. However it has been observed a significant improvement compared to patients with hemodialysis and periton dialysis. Decoyreceptor3 (DcR3), is a member of the TNFreceptor superfamily and associated with inflammation and atherosclerosis. The aim of this study is to show the relationship between DcR3 level with inflammation and atherosclerosis in patients with chronic kidney and renal transplant patients. For this purpose, we intend to measure serum levels of DcR3, ICAM-1,VCAM$1, \mathrm{IL}-8$ and evaluation of endothelial dysfunction via measurements of carotid intima-media thickness (CIMT) and presence of plaque.

MATERIALS and METHODS: A total of 150participant were obtained from 50 renal transplant patients, 40 patients undergoing hemodialysis, 30patients with pre-dialysis CKD and 30 control. Serum DcR3, VCAM-1, ICAM-1 and IL-8 levels measured with ELISA method. CIMT and presence of carotis arter plaque performed by ultrasound probe, non-invasively.

RESULTS: All parameters were measured in serum and CIMT were higher in HD andpre-dialysis CKD groups compared to renal transplant and control groups $(p<0,05)$. The levels of renal transplant group were higher from control group. There was nodifference between HD andpre-dialysis CKD groups. There was no difference between patient groups in terms of the presence of plaque. Control group didn't show anyplaque. Pre-dialysis group was nosignificant difference between the stages in any parameter except CIMT. CIMT levels was highest in stage 3. CONCLUSIONS: Although renal transplantation provides a significant improvement in the inflammatory process, not return completely. Inflammatory process associated with uremic milieu may predispose to atherosclerosis in predialysis CKD and hemodialysis patients. Increased CIMT and presence of plaque in HD and pre-dialysis CKD groups supports this state.

Keywords: Atherosclerosis, CIMT, DcR3, Inflammation

\section{OP-112 \\ THE RELATIONSHIP BETWEEN SERUM VITAMIN D AND SERUM ZINC LEVELS IN CHILDREN}

Zeynep Adiyaman Kocer ${ }^{1}$, Gulsen Sener ${ }^{1}$, Alper Gumus ${ }^{1}$, Tulin Bayrak ${ }^{2}$ ${ }^{1}$ Basaksehir Cam and Sakura City Hospital, Medical Biochemistry, Istanbul, Turkey

${ }^{2}$ Ordu University Faculty of Medicine, Medical Biochemistry, Ordu, Turkey

OBJECTIVES: The aim of this study was to evaluate the relationship between serum 25 Hydroxy Vitamin D $(25(\mathrm{OH})$ vitD) and serum zinc levels in pediatric patients.

MATERIALS and METHODS: Serum 25(OH)vitD and serum zinc levels of 358 children, 271 boys and 87 girls, aged between 0 and 18 , who applied to Basaksehir Cam and Sakura City Hospital Pediatrics Department, were retrospectively analyzed. Serum $25(\mathrm{OH})$ vitD levels were measured by electrochemiluminescence method, and serum zinc levels were measured by atomic absorption method. RESULTS: The mean age of boys and girls were $6.9 \pm 4$ and $6.5 \pm 4$ years, respectively. Serum 25(OH)vitD and zinc levels median and interquartile range were $31.1 \pm 13$ $\mathrm{ng} / \mathrm{mL}$ and $958 \pm 137 \mu \mathrm{g} / \mathrm{L}$ in boys; $26.3 \pm 11 \mathrm{ng} / \mathrm{mL}$ and $900 \pm 137 \mu \mathrm{g} / \mathrm{L}$ in girls, respectively. Serum $25(\mathrm{OH})$ vitD and zinc levels were significantly higher in boys than girls $(\mathrm{p}<0.01)$. There was a positive significant correlation between serum $25(\mathrm{OH})$ vitD and zinc levels $(\mathrm{r}=0.213, \mathrm{p}<0.01, \mathrm{n}=358)$, a negative significant correlation between serum $25(\mathrm{OH})$ vitD levels and age $(\mathrm{r}=0.196, \mathrm{p}<0.01, \mathrm{n}=358)$. In boys, there was a negative significant correlation between serum $25(\mathrm{OH})$ vitD levels and age $(r=0.147, p<0.05)$, a positive significant correlation between serum zinc levels and age $(\mathrm{r}=0.178, \mathrm{p}<0.01)$. In girls, there was a significant negative correlation between serum 25(OH)vitD levels and age $(\mathrm{r}=0.403$, $\mathrm{p}<0.01)$, no significant correlation between serum zinc levels and age $(\mathrm{p}>0.05)$. CONCLUSIONS: In our study, it was found that serum zinc levels in the pediatric population increased significantly depending on the serum $25(\mathrm{OH})$ vitD levels. Based on this possible contribution in children with zinc deficiency, we think that vitamin D supplementation may be beneficial in order to reduce the rate of growth and development retardation, regulate bone development, and contribute to immune system development.

Keywords: $25 \mathrm{OH}$ Vitamin D, Zinc, Pediatric Population 


\section{OP-113 \\ EFFECTS OF COVID-19 PNEUMONIA PATIENT'S SERA ON CANCER CELLS}

Aycan Sezan ${ }^{1}$, Ezgi Derinoz ${ }^{1}$ Eylem Nas ${ }^{1}$, Efraim Guzel $^{2}$, Burcu Saygideger Demir ${ }^{1}$, Aslihan Candevir ${ }^{3}$, Yesim Tasova $^{3}$,

Ezgi Ozyilmaz ${ }^{2}$, Hikmet Akkiz ${ }^{4}$, Yasemin Saygideger ${ }^{5}$

${ }^{1}$ Cukurova University, Graduate School of Science, Department of

Biotechnology, Adana, Turkey

${ }^{2}$ Cukurova University School of Medicine, Department of Pulmonary, Adana,

Turkey

${ }^{3}$ Cukurova University, School of Medicine, Department of Infectious Diseases, Adana, Turkey

${ }^{4}$ Cukurova University, Faculty of Medicine, Department of Internal Medicine,

Adana, Turkey

${ }^{5}$ Cukurova University Graduate School of Health Sciences, Department of

Translational Medicine, Adana, Turkey

OBJECTIVES: The aim of this research is; to examine the effects of COVID-19 patient's serums to the Epithelial to Mesenchymal Transition (EMT) related genes in A549, MCF7 and HCT116 cells.

MATERIALS and METHODS: Serum samples from COVID-19 patients and healthy volunteers were collected. Cancer cells were incubated in serum-free media for 16 hours prior to the experiment. Cell viability was assessed via MTT test and cells were incubated with equal amounts of the selected patient and normal serum samples. RNA was isolated within 6th hour of the treatment. $18 \mathrm{~S}$, E-cadherin, Vimentin, ZEB1 and SNAIL primers were designed for SYBR green based quantitative PCR assay. The rates of increase and decrease in gene expressions were calculated with $2^{\wedge}$-(delta???-delta CT) formula. RESULTS: Seven different patients and three control serums of similar age and gender was used for the experiments (Patient group (P) and Control group (C)). As a result of cell viability assay, $50 \%$ dilution did not kill the cells and $0.3 \%$ dilution used for further analysis. The results of qPCR assays revealed that there was a significant increase in the expression of EMT genes in P group especially in ZEB1 and SNAIL in HCT116 and A549 cells and SNAIL in MCF7 cells, comparing to $\mathrm{C}$ group.

CONCLUSIONS: In-vitro modeling was generated to examine the effects of cellular products released from the lungs and found in serum after SARS-CoV-2 infection to cancer cells, and an increase is seen in the expression of EMT related genes in A549, HCT116 and MCF7 cells

Keywords: COVID-19, Epithelial to Mesenchymal Transition, Cancer

\section{OP-114 \\ TRIPLE COMBINATION OF METFORMIN, DICHLOROACETATE, AND CETUXIMAB EXERTS ANTI-TUMORIGENIC ACTIVITY IN UPCI-SCC-131 ORAL SQUAMOUS CARCINOMA CELLS}

Seniz Inanc Surer ${ }^{1}$, Didem Keles ${ }^{2}$, Murat Sipahi ${ }^{1}$, Gulgun Oktay ${ }^{1}$ ${ }^{1}$ Dokuz Eylul University, School of Medicine, Department of Medical Biochemistry, Izmir, Turkey

${ }^{2}$ Izmir University of Economics, Vocational School of Health Services, Department of Medical Laboratory Techniques, Izmir, Turkey

OBJECTIVES: Oral squamous cell carcinoma (OSCC), a highly hypoxic, is the sixth most common epithelial cancer worldwide and associated with high mortality. The purpose of this study is to determine the effects of the combination of metabolic drugs which are Metformin and Dichloroacetate (DCA) with chemotherapeutic agent, Cetuximab, on cell viability, proliferation, apoptosis, and reactive oxygen species (ROS) levels in UPCI-SCC-131 cells under normoxic and hypoxic conditions. MATERIALS and METHODS: First of all, WST-1 cell viability assay was carried out to determine IC50 values of each drug for 72 hours and to evaluate triple-drug combination studies on cell viability. The triple-drug combination index was calculated based on Chou-Talalay method using CompuSyn software. The long-term effects of drugs were assessed with clonogenic assay based on the potential of single cells to survive. We also evaluated the effect of triple-drug combination on cell proliferation by using both BrdU incorporation and 3D-spheroid proliferation assays. In addition, we analyzed apoptosis and ROS levels by flow cytometry and DCFDA assay, respectively. All experiments were performed under both hypoxic and normoxic conditions. RESULTS: IC50 doses of Metformin, DCA, and Cetuximab under normoxic conditions were $3 \mathrm{mM}, 30 \mathrm{mM}$, and $1200 \mu \mathrm{g} / \mathrm{ml}$, respectively, while IC50 doses under hypoxic conditions were determined as $14 \mathrm{mM}, 40 \mathrm{mM}$, and $1200 \mu \mathrm{g} / \mathrm{ml}$, respectively. According to the CompuSyn analysis of triple-drug combination, the IC50 dose of the Metformin/DCA/Cetuximab was calculated as $3 \mathrm{mM} / 9 \mathrm{mM} / 225 \mu \mathrm{g} / \mathrm{ml}$ for normoxia and $1 \mathrm{mM} / 7.5 \mathrm{mM} / 225 \mu \mathrm{g} / \mathrm{ml}$ for hypoxia. We found that triple-drug combination i) showed synergistic effect $(\mathrm{Cl}<1)$ on cell viability, ii) reduced the colony formation (pnormoxia $=0.0002$, phypoxia $=0.0032$ ), cell proliferation (pnormoxia $=0.0047$, phypoxia $=0.0004$ ), and $3 \mathrm{D}$-spheroid proliferation (pnormoxia $=0.4741$, phypoxia $=0.005$ ), iii) increased the ROS production (pnormoxia $<0.0001$, phypoxia $=0.0016$ ) and apoptosis (pnormoxia $<0.0001$, phypoxia $=0.0143$ ) in UPCI-SCC-131.

CONCLUSIONS: Drug repositioning is a process that involves existing drugs to improve new therapeutic strategies for human safety with no side effects. In this context, Metformin/DCA/Cetuximab combination may be a novel and promising therapeutic approach for OSCC treatment.

Acknowledgements: This study was supported by a grant (no.118S576) from TUBITAK

Keywords: Cetuximab, DCA, Drug Combination, Metformin, Oral Squamous Cell Carcinoma

\section{OP-115 \\ A PYRROLOPYRIMIDINE DERIVATIVE CONTAINING N-METHYL PIPERAZINE MOIETY SIGNIFICANTLY INDUCED APOPTOSIS OF MCF-7 CELLS THROUGH SUPPRESSION OF MMP-9 ENZYME ACTIVITY}

Zuhal Kilic Kurt $^{1}$, Filiz Bakar Ates ${ }^{2}$

${ }^{1}$ Ankara University, Faculty of Pharmacy, Department of Pharmaceutical

Chemistry, Ankara, Turkey

${ }^{2}$ Ankara University, Faculty of Pharmacy, Department of Biochemistry, Ankara, Turkey

OBJECTIVES: The relation between oxidative stress and cancer has long been known. The studies have reported that the matrix metalloproteinase expression may be an important target for preventing cancer progression. This study aimed to evaluate the effects of some previously synthesized 1-(substituted-phenyl)3-(7-methyl-4-(4-methylpiperazin-1-yl)-7H-pyrrolo[2,3-d]pyrimidin-2-yl)urea derivatives on cell viability of various cancer cells and interprete the efficiency of compounds on modulation of oxidative stress through MMP-9 expression.

MATERIALS and METHODS: The cells were treated with some pyrrolopyrimidine derivatives for 24 and $48 \mathrm{~h}$ and the effects of compounds on cell viability were screened against A549 (lung), MCF 7 (breast) and PC3 (prostat) cancer cells, using the MTT assay. The evaluation of apoptotic effect of compound 3, the strongest cytotoxic compound, was performed through Annexin $\mathrm{V}$ binding assay. The ROS $(+)$ cell population were detected by oxidative stress assay kit and data were compared with the results of spectrofluorometric MMP-9 activity assay. Possible binding properties of compound 3 into the MMP-9 active site was evaluated by molecular docking study using Autodock vina.

RESULTS: Compound 3, 1-(4-fluoro-3-(trifluoromethyl)phenyl)-3-(7methyl-4-(4-methylpiperazin-1-yl)-7H-pyrrolo[2,3-d]pyrimidin-2-yl)urea, showed the highest cytotoxicity with $23.42 \mu \mathrm{M}$ IC50 value in MCF-7 cells, while it was less effective on A549 and PC3 cells with $28.28 \mu \mathrm{M}$ and 26.28 $\mu \mathrm{M}$ IC50 values, respectively $(\mathrm{p}<0.05)$. The results also indicated that compound 3 increased total apoptotic cell population \% to $14.80 \pm 1.34 \%$ in MCF-7 cells, significantly $(\mathrm{p}<0.05)$. It increased the ROS $(+)$ cell population to $39.72 \%$ in MCF-7 cells, while MMP-9 activity has significantly reduced. In molecular docking results, compound 3 formed two hydrogen bond interactions with Glu402 and Ala189 into the MMP-9 active site. CONCLUSIONS: Our results showed that compound 3 has potent cytotoxic activity on MCF-7 cells and significantly reduced MMP-9 activity, suggesting cytotoxic and apoptotic activity of compound 3 can be result from suppression of MMP-9 activity. Compound 3 may be a lead for development of new pyrrolopyrimidine derivatives.

Keywords: Cytotoxicity,Apoptosis, Oxidative Stress, MMP-9, Pyrrolopyrimidines

\section{OP-116 \\ THE EFFECTS OF 1,9-DIMETHYL-METHYLENE BLUE ON SECRETASES IN COLON CANCER CELLS}

Kevser Biberoglu

Department of Biochemistry, School of Pharmacy, Hacettepe University, Ankara, Turkey

OBJECTIVES: Colon cancer is among the most frequent cancer types. Amyloid precursor protein (APP), well known for its association with Alzheimer disease (AD) is highly expressed in various types of cancers. APP undergoes sequential proteolytic processing through two distinct pathways: the amyloidogenic pathway, which leads to $A \beta$ formation and the non-amyloidogenic pathway, which generates soluble form of $\operatorname{APP}(\operatorname{sAPP} \alpha)$ by $\alpha$-secretase. According to recent studies SAPP $\alpha$ was suggested to promote cancer cell proliferation and inhibition APP processing by $\alpha$-secretases (ADAM10 and/or ADAM17) reduce cancer progression. Our previous studies showed that toluidine blue $\mathrm{O}$ (TBO), a phenothiazine-structured compound, reduces APP processing in vitro and in vivo models of $\mathrm{AD}$. Our purpose was to determine whether 1,9-dimethyl-methylene blue [(DMMB), Taylor's blue], structurally similar to TBO, could cause an inhibition on SAPP $\alpha$ and $\alpha$-secretase expressions. MATERIALS and METHODS: Human colon cancer cell line HT29 was treated with DMMB (0-1.25 $\mu \mathrm{M})$ for 24 hours. After treatment, the levels of sAPPo and $\alpha$-secretases (ADAM10 and ADAM17) were analyzed using Western blotting. The results were compared to those obtained with vehicle-control cells. RESULTS: Our results showed that $1.25 \mu \mathrm{M}$ DMMB decreased the levels of ADAM 10 and ADAM 17 by $32 \%$ and $88 \%$, respectively. On the other hand, sAPP $\alpha$ levels were reduced by $40 \%$ at $1.25 \mu \mathrm{M}$ DMMB CONCLUSIONS: DMMB may show useful effects in the treatment of colon cancer. 
XXXI. National Congress of the Turkish Biochemical Society 2020

Acknowledgements: This study is supported by the grants from the TUBITAK (SBAG-119S905)

Keywords: $\alpha$-secretase, 1,9-dimethyl-methylene blue, colon cancer

\section{OP-117 \\ FUSARIC ACID DOWNREGULATES MRNA EXPRESSIONS OF HISTONE DEACETYLASES (HDACS) AND TOLL-LIKE RECEPTORS IN HT-29 COLON CANCER CELLS}

Mucahit Secme

Pamukkale University, Department of Medical Biology, Denizli, Turkey

OBJECTIVES: Fusaric acid (FA) is a picolinic acid derivative and secondary metabolite first isolated from fungi of the Fusarium genus. Various therapeutic effects of FA such as anticancer and anti-inflammatory are under investigation. The aim of this study is to understand the antiproliferative effect of FA on HT-29 colon cancer cells and its effect mechanism through the expression of histone deacetylase and Toll-like receptors.

MATERIALS and METHODS: Effect of FA on cell proliferation was determined by XTT method. Total RNA isolation was performed by Trizol and subsequently cDNA was synthesized. RNA concentration and purity were determined by nanodrop mRNA expression changes of HDAC1, HDAC2, HDAC3, HDAC4, TLR1,TLR2 TLR3, TLR4 TLR5, TLR6, TLR7, TLR8, TLR9, TLR10 and MyD88 were determined by RT-PCR. The analysis of the findings was carried out with the $\triangle \triangle C T$ method and statistical analysis and fold changes were determined with the "RT2-Profiles"TM PCR Array Data Anaylsis" online system. RESULTS: IC50 dose (concentration required for the reduction of cell viability by half) of FA in HT-29 colon cancer cells was determined as $145 \mu \mathrm{M}$ at 48 th hour. RT-PCR analysis showed that HDAC1, HDAC2, TLR2, TLR4 and MyD88 mRNA expressions decreased as 9.9, 6.02, 1.9, 3.1, and 6.5 fold respectively in the FA treated cells, compared to the control. These changes were found statistically significant $(\mathrm{p}<0.05)$. Other expression changes found statistically unsignificant $(\mathrm{p}>0.05)$.

CONCLUSIONS: It has been demonstrated that FA may act as a potential HDAC inhibitor in HT-29 cells, resulting in TLR-mediated cell death and anticarcinogenic effects. In addition, preliminary findings were obtained for detailed studies to be conducted to determine the therapeutic efficacy of FA.

Keywords: Fusaric Acid, Histone Deacetylases (HDACs), HT-29 Cells Toll-like Receptors

\section{OP-118 \\ IN VITRO INVESTIGATION OF THE EFFECTS OF MESENCHYMAL \\ STEM CELLS ON BREAST CANCER}

Ilkay Guzel, Bahadir Ozturk

Selcuk University Faculty of Medicine, Department of Biochemistry, Konya, Turkey

OBJECTIVES: MDA-MB 231 is an epithelial cancer cell type derived from human breast adenocarcinoma. Mesenchymal stem cells are multipotent stromal cells that can differentiate into various cell types. In this study, it was aimed to investigate whether mesenchymal stem cells derived from human dental follicle have an effect on MDA-MB 231 cell in terms of proliferation and apoptosis.

MATERIALS and METHODS: The stem cells we used in our study were isolated from the dental follicle tissue. In order to characterize the cells brought to the third passage, flow cytometry analysis was performed using positive and negative antibodies. After the characterization analysis, the differentiation potential of the cells was observed under the microscope by applying adipogenic, chondrogenic and osteogenic differentiation kits. Proliferation test was studied by MTT method and apoptosis analysis was studied with Annexin V method in flow cytometry device.

RESULTS: The \% viability rate of the MDA-MB 231 cell line of $\% 50$ doseconditioned medium obtained from dental follicle mesenchymal stem cells was found to be \%66.6. As a result of the apoptosis analysis, the total apoptosis amount of the control group at 24 hours was $\% 12.5$ and $\% 50$ of the dosed cells Total apoptosis amount in the control group at 48 hours was $13.1 \%$ and $\% 20.35$ of the cells dosed with $\% 50$.

CONCLUSIONS: With the results we obtained, it was observed that conditioned media originating from dental follicle mesenchymal stem cells inhibited proliferation by $\% 33.4$ in MDA MB-231 cells compared to the control group and led the cells to apoptosis by $\% 4$.

Keywords: Apoptosis, Cancer, Mesenchymal Stem Cell, Proliferation

\section{OP-119 \\ INVESTIGATION OF THE SYNERGISTIC ANTI-CANCER EFFECT OF A COMBINATION OF ZOLEDRONATE AND QUERCETIN ON GLIOBLASTOMA}

Osman Yetkin ${ }^{1}$, Rasime Kalkan ${ }^{2}$, Ergul Mutlu Altundag ${ }^{3}$, Kerem Terali $^{1}$ ${ }^{1}$ Department of Medical Biochemistry, Faculty of Medicine, Near East University, Nicosia, TRNC

${ }^{2}$ Department of Medical Genetics, Faculty of Medicine, Near East University, Nicosia, TRNC

${ }^{3}$ Department of Medical Biochemistry, Dr. Fazil Kucuk Faculty of Medicine, Eastern Mediterranean University, Famagusta, TRNC

OBJECTIVES: Glioblastoma, an aggressive type of tumor that occurs in the brain/ spinal cord, is among the most difficult cancers to treat. Use of clinically proven, safe agents to combat cancer constitutes an important part of current research in cancer. Quercetin, the main dietary flavonoid, is believed to be a fatty acid synthase inhibitor. Zoledronate, an FDA-approved bisphosphonate, is a known inhibitor of the mevalonate pathway. Here, targeting cellular lipid metabolism, we aim at investigating the synergistic anti-cancer effect of a combination of zoledronate and quercetin on glioblastoma.

MATERIALS and METHODS: In cytotoxicity experiments, the DBTRG$05 \mathrm{MG}$ human glioblastoma cell line was treated with zoledronate or quercetin at increasing micromolar concentrations, applying six doses with three replicates each. Both IC50 values for the single compounds and possible dose pairs were estimated using the CompuSyn software. Cell viability was determined using the MTT cell proliferation assay.

RESULTS: At 72 hour, the IC50 value for quercetin was found to be $81.43 \mu \mathrm{M}$, while that for zoledrenate was found to be $63.29 \mu \mathrm{M}$. With a quercetin:zoledronate ratio of 1.3 , the combination index (Chou-Talalay equation) for all of the dose pairs (at low- to mid-micromolar concentrations) was in the range of $0.3-0.7$, suggesting that the quercetin-zoledronate combination exerted a clear synergistic anti-cancer effect on glioblastoma cells.

CONCLUSIONS: As modifiers of cellular lipid metabolism, quercetin and zoledronate, when used together, inhibit the proliferation of glioblastoma cells significantly. Supported by further preclinical/clinical studies, this drug regimen is predicted to hold great potential for treating glioblastoma patients, whose life expectancy is about 6-14 months.

Keywords: Cancer, Glioblastoma, Lipid Metabolism, Quercetin, Zoledronate

\section{OP-120 \\ DEVELOPMENT OF NEAR INFRARED ACTIVATABLE DUAL PHOTOTHERAPY AGENTS AGAINST CANCER CELLS}

$\frac{\text { Safacan Kolemen }}{\text { Koc University, Istanbul, Turkey }}$

OBJECTIVES: Photothermal therapy (PTT) and photodynamic therapy (PDT) are two minimally invasive light-based therapeutic modalities for treatment of cancer. Recent advancements in the design of photosensitizers (PS) for phototherapy applications have triggered the development of dual PDT and PTT agents as these multimodal agents display improved efficacies compared to single mode of action. To that end, different small organic-based agents have been proposed as dual phototherapy agents, however cancer cell selective agents remained elusive. Here, we introduce bromo-hemicyanine based near-IR activatable photosensitizers, which can serve as cancer cell selective multimodal phototherapy agents.

MATERIALS and METHODS: Generation of ROS and photothermal conversion of hemicyanine based agents as a function of laser wavelength $(640 \mathrm{~nm}, 808$ $\mathrm{nm}, 640+808 \mathrm{~nm}$ ) and power were studied initially in solution. In cell culture experiments, in vitro ROS generation was determined on colon (SW480) and cervical (HeLa) cancer cells, cell viabilities were investigated with a MTT assay and cell death mechanisms were analyzed through flow cytometry.

RESULTS: Phototherapy agents were shown to be an effective dual phototherapy agents under a single $(640 \mathrm{~nm}$ or $808 \mathrm{~nm})$ and dual laser $(640 \mathrm{~nm}+808 \mathrm{~nm})$ irradiation. Both single wavelength irradiations caused significant phototoxicity in different cancer cells. Co-irradiation, on the other side, provided complete elimination of cancer cells due to synergistic action even at low drug doses and just after 5 minutes of irradiation.

CONCLUSIONS: This work introduces easily synthesized small moleculebased synergistic phototherapy agents, which holds a great promise towards the realization of rapid and highly selective treatment modalities against cancer. Keywords: Cancer, Phototherapy, Photodynamic Therapy, Photothermal Therapy, Selective Drugs 


\section{OP-121 \\ SYNERGISTIC INTERACTIONS BETWEEN GW8510 AND GEMCITABINE IN AN IN VITRO MODEL OF PANCREATIC CANCER}

Duygu Gencalp Rustem ${ }^{1}$, Sevcan Atay ${ }^{2}$, Hikmet Hakan Aydin ${ }^{2}$, Handan Ak $^{2}$ ${ }^{1}$ Department of Medical Biochemistry, Eastern Mediterranean University, Famagusta, TRNC

${ }^{2}$ Department of Medical Biochemistry, Ege University, Izmir, Turkey

OBJECTIVES: One of the main reasons for the poor survival rates of pancreatic cancer patients is the development of gemcitabine resistance, indicating that novel treatment strategies that have the ability to improve gemcitabine sensitivity are in need to combat this devastating disease.

MATERIALS and METHODS: TCGA PAAD data was used to determine the clinicopathological significance of high RRM2 (Ribonucleotide reductase subunit M2) expression for pancreatic ductal adenocarcinoma (PDAC). The effects of GW8510 and gemcitabine on PANC-1 cell viability were determined using WST8 assay. The potential synergistic interaction between GW8510 and gemcitabine was evaluated by the combination index (CI) analysis. The effects of GW8510 treatment on apoptosis, cell cycle, and cell migration, either in combination with gemcitabine or alone,were investigated. The effect of GW8510 on RRM2 protein levels was evaluated using ELISA assay.

RESULTS: RRM2 is significantly over-expressed in PDAC compared to healthy pancreatic tissues $(p<0.0001)$. RRM2 mRNA expression was found to be corralated with the overall survival rate of patients $(\mathrm{HR}=2.17$ [1.44-3.27], $p=0.00016)$ and the pathological stages of the disease $(p=0.0054)$. GW8510 decreased the RRM2 protein levels compared to the control.Cell viability analysis showed that GW8510 has a similar effect to gemcitabine in inhibiting PANC-1 cell viability. GW8510 was found to synergize with gemcitabine to inhibit PANC-1 cell viability and migration. However, the effects of GW8510 on PANC-1 cells could not be explained by induction of apoptosis or cell cycle arrest. CONCLUSIONS: Targeting RRM2 using GW8510 may have the potential to increase gemcitabine sensitivity in pancreatic cancer.

Acknowledgements:This research was funded by the TUBITAK(Project no: 318S052).

Keywords: GW8510; RRM2; PANC-1; Gemcitabine; mRNA Expression

\section{OP-122 \\ DNA REPAIR PROTEINS AS MOLECULAR TARGETS FOR CANCER THERAPY AND ITS MEASUREMENT BY MASS SPECTROMETRY}

Gamze Tuna $^{1}$, Erdem Coskun ${ }^{2}$, Pawel Jaruga ${ }^{2}$, Alessandro Tona ${ }^{3}$,

Onur Erdem $^{4}$, Miral Dizdaroglu ${ }^{2}$

${ }^{1}$ Department of Molecular Medicine, Institute of Health Sciences, Dokuz Eylul

University, Izmir, Turkey

${ }^{2}$ Biomolecular Measurement Division, National Institute of Standards and

Technology, Gaithersburg, MD, United States

${ }^{3}$ Biosystems and Biomaterials Division, National Institute of Standards and

Technology, Gaithersburg, MD, United States

${ }^{4}$ Department of Toxicology, Gulhane Faculty of Pharmacy, University of Health Sciences, Ankara, Turkey

OBJECTIVES: DNA damage occurs in living organisms by exogenous and endogenous sources. Unless repaired, DNA damage can cause genomic instability that may give rise to disease processes including carcinogenesis. Cancer tissues overexpress DNA repair proteins, leading to therapy resistance. Measurement of DNA repair proteins in disease-free tissues and malignant tumors of patients is important to evaluate DNA repair proteins as a predictive and prognostic biomarker in cancer, to develop and use inhibitors of these proteins in cancer therapy. We aimed to develop liquid chromatography-isotope dilution tandem mass spectrometry method for measurement of poly-(ADP ribose)polymerase-1 (PARP1) and apurinic/apyrimidinic endonuclease-1 (APE1) in human tissues and cell lines.

MATERIALS and METHODS: We quantified PARP1 in human normal and malignant ovarian tissues, and in human cell lines MCF-7, MCF-10A, HEPG2, THLE-2, HeLa, Ect1/E6E7.

RESULTS: Significantly greater expression of PARP1 was observed in malignant ovarian tissues than in normal tissues. While PARP1 level in HeLa cells was significantly greater than Ect1/E6E7 cells, no statistically significant difference between MCF10A and MCF7 cells, and THLE-2 and HEPG2 cells. We also show the simultaneous measurement of PARP1 and APE1 in a given protein extract. CONCLUSIONS: Extreme expression of the PARP1 in cancer cells was observed, suggesting that cancer cells may overexpress DNA repair proteins for survival. The approach described is expected to be applicable to the measurement of expression levels of DNA repair proteins in malignant tumors vs. disease-free tissues in patients. This attribute may help develop novel treatment strategies and DNA repair inhibitors as potential anticancer drugs.

Keywords: PARP1, DNA Damage, DNA Repair Proteins, Cancer Biomarkers, Isotope-Dilution Mass Spectrometry

\section{OP-123 \\ THE EVALUATION OF METHYLTHIAZOLE DERIVATIVES ANTICANCER AND ANTIINFLAMMATORY ACTIVITIES IN C6 CELL LINES}

\author{
Dilek Erdas ${ }^{1}$, Halide Edip Temel ${ }^{1}$, Gulsen Akalin Ciftci $^{1}$, Leyla Yurttas ${ }^{2}$, \\ Asaf Evrim Evren ${ }^{3}$ \\ ${ }^{1}$ Department of Biochemistry, Faculty of Pharmacy, Anadolu University, \\ Eskisehir, Turkey \\ ${ }^{2}$ Department of Pharmaceutical Chemistry, Faculty of Pharmacy Anadolu \\ University, Eskisehir, Turkey \\ ${ }^{3}$ Pharmacy Services, Vocational School of Health Services, Bilecik Seyh Edebali \\ University, Bilecik, Turkey
}

OBJECTIVES: Studies with the aim of developing anti-inflammatory and anticancer drugs show that thiazole-derived compounds have potent antiinflammatory and anticancer effects. In this study, nine new compounds containing 4-methylthiazole-2-acetamide fragment in their main structure were synthesized and the analysis of these compounds was carried out by high resolution mass spectrometry (HRMS, LC/IT-TOF), 1H-NMR and 13C-NMR methods. Then, with the activity studies, the potential of these compounds to be drugs and their effects on the mechanisms that play a role in the anticancer effect were examined.

MATERIALS and METHODS: Cytotoxicity values of the compounds were determined by MTT method. Early/late apoptotic and necrotic cell ratio was determined by Annexin V-FITC method. Mitochondrial membrane integrity was determined by flow cytometry and caspase-3 activation levels were measured. RESULTS: It was observed that the activity of compound $3 \mathrm{c}$ containing 4,5-dihydrothiazole moiety was higher than the positive control cisplatin. The cytotoxic effect value of compound $3 \mathrm{f}$ containing 4-nitro-1H-benzimidazole moiety and positive control cisplatin was determined as $18.6 \pm 3.21$ and $17.0 \pm 4.36$ respectively. When the apoptotic effect test results are evaluated it was determined that the percentage of compound $3 \mathrm{c}(49.2 \%)$ in which the cells induced apoptosis was close to the percentage of positive control cisplatin $(50.7 \%)$

CONCLUSIONS: The findings obtained from our study show that the $3 \mathrm{c}$ compound has anti-inflammatory and anticancer effect and will contribute to drug development studies based on thiazole derivative compounds.

Acknowledgements: This work was supported by Anadolu University Scientific Research Projects Commission (Project No. 1807S251).

Keywords: Methylthiazole Derivatives, Anti-inflammatory, Anticancer, C6 Cell Line.

\section{OP-125 \\ DESIGN, SYNTHESIS AND ANTICANCER ACTIVITIES OF NOVEL OXADIAZOLE-AZCETAMID COMPOUNDS}

Gulsen Akalin Ciftci ${ }^{1}$, Halide Edip Temel ${ }^{1}$, Asaf Evrim Evren ${ }^{3}$, Mehmet Onur Aksoy ${ }^{1}$, Aslihan Kubilay ${ }^{4}$, Leyla Yurttas ${ }^{2}$

${ }^{1}$ Anadolu University, Faculty of Pharmacy, Department of Biochemistry, Eskisehir, Turkey

${ }^{2}$ Anadolu University, Faculty of Pharmacy, Department of Pharmaceutical Chemistry, Eskisehir, Turkey

${ }^{3}$ Bilecik Seyh Edebali University, Vocational School of Health Services, Pharmacy Services,Bilecik, Turkey

${ }^{4}$ Anadolu University, Faculty of Pharmacy, Department of Analytical Chemistry, Eskisehir, Turkey

OBJECTIVES: (Benz)Azoles are the ring systems frequently encountered in the structure of drugs used in cancer treatment. Therefore, they are used in the design of new drug molecules. In this study, it was aimed to determine the potential anticancer effects and structure-activity relationships of new twelve compounds containing 5-[(2-acetamidophenoxy) methyl)-1,3,4-oxadiazole as a core structure.

MATERIALS and METHODS: The synthesis of compounds (4a-41) was carried out in four steps. Their anticancer activity potential was tested by the MTT method against A549 cell line. In addition, early / late apoptotic cell ratio, mitochondrial membrane integrity, caspase-3 activation measured by flow cytometry, caspase-3 activation levels, cell cycle arrest were measured by flow cytometric analyses. Also, they were investigate on MMP-9 enzyme. RESULTS: Considering both the selectivity of the compounds between healthy cells and cancer cells and their apoptotic pathway inducing effects together, the $4 \mathrm{f}, 4 \mathrm{~h}, 4 \mathrm{i}, 4 \mathrm{k}$, and 41 compounds are remarkable. Compounds $4 \mathrm{f}, 4 \mathrm{~g}, 4 \mathrm{~h}$, and 41 exhibited strong inhibition on MMP-9. MMP-9 inhibition values of the compounds with fluorine substitution ( $4 \mathrm{f}$ and 41 ) were $75.08 \pm 2.80 \%$ and $75.26 \pm 3.73 \%$, respectively; $83.79 \pm 0.12 \%$ for the compound with ethoxy substitution $(4 \mathrm{~g})$, and $78.49 \pm 3.92 \%$ for the non-substituted phenyl analog. CONCLUSIONS: Due to results, the derivatives bearing phenyl substitution (4h-41) were found better potent than the benzothiazole analogs (4a$4 \mathrm{~g}$ ). Compound $4 \mathrm{~h}$ and 41 may be good anticancer agent candidates due to their high inhibition and high anticancer selectivity at low doses. Acknowledgements: This work was supported by Anadolu University Scientific Research Projects Commission (Project No. 1807S251).

Keywords: Cancer, Apoptosis, Matrix Metalloproteinase 


\section{OP-126 \\ NOVEL THIOSEMICARBAZIDE DERIVATIVES: ANTICANCER AND MATRIX METALOPROTEINASE ENZYME INHIBITION EFFECTS}

Halide Edip Temel ${ }^{1}$, Gulsen Akalin Ciftci ${ }^{1}$, Leyla Yurttas ${ }^{2}$, Asaf Evrim Evren ${ }^{1}$ Anadolu University, Faculty of Pharmacy, Department of Biochemistry, Eskisehir, Turkey

${ }^{2}$ Anadolu University, Faculty of Pharmacy, Department of Pharmaceutical

Chemistry, Eskisehir, Turkey

${ }^{3}$ Bilecik Seyh Edebali University,Vocational School of Health

Services,Pharmacy Services, Bilecik, Turkey

OBJECTIVES: MMP activity has gained importance in the prevention and treatment of invasion, metastasis and angiogenesis in malignancies including lung cancer. Thiosemicarbazides, which stand out with their anticancer activities, are important structural starting compounds that have the potential to show chemical functionality in biologically active molecules. Optimization of this structure may result in the discovery of a new class of anticancer agents. Therefore, in our study, the thiosemicarbazide bridge, which is considered as the main structure, was designed with 2-acetamidophenoxy moieties on one end and a phenyl group on the other end. The anticancer activities and inhibition effects of these newly synthesized compounds on MMP-9 enzyme activity were investigated.

MATERIALS and METHODS: The designed new ten compounds (3a-3j) were synthesized via three steps andtheir structures were illuminated Each derivative was investigated for cytotoxic activity on A549 cell line by MTT (3-(4,5-dimethylthiazol-2-yl)-2,5-diphenyltetrazolium bromide method and ability to inhibit Matrix metalloproteinase- 9 enzyme by colorimetric inhibitor screening assay kit.

RESULTS: Compounds $3 \mathrm{~b}, 3 \mathrm{~g}, 3 \mathrm{i}$ and $3 \mathrm{j}$ had significant cytotoxic activity. Cytotoxic activity values (IC50) of compounds $3 \mathrm{~b}, 3 \mathrm{~g}$, $3 \mathrm{i}$ and $3 \mathrm{j}$ were $11.33 \pm 0.58$, $10.33 \pm 0.58,9.33 \pm 0.58$ and $18.67 \pm 1.53 \mathrm{mg} / \mathrm{mL}$, respectively. It was shown that all of the compounds have an inhibitory effect on MMP-9 enzyme activity, it was determined that the derivate with the highest inhibition effect $(84.86 \pm 1,45, \%$ at $100 \mu \mathrm{M})$ concentration was compund

CONCLUSIONS: As a result, phenyl groups with ortho and para halogen increased the cytotoxic effect of the compounds.

Acknowledgements: This work was supported by Anadolu University Scientific Research Projects Commission (Project No. 1905S085).

Keywords: Cancer, Matrix Metalloproteinase-9, Thiosemicarbazide

\section{OP-128}

\section{IN VITRO METHODOLOGY FOR DETERMINING POTENTIAL}

\section{ANTICANCER ACTIVITY IN PLANTS}

Basak Kocdor ${ }^{1}$, Ipek Gurkebabci' ${ }^{1}$, Halil Ates ${ }^{2}$, Ilhan Kaya ${ }^{3}$, Canan Kayaalp ${ }^{4}$, Hilal Kocdor

${ }^{1}$ Basak Kocdor, Department of Basic Oncology, Enstitute of Oncology, Dokuz Eylul University, Izmir,Turkey

${ }^{2}$ Ipek Gurkebabci, Department of Basic Oncology, Enstitute of Oncology, Dokuz Eylul University, Izmir,Turkey

${ }^{3}$ Halil Ates, Enstitute of Oncology, Dokuz Eylul University, Izmir,Turkey ${ }^{4}$ Ilhan Kaya, Faculty of Agriculture, Yuzuncu Yil University, Van, Turkey ${ }^{5}$ Canan Karaalp, Faculity of Pharmacy, Ege University, Izmir, Turkey

${ }^{6}$ Hilal Kocdor, Department of Basic Oncology, Enstitute of

Oncology,Department of Molecular Medicine, Dokuz Eylul University, Izmir,Turkey

OBJECTIVES: Plants are the most important resource in anticancer drug research A standard screening method for determining suitable candidates in the plant pool of about fourteen thousand in total; it is not yet available in determining both the type of plant and the effective concentration of acceptable toxicity. In this study, different methodologies were used to investigate the anti-cancer activity of an Anatolian plant ( $\mathrm{R}$. Ribes), which has the richest plant pool in the world, in breast cancer cell lines. Among these, it's aimed to determine the appropriate screening method.

MATERIALS and METHODS: Total extract was prepared with methanol. The effective concentration range of this extract was tested in breast cancer estrogen (positive) and (negative) cell lines. Cell cycle and apoptosis analyzes were performed at the IC50 concentration obtained. Plant anticancer efficacy: compared with Doxorubicin, a standard chemotherapeutic agent. 3D mass formation analyzes were performed on agarose gel in each group with the determined effective concentration.

RESULTS: Effects of effective concentration on total extract; Compared to Doxorubicin in MCF7 and MDA-MB 231 cell lines, the extract used showed cells in apoptosis and necrosis; It was observed that it took a statistically significant $(\mathrm{P}<0.005)$ difference. Solid structures formed in agarose gel analysis performed; compared between groups with their numbers and sizes. The effect of the extract in agarose was found to be significantly different in hormone $(+)$ cell lines $(\mathrm{P}$ $<0.005)$

CONCLUSIONS: Total extract content in the chemopreventive dosage range has an anti-cancer potential. Anti-cancer activity is more pronounced in the hormone receptor $(+)$ tumor line.

Keywords: Breast Cancer, Total Extract, Agarose Gel, Anticancer Activity

\section{OP-129 \\ THE ANTIOXIDANT EFFECT OF OLEASTER FRUIT ON SACCHAROMYCES CEREVISIAE SOME MOLECULAR AND BIOCHEMICAL PARAMETERS}

\author{
Ozlem Gok ${ }^{1}$, Seda Beyaz ${ }^{1}$, Abdullah Aslan ${ }^{2}$ \\ ${ }^{1}$ Firat University, Faculty of Science, Department of Biology, Elazig, Turkey \\ ${ }^{2}$ Department of Biology-Molecular Biology and Genetics Program, Faculty of
} Science, Firat University, Elazig, Turkey

OBJECTIVES: The spindle, whose latin name is Elaeagnus angustifolia L. is a drought-resistant plant species. It begins to bear fruit at the age of 5-6. It is fruit similar to cranberry and the inside of the fruit is like flour. The fruits of the spindle have a rich content in terms of carbohydrate, protein and vitamins A, B, $\mathrm{C}$, magnesium, potassium and iron minerals. In this study, the protective role of oleaster fruit against oxidative damage in Saccharomyces cerevisiae with copper chloride $\left(\mathrm{CuCl}_{2}\right)$ was investigated.

MATERIALS and METHODS: In this study 4 groups were formed. Groups: (i) Control Group: Yeast only cultivated group (ii) Oleaster Fruit Group: Oleaster fruit $\left(\%\right.$ 8) given group (iii) $\mathrm{CuCl}_{2}$ Group: $\mathrm{CuCl}_{2}(30 \mathrm{mM})$ given group (iv) Oleaster Fruit $+\mathrm{CuCl}_{2}$ Group: Oleaster fruit $(\% 8)+\mathrm{CuCl}_{2}(30 \mathrm{mM})$ given group. Saccharomyces cerevisiae cultures were grown for 1 hour, 3 hours, 5 hours and 24 hours at $30^{\circ} \mathrm{C}$. Cell growth ( 1 hour, 3 hours, 5 hours and 24 hours), lipid peroxidation MDA (malondialdehyde) analyzes, GSH (glutathione) level and catalase activity were determined by spectrophotometer. Total protein changes were detected by SDS-PAGE electrophoresis and calculated by the Lowry protein method.

RESULTS: According to the results obtained, cell development, GSH levels, catalase activity and total protein synthesis increased, while MDA level decreased in oleaster fruit groups compared to the $\mathrm{CuCl}_{2}$ group.

CONCLUSIONS: As a result, in addition to reducing oxidative damage in the culture of Saccharomyces cerevisiae oleaster fruit has an increasing role in increasing cell growth and synthesis of total protein.

Keywords: Catalase, Copper Chloride, Oleaster, Oxidative Damage, Saccharomyces Cerevisiae

\section{OP-130 \\ PROGRAMMED CELL DEATH SUBROUTINES INDUCED BY TEMOZOLOMIDE IN SCHIZOSACCHAROMYCES POMBE}

Hizlan Hincal Agus ${ }^{1}$, Cenk Kig ${ }^{2}$

${ }^{1}$ Faculty of Sciences and Literature, Department of Molecular Biology and Genetics, Istanbul Yeni Yuzyil University, Istanbul, Turkey

${ }^{2}$ Faculty of Medicine, Department of Medical Biology and Genetics, Istanbul Yeni Yuzyil University, Istanbul, Turkey

OBJECTIVES: The aim of this study is to develop $S$. pombe model, which is planned to be used in molecular cell death study, and, to understand the potentia roles of the genes suggested for programmed cell death mechanisms by using molecular biological tools. Also, the cell death pathway along with toxic effects that are induced by temozolomide, is aimed to be enlightened.

MATERIALS and METHODS: $S$. pombe wild type (ED666 h-ade6-M210 ura4-D18 leu1-32) and mutant cells (pcal, aif1, pnu1, rad9) were used in this study. Gene expression analyses were performed using RT-PCR method. Cells were grown on standard media and all treatments were done at $30^{\circ} \mathrm{C}$ and shaking at $180 \mathrm{rpm}$. Nuclear morphology was assessed by DAPI staining. Apoptosis was monitored by Annexin V/FITC staining. Spot and colony forming assays were performed in plates containing solid agar supplemented with amino acids.

RESULTS: 1-10 mM temozolomide caused a dose-dependent cell death. The number of apoptotic cells was calculated nearly the same as of the results from spot and colony assays (20\%-60\%). While nuclear fragmentations were monitored by DAPI staining, 4-fold increments in expressions of the genes suggested to play roles in apoptosis ( was observed in mutant cells. The results from mutants other than pnul were found very close to those of wild type cells, however, apoptosis was not observed in pnul cells treated with $2 \mathrm{mM}$ temozolomide.

CONCLUSIONS: The contribution of proapoptotic genes to temozolomideinduced cell death in addition to their transcriptional regulation were clarified in $S$. pombe.

Acknowledgements: This study was supported by a grant (\#119Z186) from the Scientific and Technological Research Council of Turkey (TUBITAK).

Keywords: $\{$ S. pombe $\}$, temozolomide, apoptosis, \{pnu1\} 


\section{OP-131 \\ INVESTIGATION OF GPER-1 LEVELS IN ISCHEMIC HEART TISSUE OF OVERECTOMIZED RATS}

Mahmut Ay ${ }^{1}$, Mehmet Ozyurt ${ }^{2}$, Ergul Belge Kurutas ${ }^{2}$

Fatih Mehmet Yuzbasioglu ${ }^{3}$, Sevgi Bakaris ${ }^{4}$, Busra Citil ${ }^{2}$

${ }^{1}$ Bioengineering and Science, Institute of Science, Kahramanmaras Sutcu Imam University Kahramanmaras, Turkey

${ }^{2}$ Department of Medical Biochemistry, Faculty of Medicine, Kahramanmaras

Sutcu Imam University, Kahramanmaras, Turkey

${ }^{3}$ Department of General Surgery, Faculty of Medicine, Kahramanmaras Sutcu

Imam University, Kahramanmaras, Turkey

${ }^{4}$ Department of Pathology, Adana City Training and Research Hospital, Adana,

Turkey

OBJECTIVES: In this first study, the biochemical and histopathological effects of overeoctomized rats on ischemic heart tissue were investigated in 32 adult female rats. Rats were randomly divided into four groups; group 1; Control (n $=8)$, group 2; Overectomy group $(\mathrm{n}=8)$, group 3; Ischemia-reperfusion only group $(n=8)$, and group 4; Overectomy + ischemia-reperfusion group $(n=8)$. Overectomy groups were surgically removed 14 days before cardiac ischemiareperfusion. In order to exclude surgical stress, only the abdomen was opened and closed without overectomy. After menopause, rats in the whole group were applied to the heart of ischemia and reperfusion for 10 minutes. Blood was collected from all groups after reperfusion and plasma creatine kinase (CK-MB), estrogen and progesterone levels were measured. GPER levels were measured in tissue samples.

MATERIALS and METHODS: Biochemical parameters (CK-MB, estrogen, progesterone and GPER) were measured by commercial kits on the ELISA device.

RESULTS: At the end of biochemical examinations; CK-MB levels did not show statistically significant differences between the groups $(p>0.05)$. Estrogen levels were significantly lower in the other groups compared to the control group ( $p$ $<0.05)$. However, there was no statistically significant difference in progesterone levels between the groups $(\mathrm{p}>0.05)$. GPER levels were significantly higher in the overectomy and overectomy + ischemia-reperfusion groups compared to the other groups $(\mathrm{p}<0.05)$.

CONCLUSIONS: As a result, elevated GPER levels result from impaired and inadequate estrogen synthesis after overectomy, which leads to cardiac dysfunction.

Keywords: Estrogen, GPER, Overectomize, Cardiac Ischemia-Reperfusion Injury

\section{OP-132 \\ DEVELOPMENT OF METHAMPHETAMINE SPECIFIC DNA APTAMER}

Ezgi Man, Serap Evran

Ege University, Faculty of Science, Department of Biochemistry,Izmir, Turkey

OBJECTIVES: Methamphetamine abuse is a serious public health problem in many countries. It ranks second after cannabis as the most commonly abused illicit drug in the world. The aim of this study was to develop a DNA aptamer that could recognize methamphetamine with high affinity and specificity, which can be used in further biosensor studies. Nucleic acid aptamers are short, single-stranded DNA or RNA oligonucleotides that exhibit similar binding properties with monoclonal antibodies. Aptamers are used in various applications as alternative to antibodies due their stability and low-cost properties. MATERIALS and METHODS: Graphene oxide SELEX (GO-SELEX) method was used to develop the aptamer. Secodary structures and sequence similarities of the sequences obtained by GO-SELEX were examined by using MEME suit and mfold softwares. Binding properties of methamphetamine aptamers were characterized by isothermal titration calorimetry (ITC). Thermodynamic parameters for the aptamer-ligand interaction were determined. RESULTS: Based on the ITC measurements, $\mathrm{Kd}$ was found as $1,32 \mu \mathrm{M}$, $\Delta \mathrm{H}$ was found as $-11,6 \mathrm{kcal} \mathrm{mol}$, and $\Delta \mathrm{G}$ was found as $-8,02 \mathrm{kcal} / \mathrm{mol}$. CONCLUSIONS: Metamphetamine aptamer has the potential to be used as a recognition probe in biosensors that could be developed to determine methamphetamine levels in biological samples.

Keywords: Aptamer, Drug Abuse, Methamphetamine, GO-SELEX

\section{OP-133 \\ RECOMBINANT PRODUCTION OF THE VIRULANCE ENZYME FROM STREPTOCOCCUS PYOGENES AND DEVELOPMENT OF SPECIFIC DNA APTAMERS}

Merve Gultan, Serap Evran

EGE UNIVERSITY, Izmir, Turkey

OBJECTIVES: S.pyoges is a gram positive bacteria that causes necrotizing fasciitis (flesh eating disease) and streptococcal toxic shoch syndrome with high mortality rates. In addition, it is known to cause sepsis and pharyngitis in humans. Mortality rates of GAS infection are high in developed and undeveloped countries.S.pyogenes causes nearly 500.000 deaths each year worldwide. Streptococcal pyrogenic exotoxin B (SpeB) is a cysteine protease found in mos strains of GAS infection and plays different roles in its pathogenicity. SpeB contributes to pathogenicity by degrading many proteins such as immunoglobulin, plasminogen and fibrinogen. Aptamers are single stranded DNA or RNA molecules that can recognize their targets with high affinity and specificity. The first aim of the project is to produce recombinant active SpeB, the second goal is to develop DNA aptamers that can recognize SpeB in serum with high specificity. MATERIALS and METHODS: Recombinant SpeB was produced in E.coli Rosetta2. SpeB was purified by cation exchange chromatography. Activity of SpeB was determined by azocasein assay.Aptamers were developed by beadbased SELEX. Candidate aptamers were selected using MEME-SUIT, MFOLD and CLUSTALW programs.

RESULTS: Approximately $1.5 \mathrm{mg}$ of recombinant SpeB was obtained from 50 $\mathrm{mL}$ of bacterial cell culture. The activity of SpeB was calculated to be $270 \mathrm{U} / \mathrm{mg}$. Five aptamers were selected for further studies and their secondary structures of these aptamers were determined.

CONCLUSIONS: As a result of the study, DNA aptamers were developed to recognize SpeB in serum.The aptamer which shows the highest affinity among the developed aptamers, can be used for the diagnosis of GAS infection.

Keywords: SpeB, SELEX, Aptamer, \{Streptococcus Pyogenes\}, GAS infection

\section{OP-134}

\section{DIAGNOSTIC VALUE OF SERUM GALECTIN-3 IN ENDOMETRIOSIS}

\section{Sema Misir}

Sivas Cumhuriyet University, Faculty of Pharmacy, Department of Biochemistry, Sivas, Turkey

OBJECTIVES: Endometriosis (EM), an estrogen-dependent inflammatory and immune-associated disease, is defined by the presence of endometrial glands and stroma grow in areas outside the uterus. A simple blood test for endometriosisspecific biomarkers would offer a more timely accurate diagnosis of the disease and could lead to earlier treatment intervention. The pathophysiology of endometriosis is still not fully understood. Galectin-3 is a essential protein that play vital roles in many biological processes, such as cell growth, differentiation, apoptosis, angiogenesis, inflammation, and tumour progression. The aim of this study is to evaluate galectin-3 expression levels on the development of endometriotic lesions in peripheral blood (PB).

MATERIALS and METHODS: PB samples from 70 female patients that underwent surgery were treated and were diagnosed with endometriosis according to the histopathological evaluation of the biopsy material and 50 healthy cases that had no concomitant malignancy or chronic inflammatory diseases were used in the study. Expression levels of galectin-3 were performed by quantitative realtime polymerase chain reaction (qRT-PCR) and Elisa assay.

RESULTS: All of the results showed that galectin-3 expression levels were increased significantly in the endometriosis patients compared to the control group $(\mathrm{p}<0.05)$.

CONCLUSIONS: Serum galectin-3 level may have a potential role in the development of endometriosis and treatment target for endometriosis. It is clear that more work is needed in this area.

Keywords: Endometriosis, Galectin-3, Non-invasive Diagnosis

\section{OP-135 \\ PRODUCTION OF RNA-BASED SARS-COV-2 VIRUS REFERENCE MATERIAL FOR RT-QPCR TESTS}

Sema Akyurek, Sumeyra Nur Sanal Demirci, Zeynep Bayrak, Alper Isleyen, Muslum Akgoz

TUBITAK National Metrology Institute, Kocaeli, Turkey

OBJECTIVES: The purpose is the production of RNA-based reference material to meet the quality requirements in the measurements made with Reverse Transcription - Real Time Polymerase Chain Reaction (RT-qPCR) of SARSCoV-2 (2019-nCoV) virus.

MATERIALS and METHODS: RNA-based reference material has been produced to be used in the measurements of the SARS-CoV-2 virus with RT-qPCR. The reference material produced contains fragments corresponding to 10 different SARS-CoV-2 gene regions and human RNaseP gene region published by the World Health Organization for RT-qPCR tests.

RESULTS: RNA-based reference material was produced for the control of both steps in the RT-qPCR measurements of the SARS-CoV-2 virus.

CONCLUSIONS: For RT-qPCR measurements of the SARS-CoV-2 virus, the RNA-based reference material produced is suitable for use as a positive quality control material in the laboratory's method development studies, method validation, method verification of test kits and comparison of different methods and PCR designs.

With the infrastructure and technical experience developed in TUBITAK UME Laboratories, production of new RNA-based reference materials can be completed in a very short time in case of;

i) a new RT-qPCR design containing a different gene region of the SARS-CoV-2 
virus is required,

ii) mutations occur on the the SARS-CoV-2 virus,

iii) emergence of a completely new virus.

RNA-based reference materials available for sale in frozen (UME RM 2019) and lyophilized (UME RM 2020) form can be ordered from the link below. Lyophilized form can be delivered to customers without any cooling.

(https://rm.ume.tubitak.gov.tr/urun_grup.aspx?p=4).

We would like to thank Eastern Marmara Development Agency for the project support with reference number TR42/20/COVID/0035.

Keywords: COVID-19, SARS-CoV-2, 2019-nCoV, RT-qPCR

\section{OP-136 \\ DETERMINATION OF SALIVARY LEVELS OF ALKALINE \\ PHOSPHATASE (ALP), C-TERMINAL TELOPEPTIDE (CTX), \\ OSTEOCALCIN AND SCLEROSTIN GEN EXPRESSIONS IN DIFFERENT AGE GROUPS BY REAL TIME PCR}

Aslihan Coban $^{1}$, Erdal Ergunol ${ }^{2}$, Aylin Sepici Dincel $^{1}$

${ }^{1}$ Department of Medical Biochemistry, Faculty of Medicine, Gazi University, Ankara, Turkey

${ }^{2}$ Department of Oral and Maxillofaxial Surgery, Faculty of Dentistry, Health and Social Sciences University, Guzelyurt, Faculty of Dentistry, International Cyprus University, Nicosia, TRNC

OBJECTIVES: The aim of this study was to investigate the levels of alkaline phosphatase, osteocalcin, C-terminal telopeptide as a destruction marker and sclerostin as a bone formation inhibitor in all individuals using saliva samples that do not require an invasive procedure.

MATERIALS and METHODS: In our study, tubes called Saliva RNA Collection and Preservation Devices, which prevent the degradation of RNA at room temperature for two months during the sample collection and storage phase, and which provide high analytical performance, are used. After saliva RNA isolation, cDNA synthesis was performed using qPCR and cDNA quantitation was performed. SOST for sclerostin, COL1A1 for C-terminal telopeptide, BGLAP for osteocalcin, APLP for alkaline phosphatase were designed and the amount of bone resorption biomarkers was determined by qPCR. In order to determine the optimum working range of each primer, melting curve analyzes were performed and the PCR method was validated accordingly. Melting point and gene expression were determined.

RESULTS: Before the polymerase chain reaction, we determined that cDNA concentrations of 300-700 ng / $\mu \mathrm{L}$ and OD 260/280 of all samples were in the range of $1.8 \pm 0.1$. According to the data analysis, although sclerostin, $\mathrm{C}$-terminal telopeptide and alkaline phosphatase levels were found to be low, the presence of gene expression was observed from the saliva sample. However, the dimer formation occurring in the melting temperature curve indicates that primer design optimization should be made.

CONCLUSIONS: Sclerostin, C-terminal telopeptide and alkaline phosphatase were obtained from saliva regardless of age, and osteocalcin could not be detected. Although it was seen that new primers used for PCR should be designed, when evaluated within this scope, the emission of all parameters except osteocalcin was considered to be significant and it was decided that there were biomarkers to be detected in saliva. These data may have an effective role in the diagnosis and treatment follow-up of diseases associated with bone metabolism. Keywords: Biomarker, Saliva, Sclerostin, Alkaline Phosphatase, C-Terminal Telopeptide

\section{OP-137 \\ INVESTIGATION OF THE EFFECT OF GONADOTROPIN \\ TREATMENT FOR SUPEROVULATION ON THE EXPRESSION OF PROTEINS THAT HAVE A ROLE IN THE PIRNA PATHWAY IN A MOUSE MODEL}

Ismail Sari ${ }^{1}$, Erkan Gumus ${ }^{2}$, Ahmet Sevki Taskiran³ ${ }^{3}$ Lale Karakoc Sokmensuer ${ }^{1}$ Department of Medical Biochemistry, Faculty of Medicine, Nigde Omer Halis Demir University, Nigde, Turkey

${ }^{2}$ Department of Histology and Embryology, Faculty of Medicine, Aydin Adnan Menderes University, Aydin, Turkey

${ }^{3}$ Department of Physiology, Faculty of Medicine, Sivas Cumhuriyet University, Sivas, Turkey

${ }^{4}$ Department of Histology and Embryology, Faculty of Medicine, Hacettepe University, Ankara, Turkey

OBJECTIVES: The piRNA pathway is crucial for early development, epigenetic regulation, gametogenesis, tumorigenesis, and silencing of transposons. The aim of this study is to examine whether there is an effect of different doses of PMSG / $\mathrm{hCG}$ and repeated ovarian stimulafion (OS) on the expression of the Mili, Miwi, Mael, Tdrd1, Tdrd9, Mitopld.

MATERIALS and METHODS: Female mice in the experiment I was injected with 5 i.u. (group I), 7.5 i.u. (group II), 10 i.u. (group III), 12.5 i.u. (group IV) PMSG followed 48 hour later by $5,7.5,10,12.5$ i.u. hCG to each group, respectively. Controls (group V) was injected twice with $0.1 \mathrm{ml}$ sterile serum physiologic isotonic solution. Female mice in experiment II were stimulated with 5 i.u. PMSG/hCG at 1-week intervals for 3 weeks (Group 6-8). Mili, Miwi, Mael, Tdrd1, Tdrd9, Mitopld gene, and protein expression levels were determined in the M2 oocyte and ovarian tissues by qPCR and immunofluorescence method, respectively. Furthermore, plasma levels of 17- $\beta$ estradiol of the study groups were determined by ELISA. RESULTS: Plasma E2 levels were most increased in group III among dosedependent groups and in group VI among repeated stimulation groups. It was found that Tdrd9, Tdrd1, and Mael expressions decreased significantly in groups III and VI, Mitopld, Miwi, and Mili expressions in group 5.

CONCLUSIONS: In conclusion, exogenous gonadotropin administration led to remarkable decreases in expression of Mili, Miwi, Mael, Tdrd1, Tdrd9, MITOPLD, and changes in the expression levels of Tdrd9, Tdrd1, and Mael may associate with plasma E2 levels.

Keywords: Gonadotropin, Ovarian Stimulation, In-vitro Fertilization, piRNA

\section{OP-138 \\ INVESTIGATION OF THE EFFECT OF R381Q IL-23 GENE VARIANT ON DISEASE OCCURRENCE IN CORONARY ARTERY DISEASE}

\author{
Aysegul Basak Teker \\ Giresun University,Department of Molecular Genetic,Giresun, Turkey
}

OBJECTIVES: More and more evidence is being presented that coronary artery disease (CAD), a clinical form of coronary atherosclerosis, is a chronic inflammatory disease. Interleukin-23 (IL-23), an important mediator and modulator of inflammation, is a proinflammatory cytokine. IL-23 plays a role in the regulation of immune responses against infections and tumor development through the activation of the IL-23 respector (IL-23R). As an essential part of the IL-23 / IL-17 axis, IL-23R may also play critical roles in atherosclerosis and diseases related to atherosclerosis. Specific polymorphisms in genes encoding IL-23 and its receptor subunits have recently been consistently found to be associated with chronic immune-mediated diseases. However, the number of studies investigating the relationship between CAD and IL-23R is quite limited. Therefore, in this study, we aimed to evaluate the relationship between R381Q IL-23 receptor gene polymorphism and atherosclerosis.

MATERIALS and METHODS: In this case-control study, a study group of 513 people was examined in terms of IL-23R R381Q polymorphism using the PCRRFLP method.

RESULTS: Only AA and AG genotypes were observed in the study groups. The $\mathrm{G}$ allele was observed only in the patient group. This situation highlights the role of the $\mathrm{G}$ allele in the development of the disease. $(\mathrm{P}=<0.001)$

CONCLUSIONS: Our study confirms the importance of hypertension, smoking, and hyperlipidemia in the pathogenesis of male CAD and indicates that R381Q IL-23 polymorphism is also a risk factor for CAD in the presence of these risk factors. In conclusion, determining IL-23 gene variants can be used as biomarkers for CAD risk.

Keywords: IL-23, Atherosclerosis, Coronary Artery Disease, Polymorphism

\section{OP-139}

\section{DETERMINATION OF CANDIDA SPECIES BY REAL TIME PCR}

Petek Curuk ${ }^{1}$, Erkan Oguz ${ }^{2}$, Mehmet Akif Curuk $^{3}$

Department of Microbiology, Medical Faculty, Cukurova University, Adana, Turkey

${ }^{2}$ Department of Biochemistry, Faculty of Pharmacy, Mersin University, Mersin, Turkey

${ }^{3}$ Department of Biochemistry, Medical Faculty, Cukurova University, Adana, Turkey

OBJECTIVES: The number of invasive candidiasis cases has risen especially with an increase in the number of immunosuppressed and immunocompromised patients in hospitals. This study aims to develop a new method for the detection, identification and quantitation of medically important Candida species through quantitative polymerase chain reaction (qPCR).

MATERIALS and METHODS: A couple of spesific primers were used for amplification of ITS-1 or ITS-2 fragments. Real Time Polymerase Chain Reaction (PCR) and consecutive High Resolution Melting Analysis (HRMA) was used for the detection and differentiation of Candida species from colony and oral rinse solutions.

RESULTS: Candida species were successfully detected, identified and quantitated based on the ITS-1 or ITS- 2 genes. This procedure proved appropriate for discrimination of the 6 most relevant Candida species (C. albicans, C. Dubliniensis, C. Glabrata, C. Krusei, C. Parapsilosis, C. tropicalis) in one PCR tube.

CONCLUSIONS: Real-time PCR followed by HRMA is a simple, rapid and inexpensive tool to identify Candida species. Correct identification of this species is important for targeted antifungal therapy and for epidemiological purposes. Keywords: Candidiasis, Real Time PCR-HRMA 


\section{OP-140 \\ LONG-TERM STABILIZATION OF RNU6 USED IN NORMALIZATION IN MICRORNA MEASUREMENTS}

Yakup Dulgeroglu

Kulu State Hospital, Medical Biochemistry Laboratory, Konya, Turkey

OBJECTIVES: The aim of this study was to investigate the long-term stability of RNU6 used in normalization as an endogenous control in micro RNA measurements at $-80^{\circ} \mathrm{C}$

MATERIALS and METHODS: RNU6 levels were measured in the qRT-PCR device using Qiagen brand kits in 50 serum samples collected within the scope of a scientific study completed in 2013. Then, samples were stored for 5 years at $-80^{\circ} \mathrm{C}$. In 2018 , measurements were repeated using the same brand kits. Whether there is a statistical difference between these two results was analyzed with the paired sample T test.

RESULTS: While the average threshold cycle $(\mathrm{Ct})$ in RNU6 measurements was 32.74 in 2013 , it was determined as 34.44 in 2018. In the measurements made in 2018, an increase of $5.69 \%$ was observed in $\mathrm{Ct}$ values. Therefore, the amount of RNU6 decreased in samples stored at $-80^{\circ} \mathrm{C}$ for 5 years. This difference was found to be significant in the statistical analysis $(\mathrm{p}<0.001)$. CONCLUSIONS: In some studies in the literature, it was reported that the serum levels of miRNAs decreased within 24 hours at room temperature, but did not change even after 4 years at $-80^{\circ} \mathrm{C}$. However, the $5.69 \%$ increase in $\mathrm{Ct}$ values observed in our study showed that RNU6 serum levels decreased. It was evaluated that it would be more appropriate to use exogenous controls such as ce-miR-39 instead of endogenous controls such as RNU6 for normalization in miRNA studies to be carried out with samples stored for a long time. Keywords: RNU6, Long-Term Stabilization

\section{OP-141 \\ ERYTHROCYTE REDUCED/OXIDIZED GLUTATHIONE AND SERUM THIOL/DISULFIDE HOMEOSTASIS IN PATIENTS WITH AGE- RELATED MACULAR DEGENERATION}

Serdar Bilici ${ }^{1}$, Mehmed Ugur Isik ${ }^{2}$, Murat Alisik ${ }^{3}$

${ }^{1}$ Department of Ophthalmology, Kahramankazan State Hospital, Ankara, Turkey ${ }^{2}$ Department of Ophthalmology, Kastamonu University, Kastamonu, Turkey ${ }^{3}$ Department of Medical Biochemistry, Bolu Abant Izzet Baysal University, Bolu, Turkey

OBJECTIVES: Age-related macular degeneration (AMD) is characterized by a progressive degenerative disease of the macula. It was aimed to evaluate the relationship between AMD and oxidative damage by measuring extracellular disulphide/thiol $(\mathrm{SS} / \mathrm{SH})$ levels and intracellular oxidized/reduced glutathione (GSSG/GSH) levels, and to compare these parameters in non-exudative/ exudative AMD patients and healthy individuals.

MATERIALS and METHODS: 30 non-exudative AMD, 28 exudative AMD, and 36 age-matched healthy control subjects enrolled to the study. Participants' serum native $\mathrm{SH}$, total $\mathrm{SH}$, and $\mathrm{SS}$ amounts and erythrocyte native GSH, total GSH, and GSSG levels were determined and expressed as $\mu \mathrm{mol} / \mathrm{L}$. SS/SH, GSSG/GSH percent ratios were calculated.

RESULTS: In comparison with the control group both non-exudative and exudative AMD patients had higher disulfide levels (20.5(4.8) vs 15.4(3.1), $\mathrm{p}<0.001$ and $22.5(7.5)$ vs $15.4(3.1), \mathrm{p}<0.001$; respectively) and higher SS/ SH (6.64(2.57) vs 5.4(1.9), $\mathrm{p}=0,002$ and 7.05(3.14) vs 5.4(1.9), $\mathrm{p}<0.001$; respectively), in addition to higher GSSG levels (64.6(40.8) vs 27.3(21.9), $\mathrm{p}=0.015$ and $73.9(44.1)$ vs $27.3(21.9), \mathrm{p}=0.002$; respectively) and higher GSSG/ GSH ratio $(6.48(8.35)$ vs $3.14(3.31), p=0,034$ and $10.21(10.28)$ vs $3.14(3.31)$, $\mathrm{p}=0,003$; respectively). However, there was no significant difference between non-exudative and exudative AMD groups in these parameters. There was not significant difference between groups in term of total thiol; native thiol; total GSH and native GSH ( $>>0,05$ for all).

CONCLUSIONS: Greater extent of both extracellular thiol and intracellular glutathione consumption occurred in AMD patients compared to age-matched healthy controls indicates the role of decreased antioxidant status in AMD development. Further studies are needed to confirm the pathophysiologic role of homeostasis in these buffer systems in AMD.

Keywords: Age-Related Macular Degeneration, Disulfide, Thiol, Glutathione

\section{OP-142}

\section{RELATIONSHIP AMONG LIPID PEROXIDATION, ANTIOXIDANT}

\section{ENZYMES AND TUMOR MARKERS IN VARIOUS CANCER TYPES}

Ahmet Alpay Koylu

Katip Celebi Universty, Ataturk Research and Training Hospital, Izmir, Turkey

OBJECTIVES: It has been reported that oxidant radicals and oxidative stress may be increased in patients with cancer studies on the oxidant-antioxidant balance status of the organism. In this study, relationships among lipid peroxidation, antioxidant enzymes and tumor markers in various cancer types were investigated. MATERIALS and METHODS: Newly diagnosed without medical or surgical treatment ninety-two cancer patients [ lung cancer $\mathrm{n}=12$, breast cancer $\mathrm{n}=14$, gastrointestinal cancer $n=49$ and genitourinery cancer $n=17$ ] and 39 healthy subjects were enrolled into the study. Erythrocyte glutathione, glutathione peroxidase, glutahtione reductase, superoxide dismutase and plasma total antioxidant status as antioxidant indicators and malondialdehyde as an erythrocyte lipid peroxidation and indicator were studied. CEA, AFP, CA 19-9, CA 15-3 and CA 125 as tumor markers were also evaluated in both healty and patient groups. RESULTS: Plasma total antioxidant level in the cancer patients was significantly lower than the control group $(\mathrm{p}<0.001)$. Erythrocyte GSH, GSH-Px, GSH-Rx, SOD and malondialdehyde (MDA), levels in the cancer patients were significantly higher than the control group (respectively $\mathrm{p}<0.001, \mathrm{p}<0.001, \mathrm{p}<0.01, \mathrm{p}<0.001$ ). There were not found statistically relationships among tumor markers and antioxidant-oxidant parameters in cancer patients $(\mathrm{p}>0.05)$.

CONCLUSIONS: Although glutathione, glutathione peroxidase, glutathione reductase and superoxide dismutase levels were found elevated as well as malondialdehyde levels, it may be shown the presence of increased free radical and lipid peroxidation in excess of the adaptive protection system capacity of cancer metabolism. Whether the increased lipid peroxidation level is a cause or a consequence has not been fully eluciated. This may be shown the increased oxidative stres. Reducing endogenous sources and environmental carcinogen that will cause oxidative stress is very important for avoiding free radical formation and cancer prevention.

Keywords: Lipid Peroxidation, Antioxidant, Tumor Marker, Cancer

\section{OP-143 \\ ASSOCIATION BETWEEN OXIDATIVE DNA DAMAGE AND IRON STATUS IN WOMEN WITH GESTATIONAL DIABETES MELLITUS}

Mehmet Oguz Erbagci' ${ }^{1}$, Gamze Tuna², Semir Kose ${ }^{3}$,

Nazli Ecem Dal Bekar ${ }^{2}$, Merve Akis ${ }^{4}$, Melis Kant ${ }^{5}$, Sabahattin Altunyurt ${ }^{3}$, Gul Huray Islekel

'Department of Medical Biochemistry, Sanliurfa Suruc State Hospital, Sanliurfa, Turkey

${ }^{2}$ Department of Molecular Medicine, Institute of Health Sciences, Dokuz Eylul University, Izmir, Turkey

${ }^{3}$ Division of Perinatology, Department of Obstetrics and Gynecology, Dokuz Eylul University School of Medicine, Izmir, Turkey

${ }^{4}$ Department of Biochemistry, Balikesir University, Faculty of Medicine, Balikesir, Turkey

${ }^{5}$ Department of Medical Biochemistry, School of Medicine, Dokuz Eylul University, Izmir, Turkey

OBJECTIVES: To assess the relationship between oxidative DNA damage an iron status in women with gestational diabetes mellitus (GDM) compared to those with normal glucose tolerance in the first and the second trimesters of pregnancy. MATERIALS and METHODS: In this prospectively designed cohort study, maternal serum and urine samples were collected in the 11th-14th weeks and the 24th-28th weeks of gestation. In addition to oral glucose tolerance test in the second trimester, fasting blood glucose, $\mathrm{HbAlc}$, ferritin and hemoglobin levels were measured in blood samples. Urinary levels of oxidative DNA damage products 8-hydroxy-2'-deoxyguanosine (8-OH-dG) and 8,5'-cyclo-2'deoxyadenosines (S-cdA, R-cdA) were determined using liquid chromatography tandem mass spectrometry.

RESULTS: In the first trimester, urinary 8-OH-dG levels were found higher in the GDM group $(n=33)$ than in the control group $(n=84)(p=0.006)$. The increased $8-\mathrm{OH}-\mathrm{dG}$ level in first trimester was found to be associated with 2.71 times increased risk of developing GDM $(\mathrm{p}=0.028)$. When the cases were stratified according to their first trimester ferritin levels, women with $\geq 50$ th centile $(\geq 13,0$ $\mathrm{ng} / \mathrm{mL}$ ) demonstrated higher levels of 8-OH-dG and R-cdA than those under $<50$ th centile $(\mathrm{p}=0.034, \mathrm{p}=0.009)$. In the GDM group, there was a positive correlation between the second trimester $8-\mathrm{OH}-\mathrm{dG}$ and ferritin and 1st-hour glucose levels $(p=0.014, p=0.020)$

CONCLUSIONS: This is the first study where oxidative DNA damage is evaluated in both early and late periods of pregnancy. Our findings reveal an association between GDM and iron status and oxidative DNA damage. Keywords: Gestational Diabetes Mellitus, Oxidative Stress, Oxidatively Induced DNA Damage, Iron, Ferritin

\section{OP-144 \\ THE RELATIONSHIP BETWEEN SERUM APELIN LEVELS, THIOL- DISULFIDE BALANCE AND ALBUMINURIA IN PATIENTS WITH DIABETIC NEPHROPATHY}

Umran Gezici Gunes ${ }^{1}$, Huseyin Erdal ${ }^{2}$, Serdar Dogan ${ }^{3}$, Faruk Turgut ${ }^{1}$ 'Department of Internal Medicine, Hatay Mustafa Kemal University, Hatay, Turkey

${ }^{2}$ Department of Medical Genetics, Aksaray University, Aksaray, Turkey ${ }^{3}$ Department of Medical Biochemistry, Hatay Mustafa Kemal University, Hatay, Turkey

OBJECTIVES: The aim of this study is to evaluate the levels of apelin, dynamic thiol / disulfide balance and albuminuria in patients with type 2 diabetes. 
MATERIALS and METHODS: 87 patients and 24 control groups were included in the study. Fasting blood samples were taken from patient and control groups. Thiol levels were measured by the colorimetric method developed by Erel et al. Biochemistry parameters were measured by a spectrophotometric method in an autoanalyzer. GFR levels were calculated according to the creatinine-based CKD-EPI formula. Apelin levels were studied by ELISA method.

RESULTS: Native and total thiol levels were found to be significantly lower in patient group compared to the control group ( $p=0.001$ for both). On the other hand, disulfide levels were found to be similar between the patient and control groups $(p=0.182, p=0.119)$. Serum apelin levels were found to be significantly lower in patient group compared to control group $(p<0.001)$. A negative correlation was found between native thiol, total thiol and apelin levels and age. Negative correlation was found between native thiol, total thiol, apelin levels and glucose, HbAlc and albuminuria. Besides, native thiol showed a positive correlation with total thiol, apelin levels and GFR.

CONCLUSIONS: Colorimetric measurement of thiol levels can contribute to diagnosis and follow-up of the disease as a marker due to its easy application in clinical biochemistry laboratories and its relationship with disease severity in CKD. The Apelin / APJ system is thought to play a role in the pathogenesis of diabetes and its complications.

Keywords: Dynamic Thiol / Disulfide Balance, Apelin, Diabetic Nephropathy, Microalbuminuria, Diabetes Mellitus

\section{OP-145 \\ THE PROTECTIVE EFFECT OF CARDAMOM AND BROCCOLI ON HEART ISCHEMIA-REPERFUSION INJURY OF RATS UNDERGOING OVARIECTOMY}

Mehmet Ozyurt $^{1}$, Mahmut Ay ${ }^{1}$, Busra Citil ${ }^{1}$, Ergul Belge Kurutas ${ }^{1}$,

Mehmet Fatih Yuzbasioglu ${ }^{2}$, Sevgi Bakaris ${ }^{3}$

${ }^{1}$ Department of Medical Biochemistry, Faculty of Medicine, Kahramanmaras

Sutcu Imam University, Kahramanmaras, Turkey

${ }^{2}$ Department of General Surgery, Faculty of Medicine, Kahramanmaras Sutcu Imam University, Kahramanmaras, Turkey

${ }^{3}$ Department of Pathology, Adana City Training and Research Hospital, Adana,

Turkey

OBJECTIVES: In this study, it was aimed to evaluate the combined effect of cardamom and broccoli on cardiac ischemia-reperfusion (I / R) damage in rats undergoing ovariectomy.

MATERIALS and METHODS: 40 adult female rats were selected for the study. Rats divided into five equal groups; Control group, Ovariectomy group, Only I / R group, Ovariectomy + I/ R + Serum Physiological group, Ovariectomy + $\mathrm{I} / \mathrm{R}+$ Treatment group. Ovaries of the ovariectomy groups were removed 14 days ago. In other groups, the abdomen was opened and closed. For 14 days, 1 $\mathrm{mL}$ of cardamom $(25 \mathrm{mg} / \mathrm{kg})+$ broccoli $(25 \mathrm{mg} / \mathrm{kg})$ extracts were combined to the treatment group. Group IV $1 \mathrm{~mL} 0.9 \% \mathrm{NaCl}$ was given for the same period. After 14 days, 10 minutes of ischemia and 10 minutes of reperfusion were applied to the hearts of rats in the ischemia-reperfusion groups. Creatine kinase (CKMB) levels in plasma were measured by taking blood from all groups. Animals were sacrificed, heart tissues were removed, and oxidative stress parameters were measured spectrophotometrically.

RESULTS: MDA levels increased, SOD and CAT activities decreased $(\mathrm{p}<0.001)$ and severe tissue damage was observed in the I / R group compared to the sham group $(\mathrm{p}<0.001)$. Combined therapy significantly improved heart damage, and MDA levels approached control group levels $(\mathrm{p}<0.001)$. Combined therapy also increased SOD and CAT activities.

CONCLUSIONS: It was thought that combined therapy may be effective in reducing oxidative stress and tissue damage due to cardiac I / R injury.

Keywords: Ischemia-Reperfusion, Heart, Ovariectomy, Oxidative Stress

\section{OP-146 \\ THE EFFECTS OF OXIDATIVE DAMAGE INDUCED BY BLADDER ISCHEMIA REPERFUSION DAMAGE ON FAR TISSUES AND THE PROTECTIVE ROLE OF CARDAMOM EXTRACT}

Mujde Aksimsek $^{1}$, Busra Citil $^{2}$, Mehmet Ozyurt ${ }^{2}$, Ayse Humeyra Hayber ${ }^{1}$, Ergul Belge Kurutas ${ }^{2}$

${ }^{1}$ Sutcu Imam University, Department of Bioengineering, Kahramanmaras,

Turkey

${ }^{2}$ Sutcu Imam University, Department of Medical Biochemistry, Kahramanmaras, Turkey

OBJECTIVES: ischemia reperfusion injury is blamed for the etiopathogenesis of atherosclerosis, myocardial infarction, neurodegenerative diseases and chronic liver diseases. However, it is not fully known whether ischemia-reperfusion injury to the bladder cause distant tissue damage. in this study, the effects of oxidative damage induced by bladder ischemia reperfusion injury on distant tissue (heart and kidney tissues) and the protective role of cardamom extract were investigated.

MATERIALS and METHODS: Wistar rats were randomly allocated into three groups. Groups; only ischemia reperfusion group, sham group and treatment group (50 mg / $\mathrm{kg}$ cardamom). Cardamom extract and saline were given to the treatment and sham groups one day before the I/R injury was created. 30 minutes of ischemia and 30 minutes of repefusion were applied to the bladder with the aid of a clamp. At the end of the experiment, heart and kidney tissues were removed to detect distant tissue damage. Malondialdehyde (MDA) levels, catalase (CAT) and superoxide dismutase (SOD) activities were determined spectrophotometrically in these tissues. RESULTS: Increased MDA levels including sham,decreased SOD and CAT activies $(\mathrm{p}<0.001)$ and severe tissue damage were observed in the I/R group ( $p$ $<0.001$ ). It was observed that cardamom treatment significantly reduced distant tissue damage (heart and kidney). MDA levels approached the levels of sham group $(\mathrm{p}<0.001)$. Cardamom treatment also increased SOD and CAT activities CONCLUSIONS: It was thought that cardamom treatment might be effective in reducing distant tissue damage of oxidative stress induced by bladder ischemia reperfusion.

Keywords: Oxidative Stress, Bladder, Cardamom

\section{OP-147 \\ THE EFFECT OF S-ADENOSYLMETHIONINE ON LIVER LESIONS
AND OXIDATIVE STRESS INDUCED BY A HIGH FAT AND HIGH CHOLESTEROL DIET}

Ilknur Bingul

Department of Medical Biochemistry, Istanbul Faculty of Medicine, Istanbul University, Istanbul, Turkey

OBJECTIVES: Steatosis makes liver susceptible to oxidative stress, inflammation, cytokines, and triggers the formation of NASH and advanced lesions. S-adenosylmethionine (SAM) is the main methyl group donor, has antioxidant and anti-inflammatory effects, and regulates phosphatidylcholine synthesis. It has been suggested that changes in hepatic SAM levels are related to NASH pathogenesis. However, experimental studies on effects of SAM in NASH are limited. In our study, changes in SAM levels in a high-fat and cholesterol (HFHC) diet-induced NASH model, and the effect of SAM in preventing NASH formation and progression were investigated.

MATERIALS and METHODS: Female guinea pigs under HFHC-diet for 6 weeks, were injected SAM $(50 \mathrm{mg} / \mathrm{kg} ; 5$ times/week; intraperitoneally). Serum transaminases (ALT, AST), cholesterol, triglyceride, insulin resistance (HOMAIR), inflammatory cytokines (TNF- $\alpha$, IL-6) levels were determined. Hepatic cholesterol, triglyceride, SAM, reactive oxygen species (ROS), malondialdehyde (MDA), diene conjugate (DC), protein carbonyl (PC), glutathione (GSH) and antioxidant power (FRAP) levels were determined.

RESULTS: HFHC-diet increased ALT $(p=0.005)$, AST $(p=0.000)$, TNF- $\alpha$ $(\mathrm{p}=0.024)$, cholesterol $(\mathrm{p}=0.004)$, triglyceride $((\mathrm{p}=0.001)$, levels in serum, but HOMA-IR did not change. Hepatic levels of cholesterol $(\mathrm{p}=0.000)$, triglyceride $(p=0.000), \operatorname{ROS}(p=0.000), \operatorname{MDA}(p=0.010), D C(p=0.000), P C(p=0.035)$, and SAM $(\mathrm{p}=0.004)$, FRAP $(\mathrm{p}=0.004)$ decreased significantly. SAM treatment during HFHC-diet lowered ALT $(\mathrm{p}=0.000)$, AST $(\mathrm{p}=0.005)$ activities, hepatic triglyceride $(p=0.019)$, ROS $(p=0.000)$, MDA $(p=0.004)$, DC $(p=0.018)$, PC $(p=0.046)$, and increased SAM $(p=0.025), \operatorname{GSH}(p=0.002)$ and FRAP $(p=0.006)$ levels.

CONCLUSIONS: SAM treatment may be effective in preventing NASH formation by suppression of steatosis and oxidative stress.

Keywords: S-Adenosylmethionine, Nonalcoholic Steatohepatitis, Oxidative Stress, Liver; Guinea Pigs

\section{OP-148 \\ ION-BEAM RADIATION DAMAGE TO DNA BY INVESTIGATION OF FREE RADICAL FORMATION AND BASE DAMAGE}

Melis Kant ${ }^{1}$, Pawel Jaruga ${ }^{1}$, Erdem Coskun ${ }^{2}$, Samuel Ward ${ }^{3}$

Alexander D. Stark ${ }^{3}$, David Becker ${ }^{3}$, Amitava Adhikary $^{3}$, Micheal D. Sevilla $^{3}$,

Miral Dizdaroglu ${ }^{1}$

${ }^{1}$ Biomolecular Measurement Division, National Institute of Standards and Technology, Gaithersburg, MD, 20899, USA

${ }^{2}$ Institute for Bioscience and Biotechnology Research (IBBR), University of Maryland, Rockville, MD 20850, USA

${ }^{3}$ Department of Chemistry, Oakland University, Rochester, MI 48309, USA

OBJECTIVES: This work investigated the physicochemical processes and DNA base products involved in Ne-22 ion-beam (ca. $1.4 \mathrm{GeV}$ ) radiation damage to hydrated (12 waters/nucleotide) salmon sperm DNA. MATERIALS and METHODS: For this purpose, approximately 12 small (10 $\mathrm{mm} \times 4 \mathrm{~mm} \times 1 \mathrm{~mm}$ ) samples were stacked in a sample packet and then ionbeam irradiated at $77 \mathrm{~K}$. Free radicals trapped in ion-beam irradiated DNA at $77 \mathrm{~K}$ were elucidated using electron spin resonance (ESR) spectroscopy. After warming the samples to room temperature, the measurement of DNA base damage by gas chromatography-tandem mass spectrometry (GC-MS/MS) and liquid chromatography-tandem mass spectrometry (LC-MS/MS) with isotope dilution revealed the formation of a plethora of products and also the formation of $8,5^{\prime}$-cyclopurine-2'-deoxynucleosides.

RESULTS: This work is the first to use the combination of ESR spectroscopy 
and mass spectrometry, enabling a better understanding of the mechanisms of radiation damage to DNA along the ion-beam track in terms of the formation of DNA free radicals and products. ESR measurements showed that, as the linear energy transfer (LET) profile of ion-beam radiation increases, the production of cation, anion and neutral radicals of DNA increases along the ion-beam track. The yields of DNA damage products along the ion-beam track were in excellent agreement with the radical production.

CONCLUSIONS: The probability of recombination of DNA radicals in the core increases due to the rise in concentration of proximate ion radicals, the location of the highest energy deposition, the Bragg peak, may show different damage and may not be the location of the maximum damage.

Acknowledgement: NIH NCI grant R01CA04542, REF from CBR, OU, National Science Foundation under Grant No. CHE-1920110.

Keywords: Heavy Ion Therapy, Proton Therapy, Bragg Peak, DNA Damage, Free Radicals

\section{OP-149 \\ APOPTOTIC CELL INJURY IN BRAIN ISCHEMIA REPERFUSION MODEL INDUCED BY COPPER OXIDE NANOPARTICLE IN RATS}

Hadi Karimkhani

Istanbul Okan university, Istanbul, Turkey

OBJECTIVES: Brain ischemia/reperfusion (I/R) injury is an increasingly common cause of morbidity and mortality. Brain damage occurs when exposed to copper oxide nanoparticles (CuO-NP). $\mathrm{CuO}-\mathrm{NP}$ is used for different purposes in many industries. In this study; making a partial (I/R) brain model in rats given $\mathrm{CuO}-\mathrm{NP}$, the damage caused was examined at the cellular level and the systems affecting this damage were investigated.

MATERIALS and METHODS: 40 male Wistar Albino rats, aged 6-8 weeks, 250-300 g were divided into 4 groups in the experiment: 1. Control, 2. Brain I/R, 3. CuO-NP (200 mg/kg), 4. CuO-NP $(200 \mathrm{mg} / \mathrm{kg})+$ Brain I/R. In the serum of all rats; Myelin Basic Protein (MBP), S-100 Calcium Binding Protein B (S100B), Neuro-filament light protein (NEFL), Neuron Specific Enolase (NSE) and in brain tissues; BCL-2, Cytochrome C (Cyt-C), Calpain (CAPAN1), TNF- $\alpha$, Caspase-3, MDA, CAT levels were measured. RESULTS: In the serum of the CuO-NP + Brain (I/R) group according to the CuO-NP and Brain I/R groups; In MBP, S-100, NEFL, and brain tissue; Cyt-C, CAPAN1, TNF- $\alpha$, Caspase-3, MDA levels increased and BCL-2, CAT levels were decreased.

CONCLUSIONS: We investigated neuroapoptosis injury after $\mathrm{CuO}-\mathrm{NP}$ and Brain (I/R). It was also concluded that in brain cells the mitochondrial pathway of apoptosis is activated. Based on our findings we have obtained from the results of this study, our goal in future studies; It will develop antiapoptotic treatment strategies to reduce the damages of $\mathrm{CuO}-\mathrm{NPs}$ entering the organism through different ways such as water, food, cosmetic products, medicines, and drug delivery systems.

Acknowledgements: This work was supported by The Scientific and Technological Research Council of Turkey (TUBITAK) 3001.

Keywords: Copper Oxide Nanoparticle (Cuo-NP), Brain Ischemia Reperfusion (I/R), Rat

\section{OP-150}

\section{EFFECTS OF BROMELAIN ON OXIDATIVE STRESS PARAMETERS}

\section{IN METHOTREXATE-INDUCED CARDIAC OXIDATIVE DAMAGE}

\section{Kursat Kaya}

Pamukkale University, Faculty of Medicine, Department of Medical

Biochemistry, Denizli, Turkey

OBJECTIVES: Methotrexate is an antiproliferative folic acid antagonist used in the treatment of various types of cancer. The serious side effects of methotrexate limit its clinical use. In this study, it was aimed to investigate the potential beneficial effects of bromelain against cardiac oxidative damage in rats treated with methotrexate.

MATERIALS and METHODS: Rats (n:28) were randomly divided into four groups. The first group was kept as a control. A single dose of $20 \mathrm{mg} /$ $\mathrm{kg}$ methotrexate was administered intraperitoneally to the second group. To the third group, $200 \mathrm{mg} / \mathrm{kg} /$ day bromelain was given by gavage for 14 days. Methotrexate and bromelain were given together in the same doses to the fourth group. At the end of the study, heart tissues were taken and TBARS and GSH levels and CAT, SOD and GPX activities were measured. RESULTS: Methotrexate administration didn't cause any change in TBARS and GSH levels compared to the control group, but caused a decrease in SOD, GPx and CAT activities. Bromelain administration with methotrexate resulted in a partial improvement in SOD and CAT activities, but no improvement in GPx activity. In rats treated with bromelain alone, there was an increase in GSH level and SOD, GPx and CAT activities compared to the control group. CONCLUSIONS: Although methotrexate administration didn't cause lipid peroxidation in heart tissue, it caused a decrease in enzymatic antioxidant defense system activity. It was seen that the application of bromelain partially corrected this damage. Therefore, administration of particularly high doses of bromelain may be beneficial in methotrexate-induced oxidative cardiac injury. Keywords: Methotrexate, Bromelain, Cardiac Injury, Oxidative Stress

\section{OP-151 \\ THIOL AND DISULFID LEVELS IN PATIENTS WITH METABOLIC SYNDROME IN THE POSTPRANDIAL PERIOD}

\author{
Serap Ozer Yaman ${ }^{1}$, Fulya Balaban Yucesan ${ }^{1}$, Cihan Orem ${ }^{2}$ \\ ${ }^{1}$ Department of Medical Biochemistry, Faculty of Medicine, Karadeniz \\ Technical University, Trabzon, Turkey \\ ${ }^{2}$ Department of Cardiology, Faculty of Medicine, Karadeniz Technical \\ University, Trabzon, Turkey
}

OBJECTIVES: Postprandial oxidative stress is caused hyperlipidemia and /or hyperglycemia due to lipid and carbohydrate-rich diets. In postprandial period, the increase of these circulating macromolecules affects the organism's redox potential and causes an increase in oxidative stress. Thiol/disulfide homeostasis is used to evaluate the oxidant-antioxidant status of the organism. It was aimed to evaluate oxidant-antioxidant status in postprandial lipemia by applying oral triglyceride tolerance test (OTTT) to Metabolic Syndrome (MetS) subjects.

MATERIALS and METHODS: OTTT was applied to 15 healthy controls and 15 MetS subjects. Blood samples were taken from these subjects at fasting and at 4 th hour after OTTT. Serum thiol and disulfide levels were determined using method developed by Erel and Neselioglu.

RESULTS: The native-thiol levels in MetS in the fasting state were significantly lower than in 4th hour after OFTT $(\mathrm{p}<0.05)$. Native-thiol levels in MetS compared to control were found to be $11.5 \%$ (95\% CI 178 189) lower in MetS in fasting state, and this decrease was $13.8 \%(95 \%$ CI 147-165) in postprandial 4th hour $(p<0.05)$. Disulfide levels increased by $51.6 \%(95 \%$ CI $26.8-39.1)$ in MetS compared to control in fasting state and by $93.5 \%(95 \%$ CI $42.3-65.0)$ in postprandial 4 th hour $(\mathrm{p}<0.05)$ CONCLUSIONS: According to the results in this preliminary study, thiol/ disulfide homeostasis, which is an increased oxidative stress marker, was in the direction of disulfide increase in MetS, while the most significant difference was observed in 4th hour of postprandial period. It was concluded Thiol/disulfide homeostasis may play important role in postprandial lipemia and dyslipidemia. Keywords: Oxidative Stress, Sulfhydryl Compounds, Oral Triglyceride Tolerance Test

\section{OP-152 \\ A RARE INHERITED METABOLIC DISEASE: COMBINED MALONIC AND METHYLMALONIC ACIDURIA}

Sebnem Tekin Neijmann

Health Science University, Bakirkoy Dr. Sadi Konuk Research and Training Hospital, Department of Biochemistry, Istanbul, Turkey

OBJECTIVES: To diagnose rare combined Malonic and Methyl malonic Aciduria (CMAMMA) by urine organic analysis.

Its incidence is at $1 / 30,000$. It occurs on the $16 q 24$ chromosome due to mutations in the ACSF3 gene. Although the excretions of malonic acid and methylmalonic acid are seen in the urine organic acid analysis of the patients, methylmalonic acid levels are higher than malonic acid levels. In addition, 3 hydroxypropionic acid, methyl citric acid and tiglylglycine are not typically seen in urinary organic acid analysis. Although the MA is high, Malonyl CoA decarboxylase enzyme activities are normal. B12 and homocysteine levels from routine laboratory tests are normal in these patients. Since the patients do not comply with MA or MMA clinic as clinical and laboratory findings, they are considered as CMAMMA and the diagnosis should be confirmed by molecular analysis.

MATERIALS and METHODS: 2 months old male patient was referred to our metabolism outpatient clinic with complaints of neuromotor growth retardation, inability to gain weight. Physical examination revealed a short mane neck, a low ear, a short length, a flat sole. Organic acid analysis was performed in urine with GC-MS.

RESULTS: Malonic acid $27.5 \mathrm{mg} / \mathrm{g}$ crea (N:0), MMA $736 \mathrm{mmol} / \mathrm{mol}$ crea $(\mathrm{N}: 0)$, 3-hydroxybutiric acid $12.4 \mathrm{mmol} / \mathrm{mol}$ crea $(\mathrm{N}<11.1)$ and ethylmalonic acid $20.2 \mathrm{mmol} / \mathrm{mol}$ crea $(\mathrm{N}<14.6)$ levels were detected in GC-MS. Malonyl CoA decarboxylase enzyme levels were requested for further analysis. CONCLUSIONS: CMAMMA is a very rare metabolic disease that can be healed by early diagnosis and treatment. A low protein, fat and high carbohydrate diet started for the patient.

Keywords: CMAMMA, GC-MS, Metabolic Disease. 


\section{OP-153}

\section{A RARE VARIANT IN THE ALPHA GLOBIN GENE}

Ozlem Ozbas Demirel ${ }^{1}$, Dogan Yucel $^{2}$

${ }^{1}$ Medical Biochemistry Department, Ankara Health Training and Research Center, Health Sciences University, Ankara, Turkey

${ }^{2}$ Lokman Hekim University, Faculty of Medicine, Department of Medical Biochemistry, Ankara, Turkey

OBJECTIVES: Hemoglobinopathies, caused by mutations in the globin genes, are one of the most common inherited disorders. Many of the hemoglobin variants can be identified by hemoglobin analysis using electrophoresis and high performance liquid chromatography; however Hemoglobin DNA analysis may be necessary in other cases for confirmation.

MATERIALS and METHODS: We report a case of an alpha chain hemoglobin variant, in a 39-year-old man who presented a routine screening test before marriage. RESULTS: His medical history was no significant. Laboratory data showed hemoglobin $(\mathrm{Hb})$ of $16.1 \mathrm{~g} / \mathrm{dL}$, a hematocrit of $47.0 \%$, a mean corpuscular volume of $92.3 \mathrm{fL}$, and mean corpuscular hemoglobin of $31.6 \mathrm{pg}$. Hemoglobin evaluation using capillary zone electrophoresis (CZE) revealed $87.6 \% \mathrm{Hb} \mathrm{A}, 0.8 \% \mathrm{Hb} \mathrm{A} 2$ and a significant amount $(8 \%)$ of an abnormal $\mathrm{Hb}$ peak at the zone 10 . The possibility of degraded $\mathrm{Hb}$ due to pending of the specimen was the initial impression and a repeat $\mathrm{Hb}$ electrophoresis was recommended. Repeat CZE showed $9.2 \%$ of the abnormal $\mathrm{Hb}$ peak at the zone 10 . The result of $\mathrm{HbAlc}$ was $5.2 \%$, measured by ion-exchange HPLC method. DNA sequencing of the whole blood sample detected a c.335C $>$ A mutation, a globin gene variant in the HbA1/A2 gene. CONCLUSIONS: Carriers of this single gene mutation are clinically normal with unremarkable hematological indices. Capillary zone electrophoresis revealed a significant amount of a hemoglobin variant, which was further confirmed by hemoglobin DNA sequencing.

Keywords: Hemoglobinopathies, Alpha Globin Chain Variant.

\section{OP-154}

\section{POSTMORTEM DIAGNOSIS, ALKAPTONURIA: CASE REPORT}

\section{Toygun Anil Ozesen ${ }^{1}$, Kenan Kaya $^{1}$, Ziyaettin Erdem ${ }^{2}$}

${ }^{1}$ Cukurova University, Faculty of Medicine, Forensic Science, Adana, Turkey ${ }^{2}$ Ministry of Justice Forensic Medicine Institute, Adana Forensic Medicine Branch Office, Adana, Turkey

OBJECTIVES: Alkaptonuria is a rare congenital metabolic disease that occurs as a result of homogentisate 1-2dioxygenase enzyme deficiency in tyrosinerelated amino acid metabolism.Homogentisic acid accumulated due to deficiency especially settles in connective tissues and causes brown-black darkening called ochronosis.

MATERIALS and METHODS: In our study,a presumptive diagnosis of Alkaptonuria was considered when the black discoloration was detected,especially in the cartilage tissues of the autopsy case, and the diagnosis was made by examining the samples taken,and it was aimed to discuss the clinical features and the findings obtained from the autopsy. RESULTS: 59-year-old woman found dead in her home and taken to autopsy.It was observed that there were atheroma plaques that narrow the coronary artery lumen slightly to moderately,there was black discoloration in the heart valves, the thyroid cartilage was black,there was a bleeding area on the inner side of the stomach wall corpus, they were black in the sternum and rib sections, and there was a black color change around the pubis.Black pigmentation accumulation was detected in the sternum and lymph node samples in the pathological examination. CONCLUSIONS: Alkaptonuria is one of the rare congenital metabolic disorders. The most important causes of morbidity and mortality are arthropathy and cardiovascular involvement. Although clinical diagnosis is difficult,postmortem findings are remarkable.In our case, the diagnosis was reached, and the family was informed about this issue and they were directed to diagnosis and treatment. It has been observed that autopsy is not only related to determining the cause of death but also to preventive medicine, and biochemical diseases should be taken into consideration during autopsy.

Keywords: Postmortem Diagnosis, Alkaptonuria, Ochronosis

\section{OP-156 \\ INVESTIGATION OF SERUM APELIN, ELEBELA, ENDOGLIN AND METRNL LEVELS IN EXPERIMENTALLY APAP-INDUCED LIVER DAMAGE}

Huseyin Fatih Gul ${ }^{1}$, Mustafa Makav², Turgut Dolanbay

${ }^{1}$ Department of Medical Biochemistry, Kafkas University, Kars, Turkey

${ }^{2}$ Department of Physiology, Kafkas University, Kars, Turkey

${ }^{3}$ Department of Emergency Medicine, Kafkas University, Kars, Turkey

OBJECTIVES: Experimental models of hepatotoxicity induced by highdose Acetaminophen (APAP) provide a useful model for studying the mechanisms of liver cell damage. For this purpose, in acute liver damage caused by APAP; Serum levels of endogenous peptides involved in various inflammatory, angiogenesis and immunity processes such as Apelin,
Elabela, Endoglin and Meteorin-Like Protein (METRLN) were investigated. MATERIALS and METHODS: In study, a total of 14 Wistar Albino female rats were randomly divided into 2 groups. Group I (Control): The group given only $0.9 \% \mathrm{NaCl}$ orally. Group II (Toxicity): The group in which hepatotoxicity was created by giving a single oral dose of $\mathrm{N}$-acetyl-p-aminophenol (paracetamol, $1 \mathrm{gr} / \mathrm{kg}$ ). At the end of the 24 hours, animals were sacrificed and blood samples were taken, to separate serum samples. Levels of ALT and AST enzymes were studied in an autoanalyzer to show heposellular damage from separated serum samples. Apelin, Elabela, Endoglin and METRLN levels were examined in the serum samples in accordance with the kits procedure by using Rat ELISA kits.

RESULTS: While serum ALT (125.4 $\pm 9.87 \mathrm{U} / \mathrm{L})$, AST $(365.43 \pm 25.39 \mathrm{U} / \mathrm{L})$, Apelin $(264.75 \pm 90.87 \mathrm{pg} / \mathrm{mL})$, Elabela $(37.21 \pm 3.81 \mathrm{pg} / \mathrm{mL})$ and Endoglin $(1369.66 \pm 535.1 \mathrm{ng} / \mathrm{L})$ levels increased significantly in the hepatotoxic group compared to the control group $(25.9 \pm 4.21 \mathrm{U} / \mathrm{L}, 70.01 \pm 7.91 \mathrm{U} / \mathrm{L}, 178.07 \pm 21.56$ $\mathrm{pg} / \mathrm{mL}, 10.92 \pm 1.54 \mathrm{pg} / \mathrm{mL}$ and $678.15 \pm 108.8 \mathrm{ng} / \mathrm{L}, 3.62 \pm 0.4 \mathrm{ng} / \mathrm{mL})$, METRLN levels $(3.12 \pm 0.15 \mathrm{ng} / \mathrm{mL})$ were found to be low.

CONCLUSIONS: This study is the first record in the literature revealing the association of mentioned peptides with APAP-induced liver injury. More detailed studies are needed to elucidate the role of these peptides in liver damage. Keywords: APAP-induced Liver Damage, Apelin, Elebela, Endoglin, METRNL

\section{OP-157}

\section{EVALUATION OF NEWBORN SCAN RESULTS WITH TANDEM MS}

Cemile Topcu, Mehmet Gurbilek, Yasemin Mihci

Department of Medical Biochemistry, Meram Faculty of Medicine, Necmettin Erbakan University, Konya, Turkey

OBJECTIVES: The main purpose of newbornscreening is to diagnosegenetic metabolic, and other inherited disorders before clinical symptoms appear at the earliest to begin treatment. Understanding and monitoring biochemical data obtained from tandem massspectrometry is vital for earlydiagnosis of metabolic diseases associated with such disorders. In thisstudy, we aimed to share the result of newborn screening studied with tandem MS in our laboratory. MATERIALS and METHODS: Acylcarnitine screening results of 100 newborns admitted toourlaboratorywere evaluatedretrospectivelybyLC-MS/MSmethodand Tandem MS device. Age (mean \pm sd) was $764 \pm 1265$ days ( $54 \%$ male, $46 \%$ female.) RESULTS: MSUD (2), hereditary factor IX deficiency (1), aicardi syndrome (1), tyrosine metabolism disorder (1), galactosemia (1), neurofibromatosistype (1), merosine negative congenital muscular dystrophy (1), celiac (1), dravet syndrome (1), epilepsy (18), cerebral palsy (6), autism (1), growth retardation (4) liver failure (3) convulsions (3), neonatal sepsis (3) disease was diagnosed. Results with acylcarnitine values other than reference values were evaluated. 41 stearylcarnitine, 25 palmitoylcarnitine, 15 methylmalonylcarnitine, 8 propionylcarnitine, 2 free carnitine, 4 isovalerylcarnitine, 2 isovaleryl $(3 \mathrm{OH})$ carnitine $(\mathrm{C} 5 \mathrm{OH}), 2$ hexanoylcarnitine, 1dodecanoyl carnitine, 1 myristoylcarnitine, 1 decanoylcarnitine, 1 decenoylcarnitine, 1 octadecenoylcarnitine peaks were found in the Konya region.

CONCLUSIONS: Comprehensive studies on reference ranges, age, gender, birth weight and ethnicity of our region are needed.

Keywords: Newborn, Metabolic, Screening

\section{OP-158 \\ DETERMINATION OF REFERENCE RANGE OF CREATININE VALUES OF CHILDREN IN THE 0-1 AGE RANGE AT KARAPINAR STATE HOSPITAL}

Saadet Kader $^{1}$, Mujgan Ercan ${ }^{2}$

'Karapinar State Hospital Biochemistry Laboratory, Konya, Turkey ${ }^{2}$ Afyon University Faculty of Medicine Department Of Biochemistry, Afyon, Turkey

OBJECTIVES: The reference range values are interpreted taking into account the results obtained in clinical laboratories. It is recommended that each laboratory establish its own reference ranges. The aim of this study was to estimate the reference intervals for creatinin in children from the data obtained from the analyses of the laboratory in a one year period.

MATERIALS and METHODS: The creatinine test results of the 213 children (0-1 ages) who applied to our laboratory in between 01.01.2018-01.01.2019 were analysed. Creatinine values were analyzed in Mindray BS-800 device using the Jaffe method.

RESULTS: Calculation of reference intervals with $90 \%$ confidence limits showed lower values than the defined reference values by manufacturer The calculated reference interval for our data was significantly different from the provided by manufacturer. Calculated reference intervals for the creatinin assay were found as $0,1-0,5 \mathrm{mg} / \mathrm{dL}$ for $2,5 \mathrm{th}-97,5$ th percentile range. CONCLUSIONS: There is a reference range determined by the manufacture for each test. However, we cannot say how accurately this range reflects the reference values of the society we are addressing. Therefore, we must determine the reference values of our own population and use these values. Keywords: Reference Values, Creatinin, Turkey 


\section{OP-160 \\ DETERMINATION OF SERUM ATORVASTATIN AND ROSUVASTATIN LEVELS BY TANDEM MASS SPECTROMETERY}

Havva Yaglioglu ${ }^{1}$, Duygu Eryavuz Onmaz ${ }^{1}$, Kenan Erdem² ${ }^{2}$, Sedat Abusoglu ${ }^{1}$, Ali Unlu ${ }^{1}$, Abdullah Sivrikaya ${ }^{1}$, Gulsum Abusoglu ${ }^{3}$

${ }^{1}$ SelcukUniversityFaculty of Medicine, Department of Biochemistry, Konya, Turkey

${ }^{2}$ SelcukUniversityFaculty of Medicine, Department of Cardiology, Konya,

Turkey

${ }^{3}$ Department of MedicalLaboratoryTechniques, SelcukUniversityVocational School of Health, Konya, Turkey

OBJECTIVES: Statins are 3-hydroxy-3-methyl-glutaryl-CoA (HMG-CoA) reductase inhibitory agents used to reduce the risk of cardiovascular disease by lowering serum cholesterol levels. Although statins are generally well tolerated by patients, some patients may develop muscle-related toxic effects (rhabdomialysis and myopathy) or hepatotoxic effects. Therefore, monitoring of serum statin levels is important. Our aim in this study is to establish a measurement method in LC-MS/MS device for the analysis of atorvastatin and rosuvastatin levels. MATERIALS and METHODS: Mass spectrometric analyzes were performed using an integrated Shimadzu LC-20-AD (Kyoto, Japan) chromatography system with ABSCIEX API 3200 triple quadrupole mass spectrometer (USA) equipped with an electrospray ion source (ESI) operating in positive mode. After adding $100 \mu \mathrm{L}$ internal standard (200 $\mathrm{ng} / \mathrm{ml}$ carbamazepine) and $2 \mathrm{~mL}$ ethylacetate to $250 \mu \mathrm{L}$ sample, it was placed in the orbital shaker at $250 \mathrm{rpm}$ for 15 minutes, then centrifuged at $3000 \mathrm{rpm}$ for 10 minutes. Supernatants were evaporated with nitrogen gas. There sidues were dissolved in $200 \mu \mathrm{L}$ of water: acetonitrile (25: $75 \% \%$ v: v) mixture and injected.

RESULTS: The method was found to be linear between 1.22 and $2500 \mathrm{ng} /$ $\mathrm{mL}$ for atorvastatin and between 0.97 and $2000 \mathrm{ng} / \mathrm{mL}$ for rosuvastatin. Total run time was 5 minutes. \% CV values for all analytes were lower than $6 \%$. CONCLUSIONS: A new sensitive, specific, accurate and reliable method has been developed. This study is very suitable for large-scale studies as it requires a small sample volume and a simple extraction procedure.

Keywords: HMG-CoA Reductase, LC-MS/MS, Toxicity, Statin

\section{OP-161 \\ DEVELOPMENT OF A TANDEM MASS SPECTROMETRIC MEASUREMENT METHOD FOR DETERMINATION OF HYDROXYCHLOROQUINE LEVELS}

Duygu Eryavuz Onmaz ${ }^{1}$, Mustafa Onmaz ${ }^{2}$, Gulsum Abusoglu ${ }^{3}$

${ }^{1}$ Selcuk University Faculty of Medicine, Department of Biochemistry, Konya,

Turkey

${ }^{2}$ Department of Family Medicine, Faculty of Meram Medicine, Necmettin

Erbakan University, Konya, Turkey

${ }^{3}$ Department of Medical Laboratory Techniques, Selcuk University Vocational

School of Health, Konya, Turkey

OBJECTIVES: Hydroxychloroquine has been used for more than 50 years to prevent or treat malaria infections and is now widely used in the treatment of rheumatological diseases. Although hydroxychloroquine is thought to be effective in the treatment of the new type of coronavirus (COVID-19) disease, its clinical application in COVID-19 treatment is controversial. Although hydroxychloroquine is generally well tolerated by patients, it can cause serious adverse effects. Retinopathy, QTc prolongation and ventricular arrhythmias are the most common, serious side effects associated with high dose $(>5 \mathrm{mg} / \mathrm{kg})$ and prolonged use $(>5$ years). Therefore, measuring and monitoring hydroxychloroquine levels is important. Our aim in this study was to develop an LC-MS/MS measurement method for hydroxychloroquine. MATERIALS and METHODS: After adding $100 \mu \mathrm{L}$ of internal standard, 600 $\mu \mathrm{L}$ of acetonitrile to $250 \mu \mathrm{L}$ of sample, it was vortexed for 30 seconds, then centrifuged at $13000 \mathrm{rpm}$ for 10 minutes. $200 \mu \mathrm{L}$ of supernatant was injected into the LC-MS/MS system.

RESULTS: The methods was linear in the range of 2.5 and $5000 \mathrm{ng} / \mathrm{ml}$. Detection and quantitation limits were 1.25 and $2.5 \mathrm{ng} / \mathrm{ml}$, respectively. The retention time was 0.55 minutes. The total run time was 5 minutes. CONCLUSIONS: In the developed method, the ability to analyze only with precipitation without pre-treatment steps such as evaporation, extraction and short analysis time are the main advantages of the method, and it can be used for routine analysis in COVID-19 patients after necessary biosecurity measures are taken. Keywords: Adverse Effect, COVID-19, Hydroxychloroquine, Tandem Mass Spectrometry

\section{OP-162 \\ DETERMINATION OF METHOTREXATE LEVELS BY LIQUID CHROMATOGRAPHY MASS SPECTROMETRY METHOD}

Firdevs Sak, Duygu Eryavuz Onmaz, Sedat Abusoglu, Ali Unlu Selcuk University Faculty of Medicine, Department of Biochemistry, Konya, Turkey

OBJECTIVES: Methotrexate is a folic acid antagonist and inhibits the dihydrofolate reductase enzyme. It is used in cancer treatment at high doses due to its anti-proliferative properties. It is also widely used in the treatment of rheumatoid arthritis due to its anti-inflammatory effect. Methotrexate used in cancer treatment; It has side effects that can lead to nephrotoxicity. Nephrotoxicity may progress with glomerular or tubular dysfunction, hypertension and impairment of renal endocrine function. Methotrexate determination; It helps to optimize dosage, minimize the risk of toxicity and investigate possible drugdrug interactions. Our aim in our study is to develop a LC-MS/MS method for measuring serum methotrexate levels.

MATERIALS and METHODS: $250 \mu 1$ sample or standard was taken and $60 \mu \mathrm{l}$ of $\mathrm{pH} 3 \mathrm{HCL}$ was added to $100 \mu \mathrm{l}$ internal standard (Sildenafil) for the last 500 $\mu \mathrm{l}$ methanol protein precipitation and was vortexed and centrifuged at 13,000 rpm for 15 minutes. After centrifugation, $200 \mu \mathrm{l}$ of the upper phase was taken into vials and $30 \mu \mathrm{l}$ of this mixture was injected into the LC-MS/MS system. RESULTS: In our method validation study, 2500-0.305 ng / $\mathrm{ml}$ range was found to be linear for methotrexate. The $\mathrm{CV} \%$ obtained in the intra-day and between day repeatability study were calculated as $5.1 \%, 6.0 \%$ and $4.6 \%, 3.4 \%$, respectively. Total run time is 5 minutes.

CONCLUSIONS: The method we have established is a practical method with high accuracy and precision and can be used for routine analysis of methotrexate levels.

Keywords: Dose, LC-MS / MS, Methotrexate, Toxicity

OP-163

EVALUATION OF DRUG USE HABITS IN USAK PROVINCE

Ali Volkan Ozdemir

Usak Education and Research Hospital, Usak, Turkey

OBJECTIVES: In this study, it was aimed to determine the demographic characteristics and drug use habits of people who were brought to or applied to Usak Training and Research Hospital for drug abuse detection. MATERIALS and METHODS: The drug test results of those who applied to Usak Training\&Research Hospital between August 1,2019 andAugust 1,2020 and whose urine integrity tests are suitable, and the demographic information of the patients were obtained from the hospital automation system and statistically evaluated. RESULTS: 966 men and 95 women out of 1061 applicants. $85 \%$ of the total population is between the ages of $18-45$, and $10.2 \%$ is under the age of 18 Of these individuals, 2213 urine drug test panels were studied. In 495 of 1061 patients,positivity was detected during one or more applications. At least one parameter was positive in $779(35 \%)$ of the 2213 test panels studied. More than one substance use was found positive in 244 studies $(11 \%)$. The most frequently detected drugs are Cannabinoids (20.8\%) and Amphetamine/Methamphetamine derivatives $(18.3 \%)$. It has been determined that the two most commonly used substances are Cannabinoids and Amphetamine/Methamphetamine derivatives. CONCLUSIONS: The reasons that the most frequently detected drugs are Cannabinoids and Amphetamine/Methamphetamine derivatives are cheap and easily available, as well as their long half-life in the body. Although synthetic cannabinoids are less detectable,their use is known to be much more common. The fact that $10 \%$ of those who are found to be using drugs are under the age of 18 shows that the struggle against drugs in Usak should be preventive,especially by raising the awareness of this age group. Keywords: Drug Detection in Urine, Drug Use Habits,

\section{OP-164 \\ RETROSPECTIVE DETERMINATION OF THE DISTRIBUTION OF ILLEGAL SUBSTANCE USE ACCORDING TO LABORATORY DATA}

Cemal Polat

Department of Biochemistry, Isparta City Hospital, Isparta, Turkey

OBJECTIVES: Our aim is to determine the frequency of illegal substance use in our region. Further to evaluate the incidence over the years. MATERIALS and METHODS: Our study data were obtained from the Toxicology Unit of the Isparta City Hospital Central Laboratory. Data were obtained from the laboratory information system, retrospectively. The study covers data between January 1st, 2018 and September 30th, 2020. Amphetamine, barbiturate, benzodiazepine, buprenorphine, cocaine, opiate, synthetic cannabinoid and tetrahydrocannabinol tests were included in the study. In our laboratory, these tests are performed from urine samples in an autoanalyzer using the enzyme multiplied immunoassay technique (EMIT) RESULTS: In our Central Laboratory, a total of 7924 samples were accepted and 63.392 tests were reported. Samples were taken from $7364(92.93 \%)$ male and 
$560(7.07 \%)$ female. In our study, substance use was detected in 2052 individuals in total. $1893(92.25 \%)$ of the the substance users were male and $159(7.75 \%)$ were female. Concerning age of the patients, mean \pm standard deviation was determined as $26.46 \pm 6.58$ and median (minimum-maximum) as 25 (14-56). The most frequent test positivity was observed for opiate $(71.41 \%)$, amphetamine $(10.93 \%)$ and tetrahydrocannabinoid $(10.80 \%) .87 .57 \%$ of the patients showed one test positivity, $11.11 \%$ two and $1.32 \%$ three test positivities. Substance use was found to differ significantly between the years $(\mathrm{p}<001)$.

CONCLUSIONS: In our study, the mean age of substance users increased. The most commonly used substance is opiate. The use of illicit substances has decreased, especially in the last year. There has been an increase in the rate of those receiving treatment over the years.

Keywords: Amphetamine, Cocaine, Opiate, Tetrahydrocannabinol, Illegal Substance

\section{OP-165 \\ INVESTIGATION OF THE EFFECT OF HIGH DOSE NEONICOTINOID EXPOSURE ON THE BRAIN GLYMPHATIC SYSTEM}

Velid Unsal $^{1}$, Mustafa Cicek ${ }^{2}$

${ }^{1}$ Department of Nutrition and Dietetics, Faculty of Health Sciences, Mardin Artuklu University, Mardin, Turkey

${ }^{2}$ Department of Anatomy, Faculty of Medicine, Kahramanmaras Sutcu Imam University, Kahramanmaras, Turkey.

OBJECTIVES: Neonicotinoids, It is a very potent class of pesticides used in crop protection for flea control in plants and animals against puncture of sucking insects in cereals, vegetables, tea and cotton. The best known neonicotinoid today is imidacloprid. There is no known lymphatic system in the central nervous system (CNS). However, there is an alternative way defined as the glimphatic system to remove the toxins accumulated during neuro-physiological functions from the CNS. The aim of this study is to investigate the effects of neonicotinoid poisoning on the glymphatic system.

MATERIALS and METHODS: The study was designed as 2 groups (Control group and Imidacloprid group) with 10 rats in each group. At the end of the experiment, GFAP, NGF, TNF-alpha were analyzed by ELISA method, while SOD, GSH-px, MDA were analyzed by spectrophotometric method. In addition, histopathological and immunohistochemical examinations were performed on the tissues. RESULTS: Histopathological examination revealed focal vacuolar degeneration (cases of abscess) in the brain tissue, excessive dilation of multiple pycnotic cell blood vessels and necrosis foci in the mice treated with imidacloprid. In the imidacloprid group, a significant decrease was detected in AQP-1 and AQP4 protein expressions, GFAP and NGF levels, SOD and GSH-px activities $(\mathrm{p}<0.05)$. Also, TNF-alpha and MDA levels were increased in the imidacloprid group $(\mathrm{p}<0.05)$. CONCLUSIONS: In conclusion, toxin accumulation caused by high-dose acute imidacloprid exposure caused severe damage to the brain glymphatic system in edema and cellular deformation

Keywords: Imidacloprid, Brain, AQP-1, AQP-4, Glymphatic System

\section{OP-166 \\ INTERACTIVE TOXICITY ASSESTMENT FOR MN(II), CO(II), AND ZN(II) HEAVY METALS ON PHOTOBACTERIUM KISHINATII}

Ayca Ata, Bikem Ovez

Department of Chemical Engineering, Ege University, Izmir, Turkey

OBJECTIVES: The presence of non-biodegradable heavy metals in abundance amounts on environment interferes with the beneficial uses of water. These heavy metals will be emitted to the environment by different sources and this will brought a ecological biomagnification effect. So; the rational for the study was to investigate the toxicity associated with $\mathrm{Mn}(\mathrm{II}), \mathrm{Co}(\mathrm{II})$ and $\mathrm{Zn}$ (II) individually and as mixture on Photobacterium kishinatii.

MATERIALS and METHODS: Bioluminance P. kishinatii was cultivated in Marine Broth at $22^{\circ} \mathrm{C}, 120 \mathrm{rpm}$ for 16 hours. After incubation, the culture was brought to standart turbidity value as $0.5 \mathrm{McF}$ arland by micro-broth dilution method. The various individual and mixture concentrations $(5-600 \mu \mathrm{mol} / \mathrm{L})$ were added to bacteria culture mixture and bioluminance inhibition was examined at 475 and $540 \mathrm{~nm}$ by ThermoScientific VarioScan Spectrophotometer.

RESULTS: The results of $\mathrm{Mn}$, Co and $\mathrm{Zn}$ individual toxicity on $P$ kishinatii indicated a linear correlation with increasing concentrations. The $15-\mathrm{min}$ IC50 values of $\mathrm{Mn}, \mathrm{Co}$ and $\mathrm{Zn}$ were $0.537,47.93$ and $35.41 \mu \mathrm{mol} / \mathrm{L}$, respectively, and their toxic order was $\mathrm{Mn}>\mathrm{Zn}>\mathrm{Co}$. Base on the mixture toxic index (MTI), the combined effects of $\mathrm{Mn}+\mathrm{Co}, \mathrm{Mn}+\mathrm{Zn}$ were antagonistic. In the case of $\mathrm{Co}+\mathrm{Zn}$ and $\mathrm{Mn}+\mathrm{Co}+\mathrm{Zn}$ mixtures partly additive effect was observed since $0<\mathrm{MTI}<1$

CONCLUSIONS: Acccording to the environmental safeguard, antagonistic effect cannot be taken into consideration for discharge limits; due to the unexpected combinations of the toxicants. As the Microtox test is the most reliable for heavy metal toxicity assestment, the results of this study would be helpful for optimization of the bioreactors.

Keywords: Heavy Metals, Bioluminance Bacteria, Toxicity, Microtox, Mixture Toxic Index

\section{OP-167}

\section{EFFECTS OF FUMONISIN B1 ON EPIGENETIC MODIFICATIONS}

Ecem Fatma Karaman

Department of Pharmaceutical Toxicology, Biruni University, Istanbul, Turkey; Department of Pharmaceutical Toxicology, Istanbul University, Istanbul, Turkey

OBJECTIVES: Fumonisin B1 (FB1) is a mycotoxin synthesized by Fusarium speciesin maize and maize-based products. Although it is one of the most common mycotoxins that frequently contaminates maize and maize-based products, it causes serious health problems for humans due to its toxicity among all fumonisins also. IARC has classified FB1 as Group-2B. FB1 hastoxic effects by causing accumulation of sphinganine and impairment of sphingolipid biosynthesis which of these play an important role in apoptotic regulation and pathways related to cancer development. Based on its non-genotoxic effect, it is thought that epigenetic mechanisms may play a role in the carcinogenic effect of FB1. It has been shown that in rat kidney and liver cells FB1 disregulates epigenetic modifications which are key in the expressions of many tumor suppressor genes.

MATERIALS and METHODS: In our study, it is planned to enlighten key molecular mechanisms that play a role in toxicity of FB1. For this purpose, the effects of FB1 on epigenetic modifications in in vitro human kidney cell line were investigated. 5-methylcytosine levels were measured using the Eliza kit and gene expression analyzes of DNA methyltransferases (DNMT1, DNMT3a, DNMT3b) were performed

RESULTS: It was observed that FB1 caused changes in global DNA methylation and gene expressions of DNA methyltransferases decreased compared to control. Global histone modifications is underway.

CONCLUSIONS: Consequently, it has been thought that FB1 could show toxic effects through epigenetic modifications and the exposure of mycotoxins such as FB1 makes important for public health and risk assessment studies. Studies aimed at elucidating the mechanisms of chemical carcinogenesis also contribute to development of biomarkers suitable for early diagnosis of cancer.

Keywords: Cell culture, Epigenetics, Fumonisin B1, Toxicity

\section{OP-168 \\ EVALUATION OF ECSTASY TEST RESULTS IN URINE DRUG ANALYSIS}

Saliha Aksun ${ }^{1}$, Raziye Yildiz ${ }^{2}$, Cagatay Hasip ${ }^{1}$, Leyla Demir ${ }^{1}$, Figen Narin ${ }^{1}$ Izmir Katip Celebi University Faculty of Medicine, Department of Biochemistry, Izmir, Turkey

${ }^{2}$ Izmir Ataturk Education and Research Hospital, Department of Clinical Biochemistry, Izmir, Turkey

OBJECTIVES: In the last Health practice communique it was stated that the financial reimbursement of urine ecstasy studies will be made only for amphetamine-positive patients. However, physicians state that, some users only use ecstasy without amphetamine, therefore the ecstasy should also be screened in every sample and they want to see the result. This study was planned to examine the coexistence and separate rates of ecstasy and amphetamine positive test results. MATERIALS and METHODS: The study was planned retrospectively. In the medical biochemistry laboratory of Izmir Katip Celebi University Ataturk Training and Research Hospital, substance analyzes are performed by immunochemical method (EMIT, Dimension EXL, Siemens) or chromatographic separation method (LC-MSMS; Sciex,) according to the clinical demand, which is preferred between fast results and detailed test requests.

RESULTS: Substance analysis in 37035 urine has been performed with the immune chemical method. $1250(\% 3,37)$ ecstasy was found above the threshold value of $500 \mathrm{ng} / \mathrm{ml}$. In $62,7 \%$ of the ectasia positive samples, Amphetamine is above the legal threshold value of $500 \mathrm{ng} / \mathrm{ml}$. In the $37.3 \%$ ecstasy positive sample, no Amphetamine was found or was below the threshold. Among these, 21 urine samples that were firstly reported as only ecstasy positive were found below the threshold value when they reworked with the our second method LC-MSMS.

Ecstasy was found above $500 \mathrm{ng} / \mathrm{ml}$ in 374 of 6669 other urine samples analyzed by chromatographic method, $32,0 \%$ of them were found to be amphetamine negative.

CONCLUSIONS: Although amphetamine is not positive in urine scanned by immunochemical method, we have ecstasy positive results. It is known that, sometimes false positive results can be reported with immunochemica methods in drug screening analyzes. For this reason, 21 samples which firstly studied by immunochemistry were reworked by chromatography. And none of them found above the threshold in terms of ecstasy. These results seem to support the idea that ecstasy should be studied only in amphetamine positive samples. However, only ecstasy tests were found positive even though the amphetamine results were negative in $32.0 \%$ of the cases in our screenings performed with the reference method LC-MSMS, which has a high diagnostic value. This proves that it is necessary to study ecstasy for amphetamine negative patients, otherwise, some ecstasy users cannot be detected because they are not tested. In this case, the necessity of updating this restriction in the Health application notification according to the method used should be discussed. Keywords: Amphetamine, Ecstasy 


\section{OP-169 \\ A BDNF AGONIST 7,8-DIHYDROXYFLAVONE REDUCES OXIDATIVE STRESS IN LIVER OF ELDERLY MICE}

Elif Sahin, Neslihan Saglam, Seniz Dogramaci, Ahmet Alver

Department of Medical Biochemistry, Karadeniz Technical University, Trabzon, Turkey

OBJECTIVES: The elderly population of the world is increasing day by day and one of the underlying mechanisms of aging is thought to be oxidative stress. Since aging brings along many metabolic diseases, ways of healthy aging are sought. Our aim is to determine the effect of 7,8-dihydroxiflavone (7,8-DHF) on oxidative stress of elderly mice. Thus, it will be demonstrated whether 7,8-DHF, which is a member of the flavonid family and is known to have good antioxidant properties, has a protective effect on oxidative stress increasing with aging. MATERIALS and METHODS: Three groups of C57BL/6 male mice, young, elderly and elderly drug group were formed. For the elderly group, 18-24 month old mice were used. The elderly drug group received 7,8-DHF $(5 \mathrm{mg} /$ $\mathrm{kg}$ /day) for three weeks. At the end of the experiment, superoxide dismutase (SOD), catalase (CAT) and malondialdehyde (MDA) were measured in the liver of the mice and biochemical parameters were measured in the serum. RESULTS: 7,8-DHF reduced the MDA level and increased SOD concentrations significantly $(p<0,05)$. Also, glucose and triglyceride levels significantly increased in elderly drug group $(\mathrm{p}<0,05)$.

CONCLUSIONS: 7,8-DHF showed a strong antioxidant effect on liver and reduced oxidative stress increasing by aging. Also, improved the blood glucose levels closer to young group. So, 7,8-DHF may be an agent used in healthy aging. Keywords: Aging, 7,8-DHF, Liver, Oxidative Stress

\section{OP-170 \\ SERUM ALBUMIN LEVEL AND MORTALITY IN ELDERLY CHRONIC HEART FAILURE PATIENTS}

Gulsum Meral Yilmaz Oztekin

University of Health Sciences, Antalya Education and Research Hospital,

Department of Cardiology, Antalya, Turkey

OBJECTIVES: Hypoalbuminemia is especially common in elderly patients and is associated with an increased risk of death in heart failure (HF). MATERIALS and METHODS: This is a single-center observation study conducted in a tertiary hospital in Turkey. Patients who were followed up in the outpatient clinic with the diagnosis of HF were included in the study. RESULTS: 465 patients $>65$ years old whose serum albumin levels were monitored in the heart failure outpatient clinic were included in the study. $35.1 \%$ of the patients included in the study were female and $64.9 \%$ were male. While the median ejection fraction of the patients were $30 \%(25-35), 69.5 \%$ were New York Heart Association (NYHA) I-II and 30.5\% were NYHA III-IV patients. During follow-up, $21.3 \%$ (n:99) of patients died. These patients were significantly older [76 (71-82) vs $72(68-78)$ years, $p<001]$ and serum albumin levels were lower $[3.7 \mathrm{~g} / \mathrm{dL}(3.2-4.1)$ vs $4.2 \mathrm{~g} / \mathrm{dL}(3.9-4.4), \mathrm{p}<0.001]$. In patients who died, creatinine $(\mathrm{p}<0.001), \mathrm{N}$-terminal pro-brain natriuretic peptide $(\mathrm{NT}$-proBNP) $(\mathrm{p}<0.001)$, and C-reactive protein $(C R P)(p<0.001)$, were higher, estimated glomerular filtration rate $(\mathrm{eGFR})(\mathrm{p}<0.001)$, total protein $(\mathrm{p}<0.001)$, total cholesterol $(\mathrm{p}<0.001)$, sodium $(\mathrm{p}<0.001)$, uric acid ( $\mathrm{p}: 0.005)$, calcium $(\mathrm{p}<0.001)$, hemoglobin $(\mathrm{p}<0.001)$, serum iron $(\mathrm{p}<0.001)$, transferrin saturation $(\mathrm{p}<0.001)$, and parathyroid hormone levels $(\mathrm{p}<0.014)$ were significantly lower. With multivariable analysis, serum albumin level $(\mathrm{p}<0.001)$, sodium $(\mathrm{p}<0.001)$ and being ex-smoker (p:0.008) as independent predictors of mortality. Serum albumin level had a hazard ratio of $7.45(95 \%$ CI $3.78-14.70)$ for mortality in elderly HF. CONCLUSIONS: These data showed that serum albumin level is associated with increased risk of mortality in elderly HF patients

Keywords: Serum Albumin, Heart Failure, Elderly, Mortality

\section{OP-171 \\ ANALYSIS OF MTOR INHIBITORS AS SENOTHERAPETICS IN AGED LUNG FIBROBLAST CELLS}

Perinur Bozaykut

Acibadem University, Molecular Biology and Genetics, Istanbul, Turkey

OBJECTIVES: During aging process, accumulation of senescent cells results in increased inflammation and contributes to organismal aging, as well as the pathophysiologies of many age-related diseases. Therefore, the discovery of senotherapeutic drugs targeting cellular senescence might be an emerging strategy for the treatment of age-related diseases. The aim of the present study is to determine the senotherapeutic effect of mTOR inhibitors on aged cells. MATERIALS and METHODS: mTOR inhibitors to be tested were predicted by the systems biology analysis of available aging transciptomics data and by using drug repurposing. Predicted drugs $(10 \mu \mathrm{M})$ were applied to early passages of human lung fibroblasts (WI-38) and were serially passaged until p30, a lenght of time sufficient to induce cellular senescence. Senescent phenotypes of these cells were determined by the analysis of SA- $\beta-$ Gal and immune markers of senescence by RT-qPCR. Viability of the cells are determined by MTT test. ( $\mathrm{n}=4$ ) RESULTS: Among predicted drugs, an mTOR inhibitor KU-0063794 showed a consistent positive association with aging biomarkers $(\mathrm{p}<0.05)$ CONCLUSIONS: The study described new drug candidates that could potentially extend healthspan based on the concept of senotherapeutic. Keywords: Aging, Cellular Senescence, Senotherapeutic, mTOR Inhibitor, Inflammation

\section{OP-172}

\section{SERUM LDL CHOLESTEROL SIZES IN ELDERLY SUBJECTS}

Murat Cihan $^{1}$, Hideko Tsukamoto ${ }^{2}$

${ }^{1}$ Ordu University Hospital, Ordu, Turkey

${ }^{2}$ Keio University, Tokyo, Japan

OBJECTIVES: We studied LDL sizes in relatively healthy elder objects with our new method

MATERIALS and METHODS: We used polyacrylamide gradient gel electrophoresis to eliminate the interference by fatty acids and devised a simple precise method of polyacrylamide gradient gel electrophoresis to measure the diameter of small, dense, low-density lipoproteins in serum. We used apoferritin and thyroglobulin, which have a molecular diameter of $12.2 \mathrm{~nm}$ and $17.0 \mathrm{~nm}$, respectively, and standard low-density lipoprotein particles having a diameter of 25.7 and $27.0 \mathrm{~nm}$ as calibrators, estimated by measurement of negative staining of electron microscopy. The only stain used was Coomassie brilliant blue, and it was used for lipoprotein staining. When we used lowdensity lipoprotein of $25.73 \mathrm{~nm}$ in diameter as a quality control specimen, the coefficient of variation of the size measurements obtained by our method was less than $1.2 \%$. The new method markedly improved the laboratory procedure for measuring the diameter of low-density lipoproteins. We used medcalc and SPSS programs for comparing results.Healthy 123 (between 65-94 years old) elderly people and 98 (between 20-44 years old) young people were chosen. RESULTS: We found LDL size is lower than in young normal group (elderly group n:123 LDL size: $25.5 \pm 0.9 \mathrm{~nm}$, young group n:98 LDL size: 26.6 $\pm 1.1 \mathrm{~nm}$.).Also we found LDL sizes in elderly people differs by gender ( male elderly people n:63 LDL size $24.4 \pm 0.6$; female n:60 LDL $25.7 \pm 0.8$ ) CONCLUSIONS: LDL size were lower in male elderly group than normal group. Keywords: LDL Size; LDL Size in Elderly Objects

\section{OP-173 \\ INCREASED PUFA LEVELS IN KIDNEY EPITHELIAL CELLS IN THE COURSE OF DICLOFENACTOXICITY}

Cagatay Yilmaz ${ }^{1}$, Esma Kirimlioglu², Ebru Afsar ${ }^{1}$, Tugce Ceker ${ }^{1}$, Mutay Aslan ${ }^{1}$ Department of Medical Biochemistry, Akdeniz University, Antalya, Turkey ${ }^{2}$ Department of Histology and Embryology, Akdeniz University, Antalya, Turkey

OBJECTIVES: This study evaluated polyunsaturated fatty acids (PUFAs) in human kidney epithelial cells exposed to diclofenac (DCL) toxicity. MATERIALS and METHODS: Kidney cells were treated with DCL to induce cytotoxicity and thymoquinone (TQ) was administered to decrease cytotoxic effects. Levels of arachidonic acid (AA, C20:4n-6), dihomo-gamma-linolenic acid (DGLA, C20:3n-6), eicosapentaenoic acid (EPA, C20:5n-3) and docosahexaenoic acid (DHA, C22:6n-3) were determined by liquid chromatography coupled with tandem mass spectrometry. Cytosolic phospholipase A2 (cPLA2), cyclooxygenase 1 (COX-1) and prostaglandin E2 (PGE2) were measured to evaluate changes in enzyme activity. Immunofluorescence staining and western blot analysis was performed to determine protein levels of COX- 1 .

RESULTS: Renal cell toxicity was accomplished by DCL and was alleviated by TQ treatment. Diclofenac significantly increased all measured PUFAs while pretreatment with TQ decreased PUFA levels in DCL treated cells. Cytosolic PLA2 and total COX activity was significantly decreased in DCL treated cells. Immunofluorescence staining and western blot analysis confirmed significantly decreasedCOX-1 levelsinDCLandDCL+TQtreatedgroups. Theresultsofthisstudy reveal that DCL treatment is associated with accumulation of PUFAs in kidney cells. CONCLUSIONS: We suggest that PUFA accumulation in DCL toxicity might be a consequence of both cPLA2 and COX-1 inhibition. Thymoquinone administration, along with DCL treatment alleviated the buildup of PUFAs and DCL-induced cell death in kidney cells.

Acknowledgements: This study was supported by a grant (\#118Z874) from the Scientific and Technological Research Council of Turkey (TUBITAK) Keywords: Diclofenac, Kidney Cells, Thymoquinone, Polyunsaturated Fatty Acids 


\section{OP-174 \\ EFFECT OF ENDOPLASMIC RETICULUM STRESS ON SPHINGOLIPID LEVELS AND APOPTOTIC PATHWAYS IN RETINAL PIGMENT EPITHELIAL CELLS}

Ebru Afsar ${ }^{1}$, Esma Kirimliogluํㅜ Tugce Ceker ${ }^{2}$, Cagatay Yilmaz ${ }^{1}$ Necdet Demir ${ }^{2}$, Mutay Aslan ${ }^{1}$

${ }^{1}$ Department of Medical Biochemistry, Akdeniz University, Antalya, Turkey

${ }^{2}$ Department of Histology and Embryology, Akdeniz University, Antalya,

Turkey

OBJECTIVES: We aimed to determine sphingolipid levels and examine apoptotic pathways in human retinal pigment epithelial cells (ARPE-19) undergoing endoplasmic reticulum (ER) stress.

MATERIALS and METHODS: Cells were treated with tunicamycin (TM) to induce ER stress and tauroursodeoxycholic acid (TUDCA), an ER stress inhibitor, was administered to decrease cytotoxicity. Cell viability was measured by MTT assay. Levels of C16-C24 sphingomyelins (SM) and C16-C24 ceramides (CERs) were determined by LC-MS/MS. Glucose- regulated protein 78-kd (GRP78) and nuclear factor kappa-b subunit 1 (NFkB1) gene expressions were evaluated by quantitative PCR analysis, while GRP 78, NF- $\mathrm{kB}$ p 65 , cleaved caspase-3 and caspase-12 protein levels were assesed by immunofluorescence. Ceramide1-phosphate (C1P) levels were determined by immunoassay, while caspase -3 and -12 activity in cell lysates were measured via a fluorometric method. RESULTS: Induction of ER stress in TM treated groups were confirmed by significantly increased mRNA and protein levels of GRP78. TM significantly decreased cell viability compared to controls. Treatment with TUDCA along with TM significantly increased cell viability compared to the TM group. A significant increase was observed in C22-C24 CERs, C1P, caspase-3,

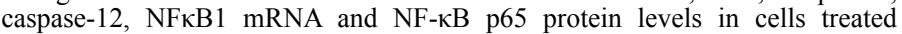
with TM compared to controls. Administration of TUDCA lead to a partial

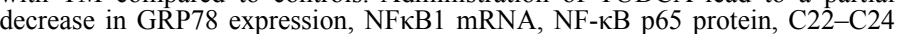
CERs and C1P levels along with a decrease in caspase- 3 and -12 activity. CONCLUSIONS: The results of this study reveal the presence of increased long chain CERs, C1P and apoptotic markers in retinal cells undergoing ER stress. Keywords: Sphingolipid, Tunicamycin, Retinal Pigment Epithelial Cells

\section{OP-175 \\ LABORATORY WATER AND INSTALLATION CONSIDERATIONS ON WATER PURIFICATION SYSTEMS}

Oguzhan Zengi

Basaksehir Cam and Sakura City Hospital, Central Laboratory, Istanbul, Turkey

OBJECTIVES: Laboratory reagent water and water purification systems are components and essential equipment used in all clinical and analysis laboratories. The Turkish Biochemical Society Water Standards Working Group published a guideline in 2019. The aim is to evaluate the Cam and Sakura City Hospital Core Laboratory's water purification system under this guide's leading. MATERIALS and METHODS: Evaluation of the water purification system installed in Cam and Sakura City hospitals' central laboratory over the main features of the water purification systems of the "Guideline for the Preparation, Distribution, and Testing of Purified Water for Clinical Laboratories." RESULTS: The water purification system has been installed and operated by the requirements of the Guidelines for Preparation, Distribution, and Testing of Purified Water for Clinical Laboratories.

CONCLUSIONS: The published guideline aims to bring standardization and awareness to laboratory water, a forgotten parameter. The use of required standards and control/measurement parameters in clinical laboratories should be sought, especially in newly established systems and large central laboratories. Keywords: Water system; Water Purification System; Laboratory Reagent Water; Water Guideline

\section{OP-176 \\ THE PROCESS OF ESTABLISHING A NATIONAL STANDARD FOR THE PREPARATION, DISTRIBUTION AND TESTING OF PURIFIED WATER FOR CLINICAL LABORATORIES}

Suat Hayri Kucuk

S.B.U. Bagcilar Training and Research Hospital, Department of Medical Biochemistry, Istanbul, Turkey

OBJECTIVES: Purified water is the main component of reagents, buffers and diluents used in clinical laboratory tests, as well as for washing and sterilization of devices and laboratory products. Purified laboratory water is necessary to obtain accurate and sustainable results in laboratory analysis. However, there was no guideline or standard for clinical laboratories in our country. In order to eliminate this gap, a guide covering water to be used in the clinical laboratory, water purification technologies, storage, distribution, installation, assembly, testing, validation, sanitation, monitoring methods, operation, maintenance and controls by the Turkish Biochemistry Association Laboratory Water Working Group in April 2019. prepared. In this process, a wide consensus was achieved with the participation of an international company producing purified water for laboratories and two domestic companies. MATERIALS and METHODS: Pre-informative presentations about the "Preparation, Distribution and Testing Guide of Purified Water for Clinical Laboratories" were held at the 29th National Biochemistry Congress of the Turkish Biochemistry Association International Biochemistry Congress 2018 in Bodrum and a promotional symposium in Istanbul in June 2019 RESULTS: Our water guide, which was prepared to create a national standard for clinical laboratories, was sent to the Turkish Standards Institute (TSE) by the Turkish Biochemistry Association in March 2020 with a justification report. It was held at a meeting with a committee formed later. At the meeting, a standard that we can take as an example was given for us to apply. According to this sample standard, a water standard reference text was prepared for clinical laboratories. It will be delivered to TSE next week CONCLUSIONS: TSE will evaluate our application with the technical committees it will establish. I wish this application to become a national standard and to be beneficial to the laboratory community in our country. Keywords: Purified Water, Pure Water, Clinical Laboratory Reagent Water, Clinical Laboratory Water Standard

\section{OP-177 \\ DETERMINATION OF THE TARGET PROTEINS IN CHEMOTHERAPY RESISTANT BREAST CANCER STEM CELL-LIKE CELLS BY PROTEIN ARRAY}

Meltem Demirel Kars ${ }^{1}$, Gamze Yildirim 2

${ }^{1}$ Meram Vocational School, Medicinal and Aromatic Plants Program, Necmettin Erbakan University, Konya, Turkey

${ }^{2}$ Department of Nanotechnology and Advanced Materials, Institute of Science, Selcuk University, Konya, Turkey

OBJECTIVES: Breast cancer comes second among the causes of cancer death of women. Although new generation hormone therapy is a promising strategy, re-occurrence or emergence of drug resistance limits the success. According to the theory of cancer stem cells (CSCs); CSCs are immortal, tumor inducing and self renewing pluripotent cells and multiply as chemotherapy proceeds, making the chemotherapy inefficient. Emerging scientific reports indicate that the mechanisms of drug resistance are the main features that CSCs gain actually. Due to this fact, cancer stem cell markers should be clarified to target CSCs and this will play important role to reverse drug resistance. MATERIALS and METHODS: In this study, MCF-7/Pac, a cell line resistant to microtubule inhibitor paclitaxel and multiple drugs permanently, was used as a reference cell line for drug resistant mammary cancer. It has some properties that breast cancer stem cells possess. The chemotherapy resistant breast cancer stemlike (BCSC-like) cells were sorted from MCF-7/Pac population by using markers $\mathrm{CD} 44, \mathrm{CD} 24$ and ALDH. At the next step the proteins that are up-regulated in BCSClike cells were determined by protein array analysis. Additionally the effect of paclitaxel on BCSC-like cell proliferation was determined. RESULTS: The MCF-7/Pac population contains $12.4 \%$ BCSC-like cells. The cells bearing BCSC-like cell phenotype exhibited resistance to paclitaxel. Inhibition of P-glycoprotein may still be a good strategy to reverse drug resistance. Additionally FGF-5, Frizzled-3, $-4,-6$ and Glypican-5 may be proposed as other BCSC markers. CONCLUSIONS: These results will contribute to both basic science and medical science.

Keywords: Breast Cancer Stem Cell, Protein Array, Drug Resistance, Frizzled, ALDH 